\title{
BEHAVIOR AND ECOLOGY OF THE
}

ROCK IGUANA CYCLURA CARINATA

\section{By}

JOHN BURTON IVERSON 111

A DISSERTATION PRESENTED TO THE GRADUATE COUNCIL OF THE UNIVERSITY OF FLORIDA

IN PARTIAL FULFILLMENT OF THE REQUIREMENTS FOR THE DEGREE OF DOCTOR OF PHILOSOPHY

UNIVERSITY OF FLORIDA

1977 
Dedication

To the peoples of the Turks and Caicos Islands, for their assistances in making this study possible, with the hope that they might better see the uniqueness of their iguana and deem it worthy of protection. 
1 wish to express my sincere gratitude to Walter Auffenberg, chairman of my doctoral committee, for his constant aid and encouragement during this study. Thanks also are due to the other members of my committee: John Kaufmann, Frank Nordlie, Carter Gilbert, and Willard Payne.

I am particularly grateful to the New York Zoological Society for providing funds for the field work. Without its support the study would have been infeasible. Acknowledgment is also given to the University of Florida and the Florida State Museum for support and space for the duration of my studies.

of the many people in the Caicos Islands who made this study possible, special recognition is due C. W. (Liam) Maguire and Bill and Ginny Cowles of the Meridian Club, Pine Cay, for their generosity in providing housing, innumerable meals, access to invaluable maps, and many other courtesies during the study period.

Special thanks are also due Francoise de Rouvray for breaking my monotonous bean, raisin, peanut butter, and cracker diet with incomparable French cuisine, and to Gaston Decker for extending every kindness to me while on Pine Cay. They enriched my visits to the islands more that any other two persons. For similar courtesies 1 also thank George and Marou lipanich. I am also indebted to many other Turks and Caicos islanders for information and help throughout my study. 
Don Correll, Bob Anderson, and Walter Auffenberg supplemented my plant collections and identified most of the plants. Don Buden supplied a list of birds recorded from the Turks and Caicos Islands. Arthropod identifications were made by Bob Woodruff (insects), and Martin Muma (solpugids and scorpions).

Walter Auffenberg and David Auth unselfishly allowed me access to their Caicos Islands field notes, Diderot Gicca and Tom Wiewandt generously shared with me their field experiences with other species of Cyclura. Aerial photography of the study islands was made possible by Bill and Ginny Cowles. Numerous others have, in one way or another, added to the successful completion of this work; I apologize for my failure to acknowledge each one individually.

My wife, Sheila, typed the numerous manuscript drafts, endured my frequent absences from home, and supported me in many ways during all phases of the work. All illustrations are the work of the author. 
TABLE OF CONTENTS

Page

ACKNOWLEDGEMENTS . . . . . . . . . . . . . . . . . . . . . i i i

ABSTRACT . . . . . . . . . . . . . . . . . . . . vi i

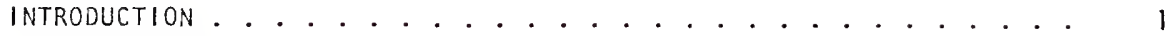

Purpose. . . . . . . . . . . . . . . . . . . . . . . . . . 1

Systematic Relationships and Distribution. . . . . . . . . 2

Study Area . . . . . . . . . . . . . . . . . . . . . . . 3

Zoogeographic Relationships. . . . . . . . . . . . . 9

Materials and Methods. . . . . . . . . . . . . . 10

MORPHOLOGY . . . . . . . . . . . . . . . . . . . . 25

HABITAT. . . . . . . . . . . . . . . . . . . 35

Climate. . . . . . . . . . . . . . . . . 35

Soil....................... . . . . . 46

Vegetation .................... . . . . . 46

Burrows. . . . . . . . . . . . . . . . . 58

REPRODUCTION..................................................... 68

Male Sexual Cycle... . . . . . . . . . . . . . . . . 68

Fenale Sexual Cycle. . . . . . . . . . . . . . . . 70

Courtship and Mating... . . . . . . . . . . . . . 76

Nesting. . . . . . . . . . . . . . . . . . . . 91

Eggs, Incubation and Hatching. . . . . . . . . . . . 103

Fertility, Prenatal and Natal Mortality. . . . . . . . . 113

General Seasonal Reproductive Pattern. . . . . . . . . . 115

Reproductive Effort and Strategy . . . . . . . . . . . 118

GROVIH.......................... . . 136

General Pattern. . . . . . . . . . . . . . . . . 136

Factors Affecting Growtin... . . . . . . . . . . . . 171

Longevity. . . . . . . . . . . . . . . . . . . . . . . 172

Regeneration . . . . . . . . . . . . . . . . . . 172

Comparisons With other Iguanines............. . 173

FOOD ANO FEEQING............................... 180

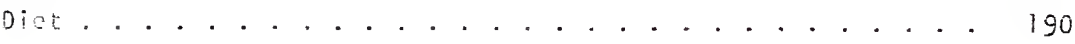


Feeding Behavior... . . . . . . . . . . . . . . 190

Gastrointestinal Tract Anatomy . . . . . . . . . . . . . 202

Digestive Efficiency..................... . . . 211

Fat bodies... . . . . . . . . . . . . . . . . 213

Food as a Limiting Factor. . . . . . . . . . . . . . . . 217

Herbivory as a Feeding Strategy. . . . . . . . . . . . . 220

ACTIVITY AHD MOVEMENTS ......................... . . . . . 224

Locanotion . . . . . . . . . . . . . . . . . . 224

Retreats... . . . . . . . . . . . . . . . . 225

Activity Cycles. . . . . . . . . . . . . . . . . 225

SOCIAL ORGANIZATION. . . . . . . . . . . . . . . . . 255

Displays . . . . . . . . . . . . . . . . . . 255

Dominance Relationships. . . . . . . . . . . . . . 272

IHTERSPECIFIC COACTIONS. . . . . . . . . . . . . . . . . . . 286

Netural Cohabitants. . . . . . . . . . . . . . . 286

Introduced Cohabitants... . . . . . . . . . . . . . 287

Broken Tail Frequency. . . . . . . . . . . . . . . 292

Epifauna . . . . . . . . . . . . . . . . . . . . . . . 298

Endofauna. . . . . . . . . . . . . . . . . . . . . 299

DENSITY AND DEMOGRAPHY . . . . . . . . . . . . . . . . . . . . 305

Sex Ratio. . . . . . . . . . . . . . . . . . . 305

Characteristics of Juvenile Population ......... . 305

Characteristics of Adult Populations. . . . . . . . . . 314

Life Tables. . . . . . . . . . . . . . . . . 328

Life History Strategy. . . . . . . . . . . . . . 332

OUTLCOK. . . . . . . . . . . . . . . . . . . . . . . . . . . 337

Populations on Turks and Caicos Islands. . . . . . . . . . 337

Easic Lizard Requirements. . . . . . . . . . . . . . . 347

Population Control... . . . . . . . . . . . . 349

Conclusions. . . . . . . . . . . . . . . . . . . . 352

LITERATURE CITED. . . . . . . . . . . . . . . . . . . . . . 353

Q:CGRAPHICAL SKETCH. . . . . . . . . . . . . . . . . . . . 379 
Abstract of Dissertation Presented to the Graduate Council of the University of Florida in Partial Fulfillment of the Requirements for the Degree of Doctor of Fhilosophy

BEHAVIOR AND ECOLOGY OF THE
ROCK IGUANA CYCLURA CARINATA

By

\author{
John Burton Iverson 111 \\ June, 1977
}

Chairman: Walter Auffenberg

Major Department: Zoology

The natural history and social behavior of the rock iguana, Cyclura carinata, was studied during 25 weeks between September, 1973, and June, 1976, on several small cays in the Turks and Caicos Islands, Eritish West Indies, and in captive enclosures in Gainesville, Florida.

Reproductive cycles were synchronized to climatic cycles. Testes sizes were maximal in April and May (the end of the dry season).

Vitellogenesis began in January (beginning of the dry season); cvulation and mating occurred in early May. Courtship was typical of most iguanid lizards; the mating system was probably primarily monogamous with serial polygyny among some males.

A single annual clutch of two to nine eggs was laid in early June in the terminal porticn of the female's retreat burrow. Clutch size was positively correlated with female size. Clutch weight averaged about $25 \%$ of preoviposition weight. Females defended their nest burrows for several days to several weeks after resting, but were not territorial during the remainder of the year. Haching cccurred aficr approximately 90 days. Neonates averaged $79.8 \mathrm{~mm} \mathrm{SV}$ and $14.6 \mathrm{gm}$. Juveni ie growth rate averaged $13.2 \mathrm{~mm}$ Sv/year. Males reached saxual maturity at 
approximately $220 \mathrm{~mm} \mathrm{SV}$ and $375-475 \mathrm{gm}$, at an age of about seven years; females, $185-200 \mathrm{~mm}, 200-300 \mathrm{gm}$, and six to seven years. Adult males averaged $276 \mathrm{~mm} \mathrm{SV}$ and $935 \mathrm{gm}$; adult females, $225 \mathrm{~mm}$ and $475 \mathrm{gm}$. The largest male measured $360 \mathrm{~mm} \mathrm{SV}$ and $1864 \mathrm{gm}$; largest female, $292 \mathrm{~mm}$ and $1135 \mathrm{gm}$. Adults grew between 2 and $17 \mathrm{~mm} \mathrm{sV} /$ year.

Rock iguanas were primarily herbivorous at all ages, and fed arboreally and terrestrially. Five partial septa partition the proximal solon region; this modification presumably increases digestive efficiency. Huge oxyurid nematode populations inhabited the colon, and their relationship with the iguana may be mutualistic rather than parasitic. Abdominal fat deposits were negatively correlated with gonadal activity.

Home range was correlated with body size and habitat productivity, and àvaraged $980 \mathrm{~m}^{2}$ for females, $1260 \mathrm{~m}^{2}$ for subdominant males, and 1590 $\mathrm{m}^{2}$ for dominant males. Diurnal activity was bimodal during warmer months; high midday temperatures resulted in reduced activity. Winter activity was generally reduced and peaked at midday. Iguanas basked following emergence; most of the remainder of the day was spent feeding, interacting with other lizards, and shuttling in the sun-shade mosaic for thamoregulatory purposes. Basking preceded the termiration uf daily activity

Rock iguanas performed ritualized "signature" displays or headbobs. Postural adjustments were among the modifiers producing variation in this display in different behavioral contexts. Displays were important to territory declaration, male challenging, and sex recognition. Males were territorial year-round in the field, but developed dominance hierarchies in captivity. Dominant males displayed less than subordinates. Male territoriai defense probably evolved as a mechanism 
guaranteeing access to 1) food resources, and 2) females for breeding.

Sex ratio was $1: 1$ in all age classes. Survivorship was positively correlated with body size. Juvenile densities reached $90.3 /$ ha in optinum habitat, adults exceeded $31.1 /$ ha. Biomass estimates were 5.15 $\mathrm{kg} / \mathrm{ha}$ for juveniles and $17.01 \mathrm{~kg} / \mathrm{ha}$ for adults. Life table data indicate replacement rate was near unity, and mean generation time was 14.0 years. In its life history strategy, $\underline{c}$. carinata is a predominately $\mathrm{K}$-selected species.

Cyclura are vulnerable to few native predators, but suffer drastic population reductions with the introduction of feral mammals. Virtually the entire iguana population of one study island ( $>15,000$ individuals) was extirpated by dogs and cats during the course of this study. The status of Cyclura carinata in the Turks and Caicos Islands was assessed and a management program congruent with the most critical aspects of the life history of the rock iguana was recommended. 


\section{INTRODUCTION}

\section{Purpose}

The genus Cyclura is one of tha most poorly known lizard genera in North America, despite being one of the most conspicuous members of the West Indian fauna. Although a sizeable literature exists regarding the genus, most of the references are faunal lists or general works and contain only anecdotal information; no thorough autecological study of any of the species has been made.

Few New World lizards have experienced as intimate a relationship with man, and suffered more from the interaction, than Cyclura. Major populations have been extirpated within historic times. Probably no presently existing population is entirely free from pressures induced by man and his animals. It is increasingly clear that a thorough knowledge of the habits and adaptations of our fauna is necessary if we are to be able to insure their survival in the face of continuing and increasing cohabitation with humans. It was for these reasons that study was begun on a still relatively common species: Cyclura carinata, the Turks Island iguana. From September, 1973, through June, 1976, C. carinata was studied both in the field in the Turks and Caicos Islands and in the laboratory.

The goals of the study were: 1) to obtain data on the behavior, adaptations, life history, and community role of this species; 2) to determine what factors 1 imit population size; 3 ) to propose methods by which the species might survive cohabitation with man, without threat 
of extinction; and 4) to provide an indepth charter study for extrapolation to similar investigations of other less common and more endangered species of Cyclura in the West Indies.

\section{Systematic Relationships and Distribution}

The genus Cyclura is most closely related to the three largest herbivorous iguanine lizard genera inhabiting continental North and Central America: Ctenosaura, Iguana, and Sauromalus. On the basis of myology and osteology Cyclura is most similar to Ctenosaura and next most similar to Iguana (Avery and Tanner, 1971). Endemic to the Antilles and Bahamas, Cyclura apparently evolved from a pre-Ctenosaura stock isolated in the islands. The genera Amblyrhynchus, Brachylophus, Conolophus, Ctenosaura, Cyclura, Dipsosaurus, Enyaliosaurus, Iguana, and Sauromalus comprise the subfamily Iguaninae (Avery and Tanner, 1971).

There are seven extant species comprising the genus Cyclura, distributed from the northern Bahamas through the Greater Antilles (Schwartz and Thomas, 1976). Pleistocene remains are known from several islands within the present range (review in Carey, 1975). Cyclura carinata is closely allied to C. rileyi (San Salvador, Bahamas). The two species share a number of characters (lack of enlarged, tubercular, median frontal shields; presence of dorsal crest, with elongate spines, interrupted on shoulders and rump; maximum size less than 1 meter, etc.) and are both distributed in the southern half of the Bahaman archipelago.

The relationship of Cyclura ricordi (Hispaniola) to $\underline{C}$. carinata deserves additional study despite the larger size (commonly exceeding one meter total length) of the former. The two species have similar 
dorsal crests, pigmentation patterns, and are the only two species of Cyclura without enlarged supracephalic scales.

\section{Study Area}

The Turks and Caicos Islands lie to the southeast of the Bahama Islands between latitude $21^{\circ}$ and $22^{\circ} \mathrm{N}$ and longitude $71^{\circ}$ and $72^{\circ} 31^{\prime} \mathrm{W}$ (Figure 1). Although politically distinct from the Bahama Islands, this British Crown Colony is geologically part of the Bahaman Archipelago. The islands are situated approximately $150 \mathrm{~km}$ north of Hispaniola and $890 \mathrm{~km}$ southeast of Miami, Florida. They consist of two groups of islands separated by a $35.5 \mathrm{~km}$ wide, deep water (> $2200 \mathrm{~m}$ ) channel, the Turks Island Passage. The Turks Islands lie east of the passage, the Caicos, to the west. The former consist of two inhabited islands (Grand Turk and Salt Cay), six uninhabited cays and numerous emergent rocks.

The Caicos Islands 1 ie along the perimeter of the Caicos Bank, a nortinest-to-southeast-lying triangular shoal with a base and altitude of approximately 125 and $75 \mathrm{~km}$, respectively. Depths frequently exceed $180 \mathrm{~m}$ within $2 \mathrm{~km}$ of the reefs surrounding the Turks and Caicos banks. Each of the banks is surrounded by depths of at least $1800 \mathrm{~m}$. The highest elevation in the islands barely exceeds $85 \mathrm{~m}$ (on Providenciales). The present surface area of the islands, as calculated by the Turks and Caicos Survey Department, is approximately $500 \mathrm{~km}$, with only $27 \mathrm{~km}^{2}$ in the Turks Islands group. Recent evidence indicates that shoaling sand is filling many of the cuts, linking previously separated cays via sandy isthmuses (Noble and Klingel, 1932). 


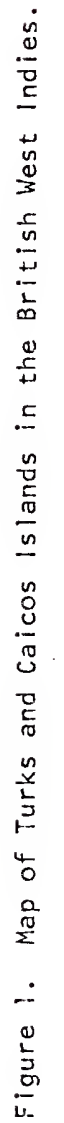




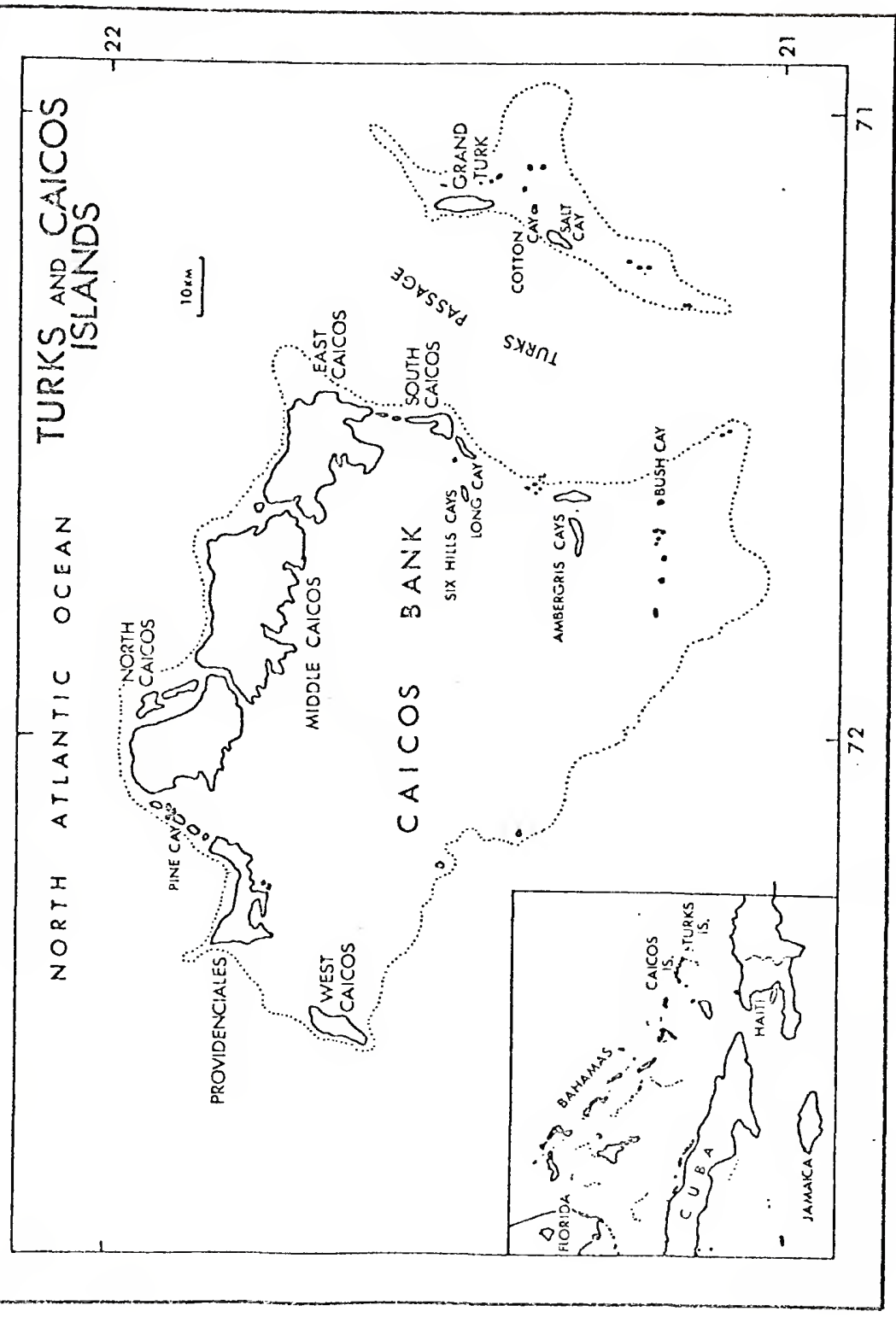


Although these changes are usually not rapid, the effects of tropical storms can be. When Hurricane Donna passed directly over the Caicos Islands in 1960 the cut between Pine and Water Cay was blocked by sand, connecting the islands. Shoaling since then has nearly filled the cut. These changes are now and probably have been in the past, very important to the dispersal of fauna and flora between islands of the bank.

My studies of Cyclura carinata in the Turks and Caicos Islands were predominately based in the West Caicos Cays. The major islands comprising this group are, from north to south, Parrot, Dellis, Fort George, Pine, Water, and Little Water Cay (see inset, Figure 2). Studies reported here were confined to the latter four. These islands are phenetically very similar. Each has its leeward sandy beaches, windward rocky coasts and mangrove swamps, inland brackish water lakes, northeast-to-southeast lying karst ridges paralleled by sandy dunes, maximum elevations of eight meters, vegetation increasing in luxuriance from west to east, and dense Cyclura populations.

Study was concentrated on Pine Cay, a privately owned island of nearly 350 ha (Figure 2). The average elevation on Pine Cay is less than three meters. Only three points on the island exceed six meters; the highest point on the island barely exceeds eight meters. Extraordinary in the Bahama Archipeligo, Pine Cay lies over an impermeable basin preventing salt water intrusion. Maintained solely by rainfall, a freshwater lens sometimes exceeding $15 \mathrm{~m}$ in thickness occupies this basin. Average storage capacity has been estimated at over 510 million liters. The water table is exposed in seven inland lakes. This availability of fresh water is in part responsible for the presence 
Figure 2. Topographic map of Pine Cay, Caicos Islands, showing locations of principal study sites: 1.) SW Blind, and 2.) Ridge Area. Letters A through $F$ indicate sectors of flush transect route (dotted line). Other trails and roads are not illustrated. Dashed line encloses limits of Hotel grounds. Unnumbered shaded areas indicate lakes. 


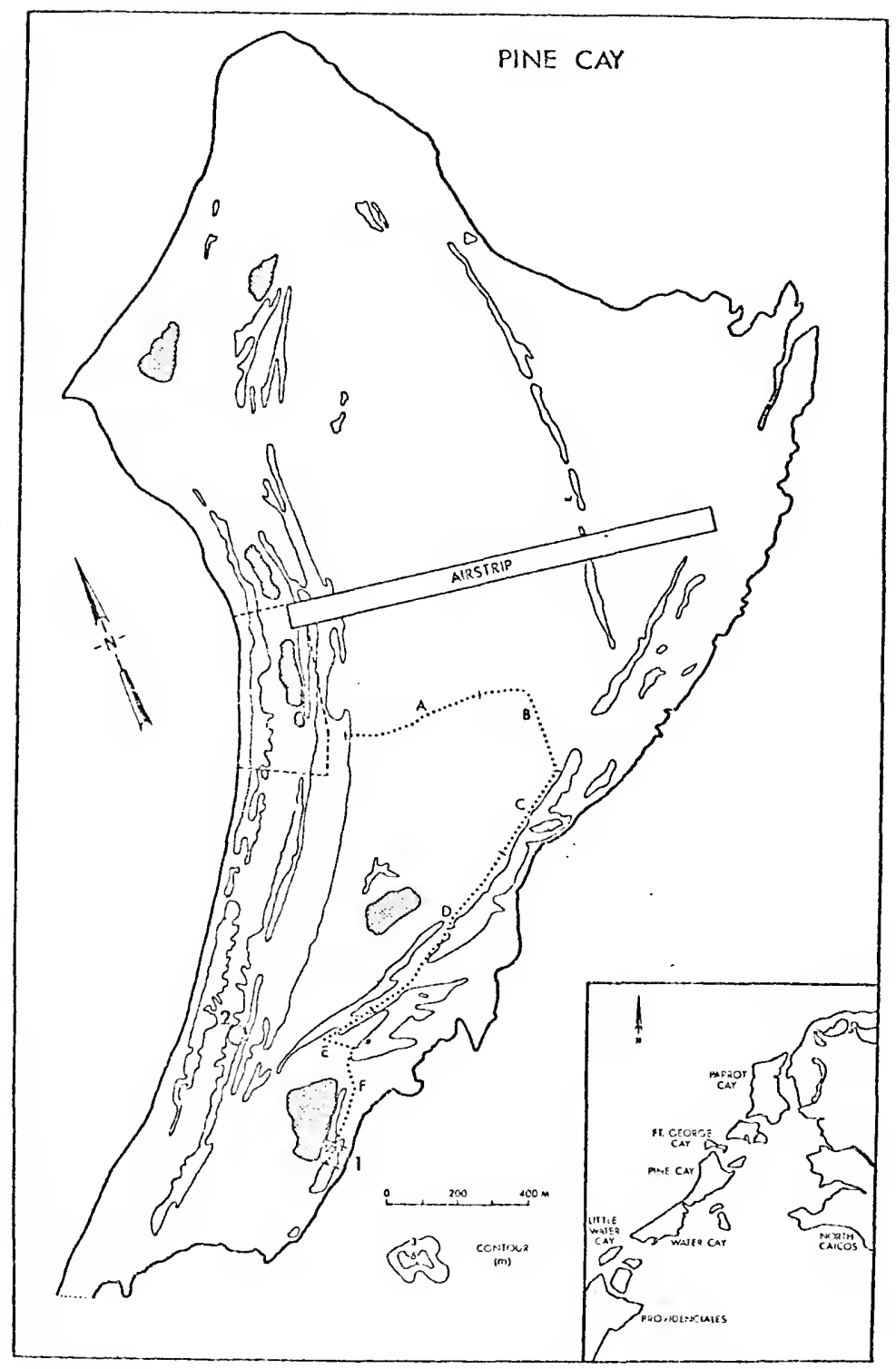


on Pine Cay of an extensive stand of Caribbean pine (Pinus caribaea) found elsewhere in the Bahamas only on North Caicos, Grand Bahama, A.baco, Andros, and New Providence (Rabb and Hayden, 1957). Vegetation on Pine Cay varies from sparse on the most recent westerly sand beach ridges to dense on the geologically older coral ridges to the east with better developed soils (see Vegetation).

During the summer of 1973, construction began on a private resort hotel, the Meridian Club, on Pine Cay. I was thus presented with an opportunity to study the consequences of increased human interference on theretofore relatively undisturbed iguana populations.

\section{Zoogeographic Relationships}

The Turks and Caicos fauna is part of a larger southern Bahaman faunal group which includes the islands southeast of the Crooked Island passage plus Rum Cay and Watling's lsland farther north. At least 19 reptiles are endemic to the area, and although strongly divergent, most have a Greater Antillean ancestry (Schwartz, 1968). This is despite the fact that the Bahaman platform has had its closest geological relationship with the North American tectonic plate since Triassic times (Freeland and Dietz, 1971).

Among the amphibians, only Hyla reaches into the southern Bahamas from the north and then only to the Mayaguana passage. None are associated with Cyclura carinata. Over 115 species of birds have been identified on the Turks and Caicos Islands (Buden, pers. comm.). Differentiation of at least two of these has occurred within the southern Bahaman faunal region: Columbina passerina and Calliphlox evelynae (Bond, 1961). The avian species most important to the biology 
of Cyclura will be discussed under sections concerning specific relationships (see I:ITERSPECIFIC COACTIONS and FOOD AND FEEDING). Among the depauperate mammalian fauna only the bat Monophyllus redmani has apparently diverged within the southern Bahamas (Buden, 1975).

\section{Materials and Methods}

Preliminary evaluations of Cyclura populations in the Turks and Caicos Islands were made by Walter Auffenberg between August 4 and 14 , 1973. Those investigations revealed Pine Cay in the West Caicos Islands to be the most feasible island for study for several reasons, including the availability of water and adequate lodging, and the presence of an extremely dense Cyclura population. Specific study sites on Pine Cay were designated during my first visit in September, 1973.

Eleven trips to the Caicos have been made, with 163 days spent on Pine Cay and nearby islands (September 15-29, December 8-22, 1973; March 2-16, June 1-July 20, August 29-September 10, November 26-December 6, 1974; April 1-14, July 29-August 16, November 4-11, 1975; and May 1 to 8, June 8 to 15, 1976). Twelve additional days were spent observing and assessing Cyclura populations on numerous eastern islands of the Caicos Bank. Field notes from the Caicos islands were made available by Walter Auffenberg (48 study days from September, 1973 through 1975) and David Auth (112 days from June, 1974 through February, 1976). Copies of all of our field notes are filed in the Herpetological Library of the Florida State Miseum.

A site of approximately 0.9 ha in the southwestern corner of Pine Cay was chosen as my major study area to be used mainly for behavioral observations with as little interference and manipulation as possible on 
my part (Figure 3). The area was initially chosen due to the abundance of lizard spoor and manure on open areas, and the generally good visibility below the canopy.

An abundance of signs typically reflects lizard density in the immediate area. Since Cyclura carinata on Pine Cay were extremely shy, it was necessary to construct a blind in this southwestern study site. Lizards generally ignored the blind after it was in place for only one day. A total of 47 days (287 hours of actual observation) was spent in this bline during the study period. In order to accurately quantify observed lizard movements, yellow marker flags, spaced six meters apart, were placed in a measured grid system around the blind. Each marker was assigned a letter $N$ (north of the blind) or $S$ (south), and a number (related to the distance from the blind). Thus a lizard at "N-5 West three meters" was located three meters west of marker number " $N-5$ ". This greatly increased the speed and accuracy of data recording, and allowed me to tabulate precise lizard movements. Over the course of field work, this entire study area was very thoroughly and accurately mapped. Surveyors and topographic maps, prepared under the direction of Liam Maguire of the Meridian Club and based on numbered cement lot markers on Pine Cay, and aerial photos (personally taken) made possible precise mapping of lizard and other landmark locations.

Field notes were recorded on a cassette tape recorder each day and transcribed in the field notebook at night. A Minolta SRT $10135 \mathrm{~mm}$ camera, Sony AV 3400 portable video camera and recorder, and GAF ST/602 Super 3 movie camera were all employed to record lizard behavior. In excess of 1400 slides, 110 minutes of video, and 50 feet of movie film were taken. The utmost care and patience was always taken at the southwestern blind to minimize inter- 
Figure 3. SW Blind Study Area 


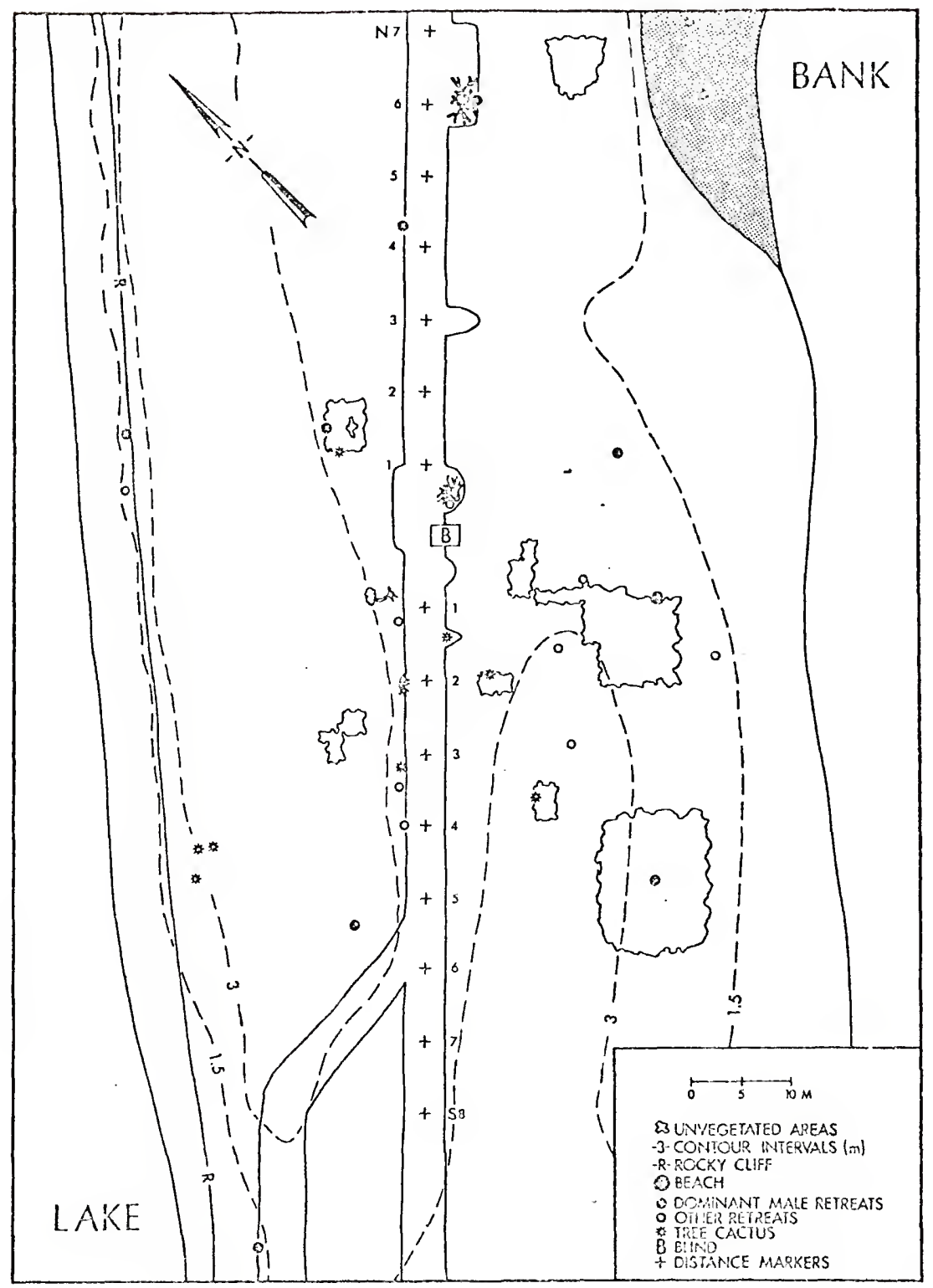


ference with the natural system. Early in the study the resident population was marked without handling by means of a "Paint Rifle", a large plastic syringe firmly mounted on the end of a $1 \mathrm{~m}, 2 \mathrm{~cm}$ diameter, dowel. Maximum range exceeded ten $m$, with accuracy possible to six to seven $m$. Lizards were not at all bothered by this technique. By shooting various colors of paint on various parts of the body, recognition of individuals was possible. Index cards with outline drawings of the right and left sides of a lizard were used to record marking and color formation, as well as sex and natural external morphological data for each lizard. The cards were modified as parts of the paint pattern were shed and/or the lizards were remarked. Even after three month absences, remnants of paint patterns, in conjunction with activity range and behavioral information, could be used to re-establish the identity of individual lizards.

As the study progressed, lizards were occasionally noosed from the blind for accurate measurement. In order to attract lizards to the blind for this purpose, as well as to induce lizard interaction, numerous substances were experimented with as "baits". Among the items tested were local fruits and flowers, soda and Ritz crackers, peanut butter, vanilla extract, crab parts, other vertebrate carrion, and sardines. The latter was the only substance that proved effective as a bait, and its effect was striking; adult males would occasionally cross the territories of at least three other territorial males to obtain the sardines. This bait was, however, less effective during the colder parts of the year and also when high winds rapidly dissipated the fishy odor. Foreign (to the study site) lizards, restrained in hardware 
cloth cages or on tethers, were sometimes introduced into the activity ranges of established lizards and the resulting behavioral interactions recorded.

Lizards on islands with even minimal human traffic were difficult to capture by noosing except from blinds, so this technique was not frequently used on Pine Cay, except at the southwestern blind study site (hereafter reforred to as the SW BIind). The technique was, however, fairly successful on islands rarely visited by humans. Juvenile lizards and occasional adults could be secured by chasing them under rocks or into hollow sticks and logs, from where they could be removed by hand. Noose snare traps and funnel traps at burrow mouths in areas of great activity were each experimented with, but met with only minimal success. Lizards were sometimes obtained by removing them from their burrows. Nests discovered in this process were either removed to the laboratory or marked for further observations. Numerous freshly killed or mortally wounded individuals were also secured from the mouths of local dogs and cats. In addition, the dried remains of many mammal-killed Cyclura were collected. An attempt was made to collect a sample of at least a few lizards during each season of the year to be used for dissection. Besides those lizards killed by dogs and cats, the bulk of this sample included lizards removed from the area on Pine Cay destined for occupation by a hotel and its adjoining beach cottages. Since most of these 1 izards would have been killed by bulldozer activity, this seemed the best source of material for dissection. Specimens for dissection ware weighed, measured, and preserved in formalin in the field. Transferred to isopropyl alcohol in the laboratory, preserved specimens were autopsied for reproductive condition, gut 
content, fat bodies, and presence of parasites. Ovaries, testes, and fat bodies were excised, blotted, and weighed to the nearest $0.01 \mathrm{gm}$. in females, all yolked ovarian follicles, oviducal eggs, and corpora lutea were measured to $0.1 \mathrm{~mm}$ with dial calipers. Testes volume was determined by water displacement.

In order to collect data on growth, lizards located in the area immediately adjacent to the site chosen for construction of the hotel were marked and released on the first visit to the study island. On each of four succeeding visits within a year, no recaptures were made despite a continued marking program all along the dunes parallel to the northwest coast. The disappearance rate in this habitat was obvious on my first return to the island (December, 1973) when not a single iguana was seen in my original mark-recapture area. A second site was sought, one less disturbed and more densely populated. In July, 1974 , another mark and recapture program was initiated on an area of approximately 1.85 ha on the north end of nearby Little Water Cay (Figure 4). Habitat and vegetation there are virtually identical to the areas of Open Scrub on Pine Cay (see HABITAT). Growth data were also collected on numerous juveniles maintained in laboratory on lettuce, cat food, and bean sprouts.

Body length (snout to vent), tail length and condition, body weight (measured to the nearest five gm on a Chatillon $3 \mathrm{~kg}$ spring balance), sex (when possible), and any other obvious external morphological characters (especially in juveniles) were recorded for all lizards during the mark and recapture program. Maximum height (in mm) and rumber of annuli on dorsal spines of the neck, back, and proximal tail regions were also recorded for each adult. Each lizard was then 


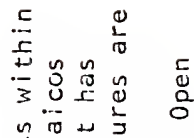

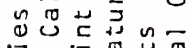

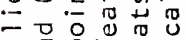

$\widehat{5}^{\frac{c}{2}}+4-\frac{\pi}{2}$

的骂

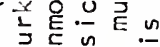

(0)

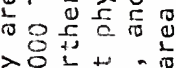

>0

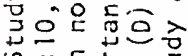

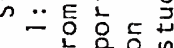

늘은 의

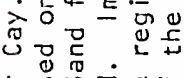

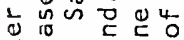

范告.

$\geqslant \hat{x}$

응응

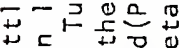

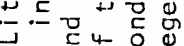

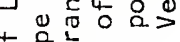

范心0.

品 0 .

뭉

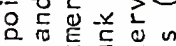

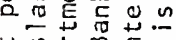

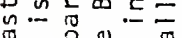

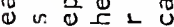

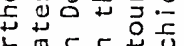

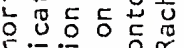

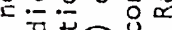

드료 $\underbrace{4}_{1}$

ॠण 范山苏

ขั

드음

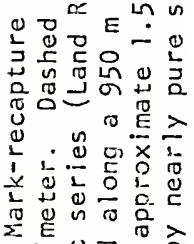

임

-

+ $\Omega$ 品

ข 문음

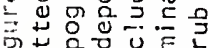

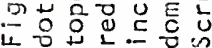




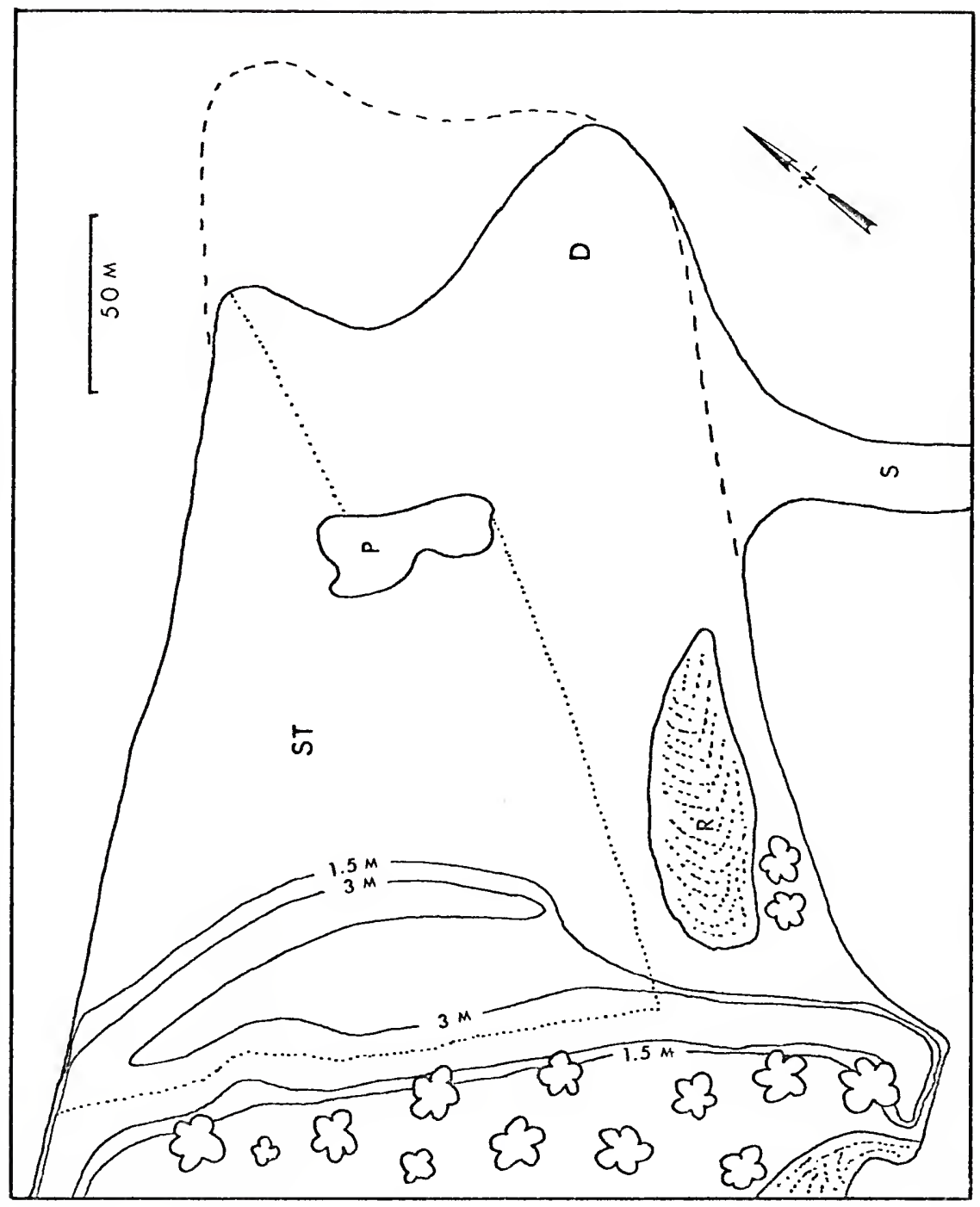


marked with a unique combination of at most two clipped digits, and released as soon as possible following capture (always within the hour). At the SW Blind "belts" of various colors modified from cat collars were secured around several lizards "waists" for later recognition. In addition to lizard movements observed at the SW Blind, it was sometimes possible in sparsely vegetated dune sand areas to map a single lizard's activity range for a single day by his spoor. Since rain and wind quickly obliterate the tracks, this method is useful only if mapping is done late in the afternoon (following lizard submergence) on days lacking high winds or precipitation. A $15 \mathrm{~m}$ length of kite string was several times secured around a captured lizard's abdomen just anterior to his hind 1 imbs. On release he would drag the string through the bush and a small portion of his movements could later be plotted. The success of this method varied, since the string occasionally became entangled in brush and was broken. A three $m$ length was similarly employed with success to locate captured lizard's home burrows at the SW Blind. Following lizard submergence, known burrows were checked for string trailing into them.

Lizards were also tracked using radio telemetry. This technique was used effectively in lizard displacement and homing experiments as well as for recording daily movements. All telemetry equipment was purchased from Mini-Mitter Co., Inc., Indianapolis, Indiana. Transmitters used were Model L Mini-mitters operating at just over 27 HhZ. A 3-channel Lafayette HA 420 walkie-talkie fitted with a Mini-Mitter Beat Frequency Oscillator served as a receiver. A Mini-Mitter Model AF Directional Antenna was employed early in the study; however, technical problems precluded its use for most of the study. Triangulation by signal 
strength received from a whip antenna along right angle transects proved much more effective, especially in areas of dense vegetation. The signal with this equipment varied from $100 \mathrm{~m}$ in sparsely vegetated dune areas to just over $50 \mathrm{~m}$ in thickly vegetated, rocky areas with greater relief. The range was entirely sufficient for successful use with this species.

Transmitters were secured to the previously described cat collar identification belts with electricians tape and strapped to the lizard's waist. A short length of twine was tied to the transmitter package atop the belt. Transmitter retrieval could then be accomplished by simply pulling the package from the lizard (leaving the belt in place for identification) as he lay in his burrow at night or early morning. In this way, a second disturbance of the monitored lizards was eliminated. The short trailing string did not seem to bother the lizards or hamper their movements in any way.

Measures of lizard activity were made in basically three ways: 1) direct observation; 2) clocking mechanisms at burrow entrances, and 3) flush transects. To record lizard emergence and submergence times, an alarm clock was remodeled as a single-event recorder in a technique similar to that of Arltan (1936). A hole was drilled through the outer case of each of several inexpensive spring wind clocks directly above the timing wheel. The gravity operated trigger mechanism consisted of a small square of cardboard over which an elongate paper clip loop was suspended. A fine nylon thread attached to the cardboard square was stretched across the entrance of a lizard burrow. Disturbance of the thread removed the cardboard allowing the wire loop to drop through the timing wheel, stopping the clock. 
A flush transect method similar to the 'King strip census' (see Giles, 1971, for discussion) was also utilized for activity patterns as well as density estimates. The technique consisted of traversing a permanent census trail at different times throughout the day during each visit to the study island (Figure 2). Distance along the transect route where each lizard was flushed and distance from trail to lizard (before being flushed) were recorded. A total of 103 transects was run during the course of the study. Data from the flush transects, coupled with direct data at the SW Blind study site provided the major basis for analysis of activity patterns and estimates of lizard density. In order to test and insure the accuracy of this transect method, the transect route passed through the SW Blind site, from which the most reliable density datawas presumably available. The success of flush transects on Pine Cay was the result of the character of the island itself as well as that of the lizard. Cyclura on the study island are very wary and typically run when a human approaches. Although many lizards were seen during transects, the location of most was possible only after they bolted off over noisy leaf litter. This technique could therefore be successful only in areas where the vegetation was dense enough to prevent the lizard from seeing the observer until he (the observer) was within audible range of the noise of his flushing. Such was the case along the transect route 1 utilized.

Lizard burrow structure was investigated by digging up several burrows. Inactive burrows were usually chosen for excavation in order to ninimize interference with lizard populations. However, several active adult burrows were unearthed in order to obtain the inhabitant 
in an attempt to correlate burrow structure with sex and size. Lizards so obtained were either displaced for homing experiments, brought to the laboratory for behavioral observation, preserved for dissection, or released into nearby inactive burrows after marking. The structure, including length, direction, depth and substrate for all parts of each excavated burrow was recorded. Eggs unearthed in nature as well as captive clutches were removed to the laboratory in Gainesville for incubation in moist sand under constant conditions. In an attempt to study turnover rates in burrow utilization, all burrows in a randomly chosen circular area (radius $26 \mathrm{~m}$, area $0.22 \mathrm{ha}$ ) along the limestone ridges of the leeward side of southwestern Pine Cay were surveyed on six consecutive visits beginning in December, 1973. This site was designated the Ridge Area (Figure 2).

Before analysis of diet in this herbivorous lizard was possible, it was necessary to collect and identify the majority of the plant species on Pine Cay. Bob Anderson, graduate student in Botany, University of Florida, accompanied and assisted me in making preliminary plant collections and identifications, and vegetation transects, on my first visit to Pine Cay, in September, 1973. Thereafter, plant samples were recollected seasonally by myself and Walter Auffenberg, so that as many vegetative forms (especially reproductive parts) as possible of each species were available to us for identification. Botanist Don Corréll of Fairchild Tropical Gardens, Miami, Florida, made further plant collections and identifications during a visit to the Caicos in August, 1974. From these various collections, a reference catalog of seeds, fruits and leaves was built up for use in identification of lizard food items. 
To supplement stomach content analysis from preserved specimens, 311 scats were collected from the SW BI ind and Ridge areas for use in food studies. Walter Auffenberg collected an additional 308 samples from other areas on Pine Cay. Old scats (those bleached and/or broken apart) were not collected on Pine Cay in order to el ininate the possibility of sampling a time period other than the current one. However, all manure encountered on other of the Caicos islands were collected for analysis. In all, over 670 scats were available for study. Seeds, elements of arthropod exoskeletons, and most leaves pass through the lizard's digestive system with almost no alteration in shape, making food item identification possible from the manure. Records were also made of species and parts of plants directly observed to be eaten by Cyclura. Indirect information on diet came from iguana tooth marks on partially cropped plant parts.

Environmental temperatures were taken with an Atkins Model $3 F 0$ recorder with remote sensing probes. Precipitation was collected in a standard $5^{\prime \prime}$ capacity rain gauge, but was monitored only when an investigator (David Auth or myself) was on Pine Cay. Climatic information collected continuously from 1900 to 1968 at Grand Turk Auxillary Airfield, Grand Turk (21 $26^{\prime} \mathrm{N}, 71^{\circ} 8^{\prime} \mathrm{W}$; elevation 4 meters) and provided by the National Climatic Center, Asheville, North Carolina, has been used to supplement data recorded on Pine Cay.

An enclosure approximately $3 \times 8 \mathrm{~m}$ with walls $1.25 \mathrm{~m}$ high, was constructed in my yard in Gainesville, Florida for captive behavioral observations. An observation blind was erected adjacent to the pen. Seven burrows of buried hollow concrete blocks were available in the 
pen. The substrate was well vegetated with lawn grasses and small weeds. Eight clumps of Opuntia sp. were added, and the pen was seeded semimonthly with lentil bean and assorted flower seeds. An ad libitum food supply of lettuce, bananas, commercial cat and dog food, sardines, tomatoes, and Opuntia blossoms (when available) was provided. A full ten liter water pan was maintained. Observations were made during mornings and were terminated during the usual midday reduction in lizard activity. Captive lizards were brought into the laboratory during the winter. They were kept in pens similar to those outdoors except in their smaller size and use of 250 Watt infrared lights a's heat sources.

Several terms used herein require clarification. The "Study Islands" include Fort George, Pine, Water, and Little Water Cays; the "Study Island" refers to only Pine Cay. The principal study sites on Pine Cay are designated as the SW Blind, and Ridge Area (Figure 2). Lizard body length or snout-vent length is abbreviated as SV; tail length as TL. All allusions to lizards, rock iguanas, or iguanas, refer to Cyclura carinata unless otherwise qualified by scienctific name. All material collected incidental to this study including other vertebrate and invertebrate specimens, has been placed in the collections of the Florida State Museum, University of Florida. Statistical methods are those of Steele and Torrie (1960) unless stated otherwise. Means are ordinarily given with \pm one standard deviation. Definitions of behavioral terms appear in text. 


\section{MORPHOLOGY}

Cyclura carinata Harlan was described in 1825 from "Turk's Island". The location of Harlan's holotype is unknown. The species can be diagnosed as follows: Nasals broadly in contact with the rostral. Frontal, fronto-parietal; and occipital regions covered by small irregular, strongly keeled scales. Circumorbital scales smaller than other supracephalic scales. Two to 4 enlarged, vertically arranged canthal scalses on each side. Dorsal crest broadly interrupted on the shoulders and rump; nuchal section of the crest with 16 to 20 spines (up to $2 \mathrm{~cm}$ ) which are longer than the 45 to 75 spines on the back. Dorsal crest spines exceed $5 \mathrm{~mm}$ in height only in males. Femoral pores average 21 on each leg (range 18-25). Verticil rows on the tail strongly keeled, with four vertical scale rows between fifth and sixth rows. Mid-dorsal tail scales enlarged and sharply keeled. Males less than $80 \mathrm{~cm}$ total length, females less than $65 \mathrm{~cm}$.

Two subspecies are recognized. The nominate subspecies can be distinguished by having the nasals separated by a large wedge-shaped scale; spinose, hexagonal scales on the outer tibial region, 3 or 4 of which equal the diameter of the tympanum; and fewere than 60 spines in the dorsal crest. Cyclura c. bartschi described from Booby Cay, east of Mayaguana Island, Bahamas Island (Cochran, 1931) is characterized by nasal scales usually in contact; 4 or more tibial scales equal to tympanic diameter, and usually more than 60 spines in the dorsal crest. 
The following morphological descriptions are based only on specimens and data obtained in Caicos Islands.

Dentition. The teeth of Cyclura carinata are heterodont. They are unicuspid at the symphysis and on the premaxillary; the remainder of the anterior teeth are strongly tricuspid. Median and posterior teeth are strongly compressed laterally and flared anterio-posteriorly, with a multicuspid cutting edge; the large median cusp is flanked by two or three smaller anterior and one or two posterior cusps. The tooth formula follows: 0-10 pterygoid; 0 palantine; 4-10 premaxillary; 17-23 maxillary; and 19-28 dentary. The dentition of $\underline{c}$. carinata is similar to the other iguanines (all herbivorous) in both tooth counts (Table I) and the presence of increasing cuspidation from anterior to posterior along the dentary and maxillary (see Avery and Tanner, 1971, for comparisons). The nearly contiguous, laterally compressed, multicusped, pleurodont teeth forming a continuous shearing surface are welladapted for leaf chopping and shearing (Hotton, 1955; Ray, 1965; Montanucci, 1968). Tooth counts (actually tooth positions) in Cyclura carinata increase ontogenetically (Figure 5) like those in Ctenosaura,

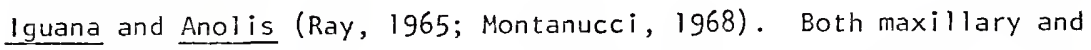
dentary counts were positively correlated with skull length $(r=0.905$ and $r=0.843$, respectively).

Skeleton. The basisphenoid is wider than long and slightly to moderately constricted behind the pterygoid processes; length/width ratio: $0.65-0.72$. Five or more foramina are present on the superficial surface of the rostral part of the premaxilla. The parietal foramen is small and pierced in the frontal or the fronto-parietal suture. The parietal is not produced 


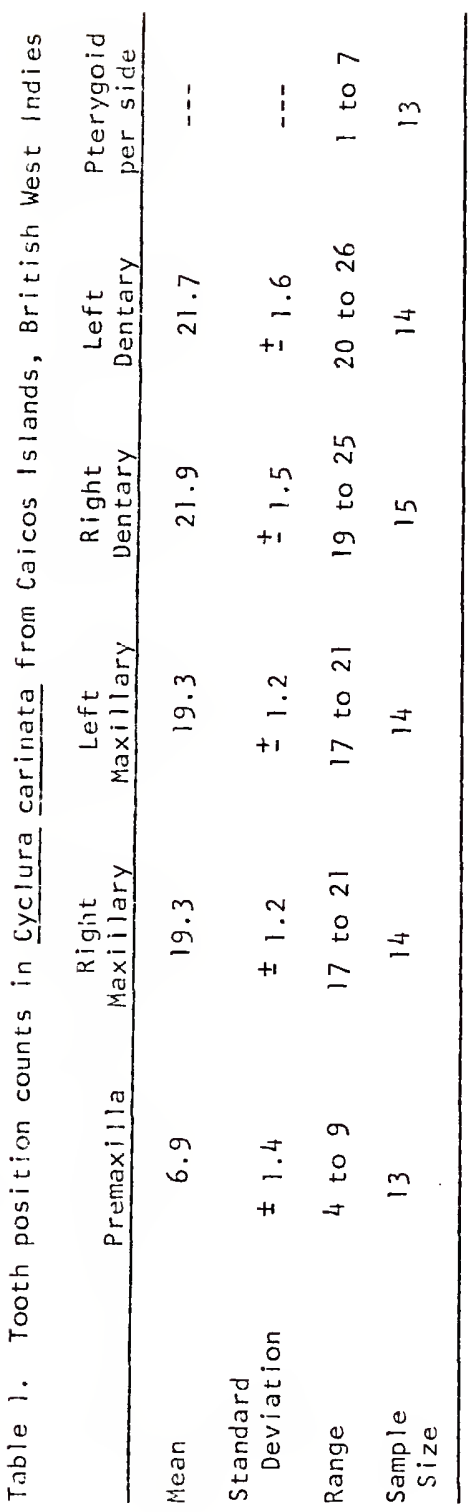




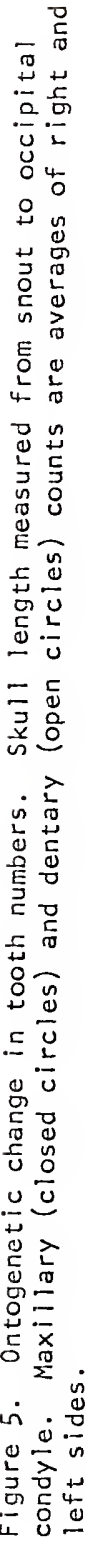




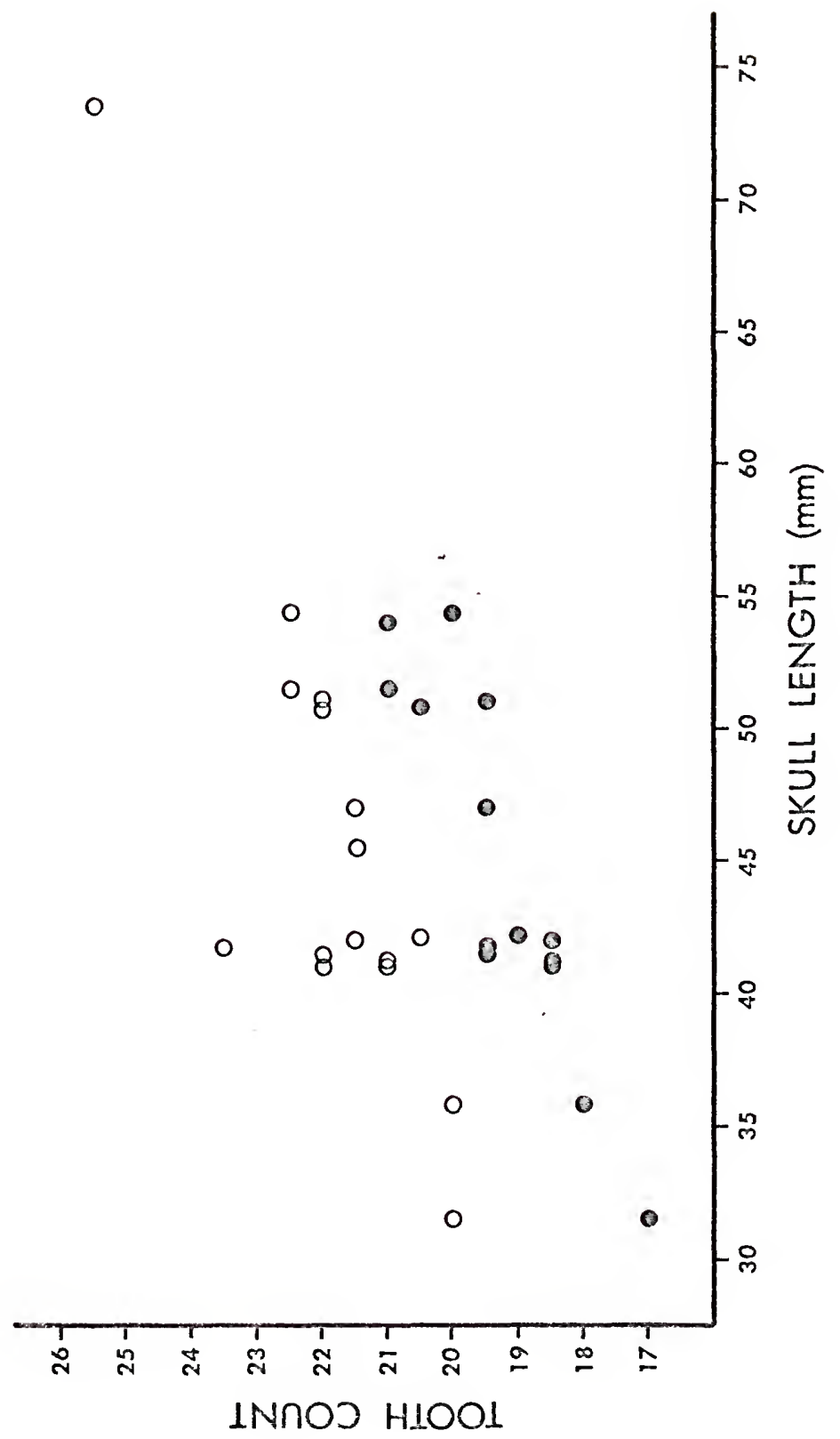


posteriorly. Angular and splenial elements are present. The splenial is long and narrow. The dorso-ventral borders of Meckel's groove are fused anterior to the splenial. The antero-ventral alveolar foramen is partially enclosed by the border of the splenial; the coronoid possesses a large process overlapping the dentary (Figure 6). 24 presacral vertebrate are usually present. The postero-ventral angular process is pointed and elongate, and directed antero-medially. Each presacral vertebra is provided with zygosphenes and zygantra in addition to zygopophyses. At least some autotomic caudal vertebrae have two pairs of transverse processes, the fracture plane passing between them. Scapular and secondary coracoid fenestrae are well-developed; clavicles are simple or with posterior hook-like processes; the interclavicle is T-shaped or arrow shaped; the sternal fontanelle is small or absent; and four sternal and two xiphisternal ribs are present (Figure 6). The hyoid apparatus of Cyclura carinata was studied by Avery and Tanner (1971) and my observations (Figure 6) do not differ from theirs.

Hemipenis. The hemipenial structure in the genus cyclura has not previously been illustrated. Since the only description available for the hemipenis in this genus is a brief one by Cope (1896), the organ in Cyclura carinata is here described. The hemipenis is single-lobed, subcylindrical to clavate. The sulcus spermaticus is a broad open groove along the posterior surface of the hemipenis. Calyces cover the distal half of the hemipenis, whereas the proximal half is covered with irregular creases. Spines or spinose structures are lacking. Based on hemipenial structure, Cyclura is most similar to the iguanine genera Iguana and Amblyrhynchus (Avery and Tanner, 1971). 

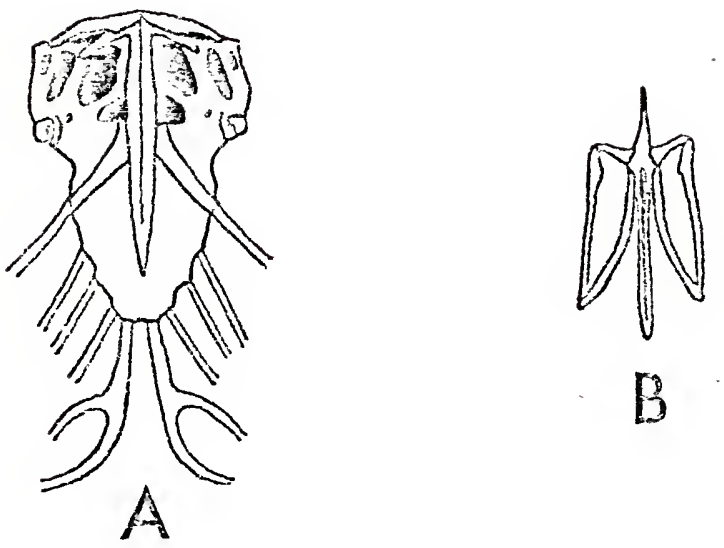

B

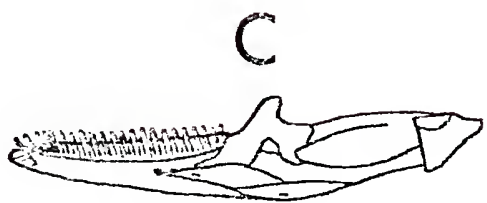

Figure 6. Skeletal elements of Cyclura carinata: A) Sternum (ventral view); UF 14354, Middleton Cay. B) Hyoid apparatus (ventral view); UF 14354. C) Mandible (medial view; tooth crown structure not illustrated); UF 32678, Middleton Cay. 
Lepidosis. Lizards in the genus Cyclura are the only iguanids possessing corneous subdigital combs on digits 2 and 3 ( $\$ 4=$ longest) of the hind limbs. Subdigital lamellae are multicarinate, not flattened, and lack a mat of hair-like processes.

Numerous other epidermal scale characteristics of Cyclura carinata were presented above; additional descriptive data are not here presented in anticipation of publication of a systematic analysis of the genus by Schwartz and Carey (in press). As previously stated, the spines of the mid-dorsal crest exhibit considerable sexual dimorphism in size. In fernales, neck spines never exceed $5 \mathrm{~mm}$ in height; maximum recorded back spine height for females was $3 \mathrm{~mm}$. Dorsal spines on the neck in males begin development (elongation) coincident with the onset of sexual maturity. Thereafter each time the skin is shed the spine increases in length and an annular impression is formed around its base. After 2 (sometimes 3) sloughs of the skin, the back spines begin development in exactly the same pattern as those of the neck. Back spines are therefore shorter and possess two fewer annuli than neck spines on most individuals. The relationship of the spines to sexual recognition and their annuli to growth and age are discussed later (see GROWTH). In old lizards the back spines approach or even exceed the neck spines in height, and the annuli become inconspicuous as the spines become smooth due to wear. The middorsal spines on the anterior portion of the tail in male iguanas also elongate with age albeit very slowly. A maximum height of $18 \mathrm{rm}$ is attained in extremely old individuals. Color. Rock iguanas exhibit great individual and population color variability. Patterns tend to be darker (gray, brown, or green, 
on population) immediately following emergence and preceding submergence each day. The midday coloration is typically light gray to bleached green (again related to population). This changing albedo is presumably an adaptation to increase absorptive radiation in suboptimal ambient temperature regimes (Cowles and Bogert, 1944). The change in color is most rapid during the morning basking period and has been $t$ imed at less than one hour. The relationships of changing albedo and skin reflectivity to thermoregulation are under study (Auth, in preparation). Seasonal color changes, related to hormonal levels, have been observed in numerous iguanid lizards (Carpenter, 1967; Ferguson, 1976) however, no such changes were evident in the studied population.

Inter-population color differences on the Caicos bank are very pronounced. Lizards from the eastern populations (Middleton and Long Cays) are very drab gray, dorsally and ventrally, with only slight changes in darkness of the gray. Lizards from Fort George and Pine Cays vary from a brownish to greenish-gray following emergence, to a nearly white-gray at midday. The venter is gray to blue-gray. A very abrupt pigmentation change occurs between Pine Cay and Water Cay to the south. Lizards from both Water Cay and Little Water Cay are the most brillantly colored of Caicos populations. Basically a dark graygreen on emergence, during basking these lizards become a pale yellowgreen. The typically lighter venter in these lizards is blue-gray flushed with yellow. The yellow coloration extends over the tail and on the ventral surfaces of the limbs and digits. Pine and Water Cays have apparently been separated throughout historic time by a deep water 
channel, allowing the maintenarice of very different color morphs. However, the channel was blocked with sand and Pine and Water Cays were linked by a sandy isthmus as a result of tropical hurricane Donna in 1960. Iguanas have not yet breached the open sand barrier of the isthmus, but will undoubtedly do so as primary succession provides the necessary shade and food plants. The effects of genetic interchange on the integrity of the two color morphs will be interesting. Cyclura carinata also exhibits a variable pattern of narrow vertical stripes on the dorsal lateral body surface. The stripes are most obvious near the anterior mid-dorsal line and become increasingly less apparent laterally and posteriorly. The stripes typically number 9 or 10 , and are areas where the pigmentation is simply lighter than adjacent regions. The pattern is most obvious in hatchlings and juveniles, and typically very obscure in adults.

Anatomy. Morphology of the thyroid gland in Cyclura carinata is discussed by Lynn et al. (1966). Digestive tract anatomy is discussed under FOODS AND FEED!NG. 
HAB ITAT

\section{Climate}

The Turks and Caicos Islands experience a typical tropical maritime climate. East-southeasterly tradewinds predominate, averaging $22.5 \mathrm{~km}$ per hour throughout the year, and annual air temperature fluctuationsare not great (Figure 7). Recorded annual air temperature extremes between 1960 and 1968 on Grand Turk ( $110 \mathrm{~km}$ to the east of the study island) were $15.6 \mathrm{C}$ and $36.0 \mathrm{C}$. However, microclimatic temperatures show much greater fluctuations both daily and seasonally. Temperatures on light coral sand substrates ranged from $12.5 \mathrm{C}$ to $60.0 \mathrm{C}$ on the study island; those on darker soils were considerably higher. Substrate temperature differentials between exposed and shaded areas were greatest during midday in July through August with a maximum recorded difference of $25 \mathrm{C}$ $(31-56 c)$. Twenty degree divergences are typical of summer days without midday precipitation. The maximum recorded winter (November-December) shaded-exposed substrate differential was $18.5 \mathrm{C}$.

To provide a general picture of the diurnal thermal environment, microclimatic temperature data from optimum days (unaffected by overcast or rainy conditions) on the study site were averaged by half hour for two periods, representing the longest and shortest days of the year (Figure 8). Data from six days in late June, 1974, and six in December, 1973, were used. These differences in sumer and winter temperatures are in part due to an annual fluctuation in day length (photoperiod) of nearly 
Figure 7. Average monthly temperature regime in Turks and Caicos Islends. Sutstrate temperatures were recorded at SW Blind, Pire Cay during study period; remaining temperatures coilected between 1900 and 1968 at Grand Turk Airfield, Grand Turk. 


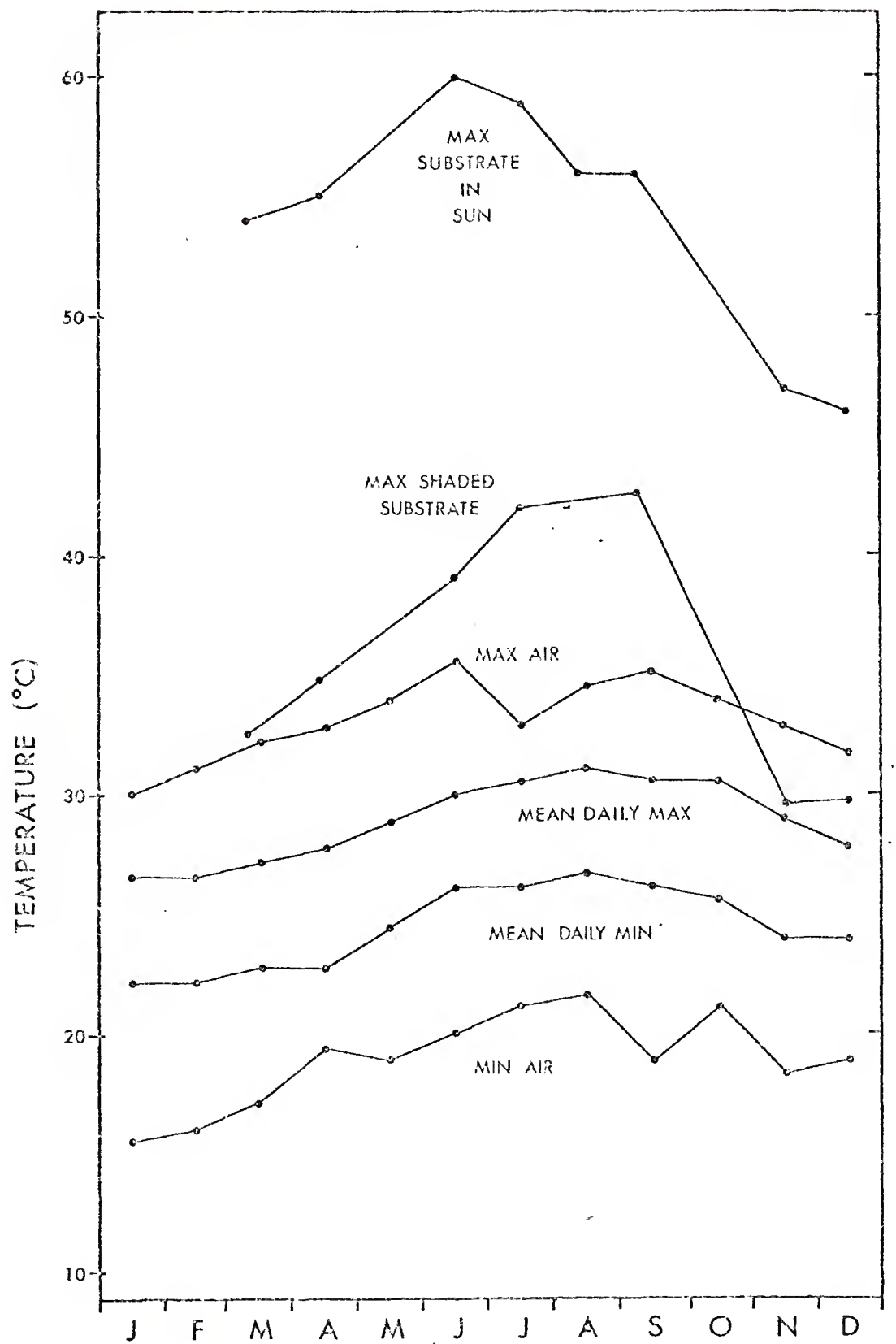


Figure 8. Average diurnal microclimatic temperatures for June and December at SW 81 ind study site. Data averaged by half hour for six storm-free days in June, and four in December. Arrows indicate sunrise and sunset. 


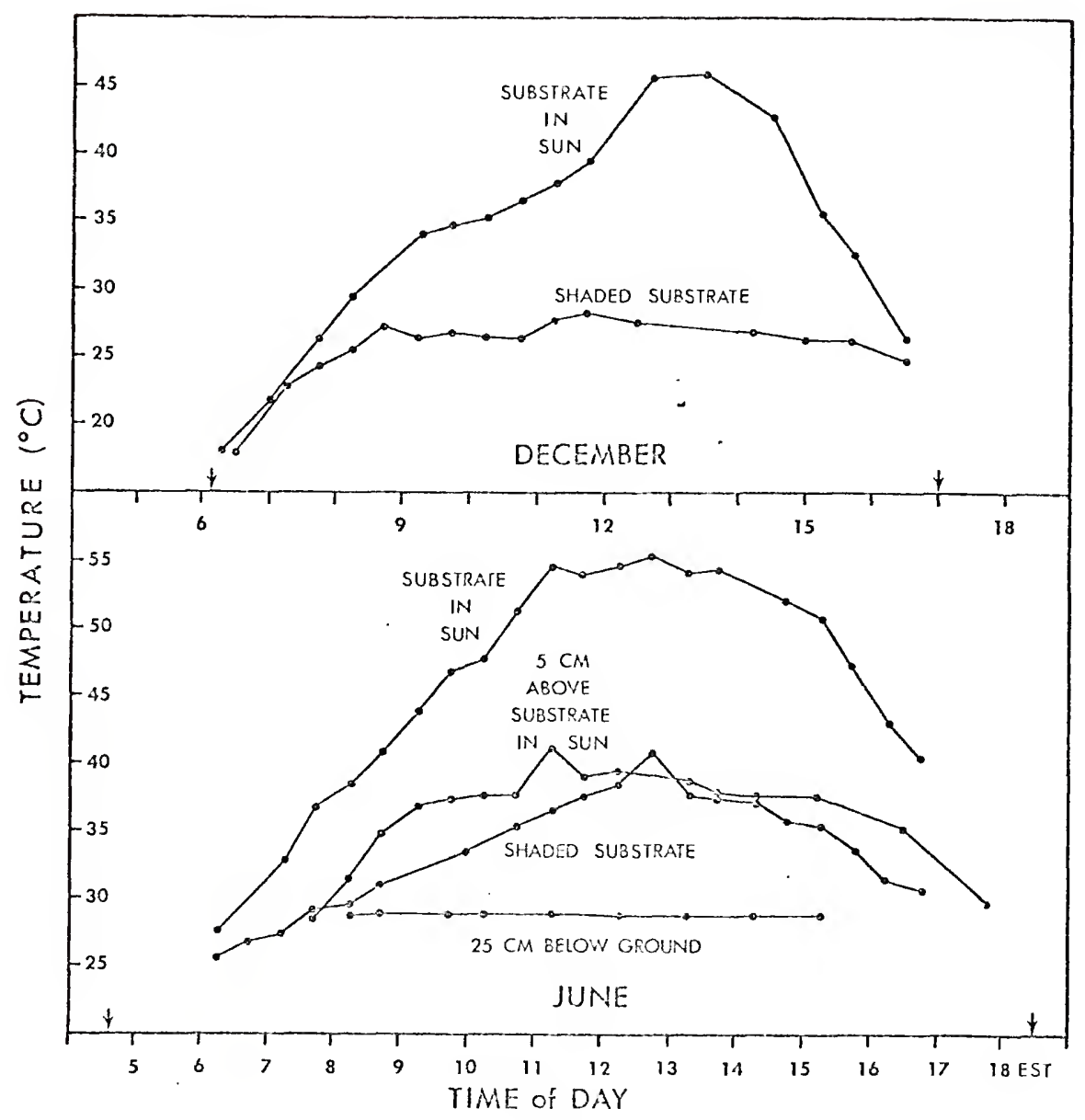


three hours (Figure 9). A more detailed analysis of the thermal environment and its relation to the biology of cyclura carinata on Water Cay, Caicos Islands, is found in Auth (in preparation).

Since it was possible for me to monitor rainfall only while on the study island, data collected between 1900 and 1968 at the Grand Turk Auxillary Airfield (Latitude $21^{\circ} 26^{\prime} \mathrm{N}$, longitude $71^{\circ} 08^{\prime} \mathrm{W}$; elevation four meters) are presented here, unless otherwise indicated. A well-defined dry season exists from January through May with monthly rainfall averaging only $13.5 \mathrm{~mm}$ (Figure 10). The wet season usually begins and ends rather abruptly in June and January, respectively, and rainfall averages $62.8 \mathrm{~mm}$ monthly. In addition to amount of rainfall, the percentage of days per month experiencing some rainfall also increases substantially during the wet season (Table 2). Average annual rainfall on Grand Turk is $597 \mathrm{~mm}$. However, based on $458 \mathrm{~mm}$ recorded on Pine Cay in 194 days over three years, the annual estimate is approximately $862 \mathrm{~mm}$, somewhat higher than on Grand Turk. Comparison of the vegetation, soil moisture, and general weather conditions across the bank on several occasions, in addition to information supplied by locals indicate that rainfall is greater on the more western islands of the bank, but probably does not exceed $760 \mathrm{~mm}$ annually.

Changes in rainfall, temperature, and photoperiod are the major aspects of climatic seasonality. The effects of each of these are reflected in lizard activity. Days are often cool enough to curtail lizard activity in the winter, but almost never so in summer. The climate in the western cays of the Caicos Islands is one of a warm dry spring (March to May), followed by a hot, wet summer (June to October) 


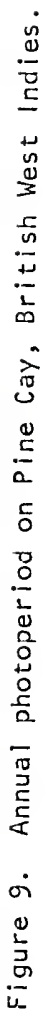




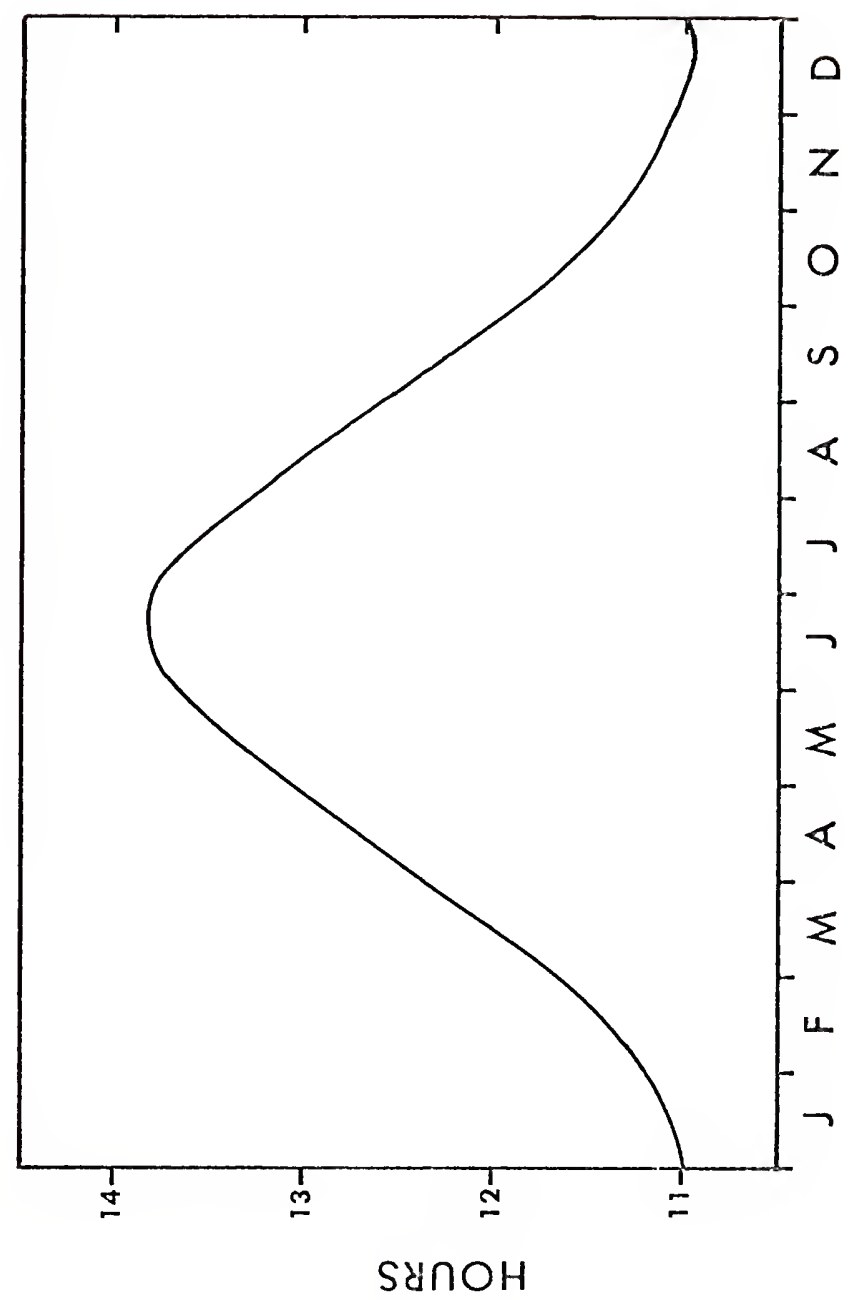




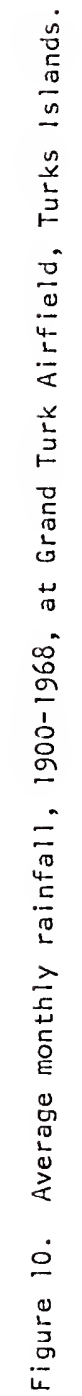




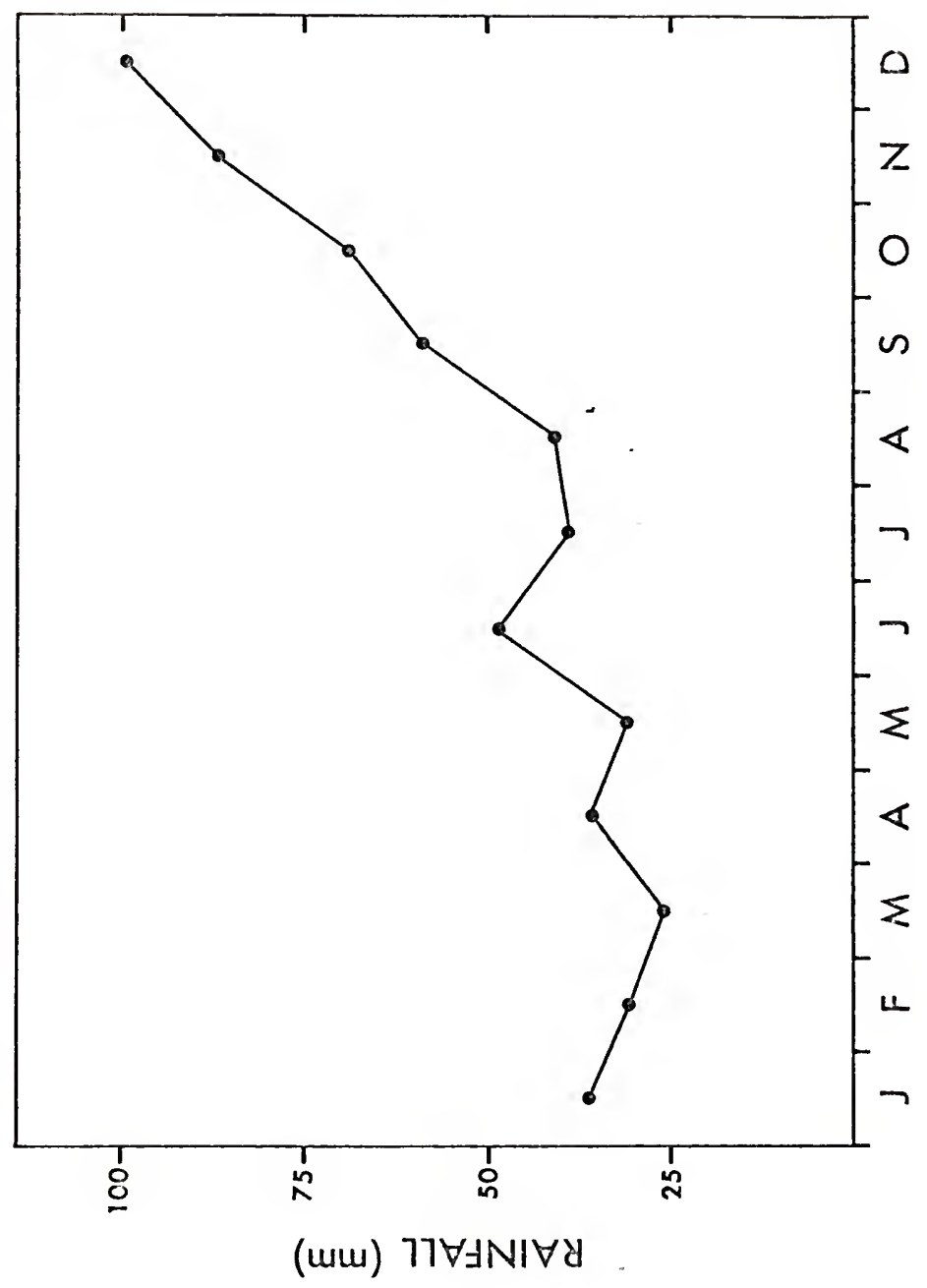


ปั่) ํํํ 웅

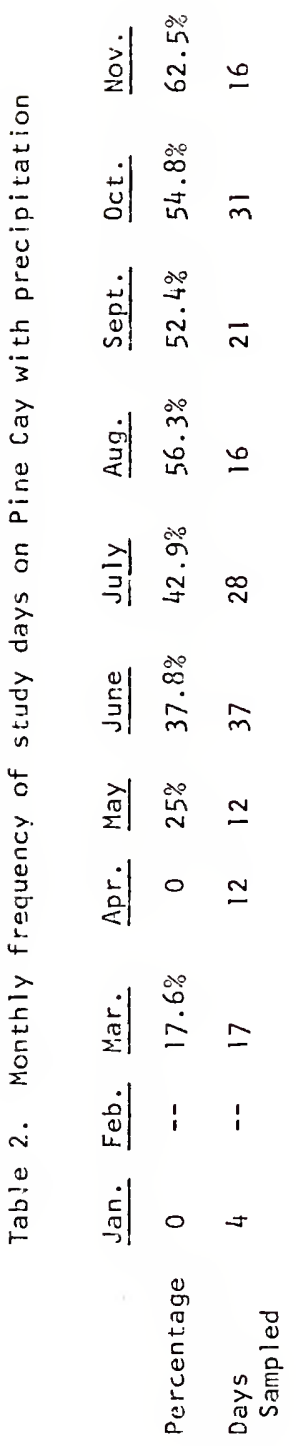


which grades into an even wetter, but still warm autumn (September to December), and is followed by cool, relatively dry winter (January to March). Abrupt changes in temperature and precipitation characterize the transition between the wet and dry seasons.

\section{So i 1}

Reflecting their reef origin, the Turks and Caicos Islands are characterized by honeycomb 1 imestone formations usually covered with coral sand. The rocks are typically exposed along the windward shores, with broad sandy beaches along the leeward. Inland accumulations of humus provide a rich nutrient source and support more luxuriant vegetation (see Vegetation).

Iguanas frequent rocky and sandy areas as well as the more elevated humus areas, but generally avoid the lower areas with thicker soils due to the proximity of the water table to the surface and their inability to dig through the root mass.

\section{Vegetation}

The spatial relationships of the principal vegetation types on Pine Cay are illustrated in Figure 11 and 1 isted in Tables 3 and 4 . The vegetation on Pine Cay corresponds to the "Evergreen Bushland" of Beard (1949), and is physiognomically very similar to that found on Anegada in the British Virgin Islands by D'Arcy (1975). The same genera (if not species) are represented in similar habitats on both islands. Although D'Arcy (1975) divided the flora of Anegada into only four primarily edaphic communities (shorelines, sandy plains, limestone 


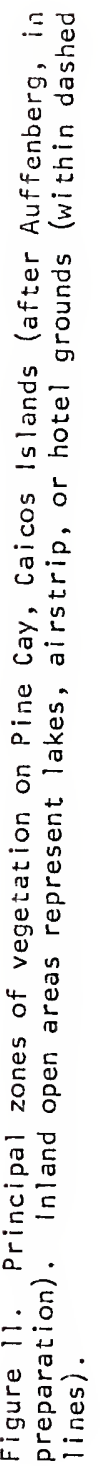




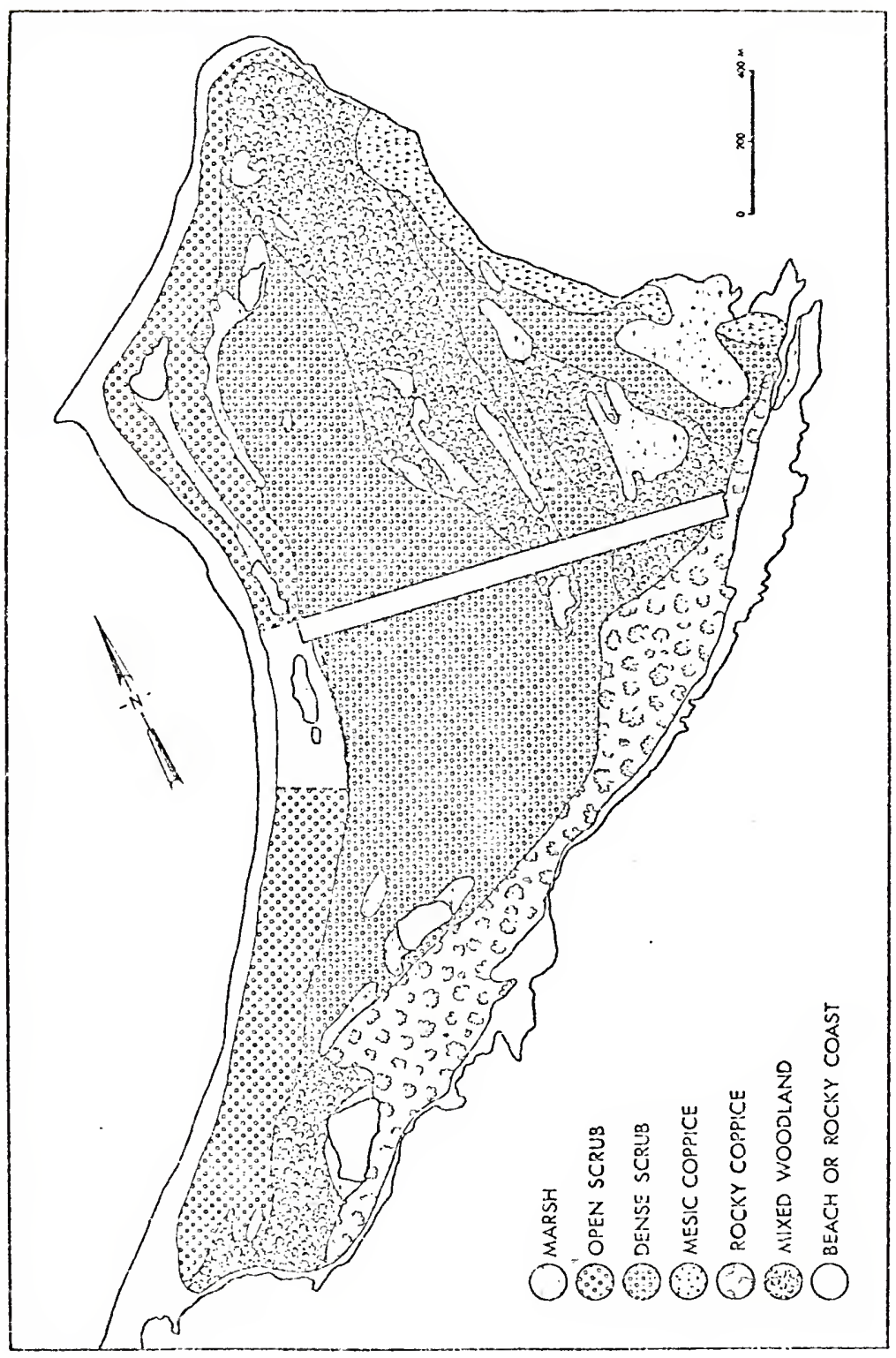




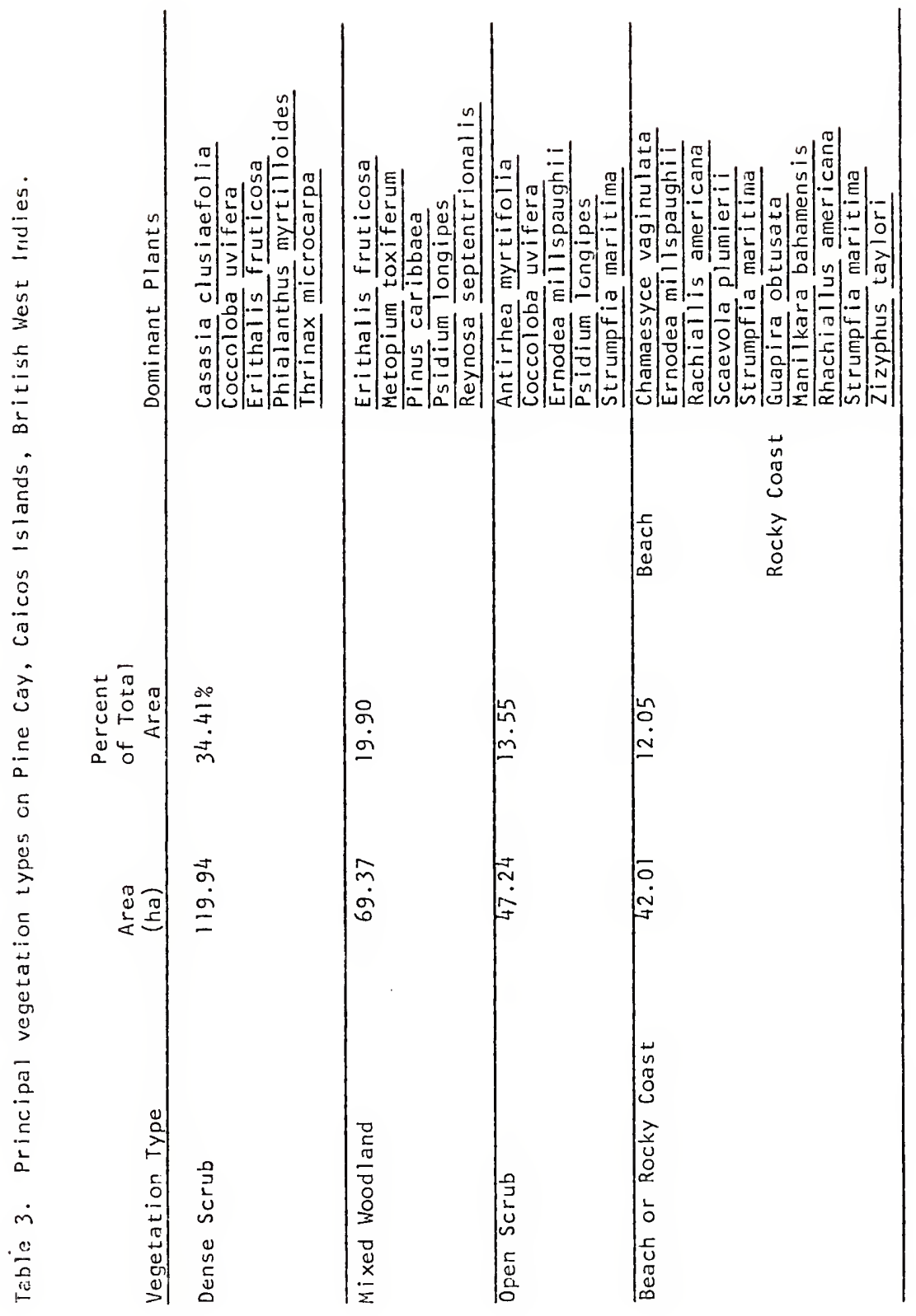




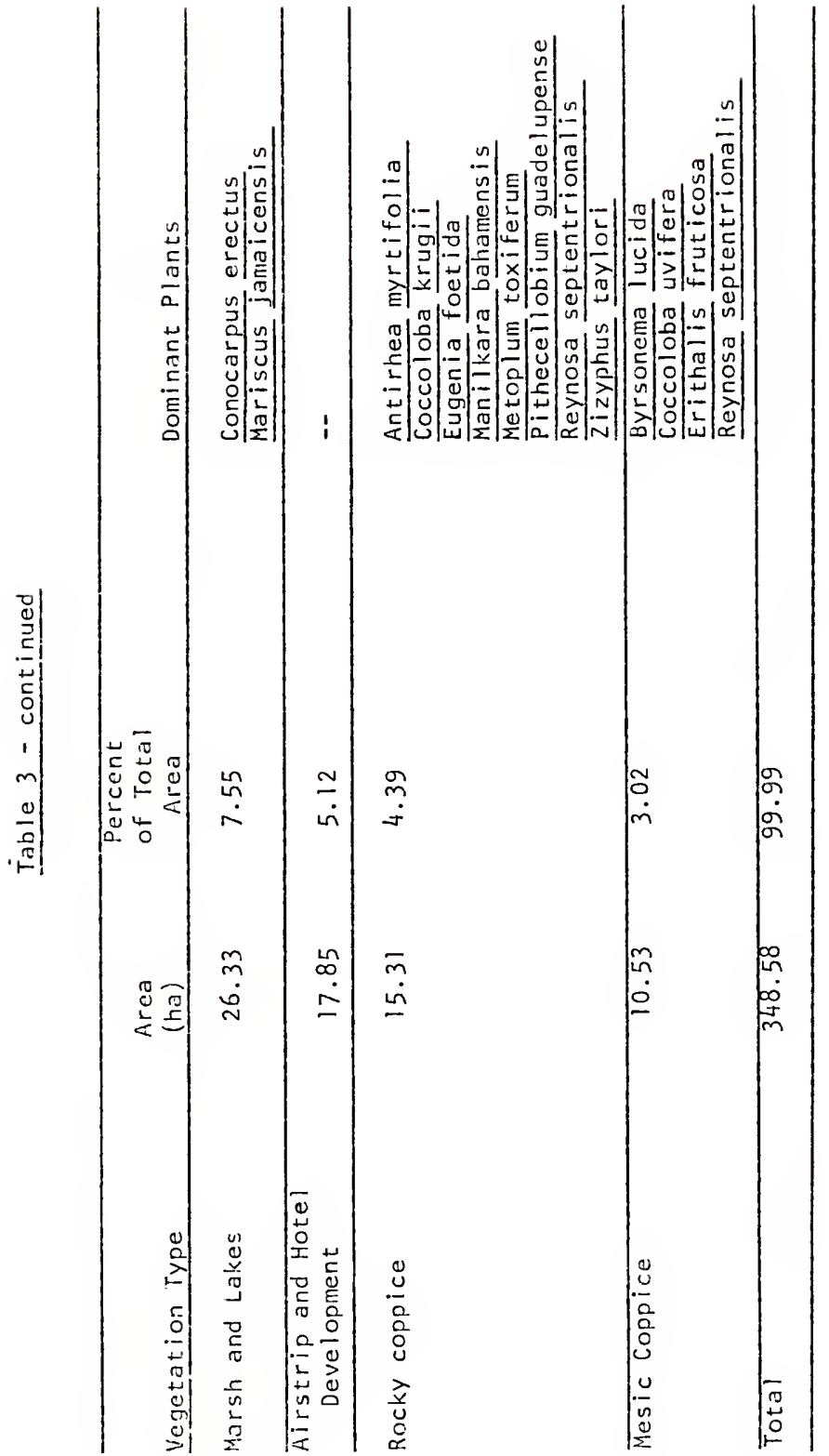




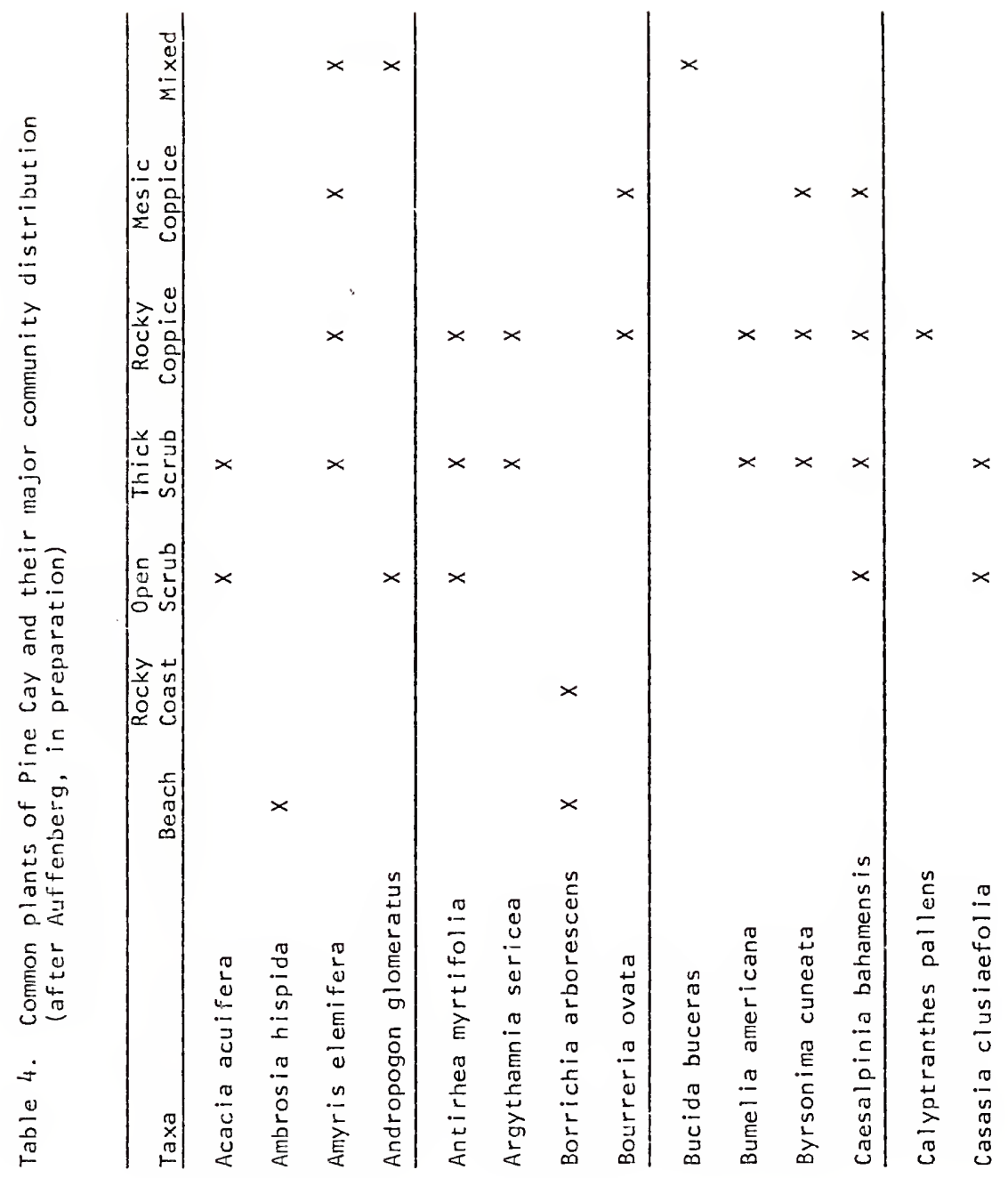




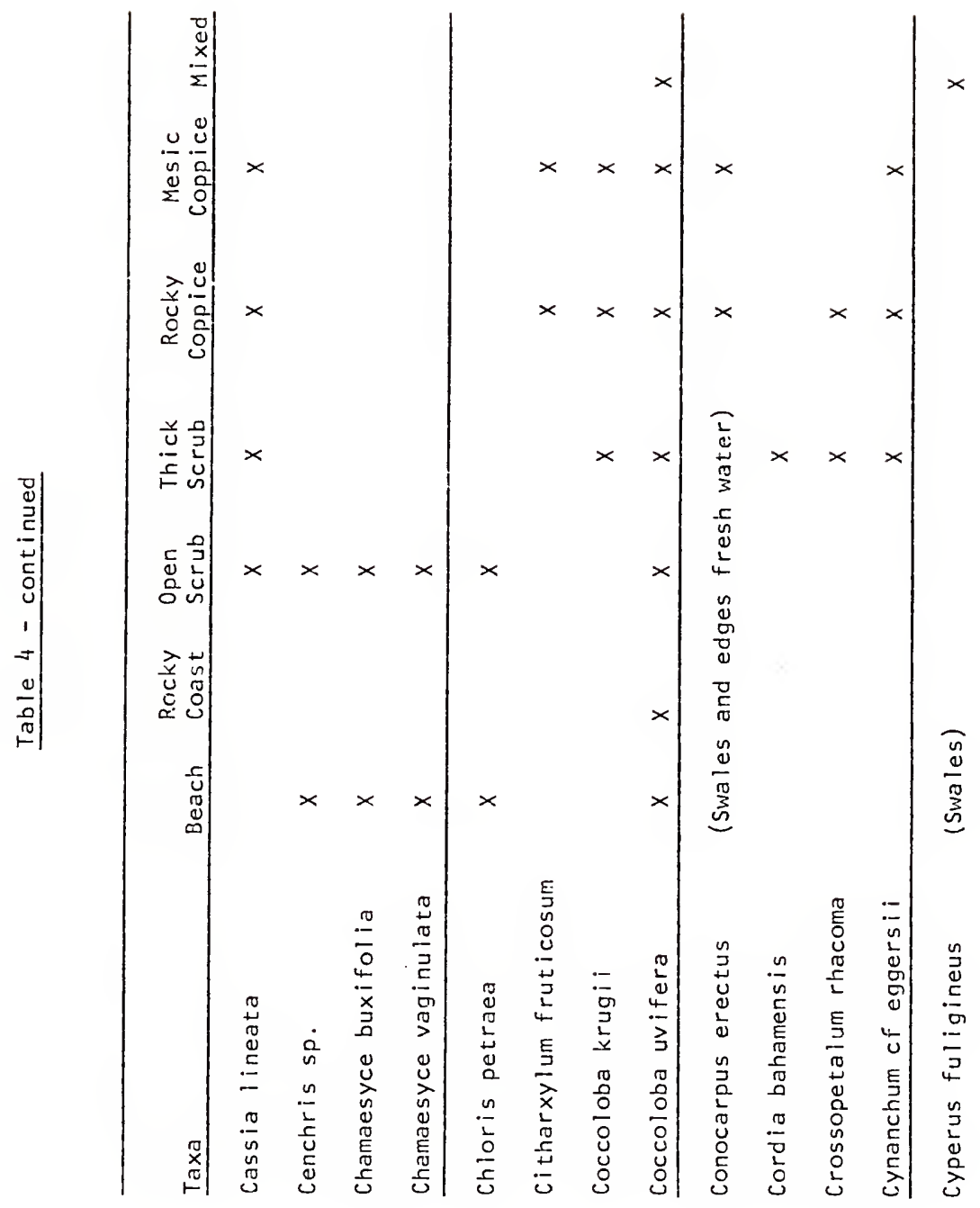




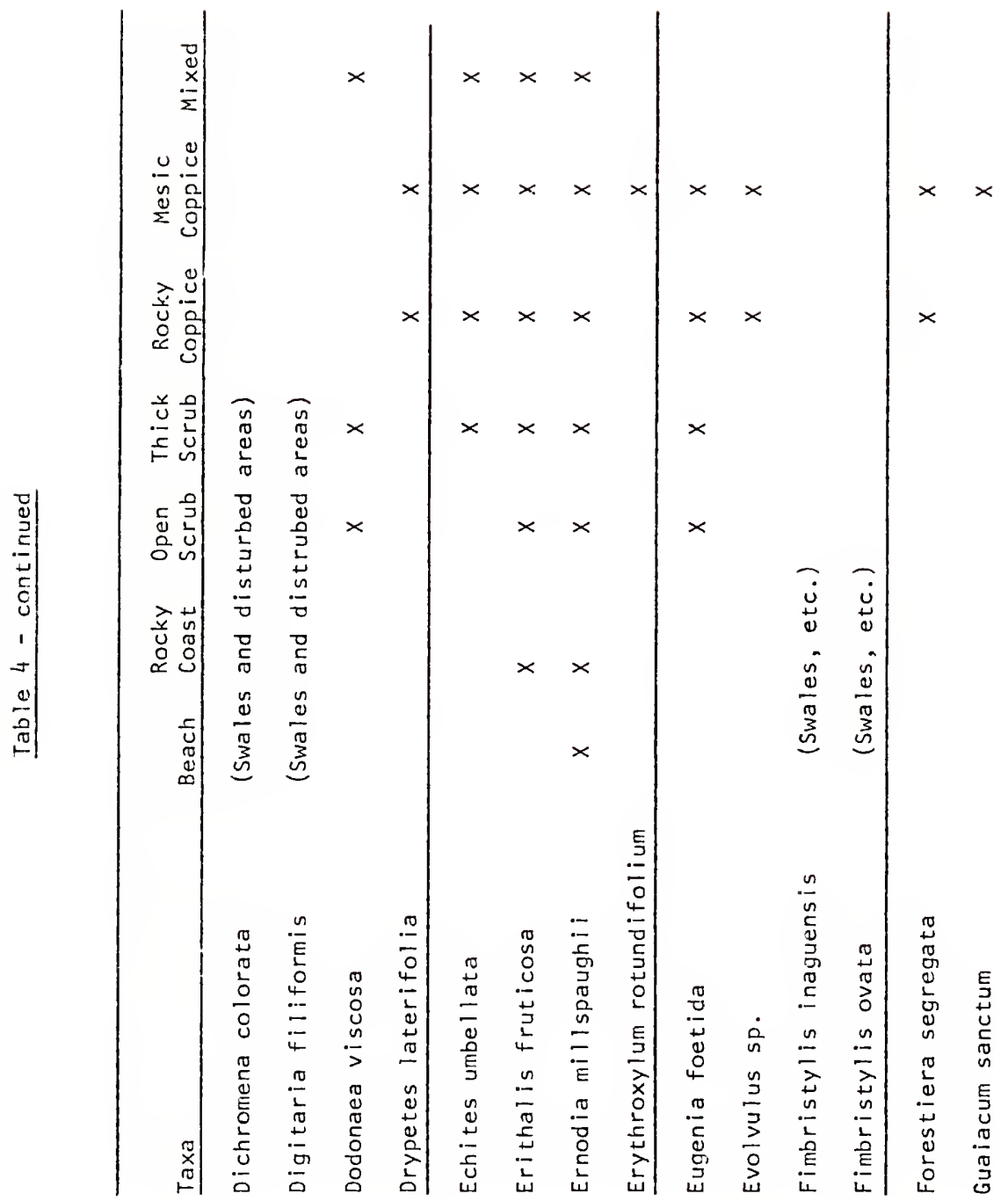




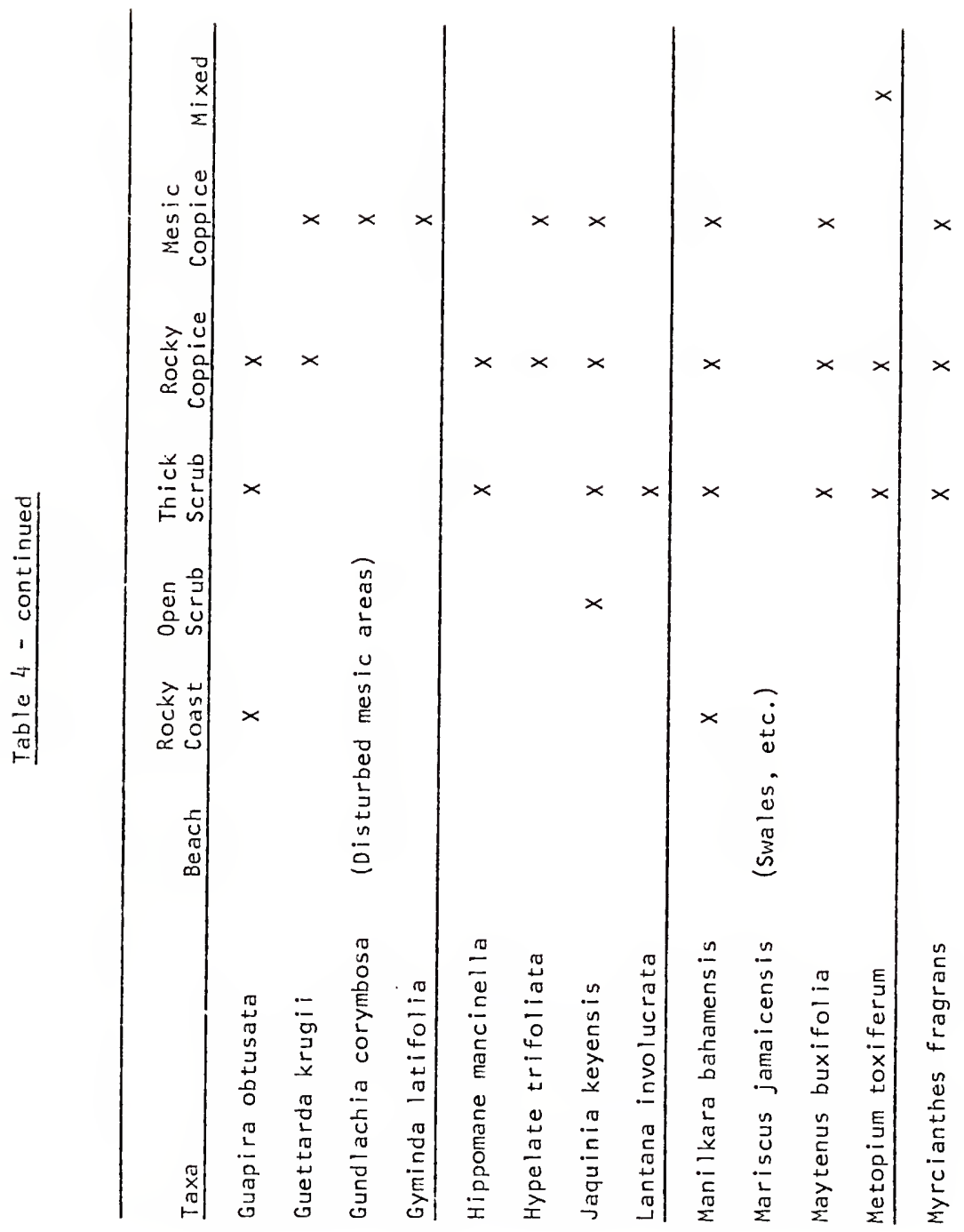




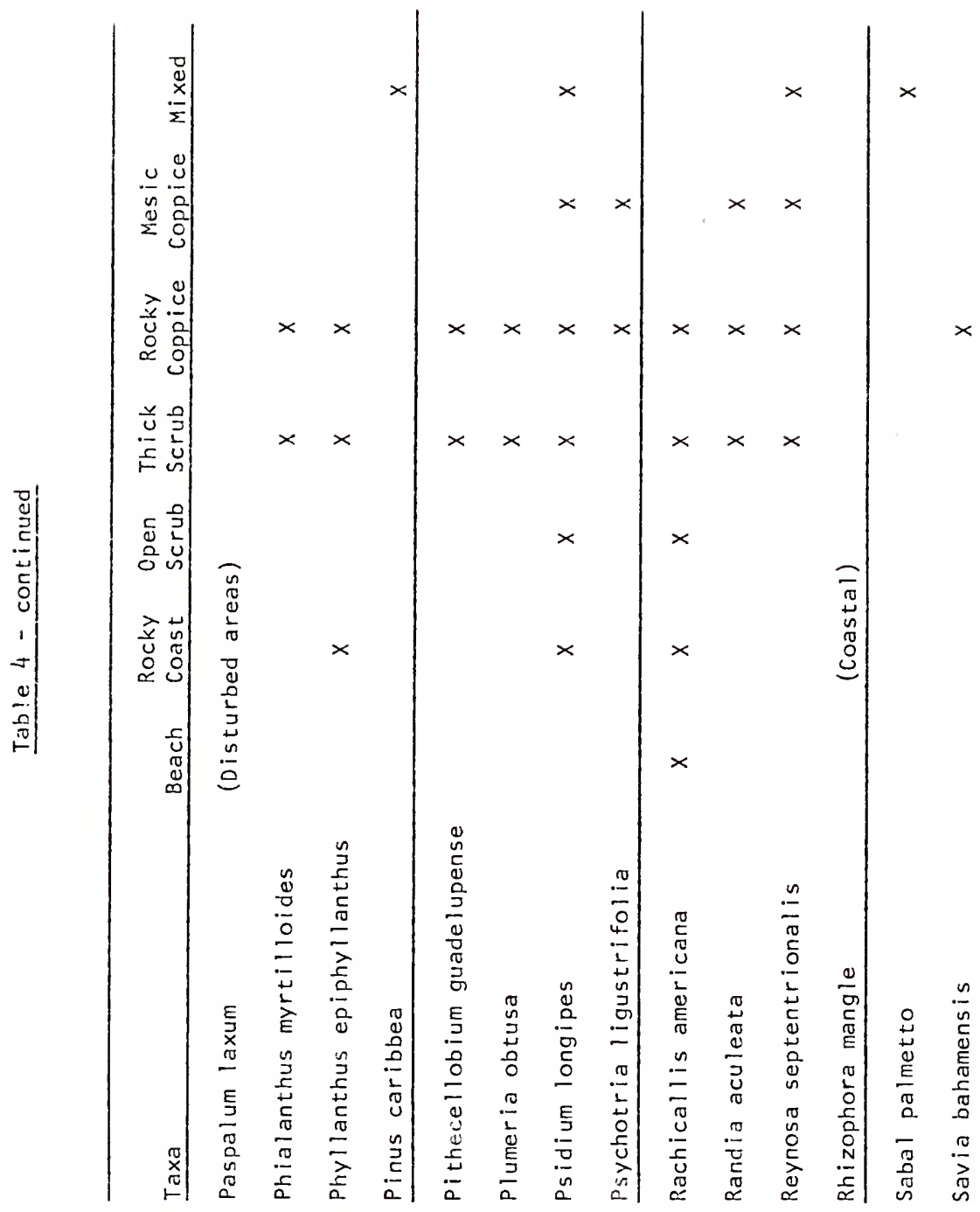




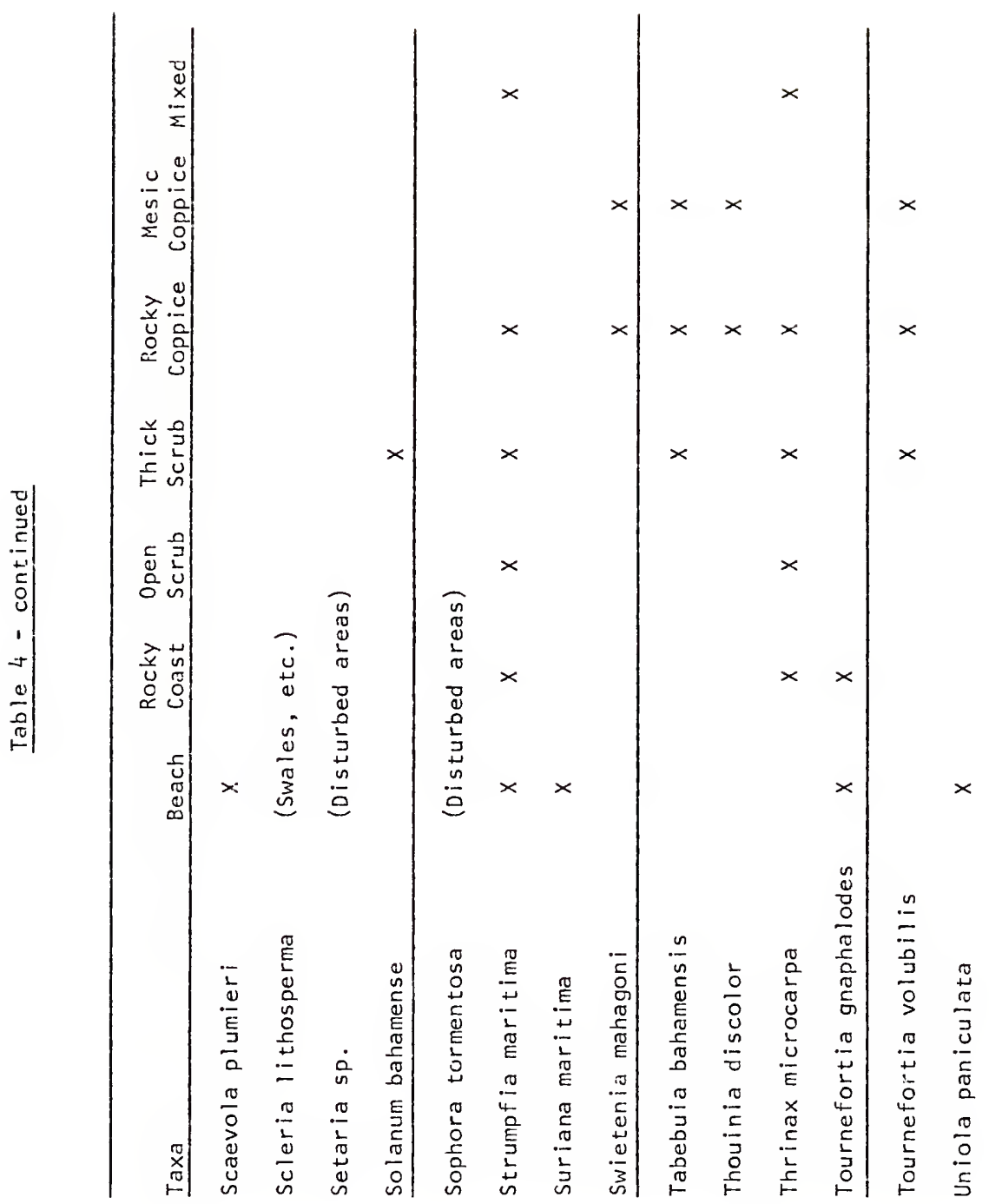




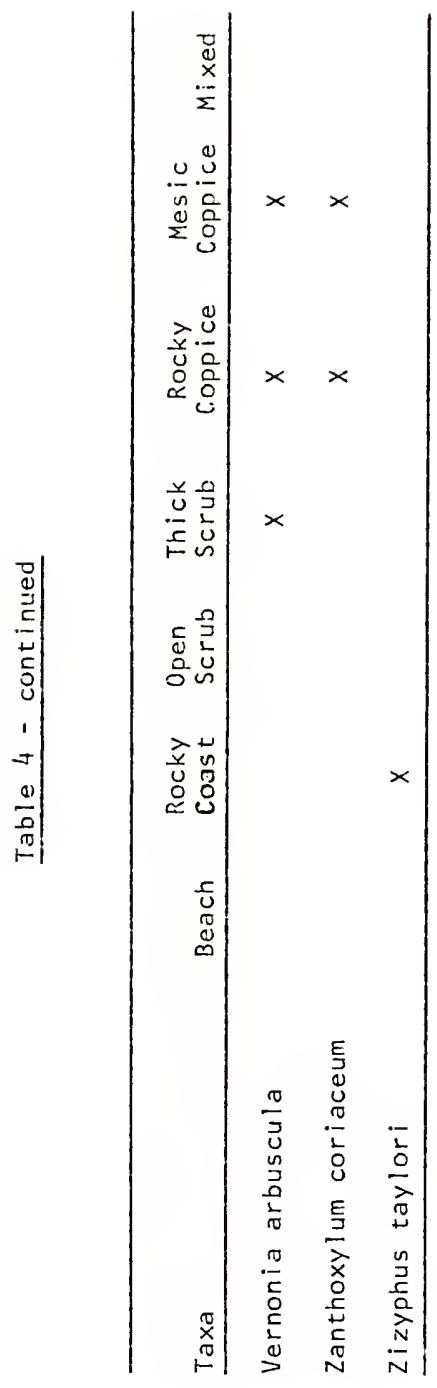


plains, and vegetation near man), it seem justified on Pine Cay to distinguish additional plant communities within at least two of his provinces. A more thorough discussion of the components of the vegetation types on Pine Cay and their relationships appears in Auffenberg (in preparation).

Cyclura carinata inhabits all of Pine Cay's plant commu: : ies except the Marsh and portiuns of the Mixed Woodland vegetation types. These are areas where the proximity of the water table to the ground surface precludes the possibility of burrow construction and vegetation is too dense for movement. Cyclura reaches its maximum adult abundance on Pine Cay in areas of Rocky Coppice. Young lizards are more commonly observed in areas of Open and Dense Scrub.

\section{Burrows}

Unless natural shelters in the form of abandoned land crab (Cardisoma guanhumi) burrows, or honeycomb limestone or coral formations are available, Cyclura carinata digs its own burrows. Since natural retreats are not abundant on the study islands, most lizards dig their burrows. Large mounds of vegetation, dirt, and rocks piled up by bulldozers while clearing roads are of ten used for retreats by lizards on Pine Cay. These sites also offer excellent elevated basking sites. Adult male iguanas exhibit great burrow tenacity. This is reflected in the greater average length, depth, and complexity of burrows dug by males versus those dug by females (Table 5). Sexual differences in burro: depth are also due, in part, to the need for shallow incubating chambers for successful nesting in females; burrow length differences 


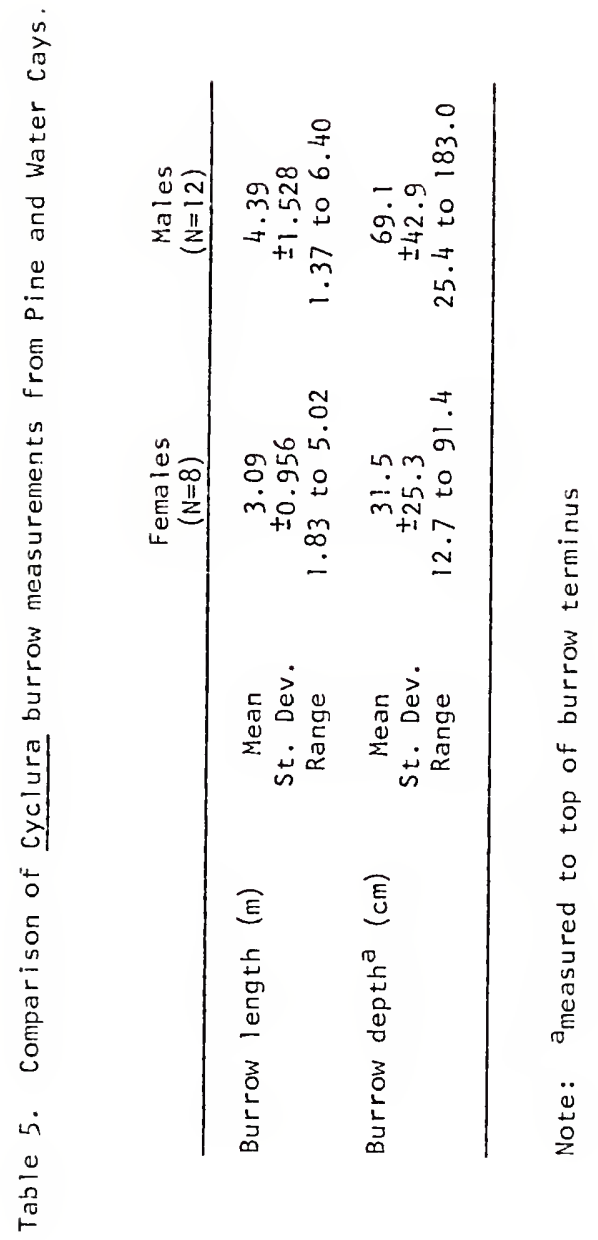


are also related to sexual dimorphism in size. Though adults of both sexes commonly use the same burrow, strongly territorial adult males never share them, unless used as a retreat after having been frightened. Although territorial adult male lizards near the SW Blind maintained a single retreat, they were nevertheless aware of all burrows (and other potential retreats) both within their own territories and well into those of adjacent males.

Even subadult lizards showed familiarity with burrows far outside their normal activity ranges. On September 20, 1973, adjacent to the Ridge Area on Pine Cay, a $178 \mathrm{~mm}$ SV lizard was removed from its burrow. Following marking, it was released at the site of its burrow. It ran directly and non-stop $16.1 \mathrm{~m}$, where it entered another active burrow. The second burrow was found to contain the marked lizard, in addition to its resident male (SV $229 \mathrm{~mm}$ ). When released after marking, this resident immediately ran over the ridge and directly to the burrow first excavated. The lizard first marked sought refuge in dense vegetation when released. Both lizards were clearly aware of the exact location of the other's burrow.

Blocking of a territorial male's primary burrow causes him to shift his retreat. Removal of the obstacle, after one to three days, is followed by his return to the primary burrow. The effect of permanent destruction of the primary burrow was not determined. The short term blockage seemed to cause no change in activity range location, but a shift is suspected if the burrow is destroyed.

Juveniles and subadults frequently shift burrows. One subadult non-territorial male, carrying a transmitter, in the 5.4 Blind area, 
utilized three different burrows on three consecutive nights. However, in some areas the unavalability of auxillary retreats necessitates the continual use of a single site. A hatchling took up residence in a small hollow tree limb in a brush pile on September 1, 1974, within only a few days of emergence. It still occupied the site in April, 1975, when last observed. Since it was never again seen on the study site, it is presumed it was killed.

The following patterns in burrow usage were observed in the Ridge Area. Large burrows active at the beginning of the study remained active throughout the study period. There was, however, considerable small burrow turnover, probably due to 1) predation on juveniles; 2) lack of burrow tenacity in juveniles; and, 3) periodic excavation of burrows by terrestrial crabs. Since the burrow is central to all activity in Cyclura carinata, its importance cannot be overemphasized. Not surprisingly, burrow construction in all species of Cyclura seems to be related to the substrate conditions. In areas where sandy dune situations predominate, as on the typically small, low islands of the Bahaman archipelago, constructed burrows are used. However, on islands dominated by cavernicolous limestone and coral exposures the fossibility of burrow excavation by iguanas may be precluded. Natural retreats are then employed (see Retreats under ACTIVITY AND MOVEMENTS).

The presence of at least some friable soil for nest construction appears to be a very important factor ultimately limiting distribution and numbers of Cyclura populations. In the species of cyclura for which the nest site has been described (Noble, 1923; Wiewandt, in preparation), a nest burron was excavated in well-insolated soil areas, sometimes 
several $\mathrm{km}$ from the female's normal activity range (see Discussion under REPRODUCTION). In addition to protection, burrows could serve a thermoregulatory function, however lizards do not use them as heat sinks, even under extreme conditions.

Adult Cyclura typically maintain their burrows by removing sand, leaves, and other debris during the middle of the day when general lizard activity is reduced due to high environmental temperatures. However, this is not a daily routine; a period of several days generally separates burrow cleaning activities. In removing debris, the lizard enters the burrow head first and kicks material backward as it moves further inside. Exiting the burrow head first, it turns and repeats the procedure several times.

The complete excavation of a burrow was never observed, so the time required is unknown. However, a young adult male completely excavated a new burrow near the SW Blind during my absence between July 20 and September 1, 1974.

Neonate lizards usually utilize natural cavities or spaces cleared beneath rocks, roots, logs, etc., for retreats. In open sandy areas, they will excavate their own burrows. These burrows are usually shallow (<15 cm deep) and short $(<50 \mathrm{~cm})$, with diameters between 2.5 and $3 \mathrm{~cm}$. Some have short side branches but these may be added by crabs.

Since many young lizards frequent more than one burrow and many small burrows are actively maintained by crabs, small burrows are not useful in estimating lizard density. Data on locations of large active burrows can, however, provide fairly accurate estimates of adult lizard density (see DENSITY AMD DEMOGRAPHY). 
Burrow dimensions and complexity are quite variable (Figure 12), dependent in part on the surface and subsurface soil texture. The longest burrow excavated was in dune sand on Pine Cay, and measured $6.4 \mathrm{~m}$. It was occupied by both a female and a male when opened. One of the biggest burrows encountered was an active one which I could not completely excavate. The burrow was in an area of deep dune sand nearly devoid of vegetation. The $16 \mathrm{~cm}$ diameter of the burrow suggested that it had been dug by a male. After $5.0 \mathrm{~m}$ of horizontal excavation, the burrow was $1.5 \mathrm{~m}$ below the sand surface. It continued downward with the same slope at least one $m$ farther. Digging was suspended due to constant collapsing of the excavation pit.

Burrow orientation on Pine and Water Cay (Figure 13), appears to be related more to micro-topographic features than to intentional directional construction. More burrows generally open to the northwest and southeast on these two islands, because these retreats lie perpendicular to the generally northeast-to-southwest lying ridges (Figures 2 and 12). Cyclura prefers digging under the limestone exposures in the sides of these ridges to digging in open flat sandy areas. In the latter areas, burrows are typically excavated into the sides of small hummocks formed by the accumulation of blown sand around the bases of clumps of vegetation. An obvious advantage in avoiding flat areas of open sand for burrow construction is the reduction of the possibility of entombment by burrow collapse.

As in the burrows of the Florida gopher, Gopherus polyphemus (Young and Goff, 1939), there are in nearly every Cyclura burrow, numerous arthropod inquilines, many apparently obligatory. The most 
Figure 12. Variation in burrow morphology and crientation in adslt Cyclura carinata. Soil depth (in $\mathrm{cm}$ ) to top of burrow is indicated; changes in depth are uniform between measurements. Letters acjacent to burrow entrance (solid circles) indicate sex of inhabitant.

Asterisks mark burrows used for nesting in previous years. 


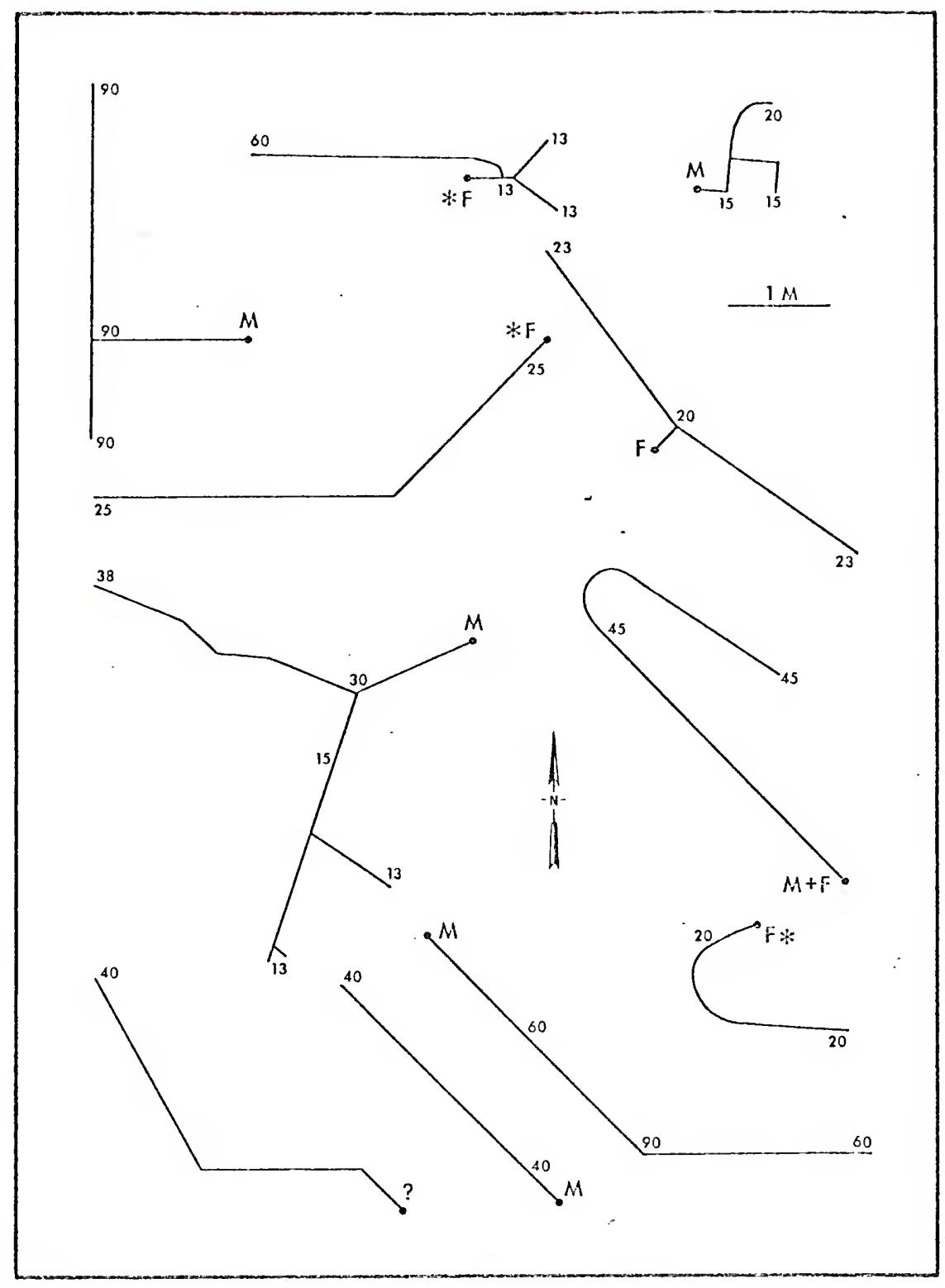




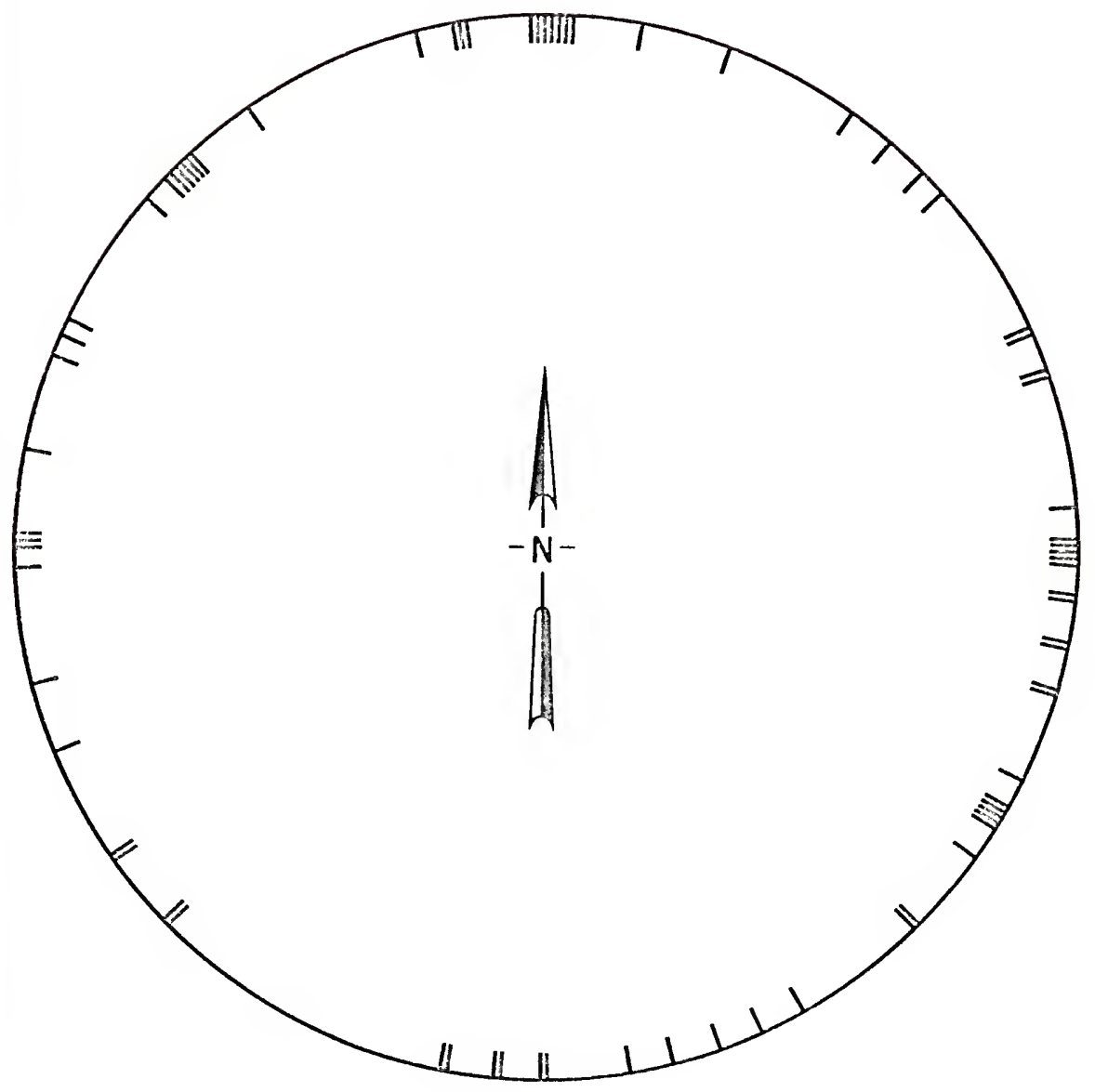

Figure 13. Orientation of burrow entrances in Cyclura carinata, recorded as compass direction into burrow. 
common and seemingly most obligatory were camel crickets (Ceuthophilus?). Also found were solpugids (genus Ammotrechella), scorpionids, amblypygids (Tarantula marginepennis), nymphal cicadas (01lanta caicosensis), and numerous unidentified spiders. 


\section{REPRODUCTION}

\section{Male Sexual cycle}

The male testicular cycle closely parallels the female reproductive cycle. Since testes weight has been shown to be an accurate indicator of testicular activity in lizards (Hahn, 1964; Marshall and Hook, 1960; Ballinger, 1973), no histological analysis was made. Testes reach maximum sizes in April and May, declining rapidly in June and July to complete regression in early fall (Table 6). Testicular size maxima are coincident with breeding in Cyclura carinata. A similar cycle (early spring maximums and late summer minimums) is typical of at least the Iguanid lizards.

Sexual maturity in male $\underline{C}$. carinata was determined by testicular enlargement between January and June, or actual observation of attempted or successful matings in May. The smallest male with enlarged testes measured $216 \mathrm{~mm}$ SV (weight approximately 440 grams). The largest males without testicular enlargement were $222 \mathrm{~mm} \mathrm{SV} \mathrm{(435} \mathrm{gm} \mathrm{live} \mathrm{weight)} \mathrm{and}$ $210 \mathrm{~mm}$ SV $(365 \mathrm{gm})$. A $219 \mathrm{~mm}$ SV captive male which attempted copulations on numerous occasions during May, 1975, was the smallest male observed to exhibit courtship behavior. These data indicate sexual maturity in males is reached at approximately $220 \mathrm{~mm}$ SV and a body weight of 375 to $475 \mathrm{gm}$. Growth data indicate this requires about seven years (see GROWTH). Adult males averaged $276.3 \mathrm{~mm}$ SV (191-360) and 935.1 gm body weight (256-1864). 
Table 6. Seasonal variation in proportional testes weight (testes weight in $\mathrm{gm} \times 10^{-5} / \mathrm{SV}$ in $\mathrm{mm}$ ) in male Cyclura carinata over $216 \mathrm{~mm}$ SV.

\begin{tabular}{llll}
$\begin{array}{l}\text { Sample } \\
\text { Date }\end{array}$ & $\mathrm{N}$ & $\bar{X} \pm$ S.D. & Range \\
\hline March 6 & 1 & 867 & $-\ldots$ \\
May 10 & 1 & 1358 & $48-454$ \\
June 30 & 7 & $178 \pm 141.13$ & $70-164$ \\
August 15 & 2 & $117 \pm 66.47$ & $-\cdots$ \\
Septeinber 15 & 1 & 47 & $151-203$ \\
December 15 & 2 & $117 \pm 36.77$ & $62-305$ \\
December 30 & 4 & $165.5 \pm 115.37$ & \\
\hline
\end{tabular}




\section{Female Sexual Cycle}

Ovaries are difficult to distinguish from testes in lizards less than one year of age, however the obvious presence of oviducts in females allows accurate sexing of even hatchlings. Immature ovaries contain numerous follicles up to $4 \mathrm{~mm}$ in diameter. Maximum follicular diameter in mature females between oviposition and spring recrudescence is also approximately $4 \mathrm{~mm}$ (Figure 14). Yolking of follicles begins between January 1 and March 1 and continues until ovulation in early May. Maximum follicular diameters reach $30 \mathrm{~mm}$ at that time.

Seasonal combined ovarian weights reflect the same trends as follicular diameters (Figure 15), with ovarian weight maxima $(63.7 \mathrm{gm}$ in a $248 \mathrm{~mm}$ SV lizard with five enlarged follicles) in mature females occurring in early May and post-reproductive minima (generally less than $0.35 \mathrm{gm}$ ) from July through December. The maximum combined ovarian weight recorded in an immature (184 mm SV) female was $0.275 \mathrm{gm}$ in March. Immature weights were normally considerably less than this. Perhaps her ovaries were developing in preparation for breeding the following year when she would surely be of adult size.

Oviducal eggs were not present before at least the last of April and were noted only as late as June 9. Yolked follicles and oviducal eggs were never found in the same female and no yolked follicles (except an occasional atretic one) were found in post-ovipository females. Fresh corpora hemoragica averaged $6 \mathrm{~mm}$ in diameter, but regression was rapid and corpora lutea were usually unidentifiable by early September (Figure 16).

of only two females with oviducal eggs, one showed evidence of transuterine migration of ova. The right reproductive tract of that 


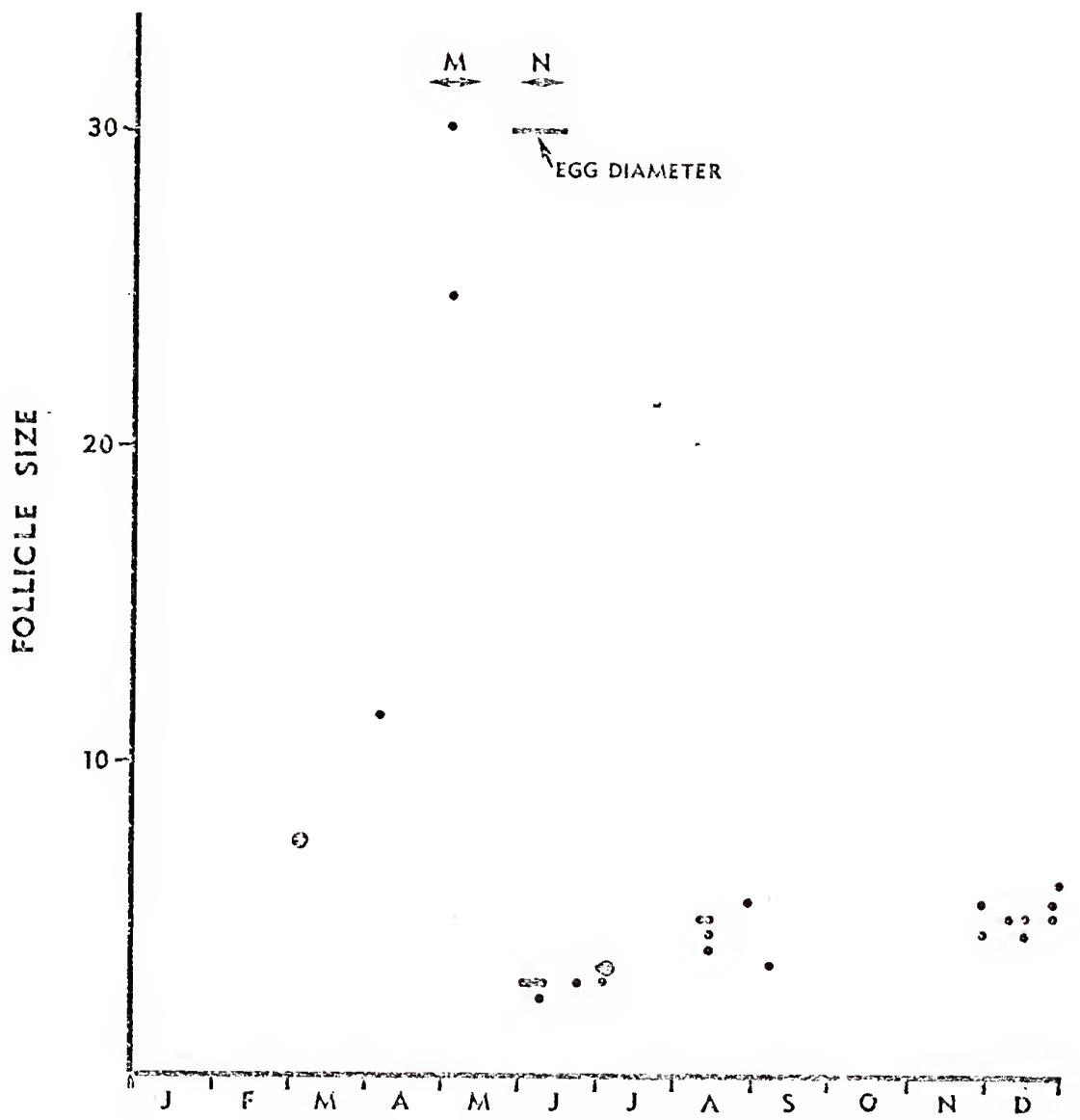

Figure 14. Seasonal variation in maximum follicle diameter (mm) in ovaries of female Cyclura carinata. Small dots indicate individual females; large dots, two or more Tizards. M and $N$ mark mating and nesting seasons, respectively. 
Figure 15. Seasonal changes in proportional ovarian weight (grams $\times 10^{-4 / S V}$ in mm) in mature female Cyclura carinata. Each point represents one individual lizard. 


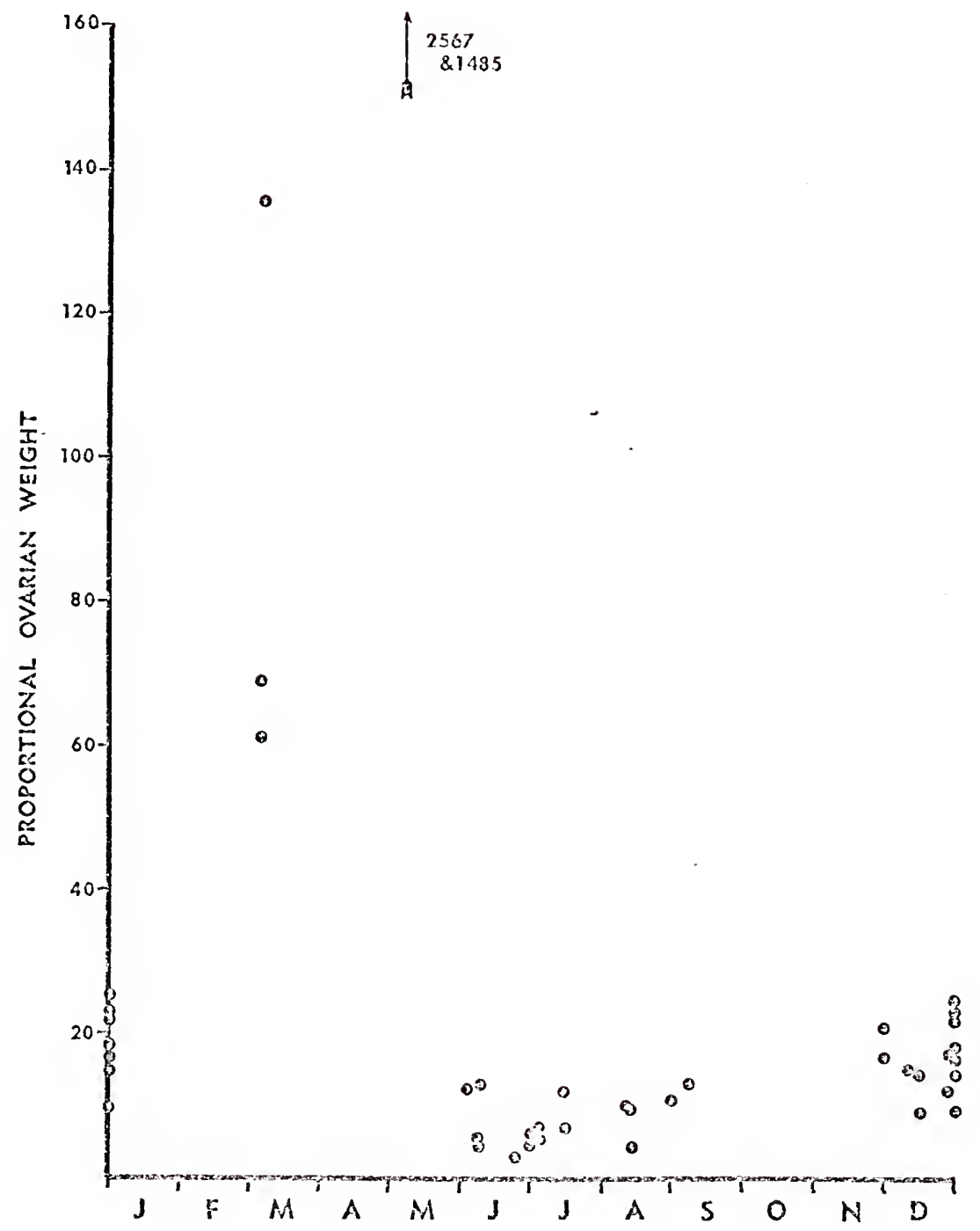




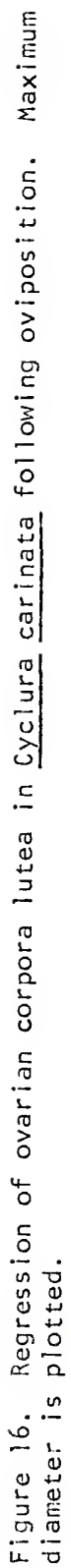




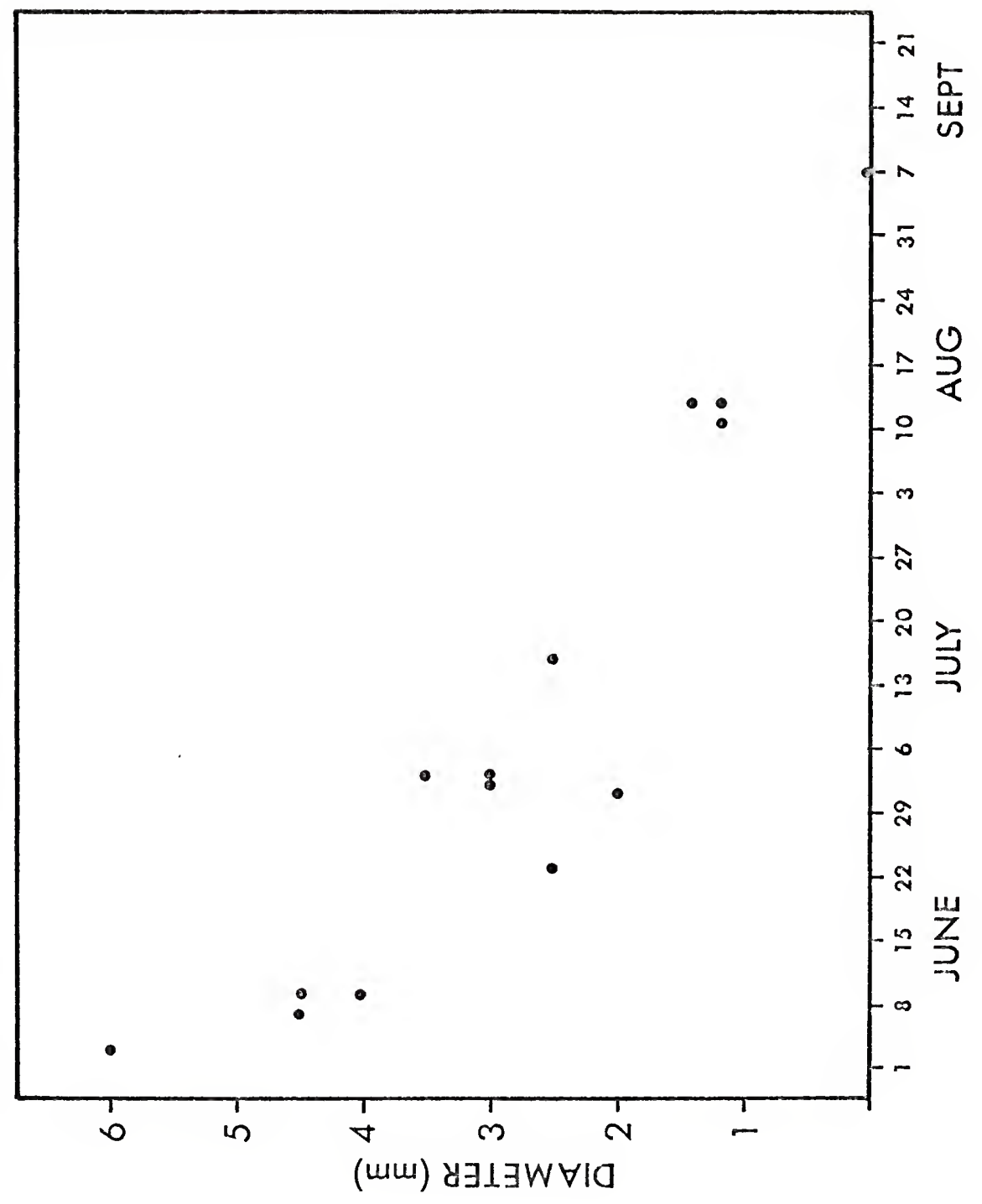


female included two corpora lutea in the ovary and three eggs in the oviduct; the left tract bore four corpora lutea and three oviducal eggs. Cuellar (1970) has previously discussed this phenomenon in lizards.

Mirimum sizes for mature females (as indicated by the presence of yolked ovarian follicles, oviducal eggs or corpora lutea) were $184 \mathrm{~mm} 5 \mathrm{~V}$ (250 gm; with enlarged yolked follicles), $190 \mathrm{~mm} \mathrm{SV} \mathrm{(280} \mathrm{gm;} \mathrm{corpora}$ lutea present), $194 \mathrm{~mm}$ SV (live weight unknown; with corpora lutea), and $197 \mathrm{~mm}$ SV (205 gm; with corpora lutea). Maturity of young adult and subadult females collected between September and January could not be accurately determined due to the regressed state of the ovaries even in obviously adult females. The largest immature females collected between January and August were $210 \mathrm{~mm}$ SV (approximately $320 \mathrm{gm}$ ), 191 $\mathrm{mm} \mathrm{SV}(240 \mathrm{gm}$ ) and $184 \mathrm{~mm}$ SV (weight unknown). Maturity in females at $185-200 \mathrm{~mm}$ SV (200-300 gm) at an age of about six years (see GROWTH) is indicated. Nearly all females presumably oviposit their first clutch of eggs between age six and seven. Adult females averaged 225.4 $\mathrm{mm}$ SV (190-292) and 475.6 gm (205-1135) body weight.

\section{Courtship and Mating}

From late March through April, males became increasingly interested in females. During April, males were frequently observed following females on the ground. At this time, the resident territory-holding male typically approached within one meter of the female, but did not display or otherwise court the feriale. The approach usually caused the female to headbob (submissively; see SOCIAL ORGANIZATION), move a short distance away, stop, and again bob to the male. The male often reciprocated with 
a headbob, and again approached the female closely and the sequence was repeated (up to a dozen times). The impression was that the male was attempting to insure his proximity to a female as the mating season approached. Perhaps this precourtship interest is necessary for the induction of receptivity as in Drosophila melanogaster (see Parker, 1974, p. 158) and Anol is carolinensis (Crews, 1975b).

Resident males terminated their female-directed activity to displace neighboring males from their (the resident's) territory (hence away from the female) at this time of the year, just as they did during the remainder of the year. However, it was my subjective opinion that the males were more willing to defend at this time of the year than at any other. There was no question that the general level of activity was greatest at this time of the year (see ACTIVITY AND MOVEMENTS). Following defense, the resident male returned to the female and resumed his interest in her. The precourtship approach behavior could be a mechanism by which a female can determine the extent of the territory and the effectiveness of its defense by a potential mate.

In some cases, the male was so persistent in his attempts to closely approach the female, that she ultimately moved out of his territory and into that of a neighboring male. However, females sometimes also moved between males' territories without this pressure from the resident males. Perhaps female Cyclura were making active choices among courting partners at this time, as Trivers (1976) suggests for Arolis garmani.

The interest of males in females increased through April, presumably until the female tolerated the close approach of a male and active courtship could proceed. Unfortunately, neither active court- 
ship nor copulation was observed in nature. However, they were frequently observed in captivity and the basic behavioral components are undoubtediy the same as those in non-captives.

Courtship was observed nearly 100 times (three times to completion) in the captive enclosure in Gainesville during nine days between April 24 and May 9, 1975 (Table 7). During this period, four mature females and at least two of four males were confined together in a pen at any one time. The lizards were captured April 5-9, 1975, on the study islands. The females and smallest male (\#4) were released into the captive enclosure on April 17, while the other males were maintained separately in the laboratory. These males were introduced into the pen at various times between April 24 and May 9 to investigate dominance relationships (see SOCIAL ORGANIZATION).

Successful mating behavior can be divided into four basic stages: approaching, displaying, neck holding, and copulating. Figure 17 illustrates the male and female components of courtship behavior.

Approach. In captivity the male and female did not always exchange headbobs prior to the male's approach to the female. In the field, the female always bobbed submissively at the appearance of the male; the male often did not reciprocate (see SOCIAL ORGANIZATION). The courting male typically approached the female laterally and from behind (their bodies aligned at approximately a 30 to $45^{\circ}$ angle). The profile of the approaching male once within $0.5 \mathrm{~m}$ of the female was very low to the ground. The body was dorsally-ventrally flattened and the chin was kept less than $5 \mathrm{~cm}$ from the substrate. A fow times the male turned his head to inspect the female's hip area, but usually approached until his head was lateral to the anterior trunk region of the female. At 
Table 7. Average number of courtships per day attempted by each male of each female in Gainesville enclosure during nine days between April 24 and May 9, 1975.

\begin{tabular}{|c|c|c|c|c|}
\hline & & & MALES & \\
\hline & & $\# 1$ & $\# 3$ & $\# 4$ \\
\hline FEMALES ${ }^{1}$ & $\begin{array}{c}\overline{S V} \\
(\mathrm{~mm})\end{array}$ & 349 & 286 & 219 \\
\hline$\# 1$ & 235 & 3.0 & 2.333 & 4.75 \\
\hline$\# 2$ & 235 & 1.67 & 1.222 & 0 \\
\hline$\# 3$ & 216 & 1.33 & 1.222 & 0.75 \\
\hline$\not 44$ & 185 & $=$ & 1.000 & 0.75 \\
\hline $\begin{array}{c}\text { Days male } \\
\text { present }\end{array}$ & & 3 & 9 & 4 \\
\hline
\end{tabular}

lAll females were present everyday. 
Figure 17. Behavioral components of courtship in Cyclura carinata. 


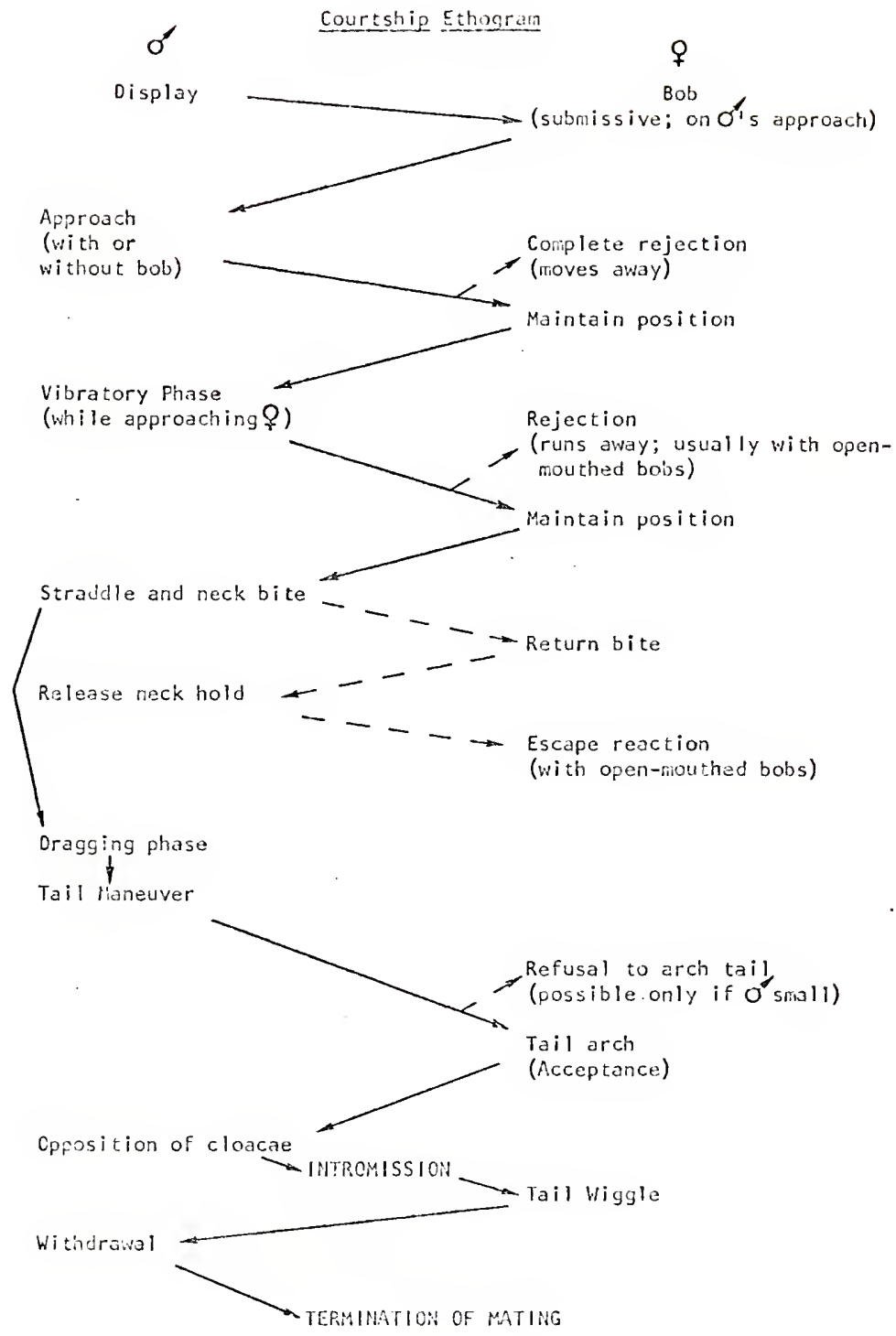


this point the female often moved away, rejecting the male's advances. If she did not (or could not, as in some captive situations) the male began his courtship display and continued to approach the female.

Display or Vibratory Phase. The courtship display of Cyclura carinata was stereotyped and very similar to that of most other iguanid and agamid lizards that have been studied (Carpenter, 1967; Gonzales, 1974). The male continued his approach toward the female while rapidly vibrating his head vertically. I have termed this behavior 'vibratory' display due to the low amplitude of the headbobs. A typical display action pattern (DAP; see Carpenter and Grubitz, 1961) of this head movement appears in Figure 18. Four videotaped displays, each including four oscillations of the head, averaged 0.36 seconds (0.32-0.40). Additional amplitudes required proportionately longer during several other displays. Males sometimes performed displays with open mouths.

This vibratory courtship display is synonomous with the "jiggling" display described by Evans (1938) and Ruibal (1967); the "courtship nod", by Carpenter (1962b); and the "shudder sequence", by Ferguson (1970) for other lizards. In each case, the display consisted of a sequence of shallow, rapid headbobs. Male Ctenosaura pectinata (Evans, 1951) and Amblyrhynchus cristatus (Carptenter, 1966) also exhibit a similar courtship display. Sauromalus obesus (Berry, 1974) is the only iguanine lizard studied to date that lacks this display.

Females rejected male courtship advances by a stereotyped rejection display or by simply running away. Either behavior was accompanied by vigorous headbobbing, typically with an open mouth. In the rejection display (Figure 19), the female compressed her body laterally, postured high on all four legs with her back strongly arched and her tail on the 


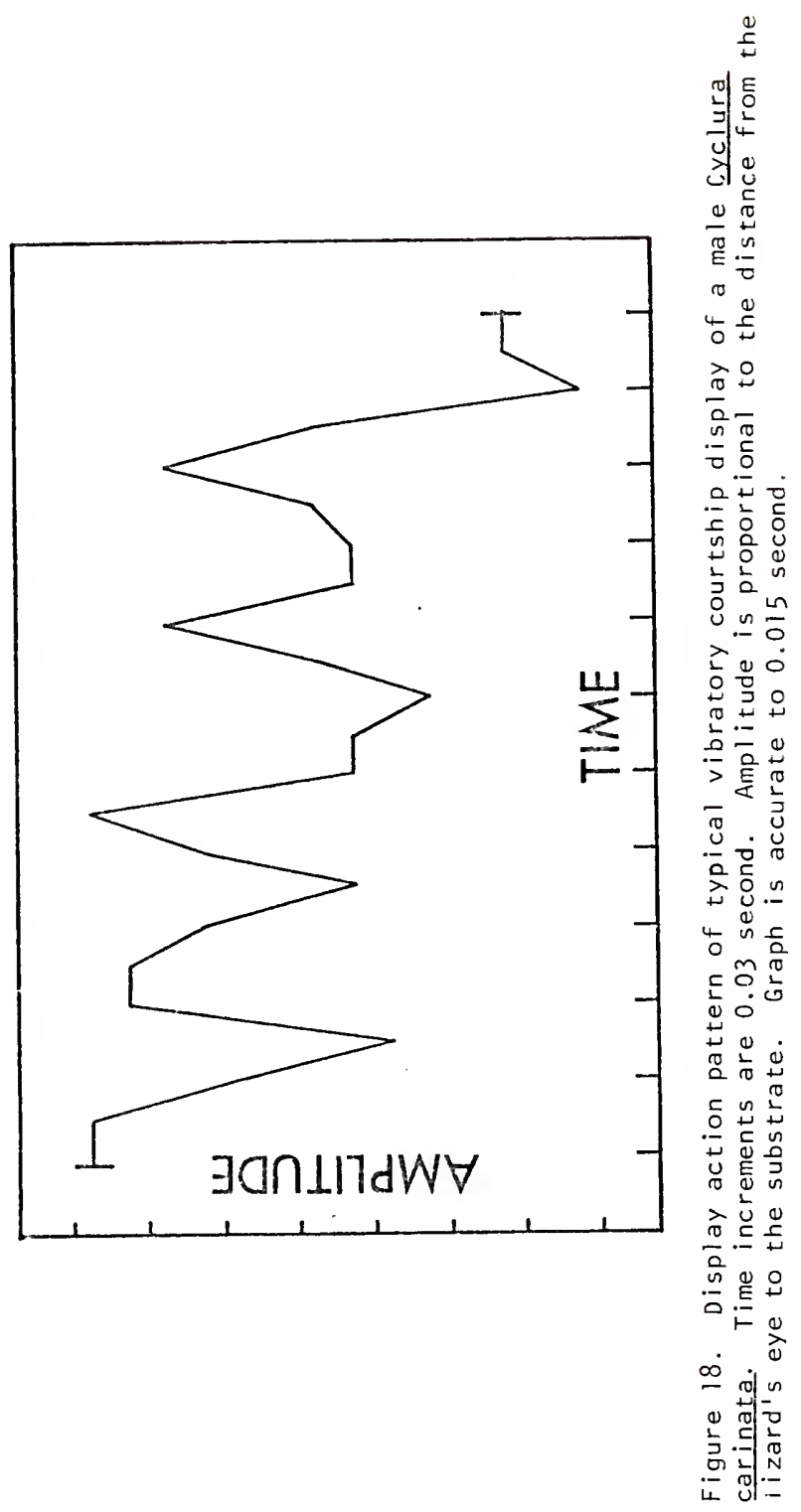




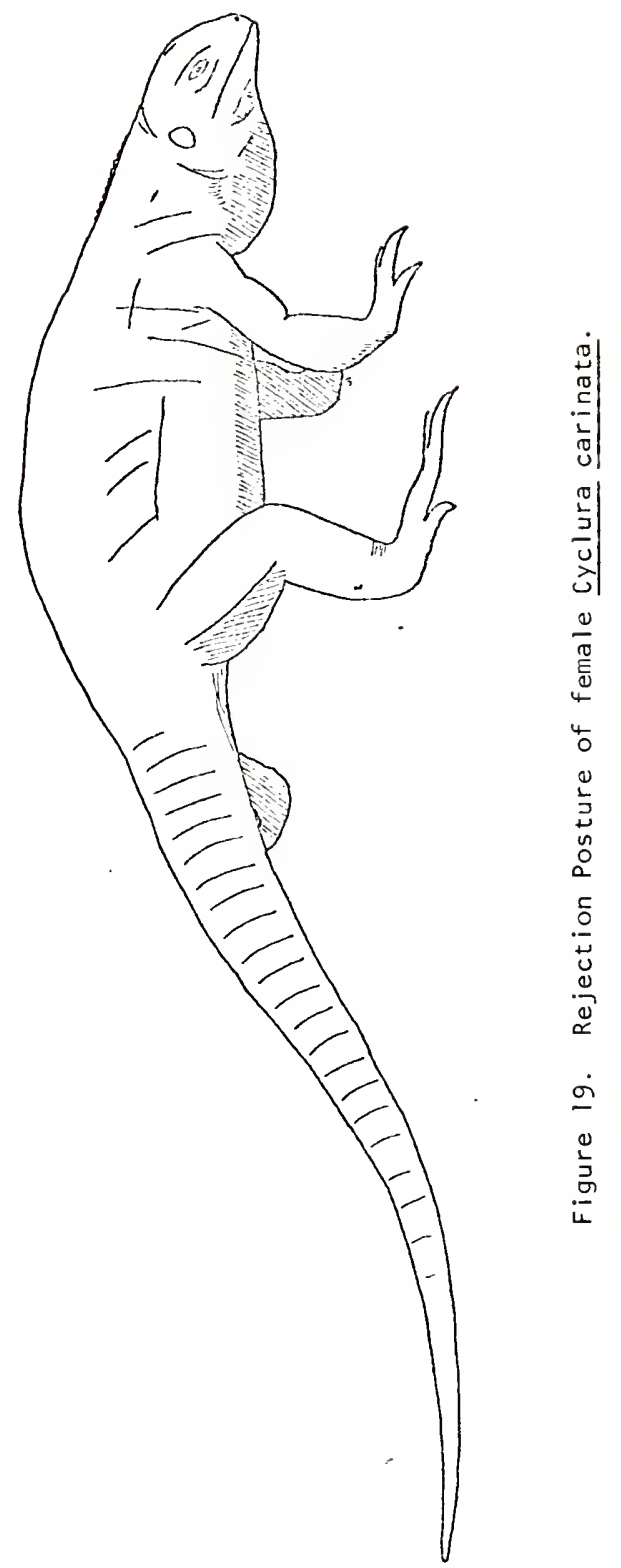


ground, and headbobbed rapidly (usually with open mouth). In the field, as in many of the captive courtships, this display is probably sufficient to thwart the males' courting interests. However, captive males of ten continued the courtship sequence despite this display. If the fenale maintained her position during the male's vibratory display and approach, the male terminated the display, raised up and gripped the female's neck in his teeth.

Many iguanid lizard species have a similar rejection posture (Fitch, 1956; Clarke, 1963; Carpenter, 1967). Noble and Bradley (1933) first described and illustrated this behavior but were unable to determine its significance. Within the subfamily Iguanina, Sauromalus obesus (Berry, 1974) also uses this rejection posture, while Amblyrhynchus cristatus apparently does not (Carpenter, 1967); other members have not been sufficiently studied.

Only one homosexual courtship (with the smallest male) was observed and $i t$ was terminated by the courting male following his vibratory display.

Neck holding. Following the vibratory phase of courtship, the male moved to straddle the female and secure a mouth grip on the dorsal region of the female's neck. The female could still terminate the courtship at this point by turning and biting at the male's head and/or struggling free. Females sometimes attempted to walk away, dragging the nale for short distances.

Once the female's neck was securely held, the male attempted to naneuver his tail under that of the female to align the cloacae. The receptive female then arched her tail upvard to facilitate the male's tail maneuvering. She could apparentiy still reject the male's advances, 
by refusing to arch her tail, only if the courting male was smaller than herself; large males could force their tails under the female's tail even if she did not arch it. This was observed once in captivity during the forced copulation (rape) of one of the females (discussed later) by a large male. The refu-al of a female to arch her tail to allow cloacal apposition was observed six times when a small male (219 mm SV) had obtained a neck grip on a larger female. Once the cloacae were finally opposed, the neck grip was maintained until hemipenial withdrawal following copulation. The mating posture was exactly like that pictured for Amblyrhynchus by Schmidt (1935).

Copulation. Once the cloacae were opposed, intromission followed immediately and lasted from 40 to 76 seconds (Mean $=58.7 ; N=3$ ). No thrusting by the male was observed. Wiggling of the distal portion of the tail by the female immediately preceded withdrawal of the penis by the male. Uncoupling was rapid; the male released his neck grip and backed away from the femle. His pelvis remained elevated from the ground until his hemipenis was fully retracted. Typically both lizards then moved very little and rested quietly. Their activity during the remainder of the day was generally depressed.

In all iguanine lizards except Iguana iguana, for which data are available (Table 9) copulation (i.e. female receptivity) occurs approximately one month before oviposition. A distinct relationship with the fenale ovarian cycle is implied. It is suggested, but not known, that receptivity in Cyclura carinata immediately precedes ovulation as it does in Anolis carolinensis (Crews, 1973a). and perhaps Crotaphytus wislizeni (Parker and Pianka, 1976). 
It could not be determined if female receptivity is terminated by copulation as Crews (1973b) has shown to be the case in Anolis carolinensis, but it is strongly suspected. One captive female was copulated with twice by the same male in a period of three days, however she was an unwilling partner in the second mating. The male was able to "rape" the female due to his much larger size $(286 \mathrm{~mm}$ SV versus $235 \mathrm{~mm}$ ) and the confinement of the enclosure. Since no female Cyclura was observed to accept a male more than once in captivity (mated females always rejected further courtship attempts), I suspect that females copulate only once, with only one male, during each breeding season. Males, however, will copulate more than once during the breeding season, but apparently only once during any one day. On April 24, male \#3 had attempted to mate once (with another female) before he copulated successfully with female \#l. He did not attempt courtship again that day. The following day he unsuccessfully courted three times. The next day he attempted to breed eleven times (with two females) before he forcibly mated \#l female. He did not try to court again that day, but did on several following days. On May 9 , \#3 male copulated successfully with the first female $(\# 3)$ he courted. She was very receptive and moved to him immediately after his morning emergence. He did not attempt courtship for the remainder of the day. It is suggested that males in the field are able to mate with more than one female if they are available.

In captivity, female \#1 accepted male \#3 on April 24, and was raped (by the same male) on April 26; female $\# 3$ accepted male $\# 3$ on May 9. The other two females were not observed to accept males, but both shelled eggs. It is therefore presumed that they also mated. The 
earliest courtship attempt was observed on April 24; none were attempted in two days of observation prior to that. Since the lizards involved were captured less than three weeks prior to that time, a two to three week mating season, centered about the first of May, is indicated.

Post-Copulatory Behavior. Captive males frequently dragged their cloacal regions on the substrate both prior to and following courtship behavior. Two captive males also exhibited a strange modification of normal defecatory behavior during the breeding season. The pelvic region was elevated above the ground in typical defecation posture; however, the abdominal contractions necessary to egest the fecal pellet resulted in eversion of the hemipenes. The organs remained everted until after the scat was deposited. As they were then withdrawn a small quantity of white viscous fluid (semen?) dripped from the region of each retracting hemipenis. I could not determine the significance of this behavior.

Probably the most significant post-copulatory behavior noted in the captive situation was when the male drove off males that courted the female with which he had copulated. Unfortunately, this behavior was clearly observed after only one of the captive matings. Following the other two copulations, other males did not attempt to court the mated female.

Two other mlaes were present in the enclosure at 1237 hours on April 26, 1975, when male \#3 copulated with female \#1. Male \#2 was old, senile, and subdominant to $\# 3$; he was never observed to court any females. Male $\# 4$ was very young (first or second year post-maturity); he courted frequently (Table 7) but was never accepted by a female. 
Approximately eight minutes after \#3's copulation, male $\# 4$ courted female $\# 4$ twice in less than 30 seconds and was rejected each time following the vibratory display. Male \#3, resting in the shade, showed no interest in this activity. However, at 1249 , \#4 approached female \#I very rapidly and after an abbreviated vibratory display, jumped up and bit at her neck. Simultaneous with her attempts to reject him, \#3 postured (see SOCIAL ORGANIZATION) and charged from his resting place and chased $\$ 4$ away from "his" female. Following the short chase, \#4 bobbed submissively, as \#3 moved back to his resting place. Within 30 seconds, \#4 again moved to court \#1 and again \#3 postured, charged, drove $\# 4$ from the vicinity of the female, and moved into the shade to rest. This same sequence was repeated five times over the following five minutes; 20 to 60 seconds separated each sequence. At that time (about 1256 hrs), male \#2 moved to the feeding station and this seemed to stifle $\# 4^{\prime} s$ advances temporarily.

No interaction occurred until 1321 when $\# 4$ resumed his courting interest in $\not 1$ and $\# 3$ again chased him away from her. The sequence was repeated six more times, each separated by 60 to 150 seconds, over the next nine minutes. Male \#4 dragged his cloaca on the substrate three times during the following nine minutes and retreated to a burrow for the remainder of the day at $1341 \mathrm{hrs}$. Number 3 male did not attempt to "guard" any female during any other day of observation. This protective behavior thus appears to be restricted to the day of copulation. Assuming ferales are receptive for only a short time during the ovarian cycle, the practice of guarding a recently-copulated female by a male in the field would help guarantee that he, alone, contributed to that female's entire brood that year. Parker (1974) has discussed the 
significance of this behavior in his theoretical treatment of femaleguarding as a male time-investment strategy.

The mating system of Cyclura carinata is apparently primarily monogamous with serial polygyny among some males (see Wilson, 1975). There appears to be pair-formation during at least the breeding season. Two females at the SW Blind lived within the home range of the same respective males for two years until all were killed by dogs and cats. Monogamy and/or polygyny seem to be the predominant systems among the iguanines. Although no breeding observations were made, pair bonding and monogamy have been suggested for Cyclura pinguis (Carey, 1975). Johnson (1965) noted male-female pairing in Sauromalus obesus, but did not observe courtship. In a more complete behavioral study, Berry (1974) found a polygynous system with pair formation for the same species. Male Mona Island Cyclura cornuta are generally polygynous but some are apparently promiscuous; females are monogamous, polyandrous, or promiscuous (Wiewandt, in preparation). Street (1952) implied that Cyclura nubila is promiscuous, but no supporting data were presented. His observations were based on tame, unrestrained lizards inhabiting a golf course in Cuba, but may not be representative of field populations. Alvarez del Toro's (1972) observations of Iguana iguana suggest a polygynous mating system for the species. However, Peracca (1891, cited in Noble and Bradley, 1933) observed that captive male iguanas mated with more than one female, but did so more with one female than another. He also noted multiple insemination of females (up to eleven tines). This suggests a polygamous if not totally promiscuous system, but it may have been an artifact of the captive situation. Mueller (1972) reported that the species is polygamous in Columbia. Further 
studies of courtship behavior as well as all aspects of social behavior are sorely needed for lizards of this subfamily if meaningful comparisons are to be made.

\section{Nesting}

Female cyclura carinata oviposit their single annual clutch in early June. Two gravid Pine Cay females had fully shelled oviducal eggs on June 3 and 9 and four recently deposited nests were excavated on June 5, June 7, and June 9 (2) on Pine and Water Cays. A female at the SW Blind site laid her eggs June 6. A female captured June 5 on Water Cay nested in an observation pen four days later. Captive lizards tended to nest later than native lizards, perhaps due to subnatural thermal regimes. A Pine Cay female collected April 4 deposited her clutch on June 12 in Gainesville. A Water Cay female, captive for nearly one year, dropped her eggs on July 25, 1975 (David Auth, personal communication). Soil for burrowing was not available in the pen in 1975 and the eggs were deposited on the enclosure's substrate. The female had ceased feeding two weeks previous to oviposition and resumed immediately after laying.

Since copulation was not observed in the field, I have no way of knowing with certainty the relation of a female's nest site to the territory of the male with which she copulated. However, burrows, or branches thereof, offering optimum nesting conditions (see later) are limited in many areas due to substrate conditions and high lizard densities. Therefore, female nest site location is probably not closely determined by the location of the territory of the male with which she copulated, but rather by nest site availability. A clustered 
nest site distribution in areas with optimal nesting conditions would thus be expected, and was in fact, observed at the SW BI ind during the summer of 1974 (Figure 20). The nest burrows were clumped in the strip of relatively deep friable soil lying midway between the rocky ledge adjacent to the lake and the rocky seashore. Availability of nest sites is probably an important factor limiting population size; the success of egg clutches laid in inferior nests is certainly reduced. The fact that several other iguanine lizard species migrate considerable distances to communal nesting areas (Rand, 1968; Montgonery et al., 1973; Wiewandt, in preparation; and perhaps Hackforth-Jones, Ms.) suggests that suitable sites may be generally limiting to members of the subfamily.

Nesting activity is apparently confined to the morning. The previously mentioned SW Blind site female failed to emerge on June 6 by the hour it typically had for the previous several days. Under continual observation, the female first emerged at 10:45 EST. She climbed immediately into a small Conocarpus tree and began eating leaves. Later in the afternoon she returned to the nest burrow to kick additional soil in to further close the nest chamber. The June 5 Water Cay captive female had finished nesting by 9:00 EST June 9, when she began to cover the nest. The female captured April 4 nested sometime during the early part of the day on June 12 .

Cyclura nubila on Little Caymen apparently oviposit late in the day; Lewis (in Grant, 1940b) found nesting females between 1730 and 1800 hrs. Cyclura cornuta (Wiewandt, in preparation), Iguana iguana (Rand, 1968; Alvarez del Toro, 1972), and Amblyrhynchus cristatus (Carpenter, 1966) will nest at any time during the day. Sauromalus obesus is known to nest at midday (Johnson, 1965). 


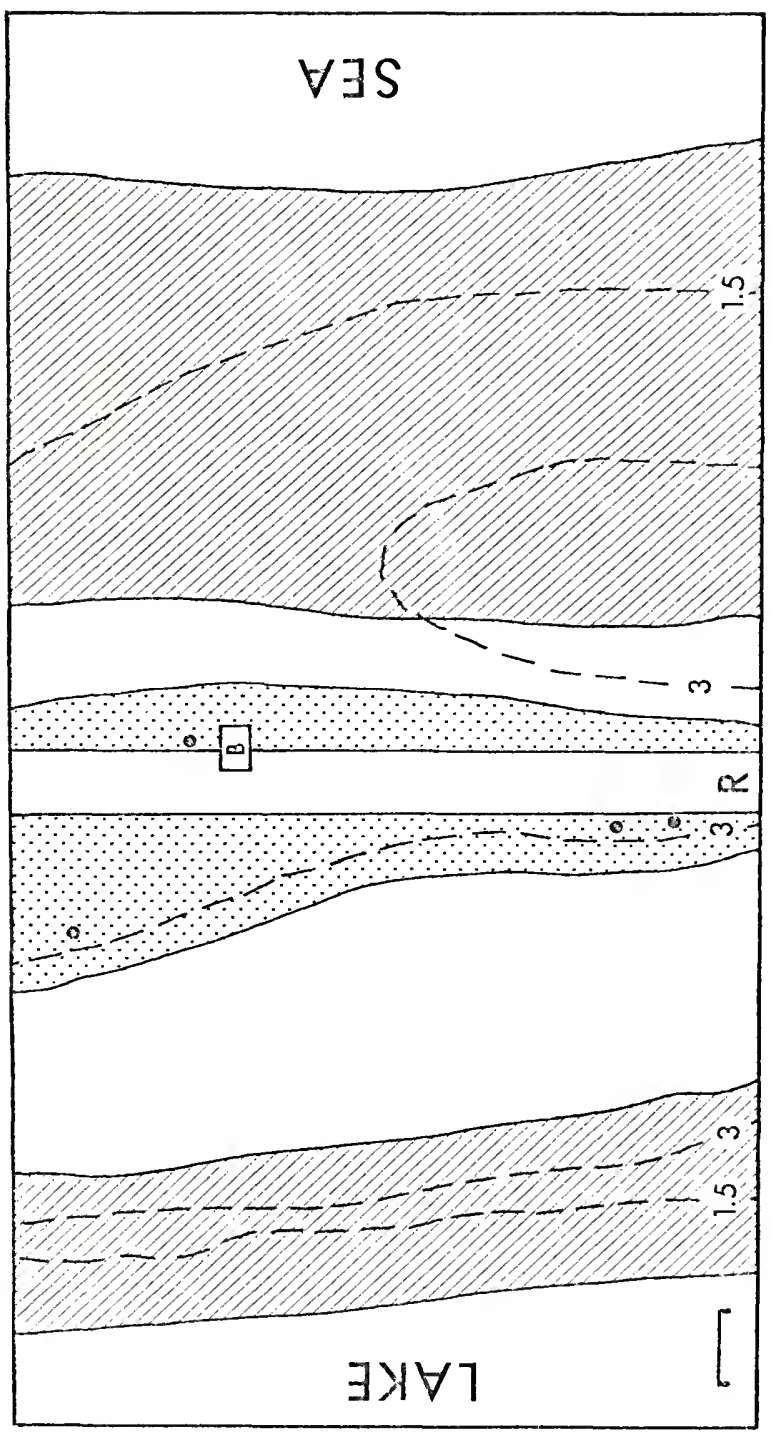

주웜

듬

ช0

है

드드

ज)

市

$\frac{n}{0} \stackrel{0}{0}$

䆓:

응 믐

$\stackrel{0}{0}$

$+\frac{n}{\pi}$

足

ㄴ.

-

넏

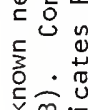

도음

4. 드.

o.

두

员 $\frac{1}{\mathrm{n}}$

$\stackrel{1}{\pi} \frac{1}{0}$

$\frac{\Phi}{\square}$

$\leftarrow$

-

芯的

든 는

¿

तथ

논

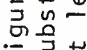

는 光 
Nest burrows are not constructed specifically for that prupose by female Cyclura carinata as in Cyclura nubila (Street, 1952; Shaw, 1954), Cyclura cychlura (Carey, 1975), Sauromalus obesus (Johnson, 1965), Iguana iguana (Rand, 1968; Hirth, 1963), Amblyrhynchus cristatus (Carpenter, 1965), Cyclura cornuta (Wiewandt, in preparation; Noble, 1923; Haast, 1969), Ctenosaura similis (Hackforth-Jones, Ms.), and apparently Ctenosaura pectinata (Evans, 1951). Cyclura cychlura on Andros apparently utilizes termite mounds for nesting in the absence of soil for digging (Waiter Auffenberg, personal communication). The terminal portion of the burrow the female occupies during the nesting season is used for nesting in $\underline{C}$. carinata. She may, however, dig a short branch off the main burrow for the nest chamber. Figure 21 illustrates a typical nest turrow found on Pine Cay, June 9, 1974. The general configuration of several nest burrows are diagrammed in Figure 12. As earlier described (see Burrows, under HABITAT), females tend to inhabit shallower burrows than males. This is certainly a function of the necessity for relatively shallow burrows by females for use as nest chambers: the roof of no nest chamber excavated was more than $25 \mathrm{~cm}$ below the ground surface. Following the deposition of the egg complement at the end of her burrow (or a diverticulum of the same), the female kicks and pushes sand around the eggs and completely blocks the burrow just proximal to the eggs, forming a sealed air chamber above the eggs. A similar chamber is also present in the nests of Amblyrhynchus cristatus (Carpenter, 1966) and Clenosaura similis (Hackforth-Jones Ms.). This chamber apparently aids in the maintenance of high humidity and perhaps also functions to facilitate respiration of the eggs. 

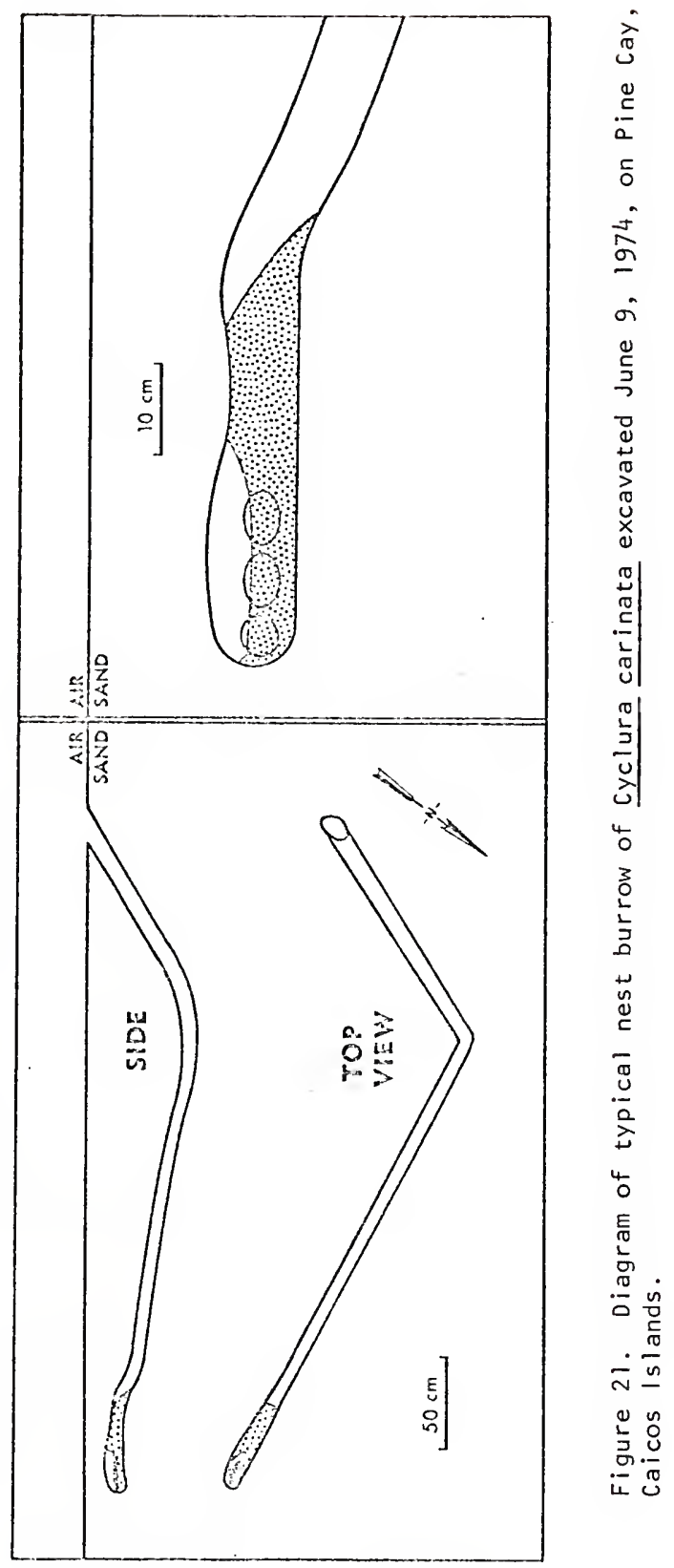
The female obtains the soil necessary for the nest plug from tile area near the mouth of her burrow. The covering process was observed in part only once in nature. As the female walked through the burrow toward and out of its entrance, she pushed soil backward with her forefeet and alternately flung dirt backward with her hind feet. Once approximately a half meter outside the burrow she would turn and re-enter the burrow and repeat the sequence. This process was repeated three times in the instance 1 observed.

The actual manipulation of the dirt at the nest plug was not observed. It is not known if female Cyclura carinata butt the soil with their heads while plugging the nest chamber to pack the earth as Amblyrhynchus (Carpenter, 1966), Iguana (Rand, 1968), and Cyclura cornuta stejnegeri (Wiewandt, in preparation) do.

Female $\underline{C}$. Carinata demonstrated their digging instinct many times as nesting season approached during early June. Foraging females would frequently stop and scratch vigorously at the substrate in the same manner as that observed in the female covering her nest. This behavior was observed at no other time of the year.

One of the most interesting behaviors associated with nesting follows the completion of the nesting process itself. Although female C. Carinata are not territorial during the remainder of the year they vigorously defend the area around their nest (and home) burrow.

A female Cyclura carinata at the SW Blind site defended her nest burrow against all conspecifics, female and male, at least until July 2 when daily observation was terminated. Perhaps my presence near her territory reinforced her defensive instinct and caused an atypical extension of this behavior. Two other undisturbed females near the 
SW 8 lind were last observed exhibiting this defensive behavior on June 10 and June 12, respectively. It is not known when the behavior terminated as they were not seen again. A captive female in Gainesville exhibited this nest defense for three days following nesting when she was removed to another pen (David Auth, personal communication). Even though she was moved to a different enclosure she continued to exhibit occasional defensive behaviors for at least 35 days after the transfer.

Subsidence of nest defense behavior seems to be related to decreases in the number of intruding lizards (i.e., a lack of positive reinforcement). At the SW Blind site, as well as in captivity, the behavior seemed to remain as long as reinforcement from interaction was continual. The adaptive significance of such a behavioral mechanism seems apparent. It is clearly advantageous for a female lizard to expend energy guarding her nest site from other females seeking nest sites and from males which might inadvertently uncover the eggs during burrow cleaning activities. Once the nesting period is completed, however, and the resident male is aware of the female's burrow, this energy is better spent on other activities.

The defended area around a female's nest burrow was accurately mapped in two cases near the SW Blind. During June, 1974, female \#18 $(222 \mathrm{~mm} \mathrm{SV}$ ) maintained an activity range of only about 155.5 square meters, centered around a low perch overlooking her nest burrow (Figure 22). I observed her defend the nest site eight times. Mean radius from the perch to the site where an intrucer was defended was $3.79 \pm 0.71 \mathrm{~m}$ (3.0 to 5.2 ). This radius defines a circular area of $45.1 \mathrm{~m}^{2}$, only $29 \%$ of the female's activity range for the month. 


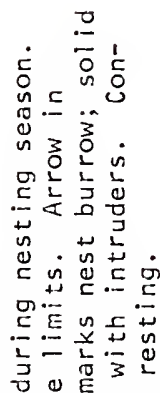

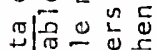

证 $0 \frac{5}{3}$

드은 5

1

Uึ

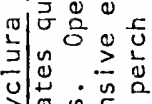

1

उीu 1 ब

(1)

万.

Eิ

过 3 立

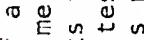

它茫菏

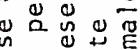

ᄃ ᄃ ᄂ

$4 \div 0$

ग

- $0 \underline{0}$

ᄃ... 芩

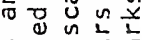

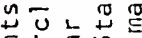

ᄃ 1 政

Ẽ્

$>0 \div \dot{0}=$

요요

- 了0 u (1) ज 0 ()) 品。 $12 \frac{0}{2}$

U @ n

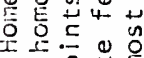

० $\Omega+0$

i地出出

NED

-

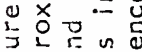

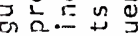

虫 


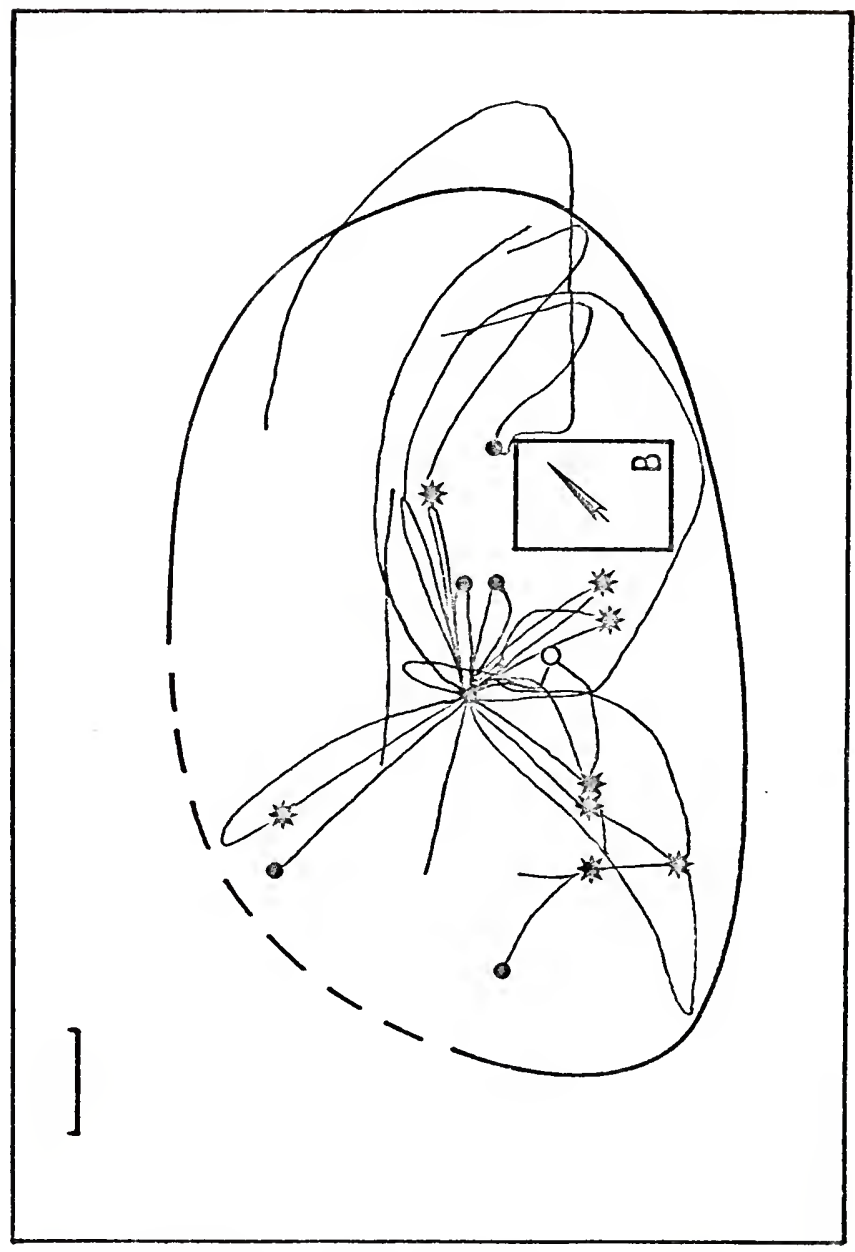


During the same month, another female was observed to guard her nest eight times. Her defense was centered about a low brush pile driectly above the entrance to her nest burrow. She defended against intruders which approached within an average of $4.60 \pm 1.93 \mathrm{~m}$ (1.2 to 7.3). A circular area averaging $66.5 \mathrm{~m}^{2}$ was thus defended. Her activity range for the month could not be accurately plotted.

Following nesting the female spends most of her time on a perch near her nest burrow vigilantly watching the area. Three females at the SW Blind site utilized piles of dead branches within two meters of the entrance to their respective burrows for their elevated guard stations. For at least the next few days, these females could nearly always be seen occupying the same perch. A female which nested on June 6 spent 6 hrs, 23 min (total active period $=9$ hrs) at her station on June 10 (with two defenses of her nest); 7 hrs, 1 min on June 12 (with only one nest defense); $1 \mathrm{hr}, 17 \mathrm{~min}$ on June 16 (a single defense); $43 \mathrm{~min}$ on June 21 (one defense); $1 \mathrm{hr}, 29 \mathrm{~min}$ on June 26 (two defenses); and, 51 min on July 2 (one defense).

On the approach of a conspecific (male or female) the guarding female would make short lunging charges accompanied by vigorous open-mouthed bobbing and defensive posturing (see SOCIAL ORGANIZATION). Biting was never observed in these interactions and is apparently not part of the female's behavioral repertoire. Most intruding females and subadult males immediately ran when initially charged by the guarding female, however, males in whose territory the nest burrow occurred were more reluctant. In order to discourage the advance of a resident male, the female usually had to make several short charges, presenting her postured body laterally to the male between lunges, and bobbing vigorously with 
opened mouth. The male always ultimately moved away, despite the smell relative size of the female; a $222 \mathrm{~mm}$ SV female (approximate weight, $400 \mathrm{gm}$ ) was repeatedly successful at driving off the $286 \mathrm{~mm}$ SV resident male (weight, about one $\mathrm{kg}$ ).

Nest defense was the rule for Cyclura carinata at the SW Blind, but it is not known if lizards at other locations on Pine Cay or on other islands always exhibit the behavior. Eibl-Eibesfeldt (1966; see also Carpenter, 1966) found that Amblyrhynchus cristatus on islands where potential nest sites were limited also defended their nests, while those on islands where nesting areas were plentiful did not. Lizard densities on Pine Cay are high and nest sites are probably at a premium in many areas. This factor probably limits population growth to some extent in those areas.

Nest defense, either before or after oviposition, has also been reported for the Iguanines Cyclura cornute (Wiewandt, in preparation), Cyclura cychlura (Carey, 1975), Cyclura nubila (Shaw, 1954; Street, 1352) and Iguana iguana (Rand, 1968) in the field, and Brachylophus

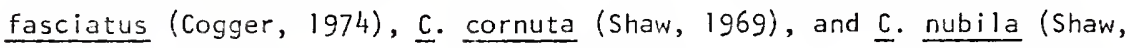
1954) in captivity. In each of these, the aggression level apparently subsides within a few hours to a few days following oviposition.

The evolution of specialized nest guarding behaviors in at least the above species of the subfamily Iguaninae suggests that nest sites may comonly be limiting to all members of the group. Female iguanines undoubtedly actively seek optimum nest sites, i.e. areas with friable soil (Carpenter, 1967), good insolation (Rand, 1972), and/or decreased predator numbers (Rand and Robinson, 1969; Sexton, 1975). 
Since these areas are often patchily distributed, communal nesting is common among iguanines: Amblyrhynchus cristatus (Carpenter, 1966), Cyclura cornuta (Wiewandt, in preparation), and Ctenosaura similis (Hackforth-Jones, Ms.). Sexton (1975) and Hackforth-Jones (Ms.) have discussed the advantages and disadvantages of communal versus dispersed nesting in Iguana iguana, and Ctenosaura similis, respectively; their comments pertain to other iguanines as well.

It should be clear that any behavior that decreases the energy spent in locating and constructing nest burrows should have a distinct selective advantage. A variety of strategies have apparently been employed by iguanines to reduce the cost of nesting. Female cyclura carinata avoid excavating a complete nest burrow for each separate clutch by simply depositing the clutch in previously excavated retreat burrows (or easily excavated short branches thereof). A portion of the energy thus saved is then allocated to short-term nest defense which decreases the probability of interference with the nest by conspecifics.

\section{Ctenosaura similis (Hackforth-Jones, Ms.) nest communally; many} females oviposit in the same connecting nest burrow system. Since many females contribute to constructing the nest burrow, average energetic cost of nest construction per individual is probably less than if separate burrows were constructed. Unfortunately, it is not known if ctenosaurs exhibit nest defense behavior within these burrow systems. Iguana iguana (Rand, 1958) nest commally; each female oviposits in a separate nest, which she may or may not have constructed. Since iguanas are physiologically incapable of completing the nesting process in a single bout, they must several times leave the partially constructed nest to rest. Since a rested fomale gains a considerable energetic 
advantage if she resumes digging in a burrow already partially completed, females compete for and dispute over these burrows. Disputes are generally settled via simple (not complex) displays rather than by actual fighting. Rand and Rand (1975) have argued stochastically that these competitive disputes are actually settled with a minimization of energetic cost to the individual. Their cost argument probably relates as well to the similar behavior of Cyclura cornuta (Wiewandt, in preparation) and Amblyrhynchus cristatus (Carpenter, 1966).

In summary, the typical pattern in a female Cyclura carinata during the nesting season is to establish itself in a suitable nest burrow, necessarily a relatively shailow one, uninhabited by conspecifics. At the end of this burrow or one of its branches, she will deposit her eggs during early June. A nest cavity is formed by plugging the end of the burrow with soil, but leaving an air space over the eggs. Following oviposition, she immediately terminates the fasting associated with the presence of eggs in her oviducts. The female then vigorously guards her nest burrow against intruding conspecifics, increasing the likelihood of survival of the contained eggs.

\section{Eggs, Incubation, and Hatching}

No information is available in the literature concerning reproductive potential in Cyclura carinata. Only a single clutch of eggs is laid annually. Based on number of oviducal eggs and/or corpora lutea, clutch size in $\mathrm{C}$. carinata averages $4.38 \pm 1.95(2-9 ; N=18)$, and is positively correlated with SV length (Figure 23). An increase of one agg for about $16 \mathrm{~mm} \mathrm{SV}$ is indicated by the least square regression estimate (clutch size $=0.064$ SV - 10.018; $r=0.741, p<0.01$ ). 


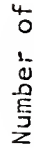

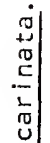

힌

.

E

$=\frac{1}{5}$

항

品焉

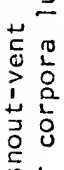

in 1

앙

य

$\therefore$

ज gू

U.

근

낭

동

点 n

$\therefore \div$

$\frac{0}{0}$

$\stackrel{0}{\circ}$

$\dot{m}$ ㅁ

v

व

它品

ㅍ 


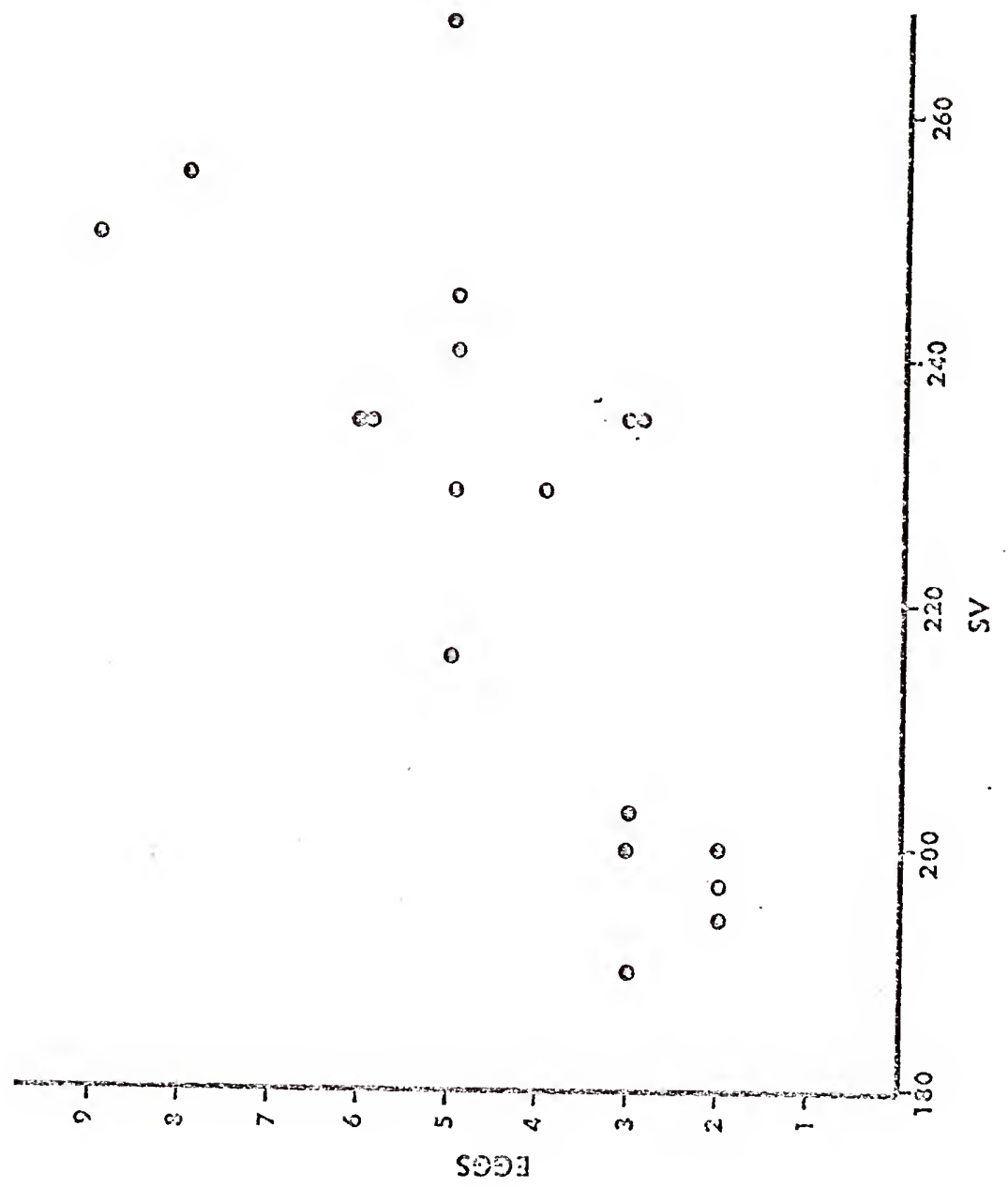


Estimation of clutch size by counting enlarged ovarian follicles from lizards collected during the spring tends to slightly overestimate the actual number of oviposited eggs $(\bar{X}=4.80 \pm 0.98 ; N=5)$. Numerous excavated burrows contained hatched egg shells somewhere along their lengths, but their numbers were deemed unreliable as an estinate of clutch size and therefore were not included in any of the above calculations. The numbers of shells found in these cases were 1, 1, 3, 5, and 7. It is doubtful that Cyclura carinata ever lays a single egg only and these shell records probably reflect my inability to find the entire clutch. The grand mean for clutch size from females with enlarged follicles, oviducal eggs, or corpora lutea; natural nestings observed; captive layings; and excavated nests is $4.65 \pm 1.77(2-9$; $N=26)$.

Clutch information from two additional females was not included in the above calculations because of their captive maintenance, and the possible implications of their captive reproductive life. A $285 \mathrm{~mm}$ SV, $770 \mathrm{gm}$ lizard (the largest female encountered in the study) was captured July 28, 1974, by David Auth on Water Cay. Maintained in captivity on a generous diet, she laid seven eggs on the enclosure floor on July 25 , 1975. She appeared very heal thy until her sudden accidental death on May 24,1976 . Dissection revealed eleven yolked follicles of nearovulatory size in the ovaries. A potential clutch size of eleven is indicated. Another Water Cay female, captured February 16, 1976, (292. mm SV) laid eleven eggs in captivity July 25, 1976. Clutch sizes in these two females thus exceed by two the nearest record. This apparent jump in reproductive output could be related to the increase in quantity 
and quality of food resources available to them in captivity. The implications of these observations will be discussed later.

Twenty eggs (oviducal or freshly laid) averaged $51.8 \mathrm{~mm}(46.0-58)$ by $31.1 \mathrm{rm}(28.5-33.5)$ and weighed an average of $25.9(19.0-29.9) \mathrm{gm}$. Eggs are elongate ovals when laid; the elastic shell is thin and translucent and an embryonic disk 1.5 to $2.0 \mathrm{~cm}$ in diameter is faintly visible through the integument. The shell soon thickens, loses its translucent character, and becomes an immaculate white.

Two clutches of 6 eggs each were incubated to hatching in the manner of Zweifel (1961); only three of six hatched successfully in both cases. To minimize disturbance the widths of only three eggs were measured during incubation. Average width had increased to $38.3 \mathrm{~mm}$ at 18 days prehatching. This increase in diameter continued to a maximum at hatching; egg length increased very little during incubation. One egg which increased exceptionally in size weighed 46.0 grams just prior to hatching. Such an increase in egg size and weight is typical of iguanid lizard eggs (e.g. Crenshaw, 1955).

One of the incubated clutches (Clutch A) was excavated from a nest burrow on Pine Cay June 9 (see Table 8) and was surely less than one week post-oviposition. Incubated at room temperature on Pine Cay until July 20 , the eggs were then transferred to a constant $28^{\circ} \mathrm{C}$ environment in the laboratory in Gainesville. Prior to July 20, two eggs had developed fungus, collapsed, and were removed. The first had shriveled on June 15 (six days after discovery) and contained an embryo of $34 \mathrm{~mm}$ total length. The second collapsed on July 4 (25 days post-location); the contained embryo measured $45 \mathrm{mn}$ total length. 
Table 8. Selected reproductive data from female Cyclura carinata.

\begin{tabular}{|c|c|c|c|c|c|}
\hline Location & $\begin{array}{c}\text { Date } \\
\text { Nesting } \\
\end{array}$ & $\begin{array}{c}S V \\
(\mathrm{~mm})\end{array}$ & $\begin{array}{l}\text { Preoviposition } \\
\text { Weight (gm) }\end{array}$ & $\begin{array}{l}\text { Clutch } \\
\text { Weight } \\
\text { (gm) }\end{array}$ & $\begin{array}{l}\text { Post- } \\
\text { oviposition } \\
\text { Weight (gm) }\end{array}$ \\
\hline Pine Cay & June $3(0)$ & 245 & 520 & 142 & $\cdots$ \\
\hline Water Cay & June $5(\mathrm{~N})$ & 255 & --- & $207.2 *$ & 645 \\
\hline Pine Cay & June $7(\mathrm{~N})$ & 200 & --- & $51.8 *$ & 250 \\
\hline Pine Cay & June $9(\mathrm{~N})$ & 200 & -- & $77.7 *$ & 285 \\
\hline Pine Cay & June $9(N)$ & --- & $-\cdots$ & $155.4 *$ & $\cdots$ \\
\hline Pine Cay & June $9(0)$ & 235 & 510 & 126.2 & 380 \\
\hline Water Cay & $\begin{array}{l}\text { June } 9 \\
\text { (C; June } 5)\end{array}$ & 250 & 815 & 250 & 568 \\
\hline Pine Cay & $\begin{array}{l}\text { June } 12 \\
\text { (C;April 4) }\end{array}$ & 235 & 570 & $155.4 \%$ & --- \\
\hline Pine Cay & $\begin{array}{l}\text { June } 18 \text {, died } \\
\text { with oviducal } \\
\text { eggs } \\
\text { (c; April } 3 \text { ) }\end{array}$ & 235 & 560 & $77.7 *$ & $\cdots$ \\
\hline Pine Cay & $\begin{array}{l}\text { Between June } \\
13 \text { - July } 15 \\
(\mathrm{C} ; \text { April 5) }\end{array}$ & 216 & 440 & $129.5 \div$ & --- \\
\hline Accumulated & Averages & 230 & 569.2 & $\begin{aligned} & 137.3 \\
& \text { (excluding } \\
& \text { estimates } \\
&= 172.7 \text { ) }\end{aligned}$ & 425.6 \\
\hline
\end{tabular}

Note: (N) below date indicates date nest found; (0) indicates female with oviducal eggs; and (C) captive nesting (with date female collected). observed range included in parentheses below means. Asterisks signify values estimated from overall average egg weight. Reproductive effort (RE) measures proportion of clutch weight in preoviposition weight of female. Expenditure per progeny (EPP) is the proportion of female weight made up by a single egg. 
Table 8 - extended

\begin{tabular}{|c|c|c|c|c|}
\hline $\begin{array}{l}\text { Eluich } \\
\text { Size }\end{array}$ & Mean Egg Size (mim) & $\begin{array}{l}\text { Mean Egg } \\
\text { Weight }(\mathrm{gm}) \\
\end{array}$ & $\mathrm{RE}$ & $E P P \times 10^{2}$ \\
\hline 5 & $\begin{array}{r}56.0 \times 32.2 \\
(54.5-58.0 \times 31.0-33.5) \\
\end{array}$ & $\begin{array}{c}28.3 \\
(27.2-29.9)\end{array}$ & 0.273 & 5.46 \\
\hline 8 & $-\cdots$ & $-\cdots$ & $0.243 *$ & $3.04 \div$ \\
\hline 2 & --- & -- & $0.172 \%$ & $8.60 \%$ \\
\hline 3 & --- & $\cdots$ & $0.214 *$ & $7.13 \%$ \\
\hline 6 & $\begin{array}{c}52.4 \\
(51.5-54.0)\end{array}$ & --- & --- & --- \\
\hline 6 & $\begin{aligned} 49.1 \times 29.5 \\
(46.0-52.0 \times 28.5-30.25)\end{aligned}$ & $\begin{array}{c}21.0 \\
(19.0-23.1)\end{array}$ & 0.247 & 4.12 \\
\hline 9 & $\begin{aligned} & 49.5 \times 31.5 \\
&(49-50 \times 31-32)\end{aligned}$ & 27.8 & 0.307 & 3.41 \\
\hline 6 & $\begin{array}{r}51.0 \times 32.2 \\
(50.5-51.5 \times 30.0-33.5) \\
\end{array}$ & --- & $0.273 *$ & $4.55 \%$ \\
\hline 3 & --- & -- & $0.139 \%$ & $4.63 \%$ \\
\hline 5 & --- & --- & $0.294 \%$ & $5.88 \div$ \\
\hline 5.3 & $5 ! .8 \times 31.1$ & 25.9 & $\begin{array}{c}0.240 \\
\text { (excluding } \\
\text { estimates } \\
=0.275 \text { ) }\end{array}$ & $\begin{aligned} & 5.20 \\
\text { (excluding } & \\
\text { estimates } & \\
= & 4.33 \text { ) }\end{aligned}$ \\
\hline
\end{tabular}


At 6:00 p.m., September 2, (85 days since discovery), hatching began. Two to four langitudinal slits were made in each egg shell by the lizard's egg tooth. Three young had completely emerged by noon on September 4. On dissection the fourth egg was found to contain a fully developed, stillborn fetus which had apparently been unable to escape the egg. The first hatchling was completely out of his egg within 18 hours of slitting the egg; the second required 10 hours; the third, 19 hours.

The other incubated clutch (Clutch B) was laid in captivity on June 12, 1975, by a female captured April 4, 1975, on Pine Cay, and maintained in an outdoor observation enclosure in Gainesville. She was first copulated with on April 26, and at least one more time on April 27 by a different male. Following deposition, the six eggs were removed immediately to an environmental chamber and incubated in sterile sand at $30^{\circ} \mathrm{C}$. Three eggs spoiled during incubation and were discarded. During the afternoon of September 22 (101 days postoviposition), hatching began. By 1815 hrs that evening, the heads of two hatchlings protruded from their respective eggs through a single longitudinal sitt $16-19 \mathrm{~mm}$ long located dorsally on the eggs approximately $1 / 3$ the distance from their ends. Because of the continual disturbance while photographing the hatching process, the young required approximately 44 and 65 hours respectively to gain complete freedom from their eggs. The third egg rad not been pipped by 0800 hrs, september 24 , and was opened. The contained fctus was fully formed and alive, but had badly deformed hind limbs. In addition all three of the young had the distal portions of their tails twisted and shortened. 
Parker and Pianka (1976) found similar tail deformities among both captive hatchlings and wild Crotaphytus wislizeni in Utah. Bustard (1969) has suggested that such tail abnormalities may result from high temperature incubation of eggs. Field temperatures measured at depths representative of nest locations indicated a nearly constant $28-29^{\circ} \mathrm{C}$ through June and July. Incubation of the captive clutch at higher than natural temperatures $\left(30^{\circ} \mathrm{C}\right)$ may have produced the observed deformities. Incubation temperatures in natural nests have been recorded for several other iguanine lizard species. Bartholomew (1966) found temperatures in Amblyrhynchus varied between 28 and $30^{\circ} \mathrm{C}$. Iguana iguana nest temperatures in Panama (Rand, 1972) were quite constant and ranged only between 31 and $32^{\circ} \mathrm{C}$; however, temperatures recorded in Costa Rica by Hirth (1963a, 1963b) and Mueller (1972) in Columbia at typical nest depths on nesting areas fluctuated from 27.8 to $31.4^{\circ} \mathrm{C}$, and 29.7 to $30.3^{\circ} \mathrm{C}$, respectively. Temperatures in nest burrows of Ctenosaura similis in Costa Rica ranged between 30.0 and $31.5^{\circ} \mathrm{C}$ (Hackforth-Jones, Ms.). Johnson (1965) found temperatures in a single nest of Sauromalus obesus varied from 32.2 to $36.1^{\circ} \mathrm{C}$. It is apparent that only minor temperature fluctuations characterize the nests of iguanine lizards. No direct field data are available for the incubation period in Cyclura carinata but evidence indicates a term of about 90 days. A metal enclosure was placed around a recently laid nest burrow excavated on Water Cay June 5, 1974. The nest had hatched and the young were above ground within the enclosure when checked on August 30 (86 days after discovery). Yolk rennants in their guts indicated they were very recently hatched. Hatchlings were seen emerging and dispersing from two previously unlocated nests at the SW Blind on Pine Cay on September 1, 1974. 
Young of the year have been captured on Pine Cay on August 31 , 1974 (2), September 5, 1974, September 8, 1974, and September 18-20, 1973 (10) and were very common during early and mid-September. The earliest collection date for a new hatchling was August 10, 1975, on Little Water Cay. On that date, 22 additional juveniles were captured and released, and all were at least one year old. An obviously recently hatched $\underline{C}$. carinata with exposed umbilicus and remnants of yolk in its gut, was collected on Fort George Cay on September 23, 1973.

Since eggs are laid during the first two weeks of June and hatch during late August and early September, an incubation period of three months (approximately 90 days) is indicated. The captive hatching of Clutch $A$, estimated to be a week old when found, after 85 days, further supports this figure.

Hatchlings measured in early September ranged from 76 to $83 \mathrm{~mm}$ SV $(\bar{X}=79.80 ; N=20)$ and 108 to $121 \mathrm{~mm}$ tail length $(\bar{X}=113.6 ; N=17)$. Captive hatchlings were smaller than those naturally hatched; three from Clutch $A$ averaged $74.1 \mathrm{~mm} \mathrm{SV}(73.0-76.2 \mathrm{~mm})$ and two from clutch $B$, $72.75 \mathrm{~mm}(72.0-73.5)$. Tail lengths from the clutch $A$ hatchlings ranged from 104.8 to $106.4 \mathrm{~mm}(\bar{x}=105.9)$.

Nine recently hatched lizards on Pine Cay weighed in early September averaged $14.62 \mathrm{gm}(12.5-15.0)$. Three captive hatchlings averaged 15.69 gn (13.4 - 17.3) immediately after leaving their eggs. The higher weight is due to the bulk of the freshly absorbed yolk sac. The same three lizards weighed ten days later averaged $14.34 \mathrm{gm}(12.2-15.6)$.

Hatchling rock iguanas are basically identical to the adult female, except for the longer tail and the proportionately larger head (see 
GROWTH), the more brilliant laterally striped pattern, and the presence of the egg tooth.

\section{Fertility, Pre-natal and Natal Mortality}

No oviducal eggs or freshly laid eggs (representing five clutches, totaling 32 eggs) examined lacked embryonic disk development. Although the sample size is quite small, a fertility rate close to $100 \%$ is indicated.

Estimates of natural prenatal mortality come from only four nest chambers excavated following the hatching period. Since spoiled eggs are easy to distinguish from the crisp parchment-like empty shells of successfully hatched eggs, mortality rates for these clutches during incubation were determined. Unsuccessful eggs and their respective total complement size included three of three, one of five, one of eight, and none of seven. Mortality rates therefore averaged $33.1 \%$ among these clutches (range 0 to $100 \%$ ). However, this estimate is not weighted with respect to clutch size and tends to overestimate mortality. If we total the number of bad eggs and compare this to the total of all four complements, the mortality rate is $21.7 \%$ and may be a more reliable estimate despite the small sample size. Wiewandt (in preparation) found a $14 \%$ mortality rate in natural nests with single clutches for Mona Island Cyclura cornuta.

One of the most critical stages in the life history of cyclura carinata occurs shortly after hatching, between the time the bulky yolk sac is drawn into the body cavity and the time the mid-ventral cleft through which the sac was drawn is securely closed. In that interval the lizard must necessarily rest since disturbances provoking movement 
by the hatchling, whether they be from siblings in nature or observers in the laboratory, will cause the closing umbilicus to rupture. The resulting hemorrage and the subsequent inability of the lizard to successfully retract the yolk sac into his body cavity lead to the eventual death of the individual. Synchronization of hatching processes in a nest chamber providing little sensory input is therefore of utmost inportance to successful hatching in Cyclura carinata.

Once the hatching process is complete, the lizards must still escape their incubation chamber. Their success at this time is reflected in the fact that of six nest burrows excavated after hatching, none contained a dead hatchling lizard. Freedom is gained via a narrow escape tunnel (or tunnels) dug by the hatchlings vertically from the nest chamber. The proximity of the nest chamber to the substrate surface simplifies the process (see Nesting). However, escape from the nest chambers constructed under flat limstone or compacted coral sand rocks is necessarily different. Only one such hatched nest was excavated. Considerable scratching at all walls of the chamber was evident and the escape tunnel had ultimately penetrated the nest plug and the lizards had apparently emerged through the main burrow. This alternative is always available should vertical escape be impossible.

The importance of sibling facilitation las noted in sea turtles; see Wilson, 1975: 58) in Cyclura carinata digging out of the nest is unknown, but it is logical to assume that the presence of more digging hands would increase the probability of a more rapid, successful emergence. Experimentation with monitored nests would be very interesting. 


\section{General Seasonal Reproductive Pattern}

The timing of the major events of the reproductive cycle of cyclura carinata is illustrated in Figure 24. A general model relating environmental, physiological, and behavioral changes during the reproductive cycles of male and female cyclura carinata is shown in Figure 25. Although partly hypothetical, this model describes well the synchronization of biotic and abiotic events in the annual cycle of the rock iguana.

Three basic patterns in the timing of tropical iguanine reproductive cycles are evident. In the first, nesting coincides with the beginning of the rainy season, with hatching occurring well into that season. This is the pattern followed by Cyclura cornuta (Wiewandt, in preparation), Cyclura cychlura (Carey, 1975), C. pinguis (Carey, 1975), and Cyclura carinata (this study). For these species, the reproductive cycle appears to be seasonally timed to reduce the possibility of egg dessication and to insure an abundant food supply, especially fruits, for hatchlings. The second strategy involves nesting during the dry season, with hatching coincident with the beginning of the rainy season. Iguana iguana and Ctenosaura similis adhere to this schedule (Davis and Smith, 1953; Hirth, 1963; Rand, 1968; Alvarez del Toro, 1972; Fitch, 1973). Both Rand (1972) and Fitch (1973) agree that this cycle is dictated by the lack of optimal incubation temperatures during any other time of the year. In addition, the cycle is advantageous to hatchlings that are folivorous or insectivorous since these resources are avallable soon after the beginning of the rainy season. 


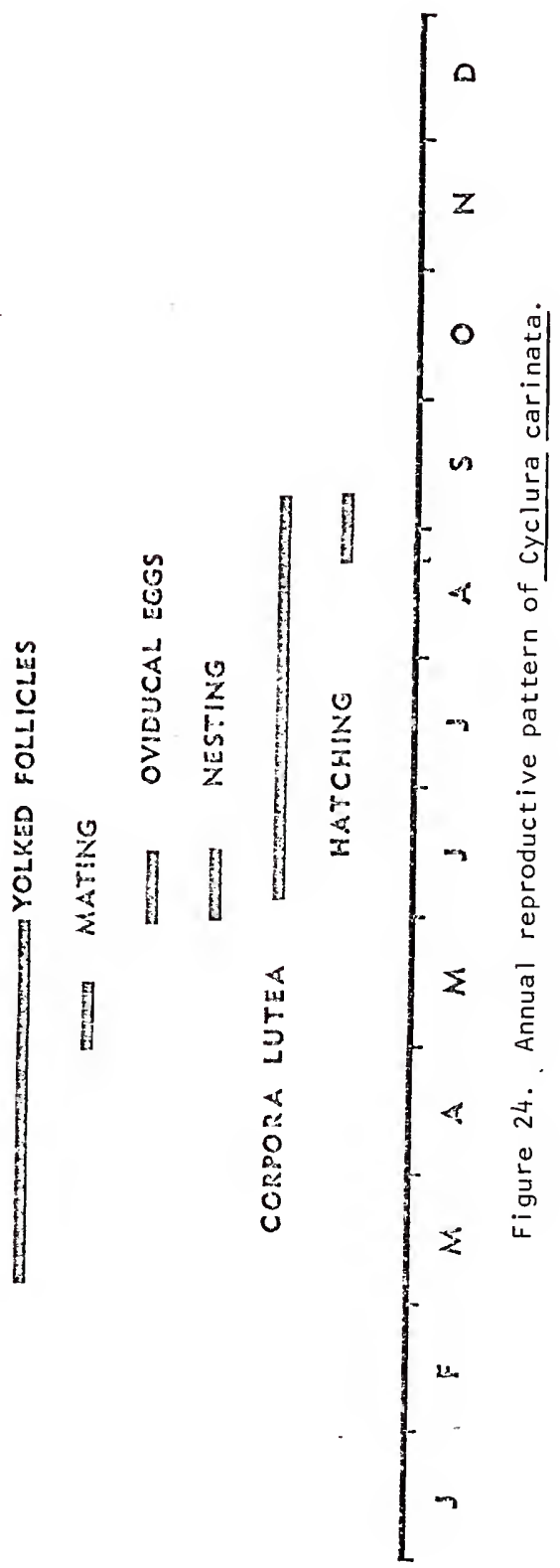




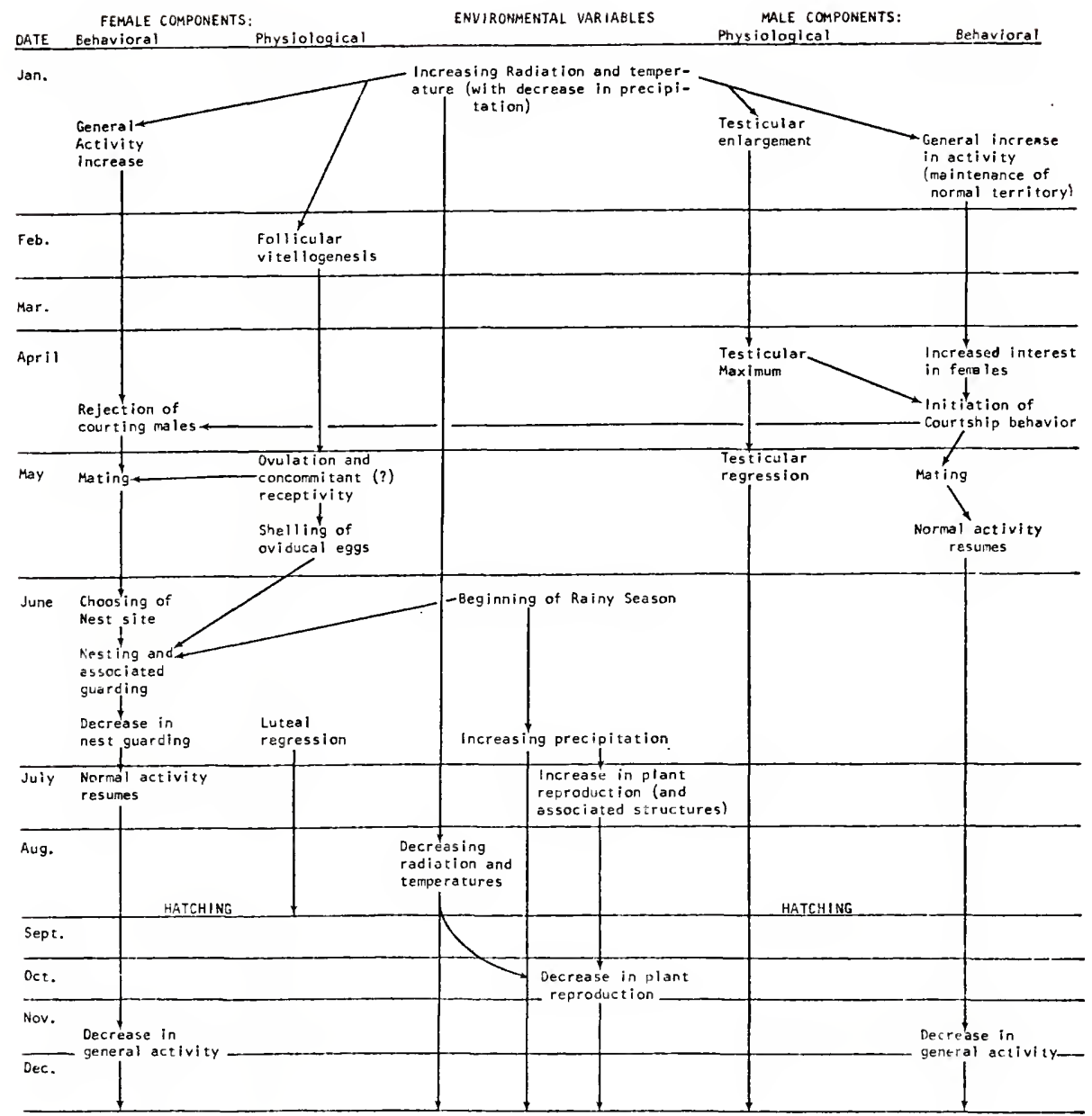

Figure 25. A hypothetical model relating environmental, physiological, and behavioral changes to the reproductive cycles of male and female Cyclura carinata. 
In the last pattern, nesting occurs toward the end of the rainy season, and hatching, early in the dry season. Amblyrhynchus cristatus is the only species known to conform to this schedule (Carpenter, 1966). Unfortunately, since this species is a littoral feeder (mainly marine algae), and food resource productivity and availability have not been studied, the significance of the timing of its reproduction cycle is unknown.

There is some disagreement concerning the timing of the reproductive cycle in the genus Conolophus; nesting in December to January (the rainy season) is suggested by Slevin's (1935) data; however, deVries (1974) reports nesting in May and June (during the dry season). This apparent paradox deserves further study.

\section{Reproductive Effort and Strategy}

Recent studies argue that the ratio of clutch weight to preoviposition body weight may not accurately reflect the proportion of energy allocated to reproduction, especially in lizards producing multipie seasonal clutches (Tinkle, 1976; Vitt, 1974; Vitt and Ohmart, 1975; Tinkle and Hadley, 1973, 1975). The clutch weight-body weight ratio (abbreviated RE, for reproductive effort) tends to underestimate a similarly derived ratio of actual calories (Tinkle and Hadley, 1975; Vitt and Ohmart, 1975). Unfortunately, the lizard literature contains considerably fewer of the latter estimates than the former. Nevertheless, the clutch-to-body-weight ratio is still of value in making general interspecific comparisons of reproductive effort.

A similar argument can be raised for estimates of expenditure per progeny (EPP) based on the proportion of preoviposition female weight in 
a single egg. However, for broad comparisons, this measure is probably adequate.

Selected reproductive data, including RE and EPP, for individual female Cyclura carinata appear in Table 8. RE in Cyclura carinata averaged slightly less than one-fourth and ranged from 0.139 to 0.307 for nine females. This value falls well within the range of similarly obtained values in the lizard literature as compiled by Pianka and Parker (1975: Range 0.05 to $0.30 ; \bar{X}=0.173 ; N=70+$ species), Tinkle (1969: 0.10 to $0.40 ; N=14)$ and myself $(0.10$ to $0.40 ; N=27)$. However, the value obtained for $\underline{c}$. carinata is greater than the average for those species. Unfortunately, speculation on specified reproductive strategies based on these data is complicated by the fact that the majority of the lizard species for which data on reproductive effort are available produce multiple clutches while the values reflect only single clutches. Since all the iguanine lizards apparently oviposit only once per year, comparisons within the group should be more meaningful.

EPP values for $\underline{C}$. carinata ranged from 3.04 to $7.13 \%$ and averaged 5.20\%. This is a relatively high value among lizard species. Estimates of EPP for several species calculated from the literature averaged from about 2 to 7\% (Telford, 1969; Vinegar, 1975; Avery, 1975a; Parker and Pianka, 1975, 1976; Pianka and Parker, 1975; Vitt and Ohmart, 1975). However, one value calculated from a single female Tachydromus tachydromoides (11.2\%) exceeded this range (Telford, 1969). This value is probably approaching the limit that is possible for lizards.

Among nine clutches, EPP is significantly negatively correlated with female sv length $(r=-0.92, p<0.01)$ and clutch size $(r=-0.85$, $p<0.01)$. Older females lay more eggs, but expend less per egg. As 
expected, RE is significantly positively correlated with clutch size $(r=0.74,0.05>p>0.01)$. It is, however, not significantly correlated with female SV $(r=0.40, p>0.05)$. In comparison to other lizard species, Cyclura carinata demonstrates a high reproductive expenditure per clutch as well as per progeny; relatively few, large eggs are produced annually.

The iguanine 1 izards have been poorly represented in previous analyses of reproductive strategies, due to a dearth in basic reproductive data for the included species. No species has been fully studied reproductively; basic reproductive parameters remain unmeasured (especially weights) even for otherwise well studied iguanines like Dipsosaurus and Sauromalus. I have scoured the literature as well as the knowledge of my colleagues in an attempt to compile and analyze reproductive data for lizards of the subfamily Iguaninae. This information, supplemented by some of my own unpublished data, appears in Table 9 .

This table illustrates the general deficiency of our knowledge of iguanine reproduction. Several comparisons can, however, still be drawn. Cyclura carinata lays the fewest eggs $(\bar{x}<5)$ of any studied iguanine except Amblyrhychus $(2-3)$ and perhaps C. cychlura (3-7). Ctenosaura similis can lay nearly 20 times as many eggs as Cyclura carinata. Only Anblyrhynchus, Conolophus, Cyclura nubila, and $\underline{C}$. cornuta are known to lay larger eggs than Cyclura carinata. However, the eggs of Ctenosaura similis are only half the length and one-fifth the weight of those of C. carinata. Each of these comparisons suggests considerable variation in reproductive expenditure among this otherwise homogeneous group of lizards. In an attempt to analyze this variation, I compiled several 
Table 9. Reproductive data for the lizard subfamily Iguanine.

\begin{tabular}{|c|c|c|c|c|c|c|c|c|}
\hline SPECIES & LOCATION & $\begin{array}{c}\text { MAXIMUM } \\
\text { SIZE } \\
\text { (mm SV) }\end{array}$ & $\begin{array}{l}\text { MAXIMUH } \\
\text { WEIGHT } \\
(\mathrm{kg})\end{array}$ & $\begin{array}{l}\text { AVIRAGE } \\
\text { ADULT } \\
\text { SIZE } \\
(\mathrm{mm} \mathrm{SV}) \\
\end{array}$ & $\begin{array}{l}\text { AVERAGE } \\
\text { WE IGHT } \\
\text { (kg) }\end{array}$ & $\begin{array}{l}\text { AVERAGE } \\
\text { CLUTCH } \\
\text { SI } 2 E \\
\end{array}$ & $\begin{array}{l}\text { AVERAGE } \\
\text { EGG SI2E } \\
(\mathrm{mm})\end{array}$ & $\begin{array}{c}E G G \\
\text { WE I GHT } \\
(\mathrm{gm}) \\
\end{array}$ \\
\hline \multirow[t]{6}{*}{$\frac{\text { Amblyrhynchus }}{\text { cristatus }}$} & Galapagos & -- & $\cdots$ & $\cdots$ & $\cdots$ & 2 & $\cdots$ & $\cdots$ \\
\hline & $\begin{array}{l}\text { Galapagos } \\
\text { (Narborough) }\end{array}$ & $\cdots$ & 3.118 & $\cdots$ & --- & 2 & -- & $80-120$ \\
\hline & & $\delta=400$ & $\delta=2.948$ & $\delta=361$ & $\delta=2.01$ & $2-3$ & $\cdots$ & --- \\
\hline & $\begin{array}{l}\text { Galapagos } \\
\text { (Narborough) } \\
\text { Galapagos }\end{array}$ & $\begin{array}{l}\delta=430 \\
\phi=350 \\
--\end{array}$ & $\begin{array}{l}\delta=2.580 \\
q=1.928 \\
---\end{array}$ & $\begin{array}{l}z=341 \\
q=290 \\
f=268\end{array}$ & $\begin{array}{l}\delta=1.984 \\
0=0.992 \\
---\end{array}$ & $\begin{array}{r}2.29 \\
(2-3) \\
3 n\end{array}$ & $\begin{array}{l}93 \times 42 \\
86.0 \times 42.5\end{array}$ & $\begin{array}{l}96.3 \\
(79-121) \\
82.0 \\
(80.2- \\
83.8)\end{array}$ \\
\hline & Galapagos & $\cdots$ & $\cdots$ & $\cdots$ & $\cdots$ & $\cdots$ & -- & -- \\
\hline & $\begin{array}{l}\text { Galapagos } \\
\text { (Santa Cruz) }\end{array}$ & $\begin{array}{l}2=510 \\
q=350 \\
\end{array}$ & -- &.-- & --- & --- & $\cdots$ &.- \\
\hline \multirow[t]{2}{*}{$\frac{\text { Brachylophus }}{\text { fasciatus }}$} & $\mathrm{F}|\mathrm{jl}| \mathrm{s}$ lands & 160 & $-\cdot$ & $\cdots$ & $\cdots$ & $3-4$ & $40 \times 30$ & --- \\
\hline & $\mathrm{Fijl} \mid \mathrm{s}$ lands & 229 & $\cdots$ & -- & -- & $\left(\begin{array}{c}5 \\
(n)\end{array}\right)$ & $19 \times 13$ & -- \\
\hline \multirow[t]{2}{*}{$\frac{\text { Conolophus }}{\text { pallidus }}$} & $\begin{array}{l}\text { Galapagos } \\
\text { (Barrington) }\end{array}$ & -- &.- & $\cdots$ & - & $7-10$ & $64 \times 35$ & --- \\
\hline & Galapagos & $\cdots$ & $\cdots$ & $\cdots$ & $1.8-2.1$ & $\cdots$ & $\cdots$ & $\cdots$ \\
\hline$\frac{\text { Conolophus }}{\text { subcristatus }}$ & $\begin{array}{l}\text { Galapagos } \\
\text { (South Plazas) }\end{array}$ & $\begin{array}{l}\delta=420 \\
q=380\end{array}$ & $\begin{array}{l}\delta=3.260 \\
q=2.410\end{array}$ & 350 & $1.700 *$ & -- & $\cdots$ & $\cdots$ \\
\hline Conclophuse sp. & Galapagos & $\cdots$ & $\cdots$ & $\cdots$ & $\cdots$ & $\cdots$ & $\cdots$ & -- \\
\hline Ctenosaura & $\begin{array}{l}\text { Veracruz, } \\
\text { Mexico }\end{array}$ & $\cdots$ & -- & $\cdots$ & -- & ${ }_{28}^{17}$ & $\begin{array}{c}30-35 \times \\
15-20\end{array}$ & -- \\
\hline $\begin{array}{l}\text { Ctenosaura } \\
\text { hemilopha }\end{array}$ & $\begin{array}{l}\text { Sonora, } \\
\text { Mexico }\end{array}$ & $\cdots$ & $\cdots$ & $q=179+$ & $q=0.215+$ & $15 n$ & $25.5 \times 12.8$ & $4.6^{\prime}$ \\
\hline \multirow[t]{5}{*}{$\frac{\text { Ctenosaura }}{\text { pectinata }}$} & $\begin{array}{l}\text { Morelos, } \\
\text { Mexico }\end{array}$ & $\begin{array}{l}\delta=320 \\
q=325\end{array}$ & $\begin{array}{l}\delta=1.000 \\
q=0.950\end{array}$ & $\cdots$ & $-\cdot$ & $49 n$ & --- & $5.10 *$ \\
\hline & & \pm & & -- & $\cdots$ & -- & $\cdots$ & --- \\
\hline & $\begin{array}{l}\text { Guerrero, } \\
\text { Mexico }\end{array}$ & $\cdots$ & $\cdots$ & -- & $\cdots$ & $-\cdots$ & -- &.- \\
\hline & $\begin{array}{l}\text { Michoacan, } \\
\text { Mexico }\end{array}$ & --- & -- & $\cdots$ & -- & --- & $\cdots$ & $\cdots$ \\
\hline & $\begin{array}{l}\text { Tamaullpas, } \\
\text { Mexico }\end{array}$ & -- & $\cdots$ & $q=191+$ & $q=0.315+$ & $17 n$ & $28.0 \times 18.0$ & 4.41 \\
\hline \multirow[t]{7}{*}{$\frac{\text { Ctenosaura }}{\text { similis }}$} & Yucatan & --- & -- & -- & $--\cdot$ & $\cdots$ & -- & -- \\
\hline & $\begin{array}{l}\text { Yucatan, Nicara- } \\
\text { gua, Costa Rica }\end{array}$ & $q=335+$ & $-\cdot$ & $q=306$ & -- & $\cdots$ & -- & --- \\
\hline & $\begin{array}{l}\text { Chiapas, } \\
\text { Mexico }\end{array}$ & $\cdots$ & --- & $\cdots$ & $\cdots$ & $20-30$ & --- & $\cdots$ \\
\hline & Belize & $\cdots$ & $\cdots$ & -- & -- & $\cdots$ & $\cdots$ & $\cdots$ \\
\hline & $\begin{array}{l}\text { Western Costa } \\
\text { RIca }\end{array}$ & $\delta=440$ & $\cdots$ & $\begin{array}{l}\delta=415 \\
q=335\end{array}$ & $\cdots$ & $21-34$ & $\begin{array}{l}24-34 \times \\
18-19\end{array}$ & -- \\
\hline & $\begin{array}{l}\text { Western Costa } \\
\text { Rica }\end{array}$ & $q=350$ & $\cdots$ & $q=298$ & $\cdots$ & $\begin{array}{l}54.9 \\
(34-87)\end{array}$ & $27.8 \times 19.1$ & -- \\
\hline & $\begin{array}{l}\text { Nicaragua, Costa } \\
\text { Rica }\end{array}$ & $\begin{array}{l}\delta=489 \\
q=347\end{array}$ & $\cdots$ & $\begin{array}{l}\sigma=345 \\
\delta=276\end{array}$ & $\begin{array}{l}8=1.034 \\
q=0.651\end{array}$ & 43.4 & $\cdots$ & $\ldots$ \\
\hline
\end{tabular}


Table 9 - extended

\begin{tabular}{|c|c|c|c|c|c|c|}
\hline $\begin{array}{l}\text { INCUBATION } \\
\text { TIME } \\
\end{array}$ & $\begin{array}{c}\text { MATCHLING } \\
\text { SIZE } \\
(\mathrm{mm} S \mathrm{SV}) \\
\end{array}$ & $\begin{array}{l}\text { HATCHL ING } \\
\text { WE IGHT } \\
(\mathrm{gm}) \\
\end{array}$ & $\begin{array}{l}\text { BREEDING } \\
\text { SEASON } \\
\end{array}$ & $\begin{array}{l}\text { NESTINE } \\
\text { SEASON }\end{array}$ & $\begin{array}{l}\text { HATCHING } \\
\text { SEASON }\end{array}$ & SOURCE \\
\hline-- & --- & --- & $\cdots$ & $\cdots$ & -- & E|b|-Elbesfeldt, 1961 \\
\hline$\cdots$ & $\cdots$ & --- & -- & Feb. $3-4$ & -- & 8artholomew, 1966 \\
\hline-- & $\cdots$ & $\cdots$ & Jan.-Mar. & early Aprll & early July & Carpenter, 1966 \\
\hline & $-\cdots$ & & Dec.-Jan. & $\begin{array}{l}\text { late Jan.- } \\
\text { Feb. }\end{array}$ & $\begin{array}{l}\text { Aprll - } \\
\text { May }\end{array}$ & Carpenter, 1966 \\
\hline $\begin{array}{l}112-113 d \\
\text { (capt Ive) }\end{array}$ & 97.0 & 58.7 & --- & $\begin{array}{l}\text { before Feb. } \\
24\end{array}$ & $\begin{array}{l}\text { June } \\
\text { (captive) }\end{array}$ & Shaw, 1966 \\
\hline$\cdots$ & $\cdots$ & & $\cdots$ & February & May & Devrles, 1974 \\
\hline-- & $105-130$ & ca. $80-120$ & $-\cdots$ & $\begin{array}{l}\text { Feb.-early } \\
\text { March }\end{array}$ & $\begin{array}{l}\text { early May - } \\
\text { early June }\end{array}$ & 8artholomew, et al. . 1976 \\
\hline $\begin{array}{l}17-23 \mathrm{w} \\
\text { (captive) }\end{array}$ & 65 & $\cdots$ & & $\cdots$ & -- & Cogger, 1974 \\
\hline-- & $\cdots$ & -- & $\begin{array}{l}\text { Sept.-Mar. } \\
\text { (captive) }\end{array}$ & $\begin{array}{l}\text { Nov. - March } \\
\text { (capt Ive) }\end{array}$ & $\cdots$ & Cahill, 1970; 8ustard, 1970a \\
\hline$\cdots$ & -- & $-\cdots$ & -- & Dec.-jan.? & -- & Slevin, 1935 \\
\hline$\cdots$ & $-\cdots$ & $\cdots$ & -- & $\cdots$ & $\cdots$ & Withoft, 1958 \\
\hline$\cdots$ & -- & -- & $\cdots$ & -- & -- & Carpenter, 1969 \\
\hline$\cdots$ & $\cdots$ & $\cdots$ & $\cdots$ & Moy-july & cet.-Nev. & Detries, 1974 \\
\hline$-\cdots$ & $\cdots$ & $\cdots$ & $\cdots$ & early May* & -- & Smlth \& 8urger, 1950 \\
\hline$\cdots$ & -- & $\cdots$ & -- & early May & $\cdots$ & $\begin{array}{l}\text { Iverson: } \\
\text { unpub:ished data }\end{array}$ \\
\hline-- & -- & $\cdots$ & -- & April 11 & --- & Evans, 1951 \\
\hline-- & --- & $\cdots$ & -- & $\cdots$ & July & Javls \& Smlth, 1953 \\
\hline$\cdots$ & $\cdots$ & $-\cdot$ & $\begin{array}{l}\text { early } \\
\text { spring }\end{array}$ & $\cdots$ & Aay-June & Dayis E Oixan, 1961 \\
\hline-- & --- & -- & $\cdots$ & -- & early July & Duel Iman, 1961 \\
\hline$-\cdots$ & --- & --- & -- & -- & $\cdots$ & $\begin{array}{l}\text { Iverson, } \\
\text { unpublished data }\end{array}$ \\
\hline-- & -- & $-\cdot$ & $\cdots$ & $\cdots$ & June-July & Ouellman, 1965 \\
\hline$\cdots$ & $\begin{array}{l}54.0 \\
(49-59)\end{array}$ & -- & --- & -- & early June & Fltch, 1970 \\
\hline $90 d$ & $\cdots$ & -- & summer? & March-May & $\begin{array}{l}\text { June- } \\
\text { August }\end{array}$ & Alvarez de! Toro, 1972 \\
\hline$\cdots$ & $53-61$ & $\cdots$ & February & $\cdots$ & june-July & Henderson, 1973 \\
\hline$\leq 90 d$ & 57 & -- & -- & Nov. T-Feb. & $\begin{array}{l}\text { late April } \\
\text {-June }\end{array}$ & Fitch, 1973 \\
\hline-- & --- & -- & --- & Aprll & -- & $\begin{array}{l}\text { Hackforth-Jones, } \\
\text { (M.S.) }\end{array}$ \\
\hline $2.5 \mathrm{~m}$ & 57 & $3+$ & $-\cdot$ & $\begin{array}{l}\text { late March- } \\
\text { early Apri! }\end{array}$ & June & $\begin{array}{c}\text { Fltch } \varepsilon \text { Henderson } \\
(\text { M.S.) }\end{array}$ \\
\hline
\end{tabular}


Table 9 - continued

\begin{tabular}{|c|c|c|c|c|c|c|c|c|}
\hline SPECIES & LOCATION & $\begin{array}{c}\text { MAXIMUM } \\
S I 2 E \\
(\mathrm{~mm} \mathrm{SV}) \\
\end{array}$ & $\begin{array}{l}\text { MAXIMUM } \\
\text { WEIGHT } \\
(\mathrm{kg}) \\
\end{array}$ & $\begin{array}{l}\text { AVERAGE } \\
\text { ADULT } \\
\text { SIZE } \\
\text { (mm SV) }\end{array}$ & $\begin{array}{l}\text { AVERAGE } \\
\text { WEIGHT } \\
(\mathrm{kg})\end{array}$ & $\begin{array}{l}\text { AVERAGE } \\
\text { CLUTCH } \\
\text { SIZE } \\
\end{array}$ & $\begin{array}{l}\text { AVERAGE } \\
\text { EGG SIZE } \\
(\mathrm{mm}) \\
\end{array}$ & $\begin{array}{c}\text { EGG } \\
\text { WE iGHT } \\
\text { (gm) } \\
\end{array}$ \\
\hline$\frac{\text { Cyclura }}{\text { carinata }}$ & $\begin{array}{l}\text { Caicos Islands, } \\
\text { BWl }\end{array}$ & $\begin{array}{l}\delta=360 \\
\mathcal{q}=292\end{array}$ & $\begin{array}{l}\delta=1.864 \\
q=1.135\end{array}$ & $\begin{array}{l}\delta=276 \\
q=225\end{array}$ & $\begin{array}{l}\delta=0.935 \\
q=0.476\end{array}$ & $\begin{array}{l}4.65 \\
(2-9)\end{array}$ & $518 \times 31.1$ & $\begin{array}{c}25.9 \\
(19.0= \\
29.92\end{array}$ \\
\hline \multirow[t]{2}{*}{$\frac{\text { Cyclura }}{\text { collei }}$} & Jama ica & $490+$ & --- & --- & $\cdots$ & $\cdots$ & $\cdots$ & $\cdots$ \\
\hline & Jamaica & $\cdots$ & --- & $\cdots$ & $\cdots$ & $20 n$ & $-\cdots$ & $\cdots$ \\
\hline \multirow[t]{6}{*}{$\frac{\text { Eyclura }}{\text { cornuta }}$} & $\begin{array}{l}\text { Dominican } \\
\text { Republic }\end{array}$ & -- & -- & -- & -- & $17 n$ & $\cdots$ & $\cdots$ \\
\hline & Captive (?) & $\cdots$ & -- & --- & -- & $20 n$ & $85 \times 38$ & --- \\
\hline & Hispaniola & $\cdots$ & -- & $\cdots$ & $\cdots$ & $\begin{array}{c}11-23 \\
(N=3)\end{array}$ & $68.6 \times 45.9$ & $\begin{array}{l}77.7 \\
(58.5- \\
88.3)\end{array}$ \\
\hline & Mona is land & $\cdots$ & $\cdots$ & -- & $\cdots$ & $12 n$ & $78 \times 47$ & $\cdots$ \\
\hline & $\begin{array}{l}\text { Mona Island } \\
\text { Dominican } \\
\text { Republic }\end{array}$ & $\begin{array}{l}8=545 \\
8=510\end{array}$ & $\begin{array}{l}\delta=6.80 \\
q=5.40\end{array}$ & $\begin{array}{l}\delta=517 \\
8=475 \\
-=\end{array}$ & $\begin{array}{l}\delta=6.10 \\
8=4.70\end{array}$ & $\begin{array}{l}12 \\
(6-19) \\
13 n\end{array}$ & $80.3 \times 50.9$ & $\begin{array}{l}104.0 \\
(82-159) \\
=-\end{array}$ \\
\hline & $\begin{array}{l}\text { Dominican } \\
\text { Republle }\end{array}$ & $\begin{array}{l}2=545 \\
8=510\end{array}$ & $\begin{array}{l}\delta=6.24 \\
g=4.76\end{array}$ & $\begin{array}{l}\delta=522 \\
g=476\end{array}$ & --- & --- & $\cdots$ & --- \\
\hline \multirow[t]{2}{*}{$\frac{\text { Cyelura }}{\text { cychlura }}$} & $\begin{array}{l}\text { nr. Great Exuma, } \\
\text { Exumas, Bahamas }\end{array}$ & -- & -- & 290 & $\cdots$ & $7 n$ & -- & $\cdots$ \\
\hline & $\begin{array}{c}\text { Guana Cay, } \\
\text { Exumas } \\
\end{array}$ & -- & $\cdots$ & --- & $\cdots$ & $3-4$ & $\cdots$ & $\cdots$ \\
\hline \multirow[t]{3}{*}{$\frac{\text { Cyclura }}{\text { nubila }}$} & Littie Cayman & $q=420+$ & $-\cdots$ & -- & $\cdots$ & $8-20$ & --- & -- \\
\hline & Cuba & -- & --- & -- & -- & $16 n$ & $76 \times 44.5$ & $\cdots$ \\
\hline & Cuba & --- & -- & $\cdots$ & -- & $17 n$ & $65.6 \times 44.5$ & $\cdots$ \\
\hline$\frac{\text { Cyelura }}{\text { pinguis }}$ & $\begin{array}{l}\text { Anegada, Brltish } \\
\text { Virgin Islands }\end{array}$ & $\begin{array}{l}\delta=550 \\
q=500\end{array}$ & $\begin{array}{l}\delta=7.75 \\
q=5.25\end{array}$ & $\begin{array}{l}\delta=534 \\
f=468\end{array}$ & $\begin{array}{l}\delta=6.72 \\
q=4.75\end{array}$ & $12-16$ & -- & -- \\
\hline \multirow[t]{2}{*}{$\frac{\text { Cyclura }}{\text { ricordi }}$} & $\begin{array}{l}\text { Doninican } \\
\text { Republle }\end{array}$ & $\cdots$ & $-\cdots$ & $q=340$ & -- & $\begin{array}{l}4.67 \\
(4-6) \\
N=3\end{array}$ & -- & $\cdots$ \\
\hline & $\begin{array}{r}\text { Dominican } \\
\text { Republic }\end{array}$ & 460 & 3.18 & 354 & 1.74 & $\cdots$ & --- & $\cdots$ \\
\hline$\frac{\text { Cyclura }}{\text { rileyi }}$ & $\begin{array}{l}\text { San Salvador. } \\
\text { Bahamas }\end{array}$ & --- & -- & $\cdots$ & --- & $5 n$ & -- & $\cdots$ \\
\hline \multirow[t]{5}{*}{$\frac{\text { Dlpsosaurus }}{\text { dorsalis }}$} & California & 133 & -- & -- & $\cdots$ & $\cdots$ & --- & -- \\
\hline & California & -- & -- & -- & $\cdots$ & $\begin{array}{l}5-6 \\
N=2\end{array}$ & $28.0 \times 16.8$ & -- \\
\hline & $\begin{array}{l}\text { California, } \\
\text { Arizona, \& } \\
\text { Nevada }\end{array}$ & $\cdots$ & -- & --- & -- & $3-8$ & $\cdots$ & $\cdots$ \\
\hline & California & $\begin{array}{l}\delta=145 \\
\phi=142\end{array}$ & -- & $\begin{array}{l}\delta=127 \\
q=120\end{array}$ & $\cdots$ & $3-5$ & $26.4 \times 15.0$ & $\cdots$ \\
\hline & Arizona & +144 & $\cdots$ & -- & $\cdots$ & --- & -- & -- \\
\hline
\end{tabular}


Table 9 - extended

\begin{tabular}{|c|c|c|c|c|c|c|}
\hline $\begin{array}{l}\text { INCUBAT ION } \\
\text { TIME } \\
\end{array}$ & $\begin{array}{l}\text { HATCHLING } \\
\text { SI2E } \\
(\mathrm{mm} \mathrm{SV}) \\
\end{array}$ & $\begin{array}{l}\text { HATCHL ING } \\
\text { WE IGHT } \\
\text { (gm) }\end{array}$ & $\begin{array}{l}\text { BREEDING } \\
\text { SEASON }\end{array}$ & $\begin{array}{l}\text { NESTING } \\
\text { SEASON }\end{array}$ & $\begin{array}{l}\text { HATCHING } \\
\text { SEASON } \\
\end{array}$ & SOURCE \\
\hline $90 \mathrm{~d}$ & $\begin{array}{l}79.8 \\
(76-83)\end{array}$ & $\begin{array}{c}14.6 \\
(12.5-15.0)\end{array}$ & $\begin{array}{l}\text { late April } \\
\text {-early May }\end{array}$ & early June & $\begin{array}{l}\text { early } \\
\text { September }\end{array}$ & This study \\
\hline-- & -- & -- & -- & $\cdots$ & $\cdots$ & Grant, $1940 a$ \\
\hline$\cdots$ & $m$ & -- & -- & April-May & --- & Lewis, 1944, 1946 \\
\hline $9 \times ?$ & -- & $-\cdots$ & $-\infty$ & $\cdots$ & $\cdots$ & Noble, 1923 \\
\hline $127 d$ & -- & $-\infty$ & -- & July 5 & November 9 & Haast, 1969 \\
\hline $\begin{array}{l}106-129 d \\
\text { (captive) }\end{array}$ & $\begin{array}{l}101.3 \\
(95-104)\end{array}$ & $\begin{array}{c}54.1 \\
(47.4-61.9)\end{array}$ & $-\cdots$ & $\begin{array}{l}\text { July } 31 \text {, Aug. } \\
4 \text {, Aug. } 11 \\
\text { (captive) }\end{array}$ & $\begin{array}{l}\text { late Nov.- } \\
\text { early Dec. } \\
\text { (captive) }\end{array}$ & Shaw, 1969 \\
\hline$-\infty$ & -- & +- & & July* & $\cdots$ & Thomas, in Carey, 1975 \\
\hline $\begin{array}{l}82.6 d \\
(78-89)\end{array}$ & $\begin{array}{c}119 \\
(105-127)\end{array}$ & $\begin{array}{l}74.0 \\
(60-92)\end{array}$ & June & $\begin{array}{l}\text { midJuly - } \\
\text { early Aug. }\end{array}$ & $\begin{array}{l}\text { mid to } \\
\text { late } 0 \mathrm{ct} \text {. }\end{array}$ & Wewandt, in preparation \\
\hline$-\infty$ & $\cdots$ & -- & $-\infty$ & $\cdots$ & $-\infty$ & $\begin{array}{l}\text { Iverson, } \\
\text { unpublished data }\end{array}$ \\
\hline 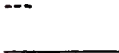 & $\cdots$ & $\cdots$ & $-\infty$ & --- & $\cdots$ & $\begin{array}{l}\text { Wiewandt and Glcca, } \\
\text { unpublished data }\end{array}$ \\
\hline$\cdots$ & --- & -- & $\cdots$ & -- & -- & Carey, 1975 \\
\hline$\cdots$ & -- & -- & $\cdots$ & early June & -- & $\begin{array}{l}\text { Cocnen, In Carey, } \\
1975\end{array}$ \\
\hline$-\infty$ & -- & $\cdots$ & -- & $\begin{array}{l}\text { May - early } \\
\text { June }\end{array}$ & & Grant, $1940 \mathrm{~b}$ \\
\hline $93 d$ & -- & $--\cdot$ & March & June 23 & Sept. 24 & Street, 1952 \\
\hline $119-123 d$ & $\begin{array}{c}102.4 \\
(95-110) \\
\end{array}$ & $\begin{array}{r}54.73 \\
(48-59) \\
\end{array}$ & $\begin{array}{l}\text { June } \\
\text { (captive) }\end{array}$ & $\begin{array}{l}\text { July } 10 \\
\text { (captive) }\end{array}$ & $\begin{array}{l}\text { Nov. } 5-9 \\
\text { (captive) }\end{array}$ & Shaw, 1954 \\
\hline--- & 1002 & $\cdots$ & --- & April-June? & Aug. $-5 \operatorname{ept} . ?$ & Carey, 1975 \\
\hline-- & $\cdots$ & $\cdots$ & $\cdots$ & $\cdots$ & -- & Carey, 1975 \\
\hline-- & -- & $\cdots$ & $\cdots$ & $\cdots$ & -- & $\begin{array}{c}\text { Wiewandt and Gleca, } \\
\text { unpublished data }\end{array}$ \\
\hline$\cdots$ & $\cdots$ & $-\infty$ & --- & Julv & -- & Stejnezer, 1903 \\
\hline-- & $\cdots$ & -- & August? & -- & -- & Smith, 1946 \\
\hline$-\infty$ & $-\infty$ & -- & $-\infty$ & $\begin{array}{l}\text { Aug. } 11 \\
\text { (captive) }\end{array}$ & $\cdots$ & Shaw, 1952 \\
\hline$\cdots$ & --- & $\cdots$ & $\begin{array}{l}\text { April - } \\
\text { early May }\end{array}$ & $\begin{array}{l}\text { late June - } \\
\text { eariy July? }\end{array}$ & Augus $t$ & Norrls, 1953 \\
\hline-- & -- & -- & -- & $\begin{array}{l}\text { early June - } \\
\text { midAugust }\end{array}$ & -- & Mayhew, $197 !$ \\
\hline-- & $47-52$ & -- & $\cdots$ & June? & Augus $t$ & Parker, 1972 \\
\hline
\end{tabular}


Table 9 - continued

\begin{tabular}{|c|c|c|c|c|c|c|c|c|}
\hline SPECIES & LOCATION & $\begin{array}{l}\text { MaxiMUM } \\
\text { SIZE } \\
\text { (mIS SV) }\end{array}$ & $\begin{array}{l}\text { MAXIMUM } \\
\text { WEIGHT } \\
(\mathrm{kg})\end{array}$ & $\begin{array}{l}\text { AVERAGE } \\
\text { AOULT } \\
\text { SIZE } \\
(\mathrm{mm} S \mathrm{SV}) \\
\end{array}$ & $\begin{array}{l}\text { AVERAGE } \\
\text { WEIGHT } \\
(\mathrm{kg})\end{array}$ & $\begin{array}{l}\text { AVERAGE } \\
\text { CLUTCH } \\
\text { SIZE } \\
\end{array}$ & $\begin{array}{l}\text { AVERAGE } \\
\text { EGG } 5 \mid 2 E \\
(\mathrm{~mm})\end{array}$ & $\begin{array}{c}\text { EGG } \\
\text { WEIGHT } \\
(\mathrm{gm}) \\
\end{array}$ \\
\hline$\frac{\text { Enyaliosaurus }}{\text { clarkl }}$ & $\begin{array}{l}\text { Michoacan, } \\
\text { Mexico } \\
\text { Michoacan, } \\
\text { Mexico }\end{array}$ & $\begin{array}{l}154 \\
\delta=165+ \\
\delta=150+\end{array}$ & $\begin{array}{l}\delta=0.200 \\
\phi=0.150\end{array}$ & $\begin{array}{l}\delta=147 \\
\delta=135 \\
\delta=153 \\
q=142\end{array}$ & $\begin{array}{l}\delta=0.131 \\
q=0.108\end{array}$ & $\begin{array}{c}7.5 \\
(4-11) \\
N=6\end{array}$ & -- & --- \\
\hline$\frac{\text { louana }}{\text { delicat issima }}$ & $\begin{array}{l}\text { Leeward } \\
\text { Islands }\end{array}$ & -- & --- & -- & -- & $\cdots$ & $47.6 \times 28.6$ & $\cdots$ \\
\hline \multirow[t]{11}{*}{$\frac{\text { Iguana }}{\text { iguana }}$} & Panama & -- & -- & -- & -- & $\begin{array}{c}32.25 \\
(21-43) \\
N=4\end{array}$ & $41.3 \times 22.2$ & --- \\
\hline & Brltish Gulana & -- & $\cdots$ & $\cdots$ & $\cdots$ & $\begin{array}{l}4-7 \\
N=2\end{array}$ & -- & --- \\
\hline & Panama & 514 & 6.01 & $\cdots$ & -- & $20-70$ & ca. 30 & $\cdots$ \\
\hline & Nicaragua & $\cdots$ & $\cdots$ & +- & -- & $4 \ln$ & $\cdots$ & $\cdots$ \\
\hline & $\begin{array}{l}\text { Eastern Costa } \\
\text { RIca } \\
\text { Colombia }\end{array}$ & $\cdots$ & -- & $\cdots$ & 1.20 & $\begin{array}{c}35.3 \\
(29-40) \\
N=7 \\
4 \ln \end{array}$ & $39 \times 26$ & $\cdots$ \\
\hline & Panama & -- & +- & $\cdots$ & -- & $\begin{array}{c}33-45 \\
N=2\end{array}$ & $\cdots$ & $\cdots$ \\
\hline & Captlve & $\cdots$ & -- & $\cdots$ & $\cdots$ & $38 n$ & $\cdots$ & $\cdots$ \\
\hline & $\begin{array}{l}\text { Chiapas, } \\
\text { Mexico } \\
\text { Panama }\end{array}$ & $\cdots$ & -- & $\cdots$ & -- & $\begin{array}{l}25-60 \\
\cdots-\end{array}$ & --- & $\cdots$ \\
\hline & Columbla & $s=420$ & $8=3.20$ & $q=290$ & $f=1.10$ & $14-70$ & --- & $\begin{array}{c}13.0 \\
(12.4-14.0\end{array}$ \\
\hline & Panaria & -- & -- & -- & --- & -- & $\begin{array}{c}32-39 \times \\
24-27\end{array}$ & $\cdots$ \\
\hline & $\begin{array}{l}\text { Hestern Costa } \\
\text { Rica }\end{array}$ & -- & $\cdots$ & $\begin{array}{l}\varepsilon=530 \\
q=390\end{array}$ & $\therefore$ & -- & --- & $\cdots$ \\
\hline \multirow[t]{6}{*}{$\frac{\text { Sauromalus }}{\text { obesus }}$} & Californla & -- & $\cdots$ & -- & -- & $8-10$ & $35.3 \times 21.6$ & $\cdots$ \\
\hline & Callfornia & 210 & $\cdots$ & $\cdots$ & -- & $6 n$ & $\cdots$ & $-\cdot$ \\
\hline & Arlzona & -- & -- & $\cdots$ & -- & $5 n$ & $\begin{array}{l}38.25-40.0 \\
\times 21.6-24.75\end{array}$ & -- \\
\hline & California & $\begin{array}{l}\delta=197 \\
f=185\end{array}$ & $\begin{array}{l}\delta=0.315 \\
g=0.255\end{array}$ & $150-160$ & $\begin{array}{c}\rho=0.05- \\
0.25\end{array}$ & $7 n$ & -- & -- \\
\hline & California & $\begin{array}{l}b=220 \\
q=205\end{array}$ & -- & $150-220$ & -- & $\begin{array}{c}7.8 \\
(6-13)\end{array}$ & -- & --- \\
\hline & California & $\begin{array}{l}\delta=203 \\
q=184+\end{array}$ &.- & 170 & $\begin{array}{l}\delta=0.250 \\
f=0.175\end{array}$ & $10 n$ & -- & $\cdots$ \\
\hline
\end{tabular}

Note: Asterisks indicate values extrapolated or interpolated from cited source. All specles probably lay at most a single clutch per year. Values in parentheses are ranges. Sample sizes for clutch size included where small, except where $N=1$ (marked with $n$ ). Incubation times in days (d). weeks (w), or months (m). 
Table 9 - extended

\begin{tabular}{|c|c|c|c|c|c|c|}
\hline $\begin{array}{l}\text { INCUBATION } \\
\text { TIME }\end{array}$ & $\begin{array}{l}\text { HATCHL ING } \\
\text { SIZE } \\
(\mathrm{mm} \text { SV) }\end{array}$ & $\begin{array}{l}\text { HATC HL ING } \\
\text { WE IGHT } \\
(\mathrm{gm})\end{array}$ & $\begin{array}{l}\text { BREEDING } \\
\text { SEASON }\end{array}$ & $\begin{array}{l}\text { NESTING } \\
\text { SEASON }\end{array}$ & $\begin{array}{l}\text { HATCHING } \\
\text { SEASON }\end{array}$ & SOURCE \\
\hline-- & ca. 46 & $\cdots$ & $-\cdots$ & Apr ll? & $\begin{array}{l}\text { early to } \\
\text { midjuse }\end{array}$ & $\begin{array}{l}\text { Duellman \& } \\
\text { Ouelliman, } 1959\end{array}$ \\
\hline$\cdots$ & -- & $\cdots$ & $\cdots$ & -- & -- & $\begin{array}{l}\text { Iverson, } \\
\text { unpublished data }\end{array}$ \\
\hline$\cdots$ & $\cdots$ & $\cdots$ & $\cdots$ & $\cdots$ & -- & Garman, 1888 \\
\hline-- & $\cdots$ & -- & $\cdots$ & Feb.-March & $\cdots$ & Hallinan, 1920 \\
\hline$\cdots$ & --- & -- & $\cdots$ & $\cdots$ & -- & Beebe, 1944 \\
\hline ca. $3 \mathrm{~m}$ & $\cdots$ & $\cdots$ & Oct.-Nov. & $\begin{array}{l}\text { early Feb. - } \\
\text { March }\end{array}$ & June? & Swanson, 1950 \\
\hline-- & $\cdots$ & -- &.-- & $\begin{array}{l}\text { eggs found } \\
\text { April } 4\end{array}$ & --- & Carr, 1953 \\
\hline ca. $3 \mathrm{~m}$ & $\cdots$ & --- & $\cdots$ & $\begin{array}{l}\text { March-early } \\
\text { Aprll }\end{array}$ & June 6 & H1rth, 1963 \\
\hline 73 d e $30^{\circ} \mathrm{c}$ & 66 & 10.25 & --- & $\begin{array}{l}\text { March } 1 \\
\text { (captive) }\end{array}$ & $\begin{array}{l}\text { May } 18 \\
\text { (captive) }\end{array}$ & $\begin{array}{l}\text { Lleht \& Moberly, } \\
1965\end{array}$ \\
\hline$\cdots$ & $\cdots$ & $\cdots$ & $\cdots$ & $\begin{array}{l}\text { late Jan.- } \\
\text { early Mar. }\end{array}$ & $\begin{array}{l}\text { late April } \\
\text {-early May }\end{array}$ & Rand, 1968 \\
\hline $\begin{array}{l}65 d \\
\text { (captive) } \\
90 \mathrm{~d}\end{array}$ & $\begin{array}{l}254 \text { (total } \\
\text { length) } \\
\cdots-\end{array}$ & $\cdots$ & $\begin{array}{l}\text { Februsry } \\
\text { (captive) } \\
\text { oct.-Dec. }\end{array}$ & $\begin{array}{l}\text { April } 19 \\
\text { (captive) } \\
\text { March-April }\end{array}$ & $\begin{array}{l}\text { July? } \\
\text { (cartive) } \\
\text { June-Aug. }\end{array}$ & $\begin{array}{l}\text { Van Aperen, } 1969 \\
\text { Alvarez del Toro, } \\
1972\end{array}$ \\
\hline ca. $3 \mathrm{~m}$ & $\cdots$ & $\cdots$ & $-\cdot$ & February & $\begin{array}{l}\text { late Aprll } \\
\text {-May }\end{array}$ & Rand, 1972 \\
\hline$\cdots$ & $\begin{array}{l}68(260 \\
\text { total) }\end{array}$ & $\cdots$ & Dec. & March & late May & Mueller, 1372 \\
\hline $\begin{array}{l}100 \mathrm{~d} \\
e^{2} 28^{\circ} \mathrm{C} \\
---\end{array}$ & $\begin{array}{l}60(253 \\
\text { total })\end{array}$ & -- & $-\cdot$ & $\begin{array}{l}\text { late Feb.- } \\
\text { early Mar. } \\
\text { Jan.-Feb. }\end{array}$ & $\begin{array}{l}\text { mid-June } \\
\text { (captive) } \\
\text { mid-Dec.- } \\
\text { early May }\end{array}$ & $\begin{array}{l}\text { Picklefs } 8 \\
\text { Cullen, } 1973 \\
\text { Fitch, ig73 }\end{array}$ \\
\hline-- & -- & -- & -- & late May & $\cdots$ & Shaw, 1945, 1952 \\
\hline$\cdots$ & $\cdots$ & -- & May-June & -- & -- & Smith, 1946 \\
\hline$\cdots$ & $60 ?$ & $\cdots$ & $\cdots$ & late June* & Sept.* & Gates, 1957 \\
\hline$\cdots$ & $68-707$ & $\cdots$ & $\begin{array}{l}\text { March 26- } \\
\text { June } 25 ?\end{array}$ & June 22 & $\cdots$ & Johnson, 1965 \\
\hline $\begin{array}{l}168-171 d \\
\text { (captive) }\end{array}$ & $46-60$ & --- & Mar-April & May-June & Sept.? & Berry, 1974 \\
\hline . & $\cdots$ & $\cdots$ & --- & -- & $\cdots$ & $\begin{array}{l}\text { iverson, } \\
\text { unpublished Jata }\end{array}$ \\
\hline
\end{tabular}


measures of reproductive effort for the better-studied species (Table 10) based on the data in Table 9. Many of the data were necessarily estimated, but 1 believe this has not clouded the basic trends.

All iguanine lizards have high, but similar reproductive efforts (RE) as measured by the proportion of pre-oviposition body weight in the egg clutch. However, as previously implied, the partitioning of energy within the clutch exhibits considerable variation. In addition to including some of the highest EPP values among all lizard species, those measures in Table 10 which estimate female expenditure per offspring reveal an interesting dichotomy in strategies among the iguanines. Iguana iguana and Ctenosaura similis, both widespread mainland species, produce many small eggs which hatch into small neonates. The remaining species of Ctenosaura, although poorly studied, probably employ the same strategy. The other iguanine species that have been studied (including c. carinata) are much less widespread--many inhabit islands--and produce relatively few, large eggs (and large hatchlings; Figure 26). In fact, the success of Iguana and Ctenosaura (as evidenced by their wide distributions) is no doubt related to their ability to produce large numbers of young in an environment crowded with predators.

The trend of decreased fecundity with increased effort per progeny has been taken to near its extreme by Amblyrhynchus cristatus which usually produces only two, relatively huge eggs. The dichotomy is well illustrated by a comparison of Ctenosaura similis and Diposaurus dorsalis. Their eggs are approximately equal in size and weight, but the average adult female ctenosaur has $21 / 2$ times the body length and nearly 15 times the body weight of the average female Dipsosaurus. 
Table 10. Measures of reproductive effort in iguanine lizards.

\begin{tabular}{|c|c|c|c|c|c|c|c|c|}
\hline \multirow[b]{2}{*}{ Species } & \multirow[b]{2}{*}{ Range } & \multirow{2}{*}{$\begin{array}{c}\text { Mean } \\
\text { Adult } \\
\text { Female } \\
\text { SV } \\
(\min )\end{array}$} & \multirow{2}{*}{$\begin{array}{c}\text { Mean } \\
\text { Adult } \\
\text { Female } \\
\text { Weight } \\
\text { (gm) }\end{array}$} & \multirow{2}{*}{$\begin{array}{l}\text { Mean } \\
\text { Clutch } \\
\text { Size } \\
\text { (Range) }\end{array}$} & \multicolumn{2}{|c|}{$\begin{array}{c}\text { Mean Egg Weight } \\
(\mathrm{gm})\end{array}$} & \multicolumn{2}{|c|}{$\begin{array}{c}\text { Average Clutch } \\
\text { Waight (gm) }\end{array}$} \\
\hline & & & & & actual & estimated & actual & estimated \\
\hline$\frac{\text { Ambiyrhynchus }}{\text { cristatus }}$ & $\begin{array}{l}\text { Galapagos } \\
\text { Islands }\end{array}$ & 290 & 990 & $\begin{array}{r}2.29 \\
(2-3)\end{array}$ & 96.3 & 132.3 & 221.5 & 303.0 \\
\hline$\frac{\text { Dipsosaurus }}{\text { dorsalis }}$ & California & 120 & 70 & $\begin{array}{c}5.8 \\
(3-8)\end{array}$ & -- & 5.4 & -- & 31.4 \\
\hline$\frac{\text { Sauromalus }}{\text { obesus }}$ & California & 170 & 175 & $\begin{array}{c}7.8 \\
(6-13)\end{array}$ & 9.61 & 11.2 & 75 & 87.4 \\
\hline$\frac{\text { Cyclura }}{\text { carinata }}$ & $\begin{array}{l}\text { Caicos } \\
\text { Islands }\end{array}$ & 225 & 476 & $\begin{array}{r}4.33 \\
(2-9)\end{array}$ & 25.9 & 34.7 & 112.1 & 150.3 \\
\hline$\frac{\text { Cyclura }}{\text { nubila }}$ & Cuba & 400 & 2500 & $\begin{array}{l}16.5 \\
(16-17)\end{array}$ & $\cdots$ & 85.2 & $\cdots$ & 1406.1 \\
\hline Cyclura & Mona Island & 475 & 4700 & $\begin{array}{c}12.0 \\
(6-19)\end{array}$ & 104.0 & 141.7 & 1248 & 1700.4 \\
\hline$\frac{\text { Conolophus }}{\text { pallidus }}$ & $\begin{array}{l}\text { Galapagos } \\
\text { Islands }\end{array}$ & 360 & 1950 & $\begin{array}{c}3.5 \\
(7-10)\end{array}$ & $\cdot--$ & 57.2 & $\cdots$ & 485.9 \\
\hline$\frac{\text { Cienosaura }}{\text { hemilopha }}$ & Sonora & 179 & 215 & $\begin{array}{l}15 \\
(N=1)\end{array}$ & 4.67 & 3.11 & 70 & $\begin{array}{c}46.6 \\
.\end{array}$ \\
\hline$\frac{\text { Ctenosaura }}{\text { pectinata }}$ & Tamaul ipas & 191 & 315 & $\begin{array}{l}17 \\
(N=1)\end{array}$ & 4.41 & 6.00 & 75 & 102.0 \\
\hline$\frac{\text { Ctenosaura }}{\text { Pectinata }}$ & $\begin{array}{l}\text { Morelos, } \\
\text { Mexico }\end{array}$ & 220 & 450 & $\begin{array}{l}49 \\
(N=1)\end{array}$ & 4.08 & $\cdots$ & 250 & -- \\
\hline$\frac{\text { Ctenosaura }}{\text { similis }}$ & Costa Rica & 347 & 651 & 43.4 & $\cdots$ & -- & -- & -- \\
\hline$\frac{\text { C.tenosaura }}{\text { similis }}$ & Costa Rica & 298 & 1000 & $\begin{array}{l}54.9 \\
(34-87)\end{array}$ & $\cdots$ & 6.49 & $\cdots$ & 356.4 \\
\hline$\frac{\text { iguana }}{\text { iguana }}$ & $\begin{array}{l}\text { Panama } E \\
\text { Costa Pic. }\end{array}$ & 390 & 2500 & $\begin{array}{l}35.5 \\
(20-70)\end{array}$ & -- & 16.6 & 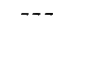 & 588.9 \\
\hline
\end{tabular}

Note: "Actual" values are based on actual egg weights. "Estimated values are based on estimated egg weights calculated by assuming the surface area of a lizard egg to be approximately equal to a sphere of radius $r$ cut into two hemispheres, moved apart, with a cylinder of diameter $2 r$ and length $L$ inserted between them. A formula related egg surface area in $\mathrm{cm}^{2}$ (in this case, S.A. $=2 r(2 r+L)$; egg length $=2 r+L$; and egg diameter $=2 r$ ) to egg weight in grams (S.A. $=4.835 \mathrm{Wt} .{ }^{6.662}$ ), based on data from bird eggs (Paganelli, 
Table 10 - extended

\begin{tabular}{|c|c|c|c|c|c|c|}
\hline \multicolumn{2}{|c|}{$\begin{array}{r}\text { Average } \% \text { Body } \\
\text { Weight in Clutch } \\
(2 E \times 100)\end{array}$} & \multicolumn{2}{|c|}{$\begin{array}{l}\text { Average \% Body } \\
\text { Weight in Single } \\
\text { Egg (EPP } \times 100) \\
\end{array}$} & \multirow{2}{*}{$\begin{array}{l}\text { \% Hatchling } \\
\text { Sv in Adult } \\
\text { Female SV }\end{array}$} & \multirow{2}{*}{$\begin{array}{c}\% \text { Hatchling } \\
\text { Weight in } \\
\text { Adult? Weight }\end{array}$} & \multirow[b]{2}{*}{ Primary Source (s) } \\
\hline actual & estiriard & ectual & estimated & & & \\
\hline--- & 22.3 & $-\cdots$ & 9.7 & 37.9 & 5.0 & Carpenter, 1966 \\
\hline-- & 44.9 & -- & 7.7 & 41.3 & 6.3 & Nurris, 1953 \\
\hline $1 \$ 2.9$ & 49.9 & 5.5 & 6.4 & 31.8 & 3.1 & $\begin{array}{l}\text { Berry, } 1974 \\
\text { Johnson, } 1965\end{array}$ \\
\hline 23.6 & 31.6 & 5.5 & 7.3 & 35.5 & 3.1 & This study \\
\hline$--=$ & 56.2 & $\cdots$ & 3.4 & 25.6 & 2.2 & Shaw, 1954 \\
\hline 26.6 & 36.2 & 2.2 & 3.0 & 25.1 & 1.6 & $\begin{array}{l}\text { Wiewandt, } \\
\text { in preparation }\end{array}$ \\
\hline-- & 24.9 & --- & 2.9 & -- & $\cdots$ & Sievin, 1935 \\
\hline 32.6 & 21.7 & 2.2 & 1.4 & -- & -- & $\begin{array}{l}\text { Iverson, } \\
\text { unpublished }\end{array}$ \\
\hline 23.8 & 32.4 & 1.4 & 1.9 & $\cdots$ & --- & $\begin{array}{l}\text { iverson, } \\
\text { unpublished }\end{array}$ \\
\hline 29.4 & -- & 0.6 & -- & -- & -- & Evans, 1951 \\
\hline--- & $\cdots$ & --- & $\cdots$ & 20.7 & ca. 0.5 & $\begin{array}{l}\text { Fitch and } \\
\text { Henderion (M.S.) }\end{array}$ \\
\hline$-\infty$ & 35.6 & -- & 0.6 & 18.1 & 0.6 & $\begin{array}{l}\text { Hackiorth-Jones } \\
\text { (ii.s.) }\end{array}$ \\
\hline$\cdots$ & 23.6 & $\cdots$ & 0.7 & 15.4 & 0.4 & Fiteh, 1970. \\
\hline
\end{tabular}

et al., 1974), was employed to estimate the weight of a typical egg. The derived weight estirjtes are high sirce these lizards lack the thickly calcified egg shell of birds. Most arersage S: lengths and body weights used in calculations are from Table 9; data for species lacking measurements were estimated from species of similar size range in Table 9. Hatchling reasirements for Amblyrhychus are estimated from Cyclura cornuta data; they have simila.ly sized eggs. Species are listed in approximate order of decreasing reproductive expenditure per progeny. 


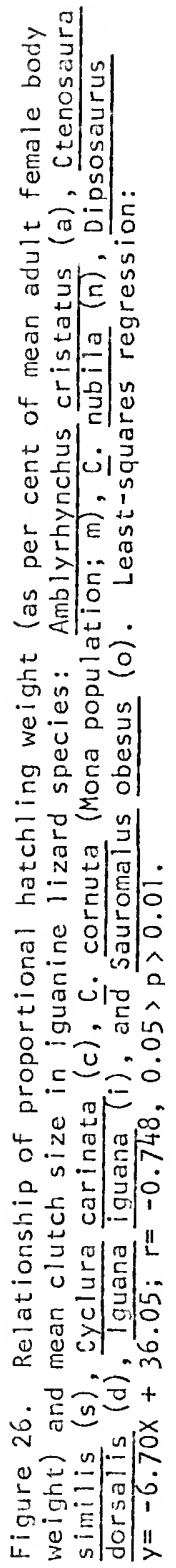




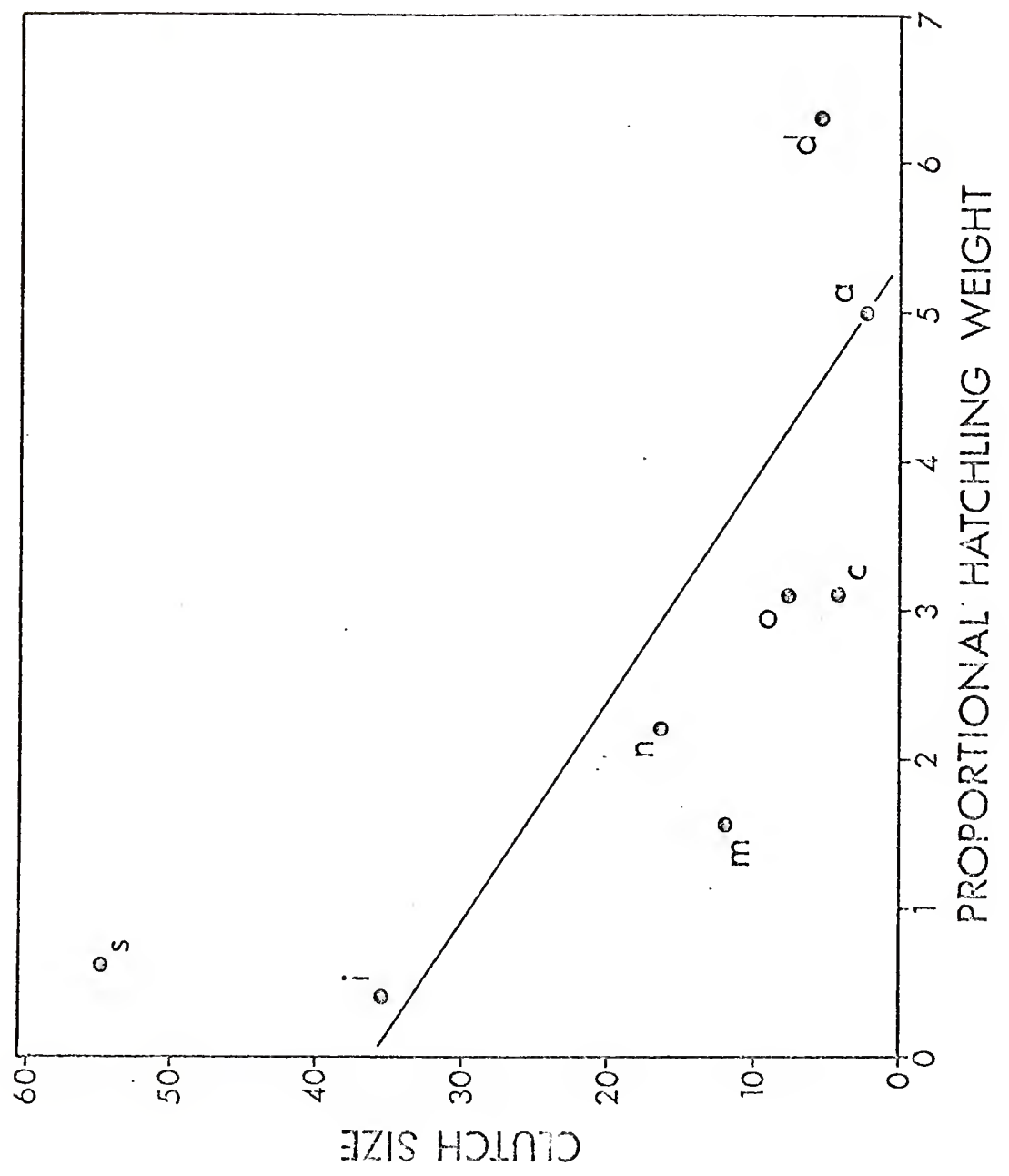


The iguanine lizards are probably more $k$-selected than any other group of lizards. In nearly all their life history characteristics, they fall clase to the k-end point (Tinkle, 1969; Tinkle et al., 1970; Pianka, 1970; Fitch, 1973). However, they are distributed broadly along the $r-k$ continuum with respect to expenditure per progeny--1guana and $\underline{C}$. similis being extremely $r$-selected. Only recently have students of lizard natural histories and/or reproductive strategies concerned themselves specifically with female expenditure per offspring (Vitt and Ohmart, 1975; Parker and Pianka, 1975, 1975; Pianka and Parker, 1975). The character is obviously an important attribute of iguanine life histories and it is hoped that it will not continue to be neglected in future studies.

Within the insular genus Cyclura there appears to have been a trend toward increasing egg size, with a concomitant decrease in clutch size. The factors affecting a species position along this continuum have received extensive discussion and theoretical treatment (Stearns, 1976, reviews the subject; see also Ballinger, 1973; Wilbur et al., 1974; and Brockelmen, 1975). For Cyclura the greatest selective advantage may obtain from the production of offspring that exceed the prey size of as many sympatric predators as possible. If this was the major force governing clutch size-egg size relationships, those populations inhabiting smaller islands should produce fewer, larger offspring, since species number, and therefore number of potential predators, is positively correlated with island size (MacArthur and Wilson, 1967). Figure 27 illustrates that such a trend (significant at the $5 \%$ level) does exist among the eight populations for which reliable data are 
4.

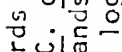

t证

N $\cdots$

E

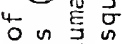

可

ᄃ

- $\frac{1}{2} \frac{1}{n}$

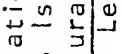

옹

을

ờ

4 年...

की

논응

है

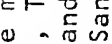

$1>-$

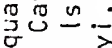

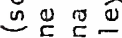

ه 들 은

的罗

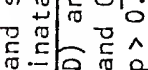

r.

$\simeq$ 吕 $\ldots \wedge$

Uล응

\& ن

일

Nㅡㄹ응

ज乎可

ᄃ드웅

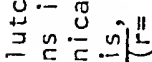

บ ․ㅡㄹ Jुb

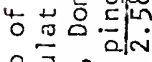

음

兵高势

ᄃ 5 능

च

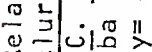

$\propto$ 젒.

$\therefore$ 을

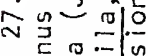

2)

उ.

다 o

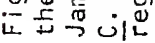




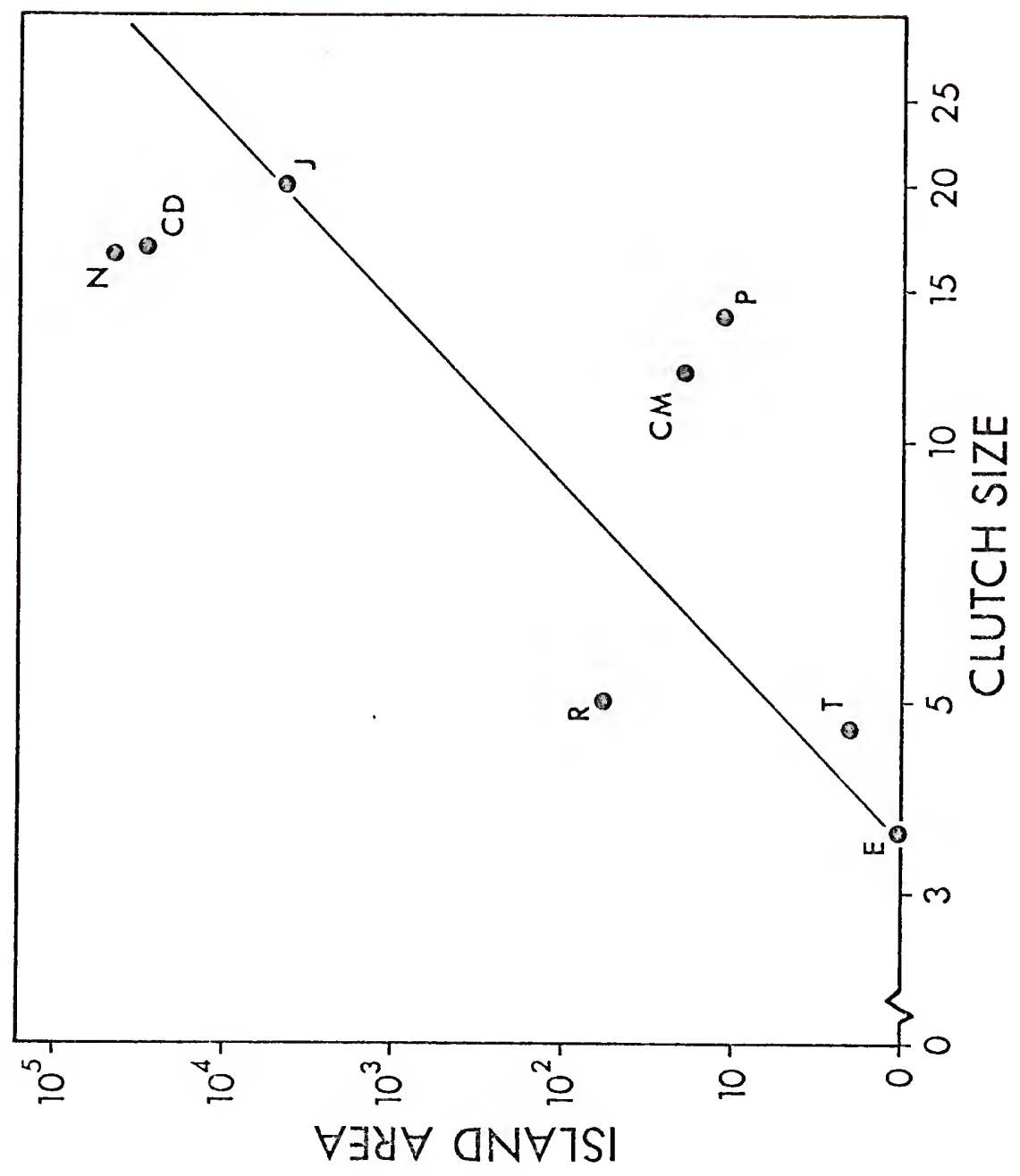


available. Larger clutch sizes, typical of most mainland species (and probably the common iguanine ancestors) have apparently remained advantageous to those species of Cyclura inhabiting larger islands with their larger predator pools. 
GROWTH

\section{General Pattern}

Cyclura carinata ranges from about $80 \mathrm{~mm} \mathrm{SV}$ and $15 \mathrm{grams}$ at hatching to over $290 \mathrm{~mm}$ SV and 1100 grams in females and nearly $360 \mathrm{~mm}$ SV and 1900 grams in males (Figure 28). The relationship between the logarithm of snout-vent length and that of body weight is significantly linear:

$$
\log W t=3.0336 \log S V-4.496(r=0.987 \text {, d.f 176, } P<0.0001)
$$

This equation is equivalent to $W T=\left(3.202 \times 10^{-5}\right) \mathrm{sv}^{3.0336}$, where $\mathrm{WT}=$ weight in grams, and $S V=$ snout-vent length in $\mathrm{mm}$. Curves for females (plus juveniles) and males (also with juveniles) are not significantly different from the overall curve.

An ontogenetic reduction in head size relative to body size occurs in Cyclura carinata from hatching to maturity in males and throughout life in fenales (Figure 29). Older males, however, do exhibit a secondary increase in proportional head size. Hypertrophy of the head musculature contributes significantly to the visual image of a massive head in ageing males. This cephalic enlargement in cyclura carinata does not however reach the magnitude that it does in old male Cyclura cornuta, but as in that species (Wiewandt, in preparation), it may be important in social contexts, especially male-riale interactions (see SOCIAL ORGANIZATION). At hatching relative tail size is maximal, decreasing in length proportional to body length throughout life (Figure 30 ). There is no sexual difference in relative tail length, however the girth at the tail 
Figure 28. Relationship of body length (SVL) to weight. Solid circles above $180 \mathrm{~mm}$ SV indicate males; open circles, females. Each symbol represents at least one individual. Data from 181 lizards. 


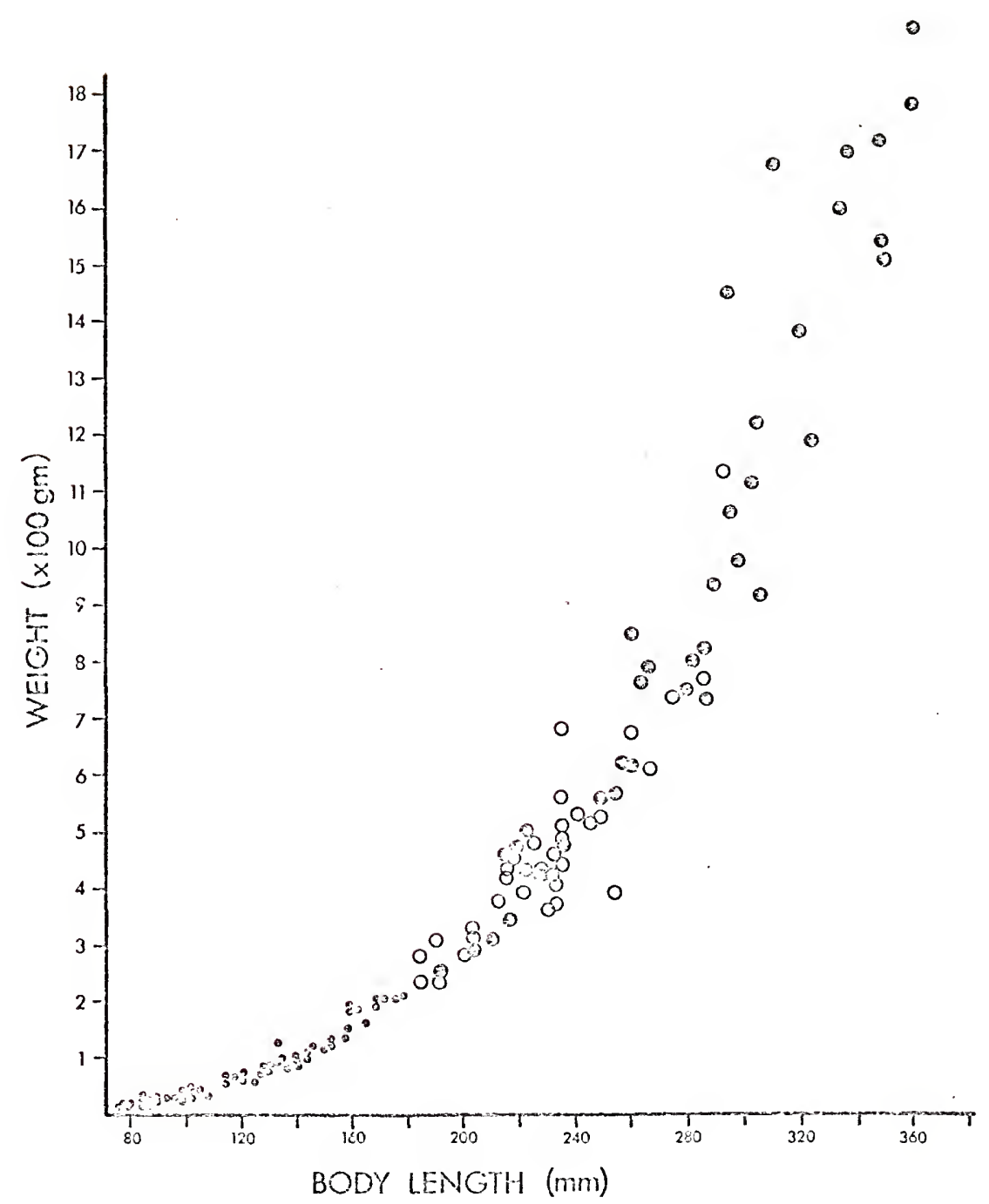




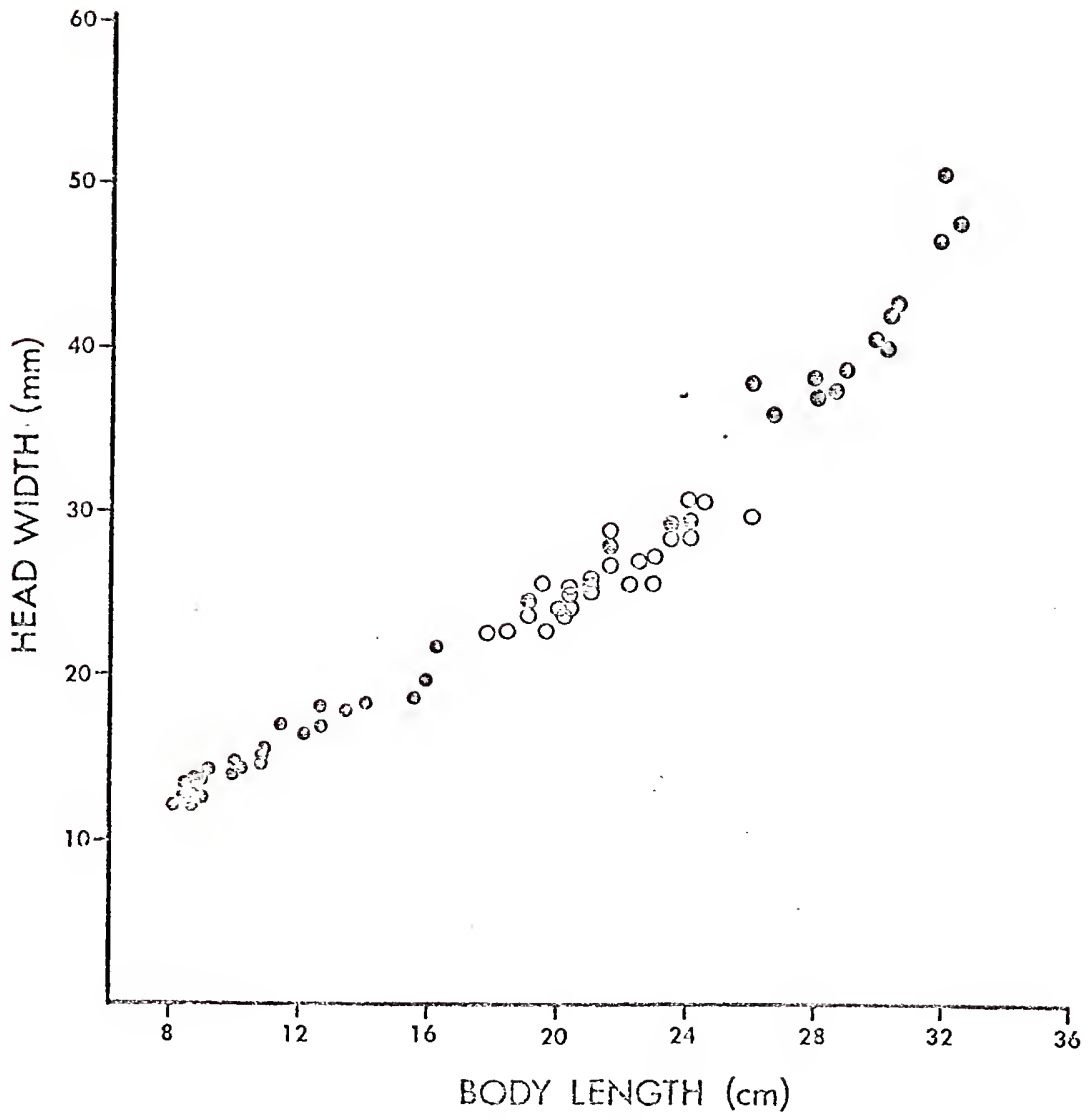

Figure 29. Relationship of headwidth across tympanum to body length (measured snout to vent). Solid circles above $170 \mathrm{~mm}$ body length indicate males; open circles, females. Each symbol represents at least one individual. Data for 77 lizards. 


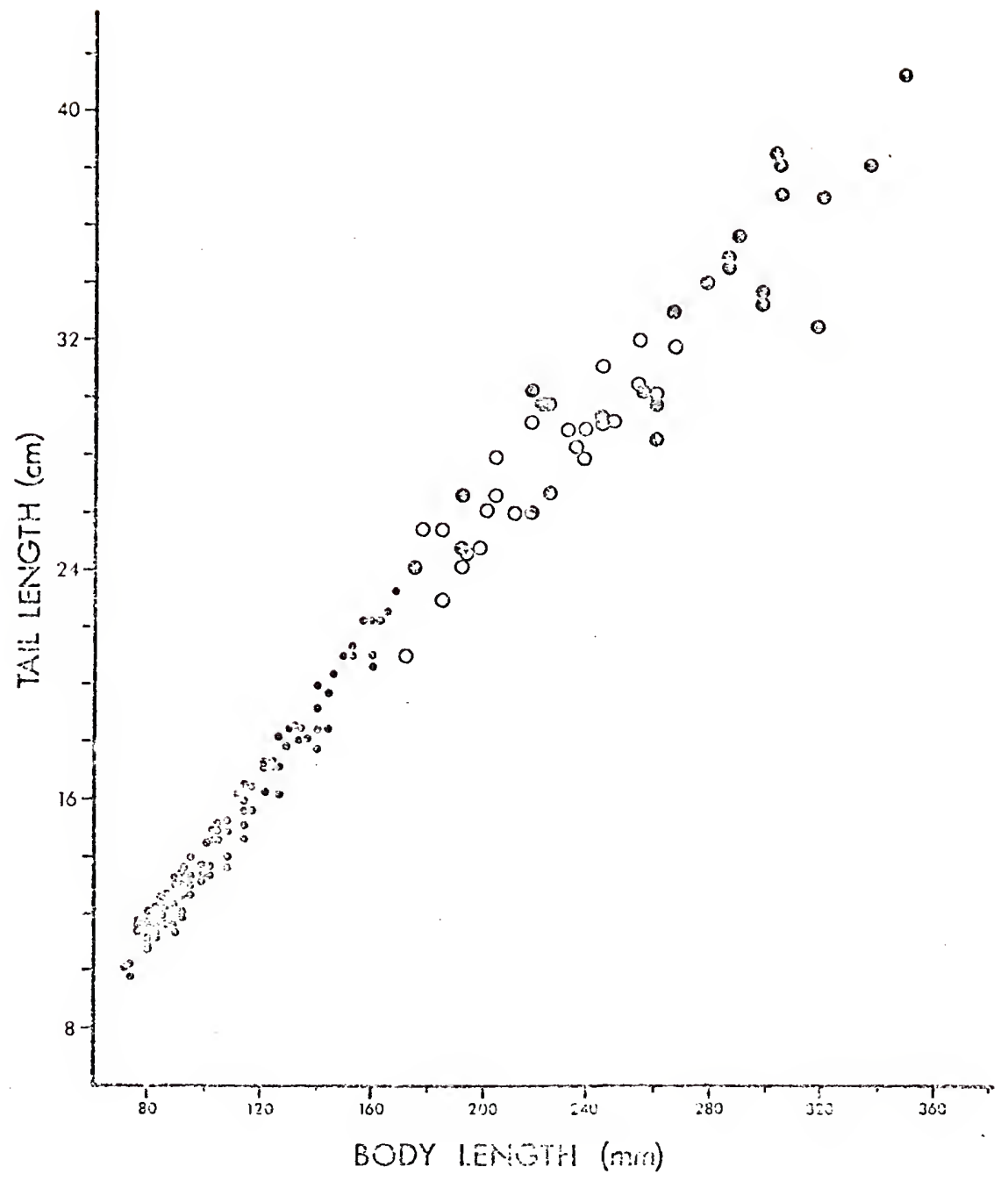

Figure 30. Relationship of body length (measured snout to vent) to tail length. Solid circles above $170 \mathrm{~mm}$ body length indicate males; open circles, females. Each symbol represents at least one individual. Data from 179 full-tailed lizards. 
base is proportionately larger in males due to the presence of the hemipenes internally.

Variation in naximum size (and weight) between populations of Cyclura on the study islands is notable (Tables 11 and 12). Adult Cyclura carinata from Water and Little Water Cays are larger (and more yellow; see Color under MORPHOLOGY) than those from Pine and Fort George Cays. Since the islands are so similar phenetically, this divergence may be related to genetic differences in the colonizers of the two groups of islands.

The sexes of Cyciura carinata are strongly size dimorphic; female SV and weight average 81.5 and $50.9 \%$ that of males, respectively (Tables 11 and 12). Amblyrhynchus, Ctenosaura similis, and Iguana iguana all exhibit this great size dimorphism. Female Amblyrhynchus average $85.0 \%$ of male SV and $50.0 \%$ of male body weight (Carpenter, 1966); female Ctenosaura similis measure 80.0 and $55.6 \%$, respectively (Fitch and Henderson, Ms); and Iguana iguana average $73.6 \%$ male SV (Fitch, 1973). Males are also larger than females for all the other iguanine species for which data are available (see Table 9), however the dimorphism is extremely reduced. Female Cyclura cornuta, Cyclura pinguis, Conolophus subcristatus, Ctenosaura pectinata, Dipsosaurus dorsalis, Enyaliosaurus clarki and Sauromalus obesus all average only slightly smaller than males of the same species (references in Table 9).

Comparisons of lizard size-frequency plots by month of capture suggest several discrete juvenile age classes. Although the use of these size distributions to estimate growth rates can be misleading (Tinkle, 1967), when used in conjunction with mark and recapture data, 


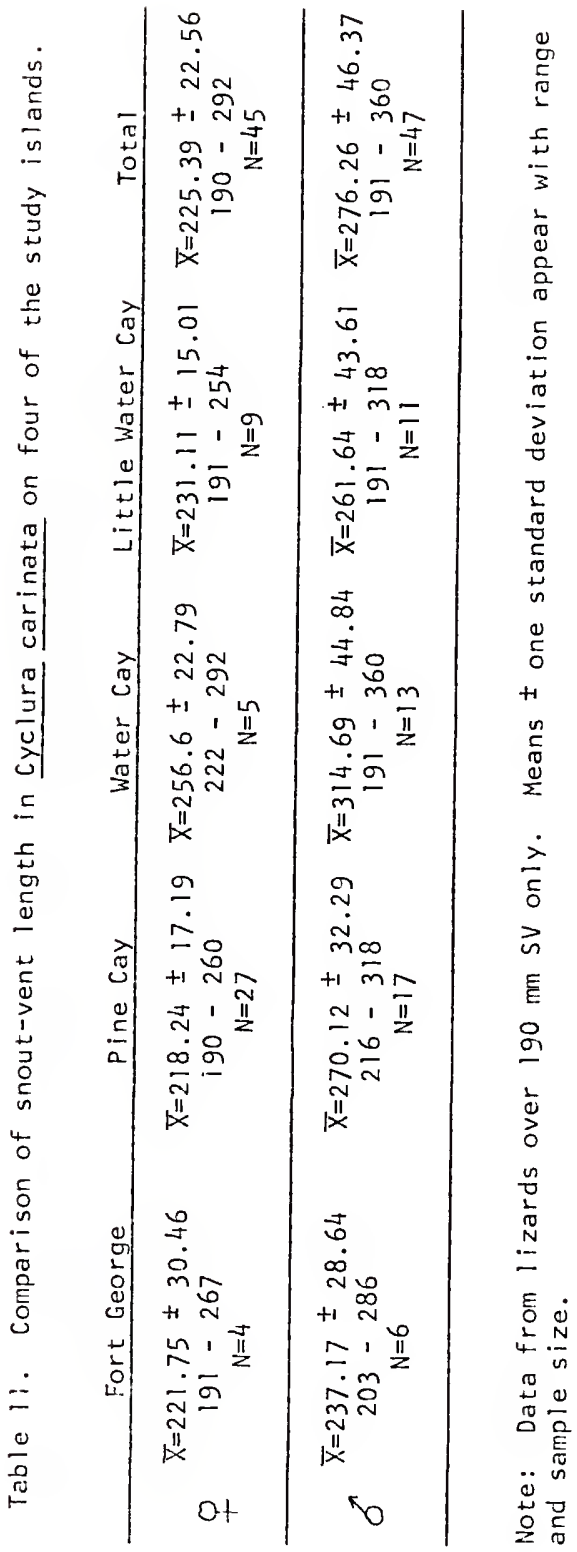




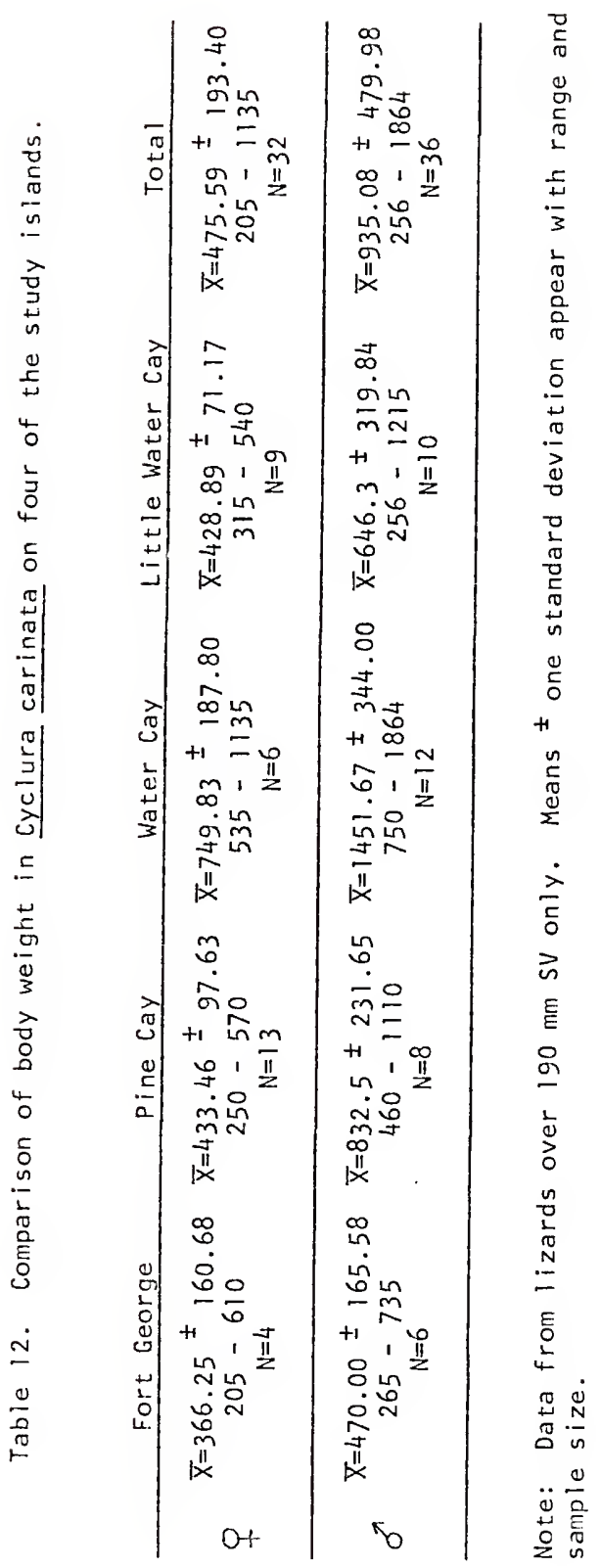


reliable growth information can be obtained. Actual growth data on Cyclura carinata are difficult to acquire even on islands uninhabited by man and his animals. Collection of such data on disturbed islands is nearly impossible. Slow adult growth and the difficulty in accurately measuring a struggling lizard with a total length of over half a meter and weighing over half a kilogram compound the difficulty in obtaining natural growth information. On Pine Cay predation on juvenile lizards by feral mammals made abortion of a mark-release-recapture program there necessary early in this study; during four visits over one year 30 juveniles were marked and none recaptured. A similar recapture program initiated on uninhabited Little water Cay (Figure 4) proved satisfactory. A total of 103 lizards was marked on five visits (July 10 and December 4 , 1974, August 10, 1975, May 5, and June 10, 1976) and nineteen were subsequently recaptured at least once (Table 13).

Growth in juvenile Cyclura carinata based on actual recapture data as well as analysis of size-class information is plotted in Figure 31 . Based on size at sexual maturity, males require seven to eight years to reach maturity (about $220 \mathrm{~mm} \mathrm{SV}$ ); females, six to seven years (185-200 $\mathrm{mm}$ SV). Size-class data indicate an average hatching $\mathrm{SV}$ of $80 \mathrm{~mm}$ (weight = $19.0 \mathrm{gm}$ from regression equation); juveniles average $100 \mathrm{~mm}(37.4 \mathrm{gm})$ at one year, $124 \mathrm{~mm}(71.8 \mathrm{gm})$ at two years, $146 \mathrm{~mm}(117.8 \mathrm{gm})$ at three years, $161 \mathrm{~mm}(158.5 \mathrm{gm})$ at four years, $178 \mathrm{~mm}(214.9 \mathrm{gm})$ at $\mathrm{five}$ years and $195 \mathrm{~mm}(283.5 \mathrm{gra})$ at six years. Only a slight decrease in growth rate (measured as change in SV length) occurs from hatching to maturity. An average growth rate of approximately $19.2 \mathrm{~mm}$ SV (range $=15-24$ ) per year or 1.6 mm per month is indicated. Similar results are obtained from 


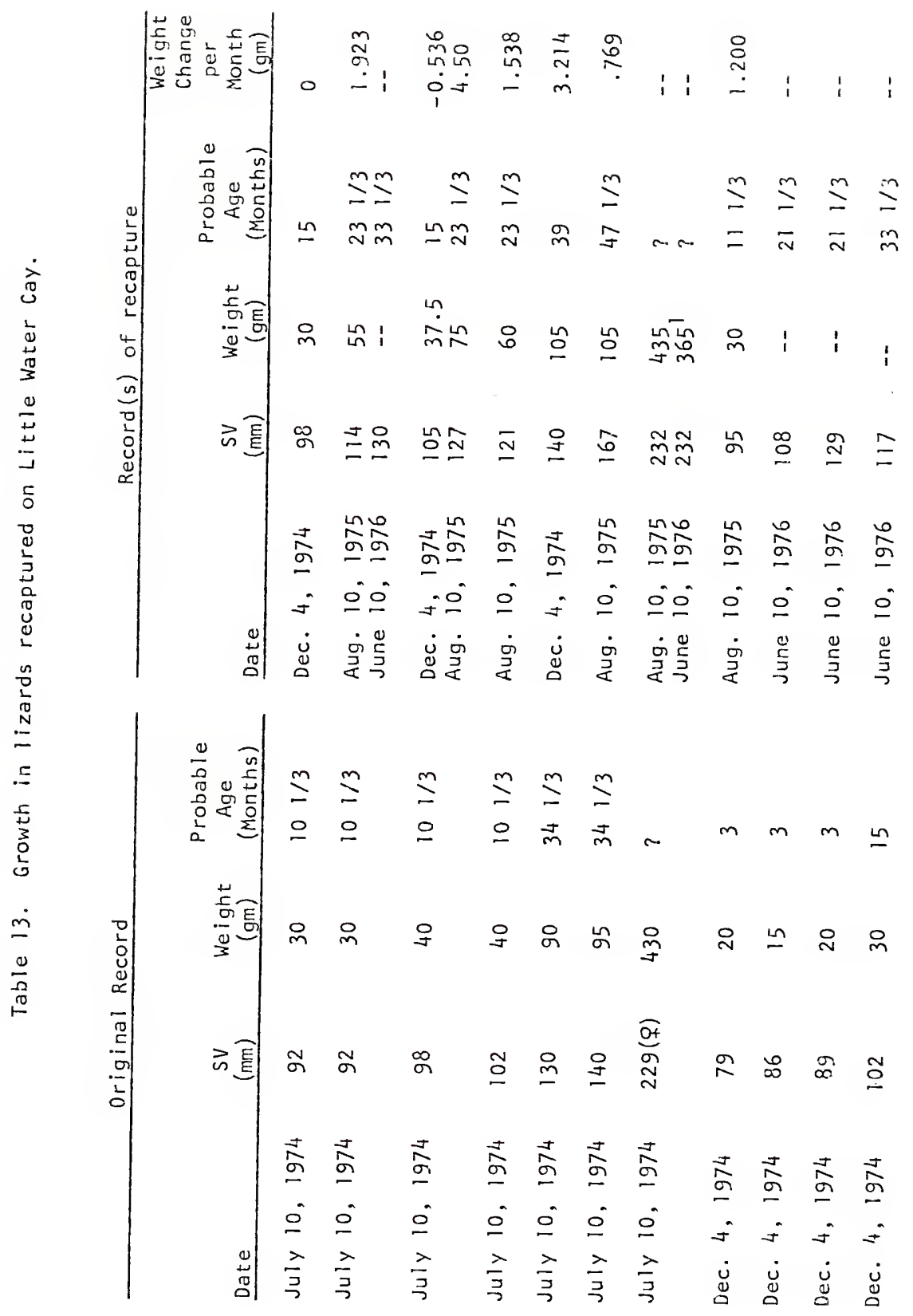




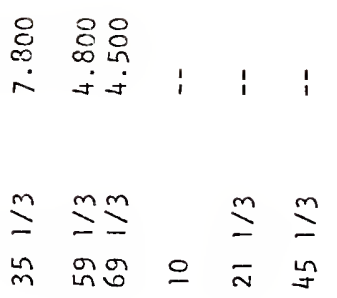

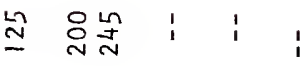

ํํำ

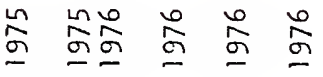

$\therefore \therefore 0000$

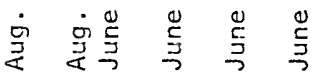

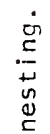

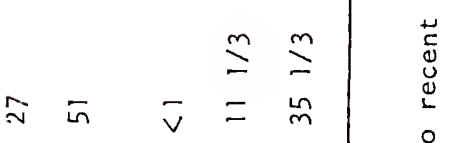

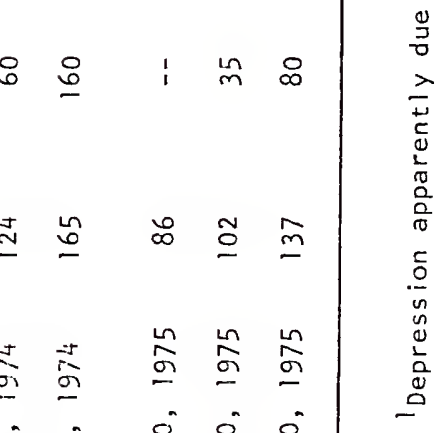

$\therefore \quad \therefore \quad 00$

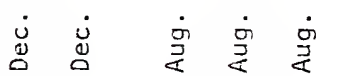

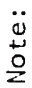


Figure 31. Growth in juvenile Cyclura carinata based on actual recapture data (top) and size class distribution (bottom). Snout vent lengths in centimeters. Means (horizontal lines connected by curve), range (vertical line), standard deviation (heavy solid vertical line) and sample size for each size range class sample are indicated. Horizontal bars below curve in lower graph mark annual period of slow growth (December to March). Total sample size $=206$. 


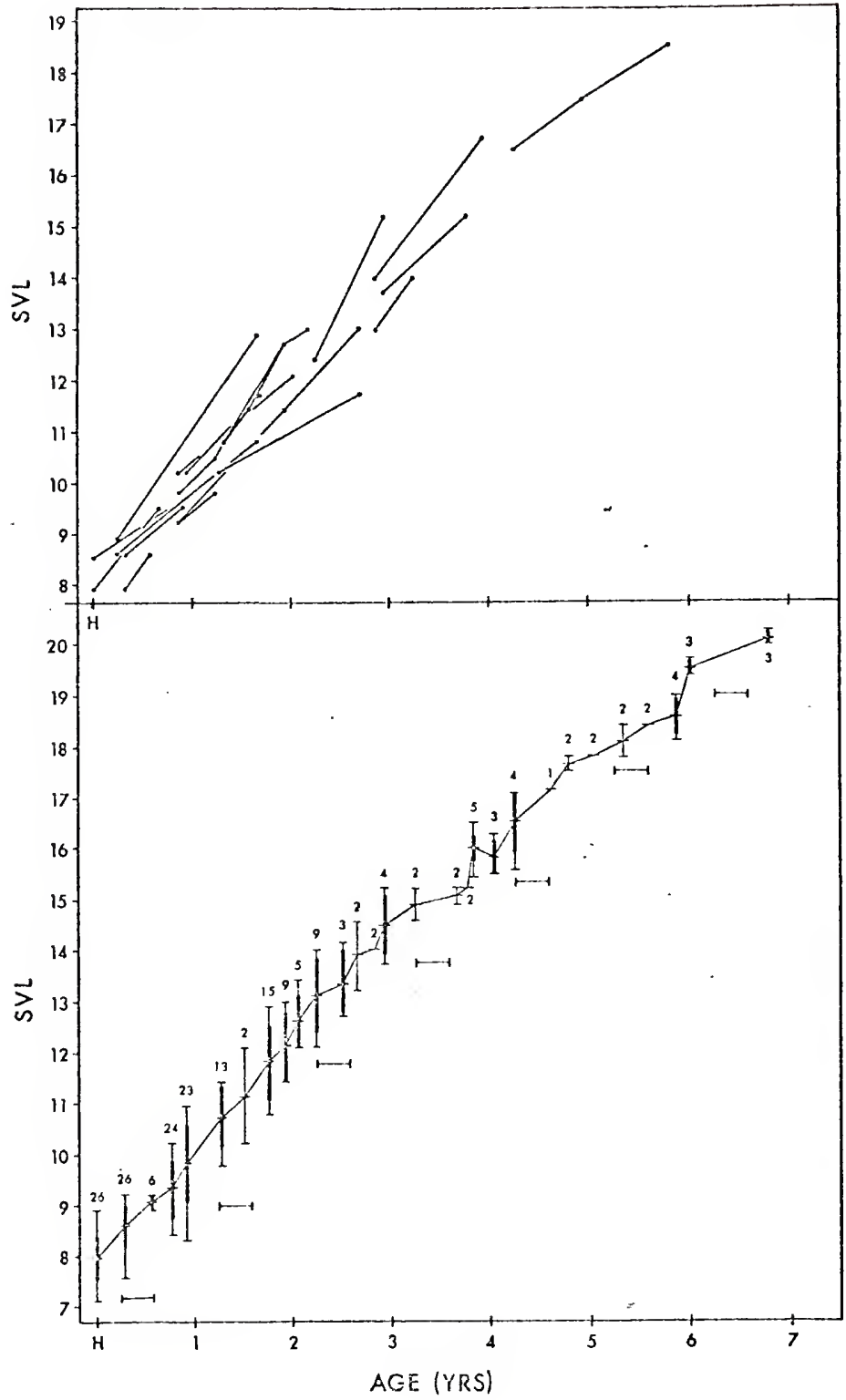


individual grouth records of recaptured Little Water Cay lizards as well as of several captive Pine Cay juveniles (Figure 32, Table 14). A single captive juvenile lizard maintained in captivity for 16 months increased in body length from 129 to $178 \mathrm{~mm} \mathrm{SV}$, a growth rate of $5.5 \mathrm{~mm} /$ month. This atypically high value was not used in any of the calculations, since it presumably represents growth under optinum conditions. The slopes of each of the regression equations in Table 14 evidence the nearly constant juvenile growth rate.

Tail growth data from recaptured juvenile iguanas on Little Water Cay appear in Table 15. Mean change in tail length per month for lizards less than $180 \mathrm{~mm}$ SV with complete tails is $2.365 \pm 1.30 \mathrm{~mm}(\mathrm{~N}=13)$. The data suggest a relatively constant rate of tail growth in juvenile Cyclura.

Despite their tropical location, there is considerable seasonality in both temperature and moisture in the Caicos Islands. This is reflected in the phenology of the vegetation and ultimately in the growth and activity of Cyclura in the islands. During the cold, dry season of late December through March, there is very little plant growth. Growth in juvenile lizards (and presumably adults) also slows considerably. This growth reduction in Cyclura is apparent in Figure 32 (bottom) if the slope of the curve during the harsh winter season (marked by horizontal bars below the growth curve) is compared to that for the remainder of the year. The slope of the curve (equivalent to growth rate) during the winter season $(\bar{X}=0.992 \mathrm{~mm} / \mathrm{month}$; range $0.30-1.39)$ is significantly different $(p<0.05)$ from the slope for the remainder of the year $(\bar{x}=1.855 ;$ range $1.15-2.30)$. This winter decrease in growth rate is related not only to a decrease in food quality and quantity (pers. 


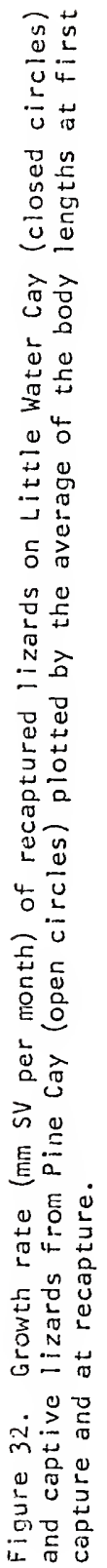




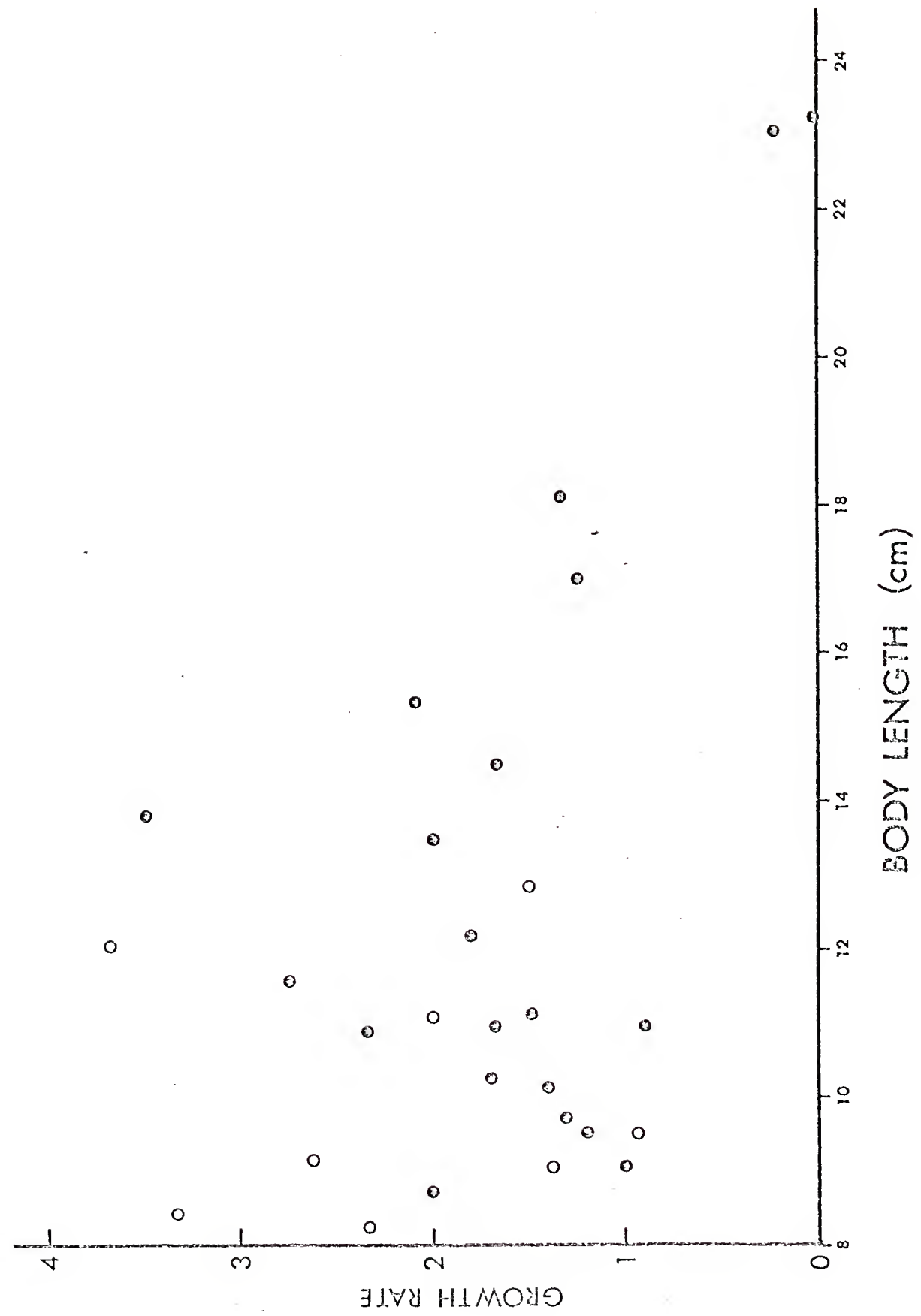




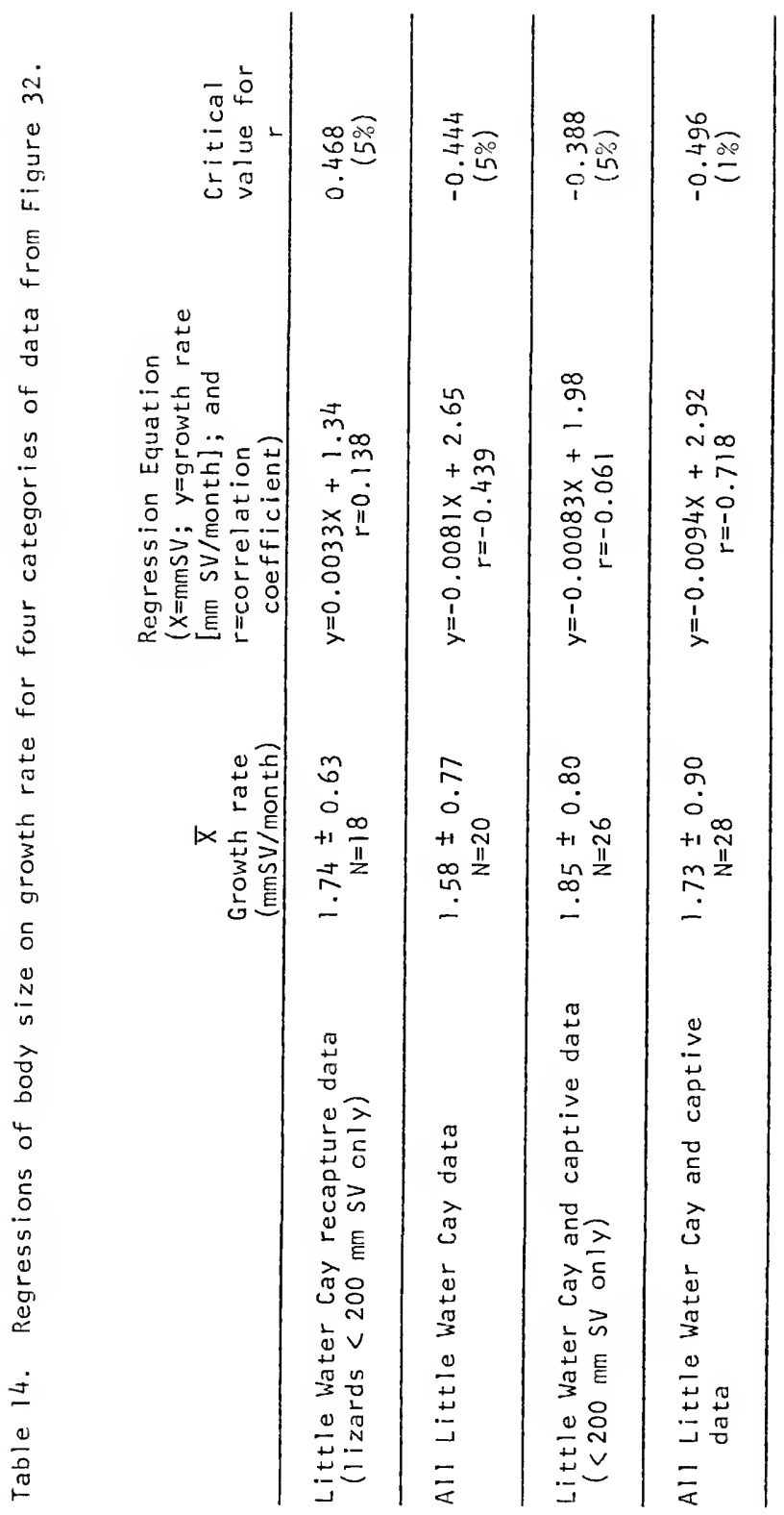




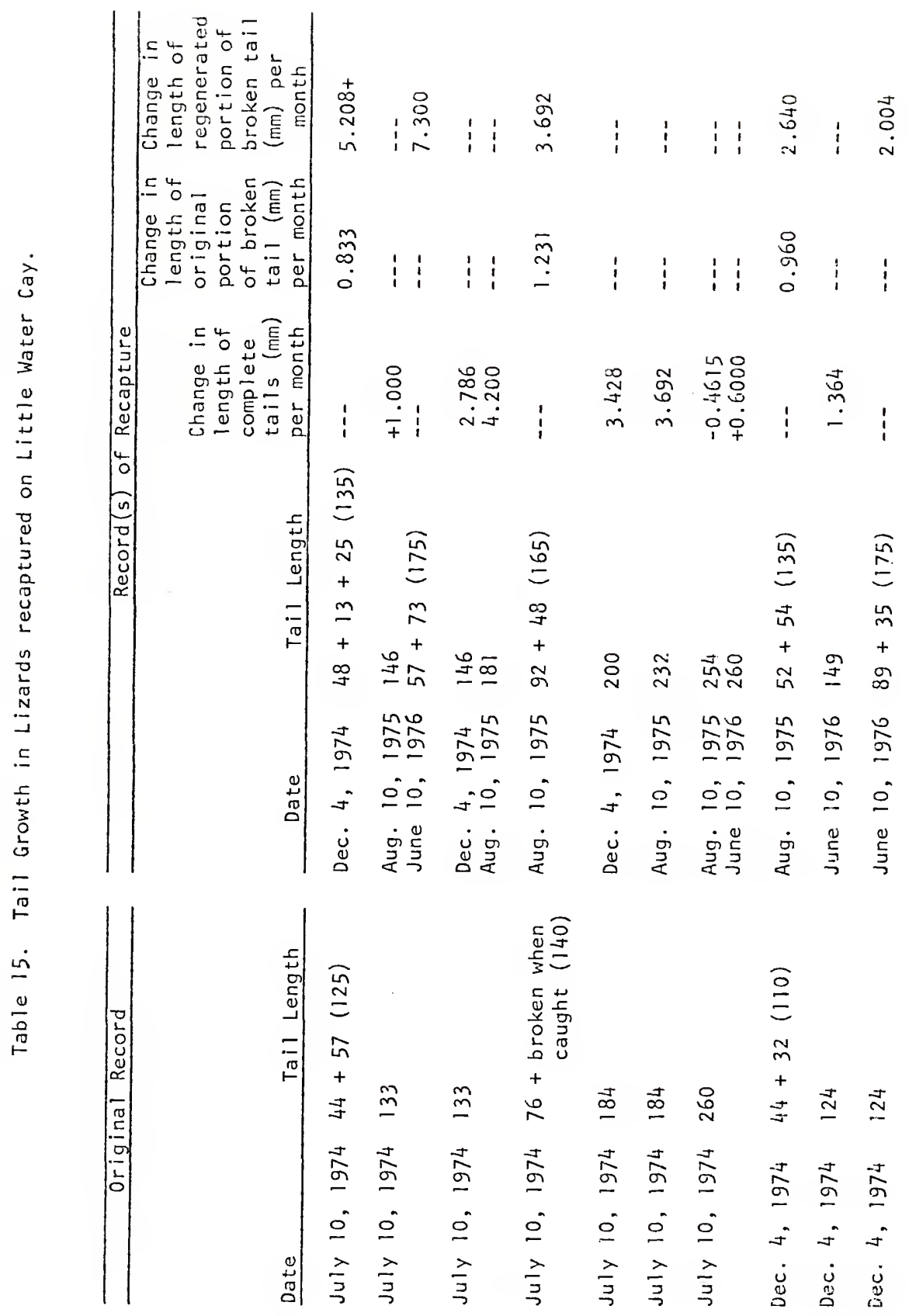




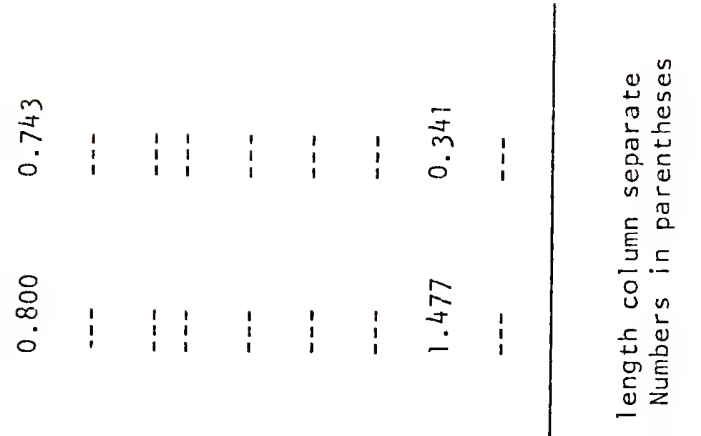

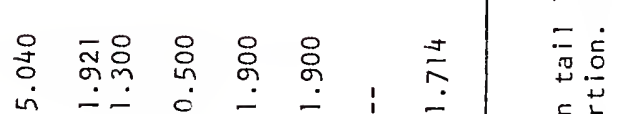

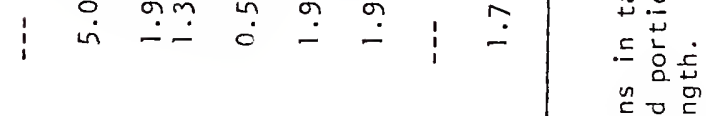

$$
\begin{aligned}
& \text { 덩 } \\
& \text { 的薄 }
\end{aligned}
$$

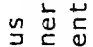

$$
\begin{aligned}
& \text { 高 }
\end{aligned}
$$

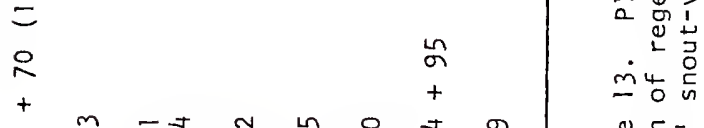

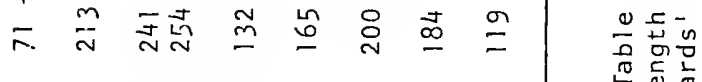

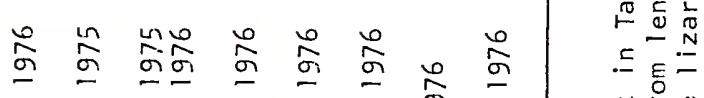

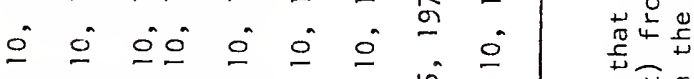

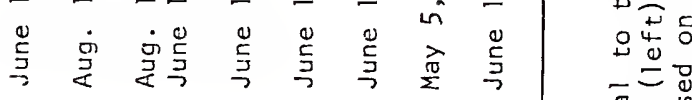

$$
\begin{aligned}
& \text { ล }
\end{aligned}
$$

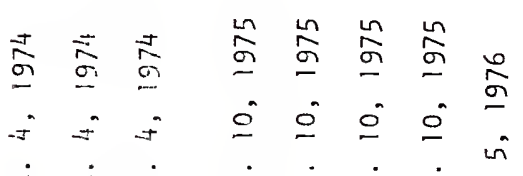

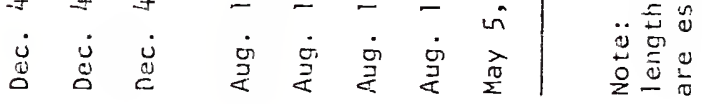


observ.; W. Auffenberg, in preparation) but also to a reduction in activity necessitated by the cooler temperatures (see ACTIVITY AND MOVEMENTS ).

Mean body size (SV) and weight for yearly intervals (see above) were utilized to construct a curve relating change in body weight to body size for juvenile $\underline{c}$. carinata. Actual weight changes in recaptured lizards for the most part fit that curve very well (Figure 33). Both sets of data indicate a nearly constant increase in body weight change $\overline{(x}=10.03 \mathrm{gm} /$ year per year $)$ through at least the first 6 years of $1 \mathrm{ife}$. Very little information on growth rates of adult cyclura carinata was obtained during the course of the study. Only one adult lizard of those few marked on Little Water Cay was recaptured (Table 13). Although many lizards at the SW Blind site were remeasured (Table 16), the value of the data is questionable due to the difficulty in accurately measuring the large lizards. The negative growth rates found in Table 16 reflect this difficulty. Nevertheless, an extremely slow adult growth rate is suggested. The mean change in SV per month for males at the SW Blind was $0.18 \mathrm{~mm}(N=12)$. However, all but three ( 4 recapture records) of these lizards were obviously old, territorial-holding males. I therefore believe that this extremely low estimate of mean growth rate reflects the very slow growth of older males. The mean growth rate (mm SV/month) in the smaller riales $(250-270 \mathrm{~mm} S V)$ is $0.659(N=4)$ and is probably a more accurate estimate of gronth in adult male lizards.

A mean srowth rate for females slightly more than half that of males $(0.461 \mathrm{~mm} S \mathrm{~V} / \mathrm{month} ; \mathrm{N}=4)$ is indicated by the SW Blind and Little Water Cay recapture data. This is as anticipated since the difference 
Figure 33. Relationship of weight change ( $\mathrm{gm} / \mathrm{month}$ ) to body size in juvenile cyclura carinata. Hollow circles are actual weight change records from recaptured Little Water Cay lizards, plotted by the average of the original and the recapture snout-vent lengths. Soid circles represent calculated weight changes: mean snout-vent lengths for one year age intervals were used to calculate body weights with the regression equation: $W t=\left(3.202 \times 10^{-5}\right)$ SV 3.0336 ; consecutive yearly weight changes were divided by 12 to give monthly values. These are plotted by the average of the mean snout-verts at the beginning and end of the sample year. 


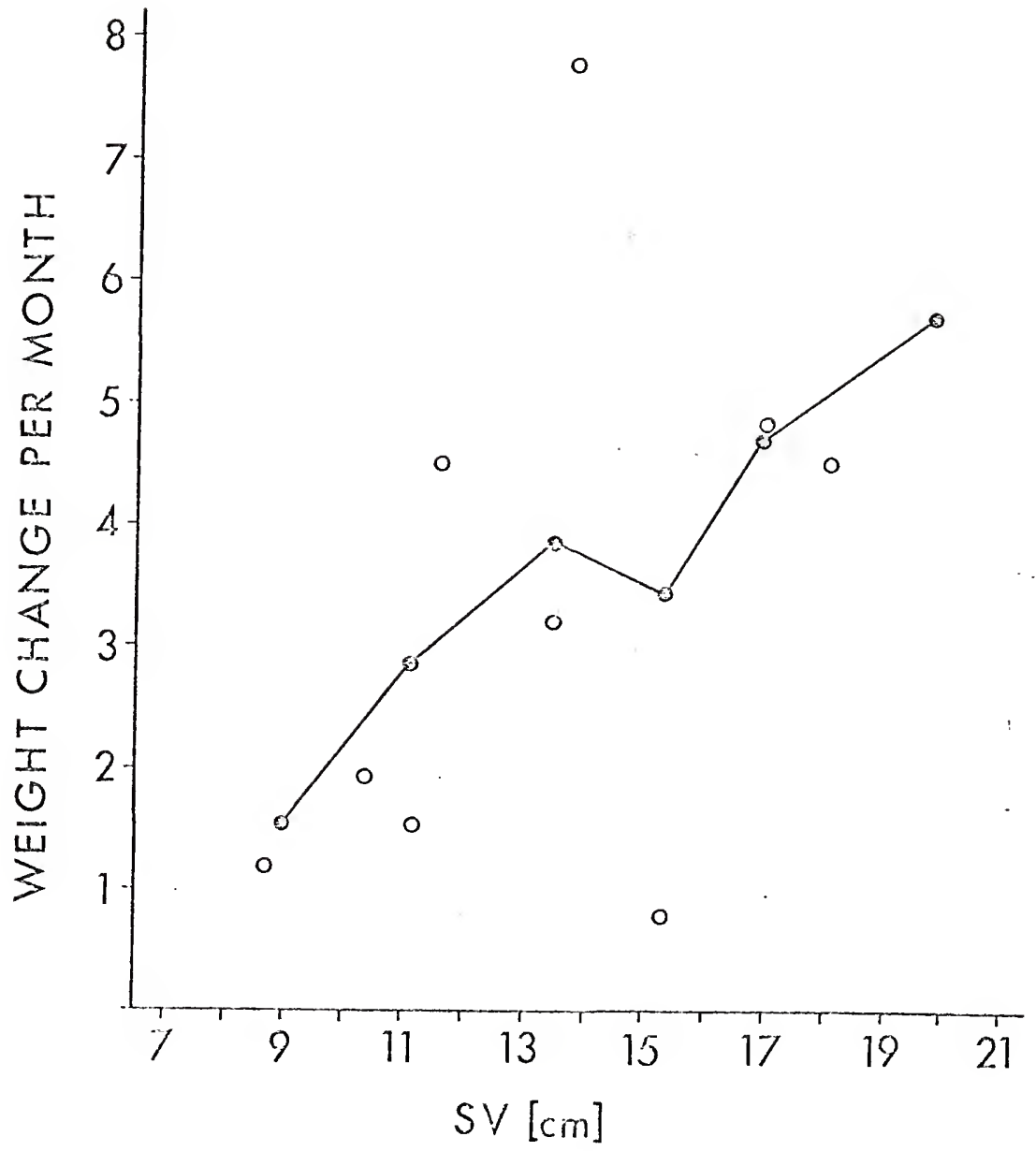


Tatle 16. Growth of Lizards recaptured at SW Blind.

\begin{tabular}{|c|c|c|c|c|c|}
\hline \multicolumn{3}{|c|}{ Original Record } & \multicolumn{2}{|c|}{ Record of Recapture } & \multirow{2}{*}{$\begin{array}{l}\text { SV } \\
\text { Change } \\
\text { (mm) per } \\
\text { month } \\
\end{array}$} \\
\hline Date & SV & Sex & Date & SV & \\
\hline March 9, 1974 & 254 & M & $\begin{array}{l}\text { June } 16,1974 \\
\text { September } 1,1974\end{array}$ & $\begin{array}{l}251 \\
254\end{array}$ & $\begin{array}{l}-0.923 \\
+1.20\end{array}$ \\
\hline June 25,1974 & 286 & $M$ & $\begin{array}{l}\text { September 1, } 1974 \\
\text { April 4, } 1975\end{array}$ & $\begin{array}{l}279 \\
292\end{array}$ & $\begin{array}{l}-3.182 \\
+1.857\end{array}$ \\
\hline March 9, 1974 & 298 & M & $\begin{array}{l}\text { June } 25,1974 \\
\text { September 1, } 1974 \\
\text { April 7, } 1975\end{array}$ & $\begin{array}{l}305 \\
292 \\
305\end{array}$ & $\begin{array}{l}+2.000 \\
-5.909 \\
+1.806\end{array}$ \\
\hline June 21,1974 & 260 & M & September 1, 1974 & 262 & +0.858 \\
\hline September 4, 1974 & 292 & M & April 4, 1975 & 286 & -0.857 \\
\hline September 6, 1974 & 305 & M & April 8, 1975 & 311 & +0.857 \\
\hline April 3, 1975 & 267 & M & August 3,1975 & 273 & +1.500 \\
\hline April 7, 1975 & 286 & $M$ & August 4, 1975 & 298 & +3.000 \\
\hline September 2, 1974 & 235 & $\mathrm{~F}$ & November 29,1974 & 241 & +2.069 \\
\hline September 4, 1974 & 241 & $\mathrm{~F}$ & April 7, 1975 & 235 & -0.857 \\
\hline
\end{tabular}


between SV at maturity and maximum size in females is only half that for males.

In a further attempt to determine the rate of growth in adult iguanas, the relationships of body size to the mid-dorsal spines were investigated. As explained under MORPHOLOGY, once maturity is reached in males, the spines on the neck begin elongation. Thereafter each time the skin is shed, an annulus is formed around the base of the spine. The back spines begin a similar development (including rate) after the skin is twice cast (Figure 34). Therefore, neck spiries possess two more annuli than back spines. Tail spines also elongate in older males, but annuli are not formed. The dorsal spines of females develop very little and generally do not bear annuli (Figure 35). With age the dorsal spines are worn smooth and the number of annuli are unaccountable. However, it is frequently possible to determine with some accuracy the number of annuli present. Unfortunately, the spine sheaths are not shed precisely at the time the adjacent skin is sloughed, and annuli counts therefore tend to be underestimated.

Since the spines offer at least some record of ecdysis, it should potentially be possible to estimate age in male lizards by the number of annuli their spines bear. Some measure of the time between skin sloughing is, however, necessary for such estimates. Accurate data on shedding frequency are difficult to obtain; Tinkle (1957: 43) has discussed the problens inherent in their estimation. From adult lizards painted both on Little water Cay and at the Sin Elind (Table 17) an annual slough is indicated. Furthernore, adult Cyclura carinata from Water Cay maintained in captivity by David Auth during the course of thermoregulatory studies 


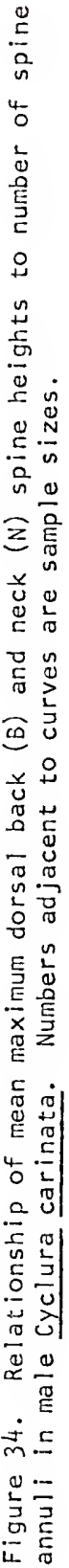




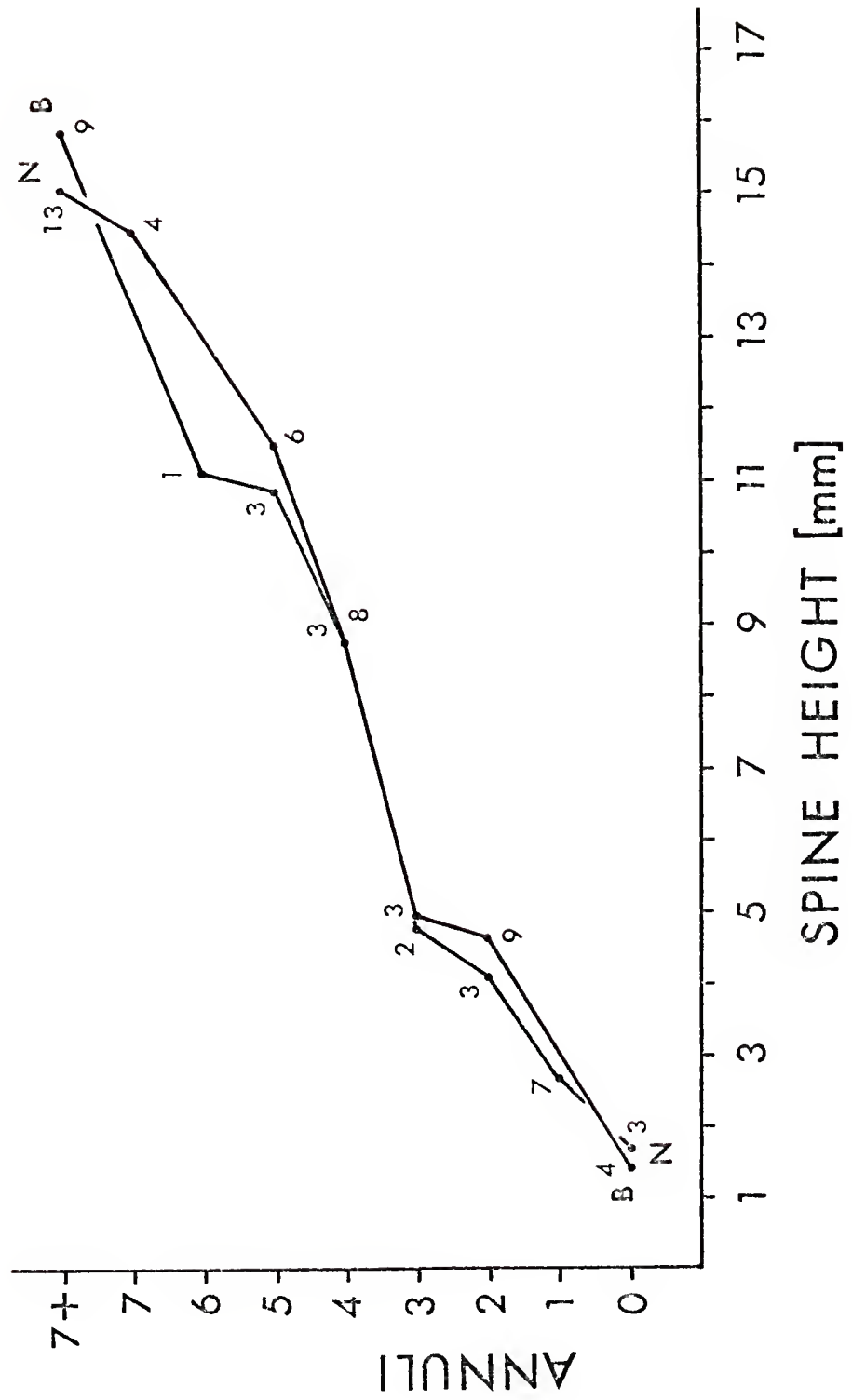




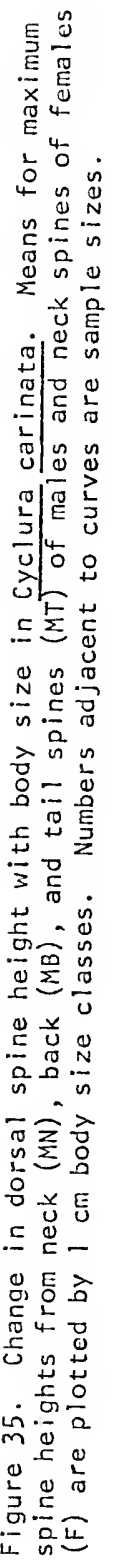




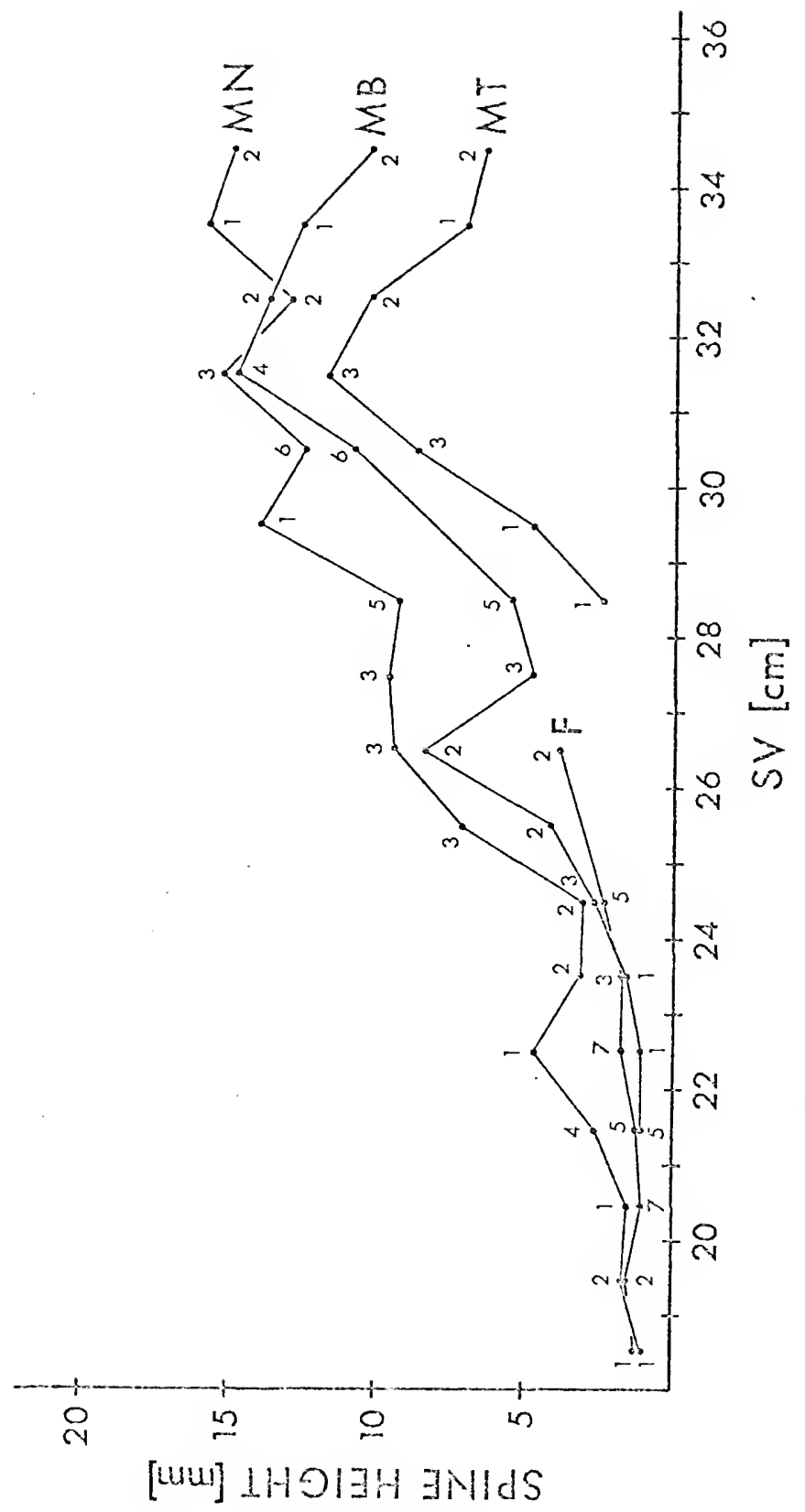


ㄴำ

足

E:-

.

E.

$\therefore \geq$

$\frac{5}{3} \mathrm{E}$

ज 4

ह

¿

$\pm 0$

齐

$=\pi$

.

剀

$\therefore \frac{\pi}{3}$

$\div 0$

풍

บ는

- $=$

व $\times$ 范

$\pm$

둥

듬

$\therefore 0$

更

U

它

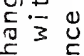

造造

$\therefore$

담

o 㟔䍃

$\div$ 政

त् $x$

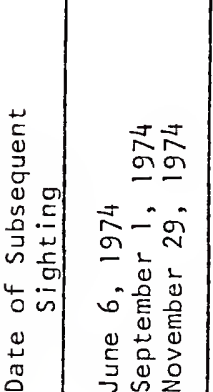

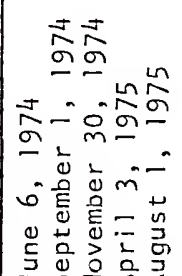

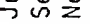
的

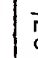
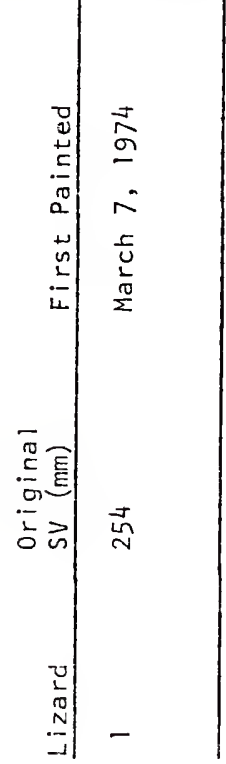

$\frac{1}{\sigma}$
$\frac{1}{n}$
$\frac{c}{0}$
$\frac{1}{2}$

ज

on

齐

ลัล

-

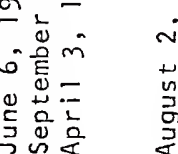

6
0
5

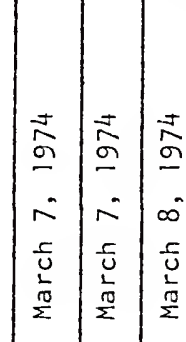

음

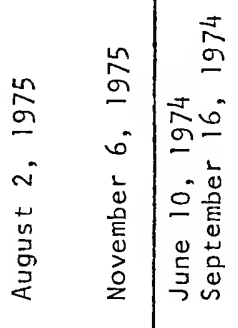

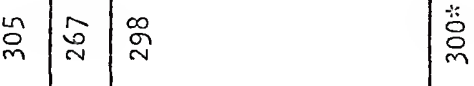

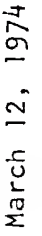

N
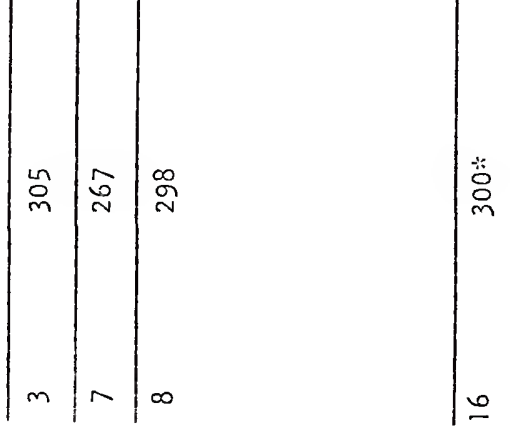


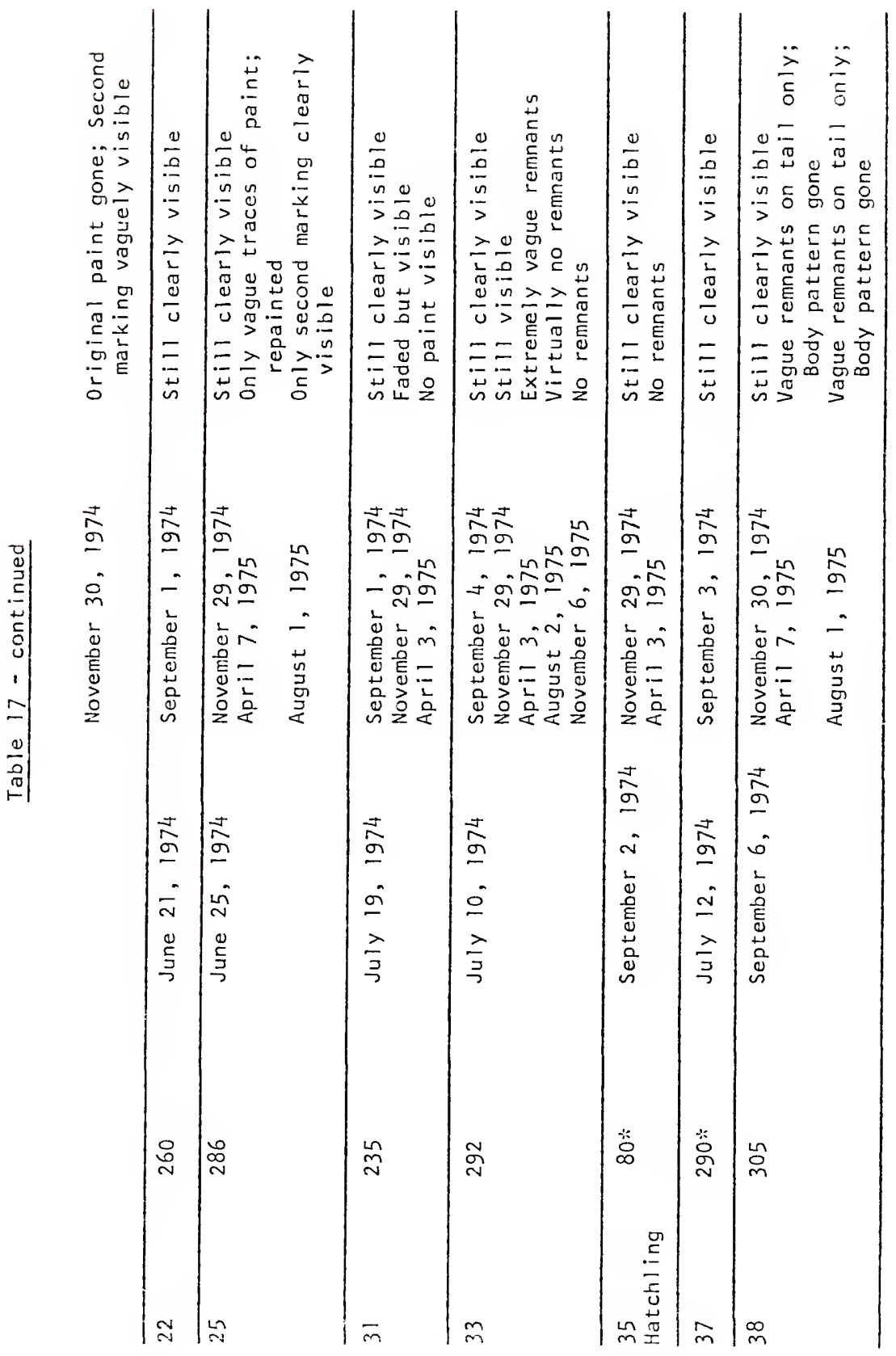




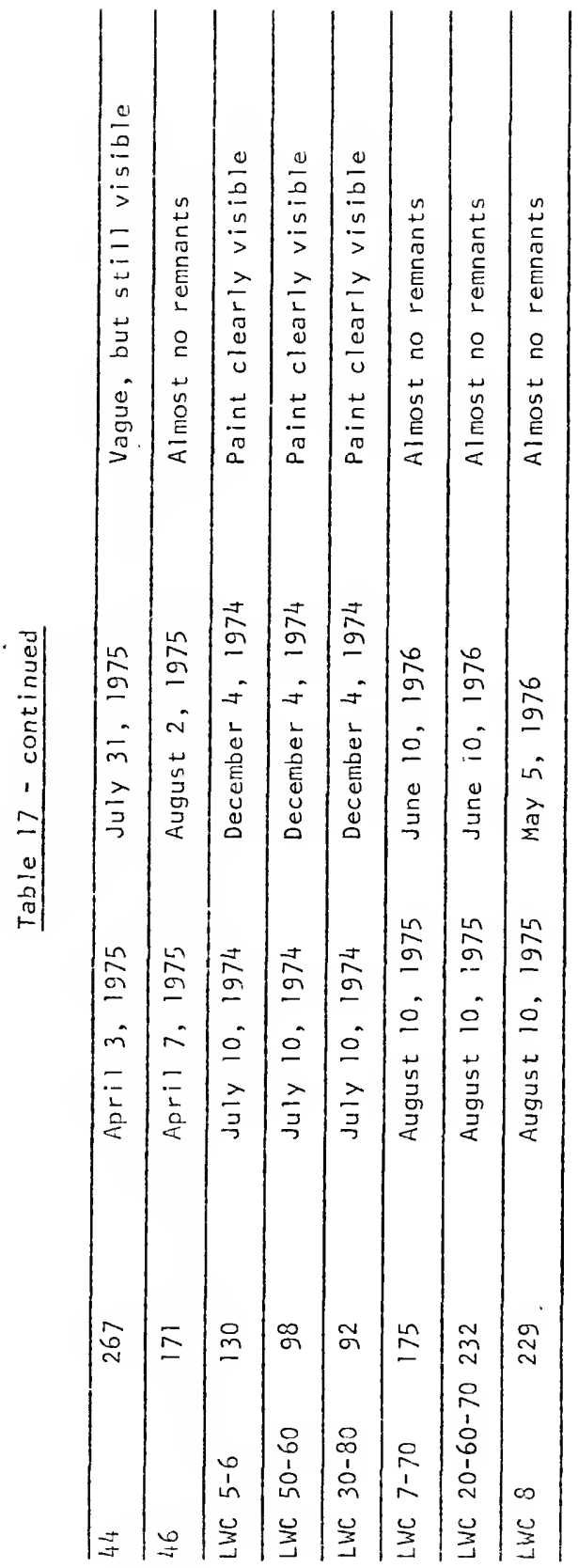


shed their skin annually. Street (1952) also believed Cyclura nubila on Cuba shed only once a year (during the spring).

The onset of shedding in Cyclura carinata seems to be coincidental with the resumption of more rapid growth following the cold and dry winter. The skin is not sloughed rapidly; ecdysis may require several months for completion. The skin of the head and upper trunk areas are shed first, followed by the lower trunk, then the limbs and ultimately the tail. In those instances where traces of paint were still visible during late summer or autumn on lizards marked the previous year (Table 17), the paint remnants were always on the tail or distally on the limbs. Although based on subjective observations, once initiated, juvenile shedding appeared more rapid than that of adults. This would be expected due to the accelerated juvenile growth rate.

With the evidence that ecdysis is an annual phenomenon, the annuli on the dorsal spines must represent yearly increments. Since annulus counts are therefore approximately equal to age post-maturity in male lizards, growth rate can be estimated by comparing these counts to lizard size. Figure 36 demonstrates the linear relationship between number of spine annuli and body length in Cyclura carinata. The leastsquares regression equation for this data $(y=0.59 x-11.849)$ indicates a SV change of approximately $1.7 \mathrm{~cm}$ with the addition of 1 annulus, i.e. 1 year. This is equivalent to a growth rate of $1.41 \mathrm{~mm}$ sV per month, more than twice the 0.66 min estimate for young adult males and only slightly less than the 1.85 mm estimate for juveniles based on actual recaptures. SV lengths calculated from weights recorded from six captive adult male lizards by David Auth (pers. comm.) for periods 


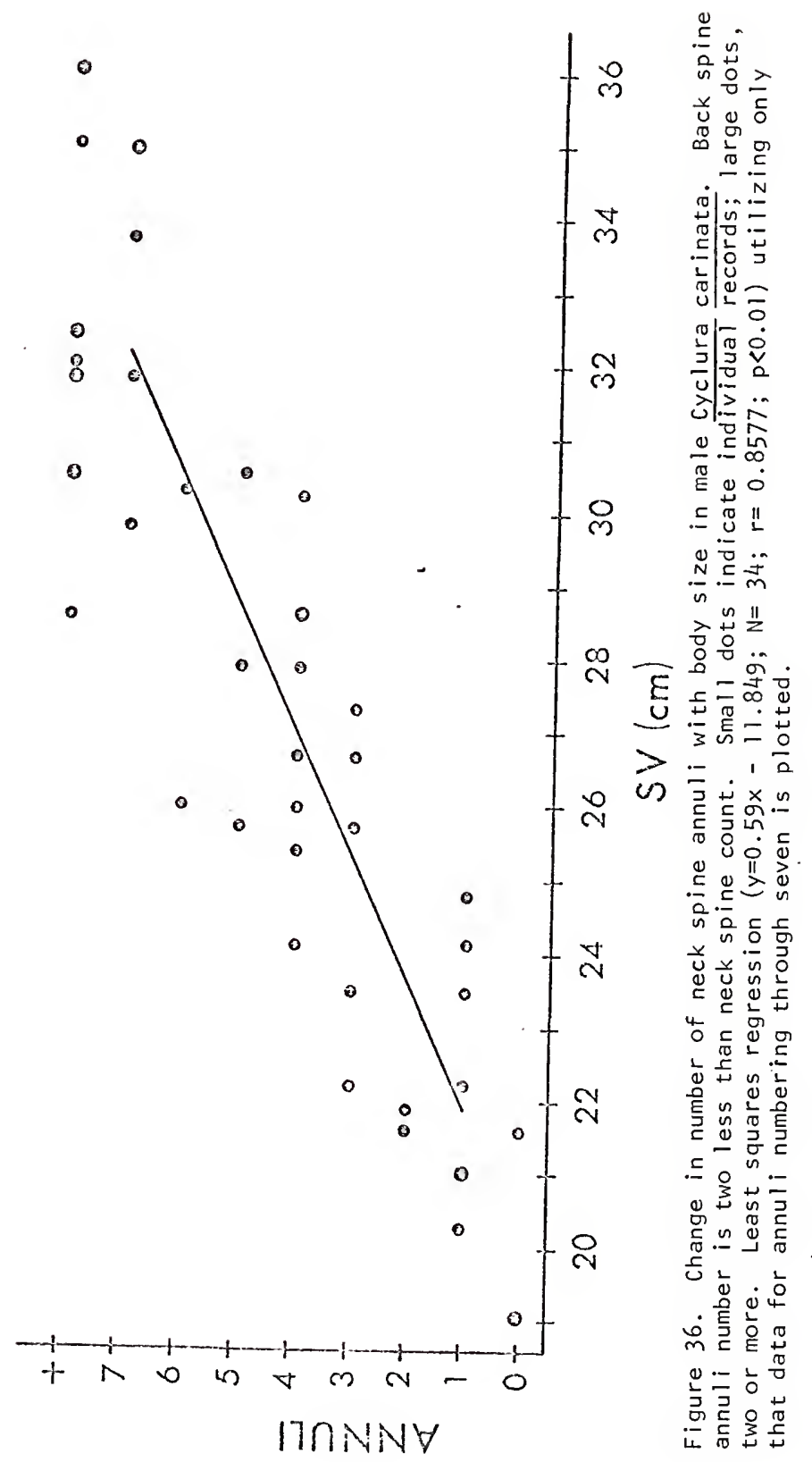


totalling almost 60 months (Range, 7.25 to 14 ) exhibited an average monthly change of $1.82 \mathrm{~mm}$. This presumably over-estimates actual growth rate since captive animals are fed more and higher quality food than wild individuals. Therefore, the actual adult male growth rate is probably close to the $1.41 \mathrm{~mm}$ per month estimate from the annulus data.

Due to small sample sizes, it was impossible to relate social status to growth rate in wild populaticns. However, in captivity, subordinate male lizards (females do not exhibit dominance relationships in nature or captivity, except during nesting) often would not eat even when food was abundantly available. In addition, their activity was greatly reduced. Berry (1974) found thet dominant male Sauromalus grew more rapidly than subordinates and I suspect a similar relationship in wild male Cyclura carinata. Males unable to establish territories in primary habitat are forced to occupy inferior peripheral habitats such as unstable dune habitats. As an example, the distal two-thirds of the sand spit formed since 1967 at the northeast point of Little Water cey is populated only by adult nale lizards.

if the juvenile growth rate (through $\mathrm{six}$ years) is $1.6 \mathrm{~mm}$ per month, as indicated by the Little Water Cay recapture data as well as age-size class analysis, and the adult male rate (after six years) is $1.4 \mathrm{~mm}$ per month, the average adut male of $276 \mathrm{~mm} \mathrm{SV}$ (Table 11) is approximately 10 years and 10 months of aze.

Unfortunately grouth rates of adult females are not so readily calculable. However, if a female lizard of mean adult female body size (225 min s Table 11) is the same age as a male of mean body size, an ificrement of monthly growth in arlult fermales of $0.52 \mathrm{~mm}$ is indicated. 
It remains to be seen whether this assumption is a valid one. In any case, this estimate supports the rate determined from four recaptured adult females $(0.36 \mathrm{~mm} / \mathrm{month})$.

SV lengths calculated from weights recorded from four captive fenale lizards by David Auth (pers. comm.) for periods totaling more than 53 months (range, 7.25 to 26 ) indicated an average monthly increase of $1.11 \mathrm{~mm}$. This value is over two times the estimated natural growth rates. One captive female gained $63 \mathrm{~mm}$ in SV (and 562 grams body weight) in only 26 months (2.42 mm per month). A similarly-sized female marked and recaptured on Little Water Cay (see Table 13) gained only $3 \mathrm{~mm}$ over 24 of the same 26 months. This accelerated captive growth may indicate that natural food resources are limiting growth (see FOOD AND FEEDING).

From the SV-body weight and the SV-spine annuli regressions, calculated annual adult male weight changes constantly increase from about $14 \mathrm{gm} /$ year/year in newly maturing individuals to almost $24 \mathrm{gm} /$ year/year in older lizards $(\bar{x}=18.9 \pm 3.1$, from ages 6 to 17 years $)$. Calculated yearly weight increases were $82 \mathrm{gm} /$ year during the sixth year and $252 \mathrm{gm} /$ year during the sixteenth year.

The slowing of the growth rate in adult females when compared to males is perhaps related to the high annual female reproductive expenditure; female Cyclura carinata deposit roughly $25 \%$ of their gravid body weight annually when nesting (see REPRoDuctIon). Applying the SV-body weight regression to the mean adult SV for males $(276.26 \mathrm{~mm})$ and females (225.9 mim) calculates body weight at $815 \mathrm{gm}$ and $440 \mathrm{gm}$, respectively. Age for males of this size was previously detemined to be approximately 10 years 10 months. Six-year-old subadult 1 izards average $195 \mathrm{~mm}$ SV and 
$283.5 \mathrm{gm}$. Therefore males increase their mass $531.5 \mathrm{gm}$ in 4 years 10 months. If we assume average sized adult females are also aged 10 years 10 months, then they experience only a $156.5 \mathrm{gm}$ increase in the same four years 10 months. (Even if this is not a strictly valid assumption, I believe its accuracy will not greatly affect the following discussion.) However, in that period of time, a female would have deposited five clutches of eggs. Since mean clutch size for females 195 to $225 \mathrm{~mm}$ SV equals 3.42 and mean egg weight equals 25.9, average clutch weight for those five clutches is approximately $88.6 \mathrm{gm}$. Adding the weight of five average clutches $(442.9 \mathrm{gm})$ to the $156.5 \mathrm{gm}$ female increase during the four years and ten months, we observe that a potential weight increase of nearly $600 \mathrm{gm}$ might be possible if reproductive output were rechanneled to growth (and maintenance costs were disregarded).

It is perhaps more than coincidental that this value is approximately equivalent to the male increase during the same five periods $(531.5 \mathrm{gm})$. It is tempting to suggest that the observed sexual size dimorphism is explainable in terms of a simple shift of a portion of the potential energy available for growth for use in reproductive output in females.

\section{Factors Affecting Growth}

As shown above for juveniles, lizards grow very little during the winter. This is probably due primarily to two factors. In response to the colder and drier conditions most plant species do not produce fruits or floners. Cyclura must necessarily become more folivorous. Since. digestion of fibrous leaves is presumably more difficult, as evidenced 
by the fact that leaves often pass through the entire gastrointestinal tract unaltered, and the caloric content of leaves is generally lower than that of fruits (Golley, 1969; Auffenberg, in preparation), the nutritive quality of the winter diet is much reduced. Secondly, lower winter environmental temperatures sometimes make it impossible for lizards to reach perferred temperatures for one to several days at a time. Feeding is therefore precluded, and digestive activity is presumably reduced (Harlow et al., 1976) as most activity certainly is. Thus, despite their tropical location, populations of Cyclura carinata are subjected to a distinct climatic seasonality which is reflected in a decrease in the physical and physiological availability of the food resources during the winter. Growth must necessarily slow during that period.

\section{Longevity}

If the previously estimated adult male growth rate (17 mm/year) were maintained from 6 years of age (195 mm SV) on, with no slowing in old age, it would require over 15 years to reach the approximate $350 \mathrm{~mm}$ maximum male SV. Even if the mean juvenile growth rate was maintained throughout $1 \mathrm{ife}$, over 14 years would be required for a male to reach that $350 \mathrm{~mm}$ maximum SV. These data suggest that large adult males commonly reach 15 years of age. Many probably live for 20 years, with occasional individuals surviving to 25 years.

\section{Regeneration}

As in most other lizards (Fitch 1954: 97, and Tinkle 1967: 58), rate and extent of tail regeneration in Cyclura carinata is dependent 
on a variety of factors, including age and site of fracture. Figure 37 illustrates the relationships of tail break site in juveniles, females and males on the total length of tails with regenerated portions. The data indicate: 1) that fully regenerated tails in juveniles are proportionately longer than those of adults and 2) that the longer the lost tail segment, the shorter the completely regenerated tail length will be.

Information on actual regeneration rates of broken tails is scanty and only data from juvenile lizards are available (Table 15). Regeneration is very rapid in juveniles, exceeding $5 \mathrm{~mm}$ per month. The fact that the majority of the broken-tailed adult lizards seen exhibited nearly maximal regeneration (note modal values in Figure 37 ) suggests that regeneration rates in adults are also very rapid. The importance of the tail for balance when running, and as an escape mechanism from predators, as well as its use in social contexts (see SOCIAL ORGANIZATION) bespeaks the selective value of rapid tail regeneration.

Occasionally incompletely severed tails will begin regeneration, producing forked tails. In this study, three lizards were encountered with bifurcate tails; one additional iguana exhibited three tail forks.

\section{Comparisons With Other Iguanines}

Cyclura carinata is a medium-sized iguanine lizard; the genera Brachylophus (one species), Ctenosaura (four species, except C. similis) Enyaliosaurus (four species), and Sauromalus (five species), and only one other species of Cyclura (rileyi) are smaller. Cyclura carinata exhibits greater sexual size dimorphism than any other iguanine (see 


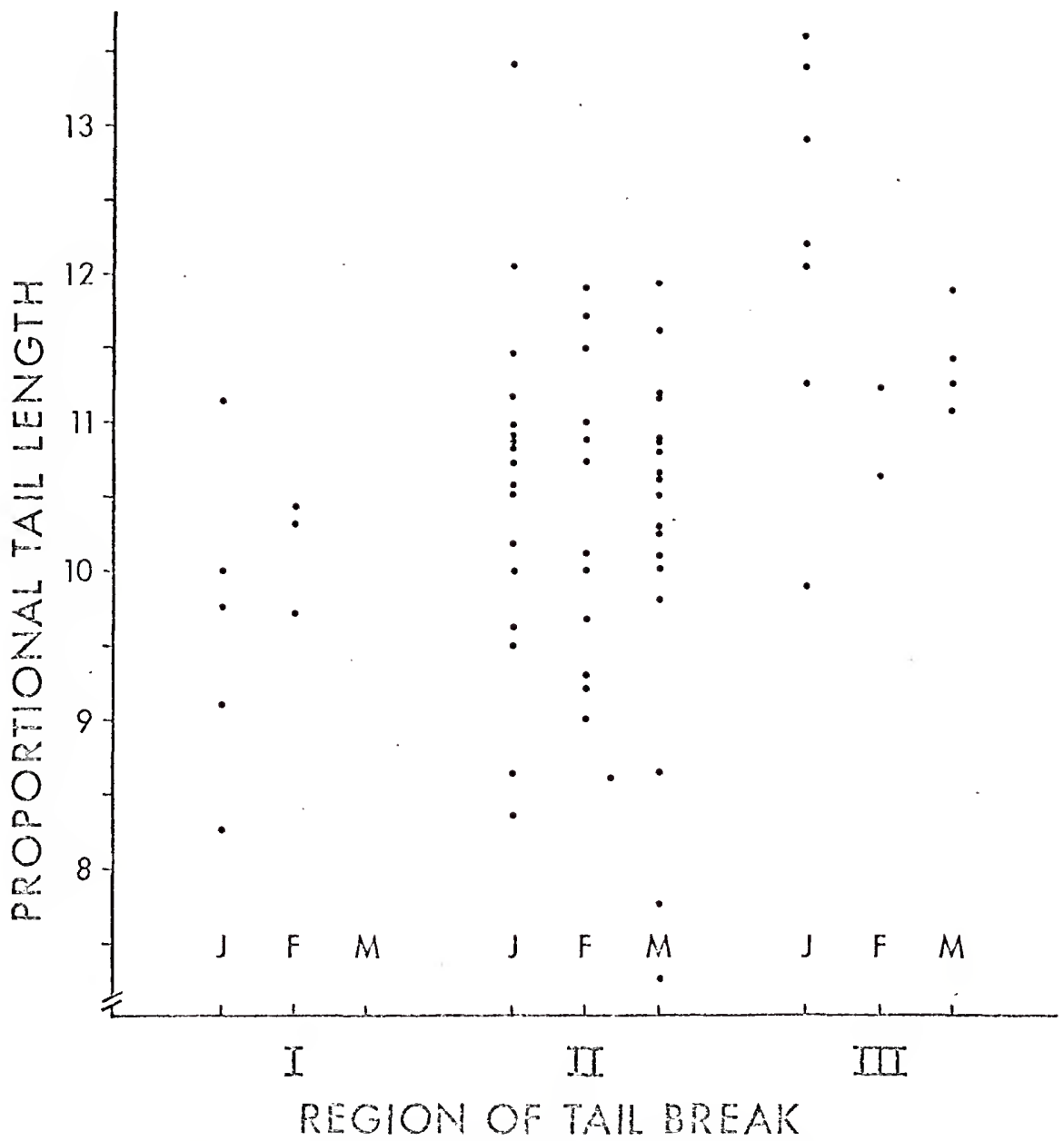

Figure 37. Proportional tail length (TL $\times 10 / S V)$ in broken-tailed Cyclura carinata for juveniles $(J)$, females $(F)$, and males (M), based on region of break. Roman numerals refer to break position: $i=$ proximal third (unregenerated portion of tail/SV $=0$ to 0.47 ), $11=$ middle third $(0.47$ to 0.93$)$, and $111=$ distal third (over 0.93). Data from tails with multiple breaks are not plotted. Unbroken tails have a mean proportional length of about 14 . 
above); adult females average only about $80 \%$ and $50 \%$ of adult male SV and body weight, respectively. Male Cyclura pinguis are also larger than females (Carey, 1975) but not to the extent found in C. carinata. Although this dimorphism may relate to the female's reproductive expenditure, it may also serve to reduce intraspecific competition (see FOOD AND FEEDING).

A juvenile growth rate of $1.6 \mathrm{~mm}$ SV per month $(0.052 \mathrm{~mm} / \mathrm{day})$ in Cyclura carinata is among the slowest yet recorded among lizards (see review in Tinkle, 1967). This is undoubtedly an artifact of the much greater size of juvenile Cyclura than previously studied juvenile lizards. Comparisons of weight changes during juvenile growth are probably more meaningful to growth discussions involving lizard species of greatly varying sizes. Unfortunately, these data are not easily extracted from the literature. Nevertheless, the rates of body length change for juvenile Cyclura carinata compare favorably with those recorded for other juvenile iguanines (Table 18). Adult growth rates are similarly congruent (Table 19).

Very little information exists on age at maturity in iguanine lizards. Fitch (1970) theorized that three years is the minimum breeding age for Ctenosaura similis in Costa Rica. Mayhew (1971), Berry (1974), and Carey (1975) similarly postulated that five to six, nine, and seven to nine years are required for maturation in Dipsosaurus dorsalis, Sauromalus obesus, and cyclura pinguis, respectively. These data correspond :ell with my estimate of seven to eight years for cyclura carinata, and Wiewandt's (in preparation) estimate of six to seven for C. cornuta. 


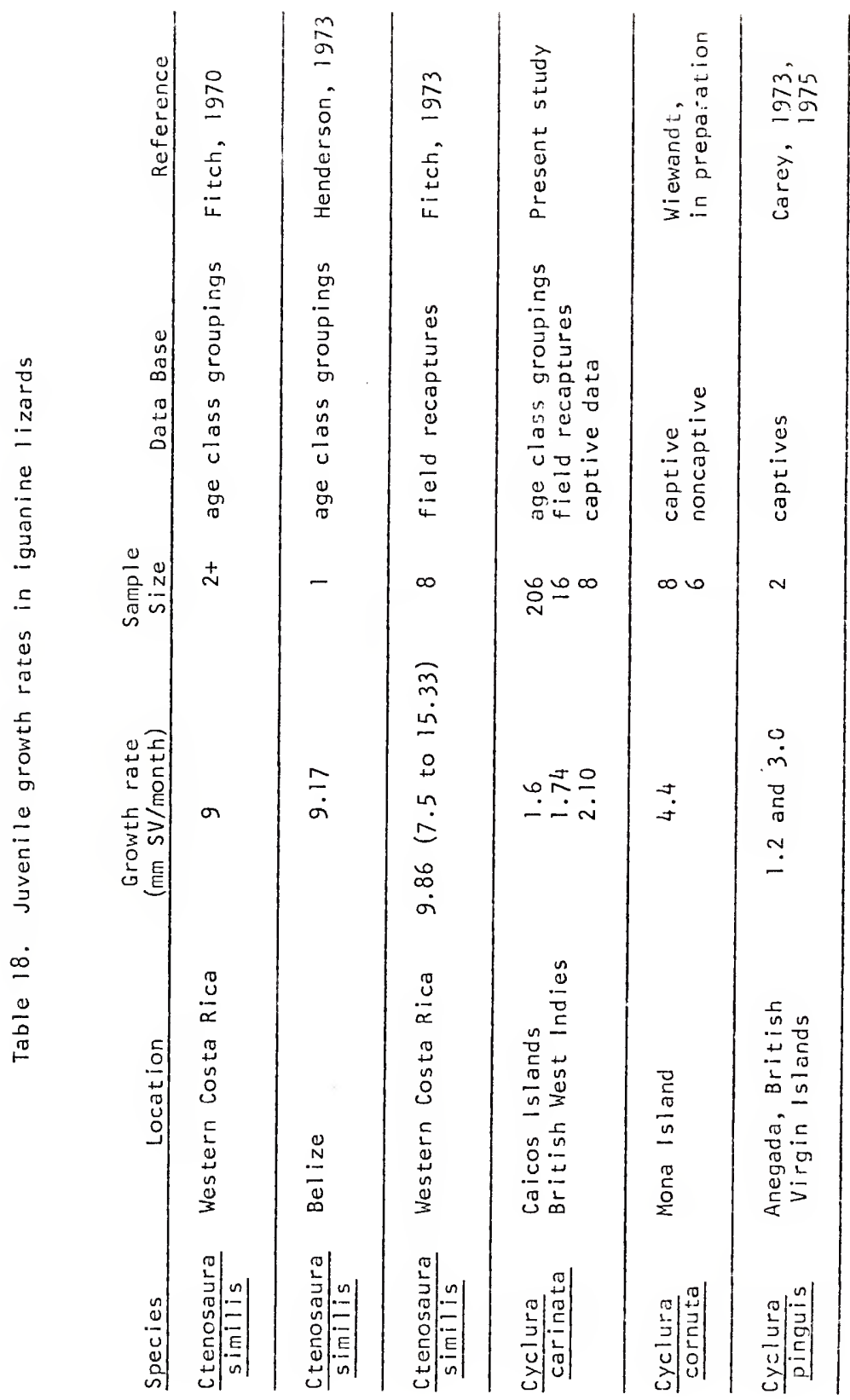




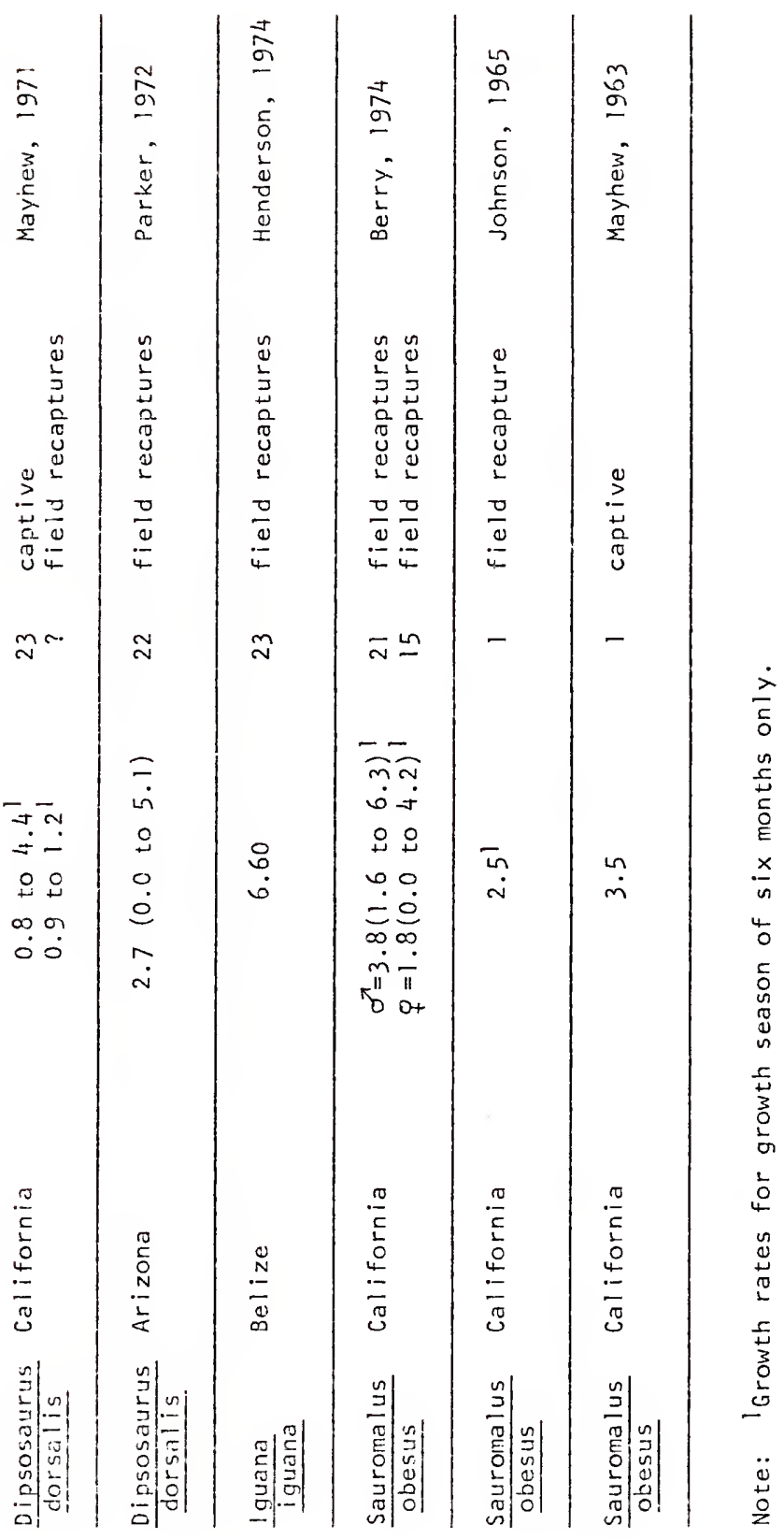




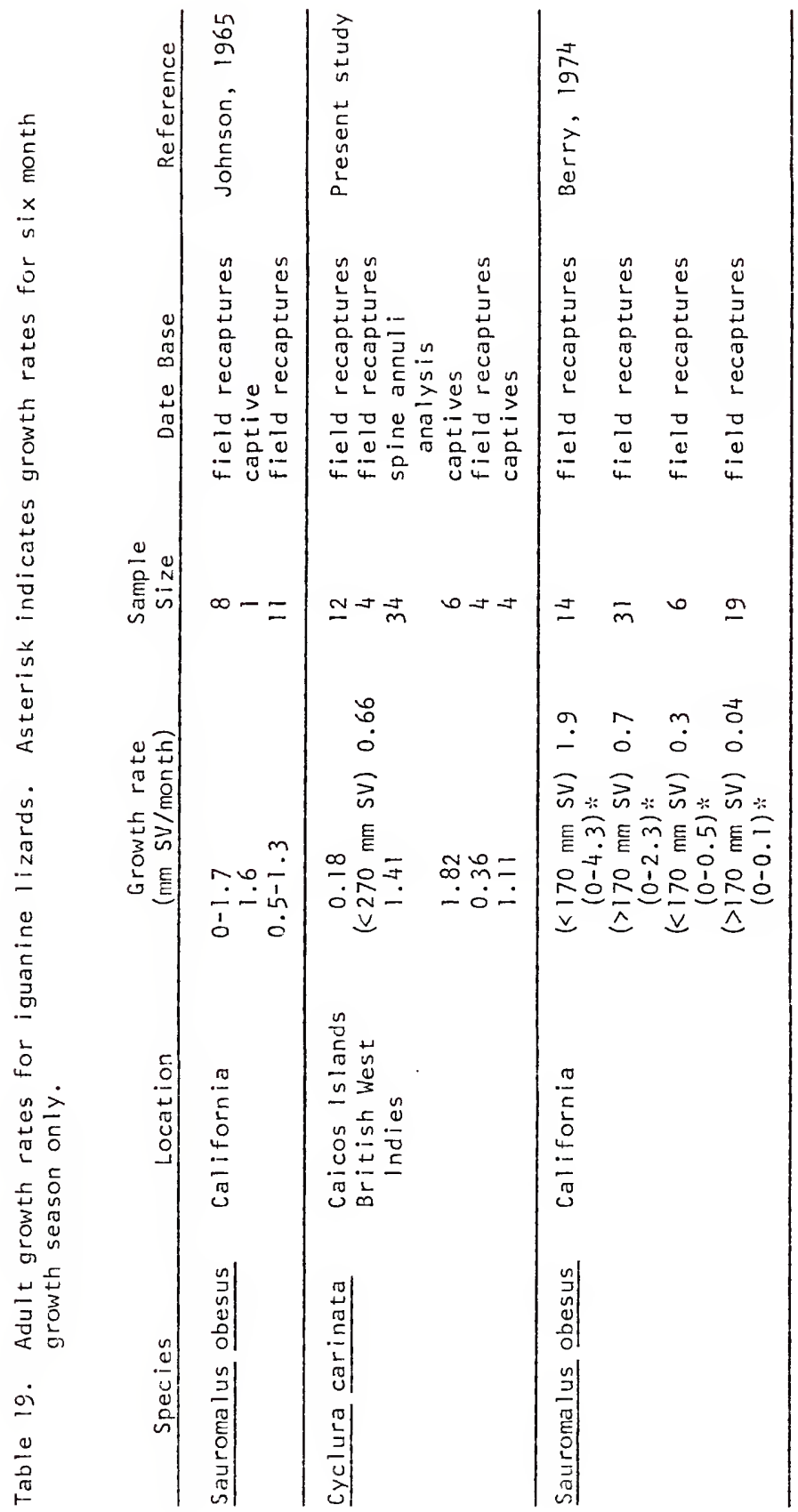


Longevity for very few iguanine species has previously been discussej. Johnson (1965) and Berry (1974) postulated 25 and 20 years, respect:.1\%, as estimates of longevity for Sauromalus obesus in the Mojave Desert. Carey (1973) maintained two Dipsosaurus dorsalis (adults then obtained) in captivity for just over $1 t_{k} 1 / 2$ years; assuming at least five years to reach adulthood (Mayhew, 1971), at death the lizards were probably more than 20 years of age. Goin and Goin (1962) considered 15 years to be the maximum age for Conolophus subcristatus and Mueller $(1968,1972)$ believed that very few Iguana iguana lived more than 10 years. Unfortunately Carey (1975) did not speculate on longevity for Cyclura pinguis in the British Virgin Islands. However, if longevity is computed by utilizing his values for size $(400 \mathrm{~mm})$ and age $(7-9$ years) at sexual maturity, maximum size (about $540 \mathrm{~mm}$ ), and the average of his two captive subadult growth records $(2.1 \mathrm{~mm} / \mathrm{month})$, a minimum longevity of nearly 14 years is obtained. Following a similar procedure, Cyclura carinata must normally 1 ive from 15 to 20 years of age.

Excepting the varanids, the iguanines are probably the longestlived of the lizards; however, the tuatara (Sphenodon punctatus) is believed to live at least 50 years (Crook, 1975). 
FOOD AND FEEDING

\section{Diet}

\section{General Comments}

Food items eaten by Cyclura carinata are listed in Tables 20 and 21. A more comprehensive analysis of diet based on stomach analysis appears in Auffenberg (in preparation). Therefore, only a few important points regarding diet are discussed here.

At least $95 \%$ of the diet (in volume or numbers of items) of lizards of all ages during all seasons is plant material (W. Auffenberg, in preparation; present study). As expected, seasonal diet variation reflects food availability; fruits and flowers are necessarily infrequently represented (leaves frequently) in the winter diet. Ontogenetic diet changes are primarily related to the increasing size of the trophic apparatus with age; adults are more efficient leaf-croppers and can swallow much larger fruits than juveniles.

Strumpfia (bay cedar) is the single most important food item in the diet of Cyclura carinata during the first year of its 1 ife. Erithalis (torch wood) and Ernodea (guanaberry) are also very important. of six neonates captured in September with food in their gastrointestinal tracts, five had eaten Strumpfia fruits; two contained Erithalis and/or Ernodea in their digestive tracts. During December of their first year (approximate age, 3.5 months), seven of twelve juveniles had fed on Strumpfia and three of twelve had eaten more than one of these 3 species. By March (age, $61 / 2$ months), each of four juveniles had 


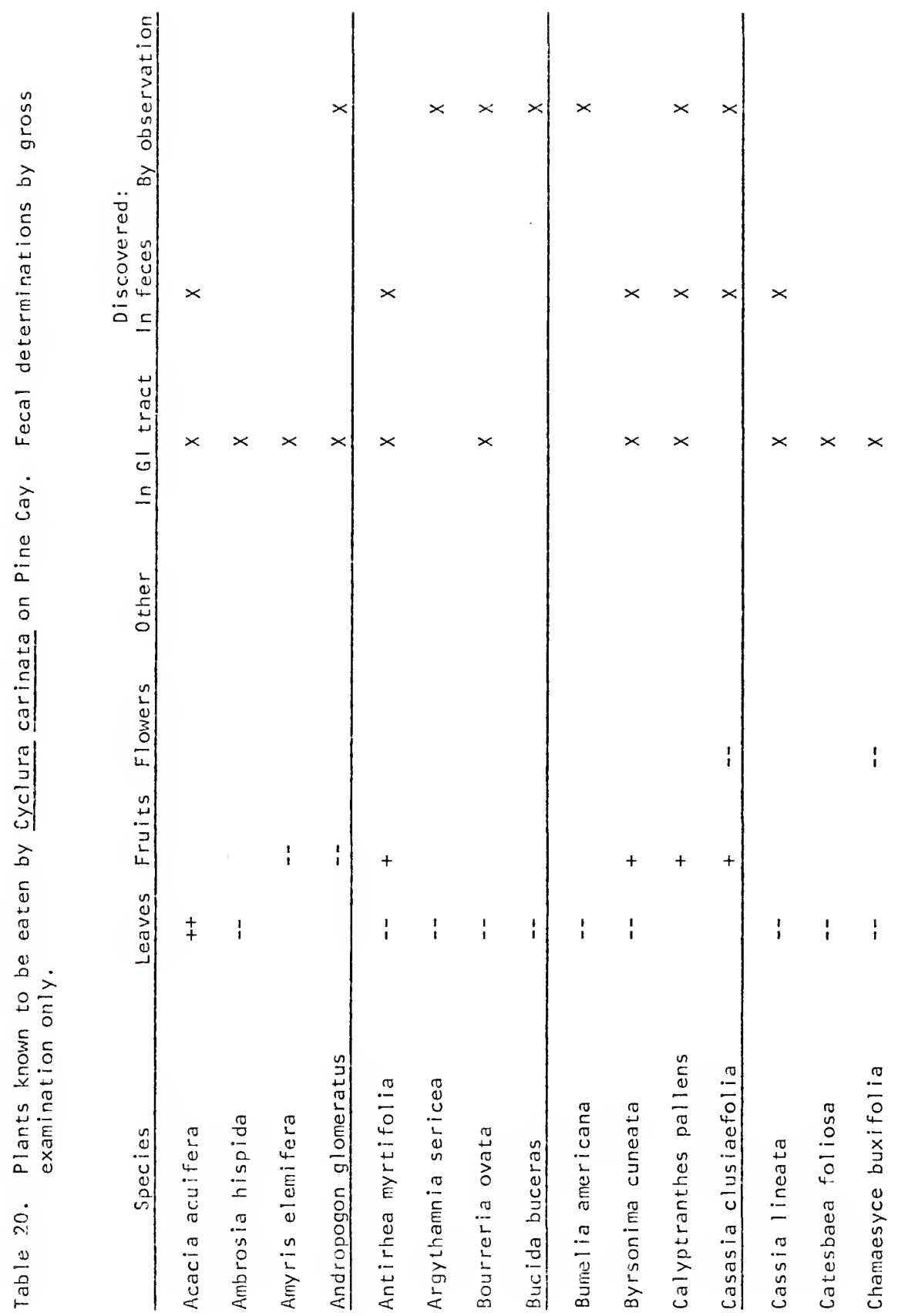




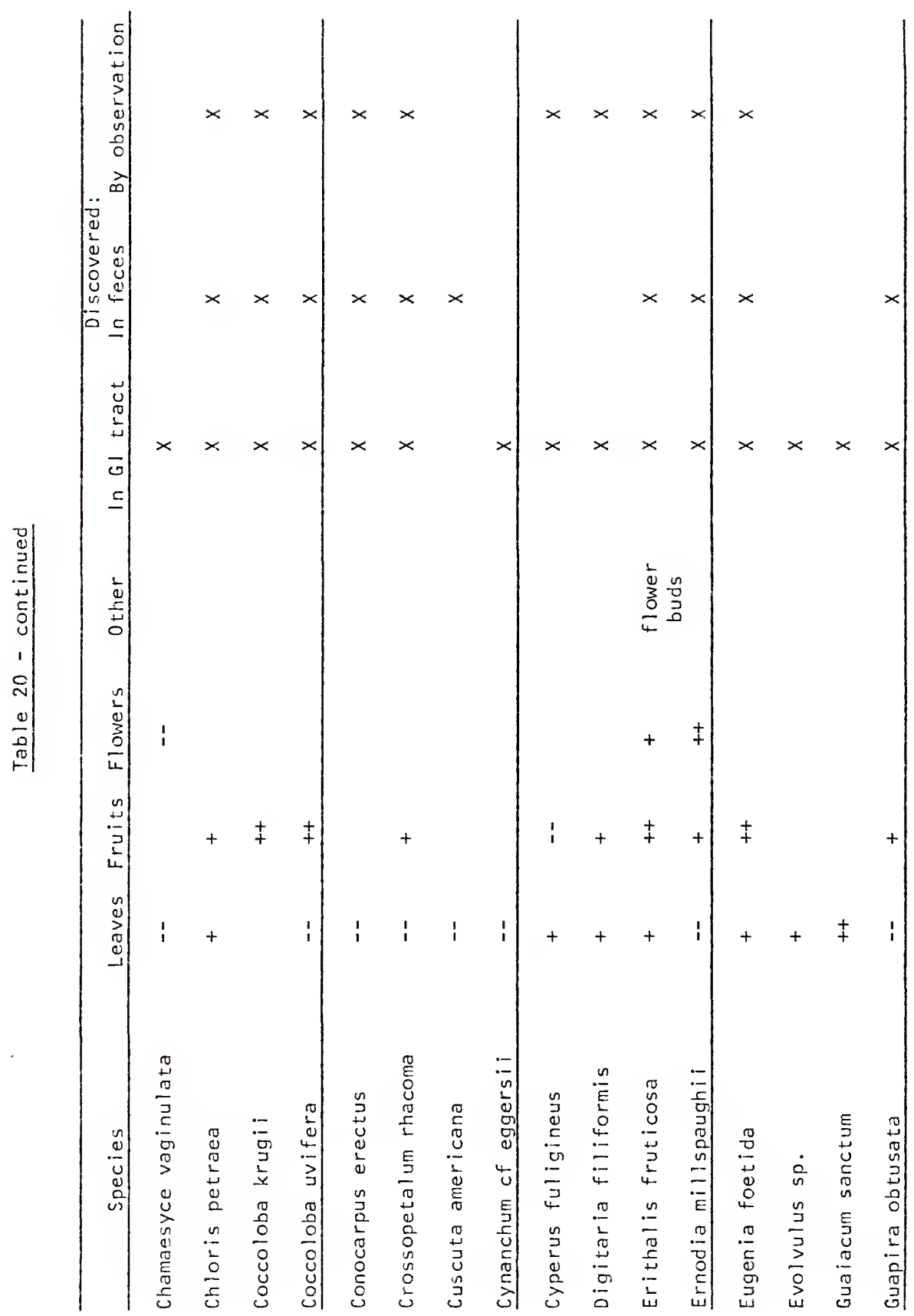




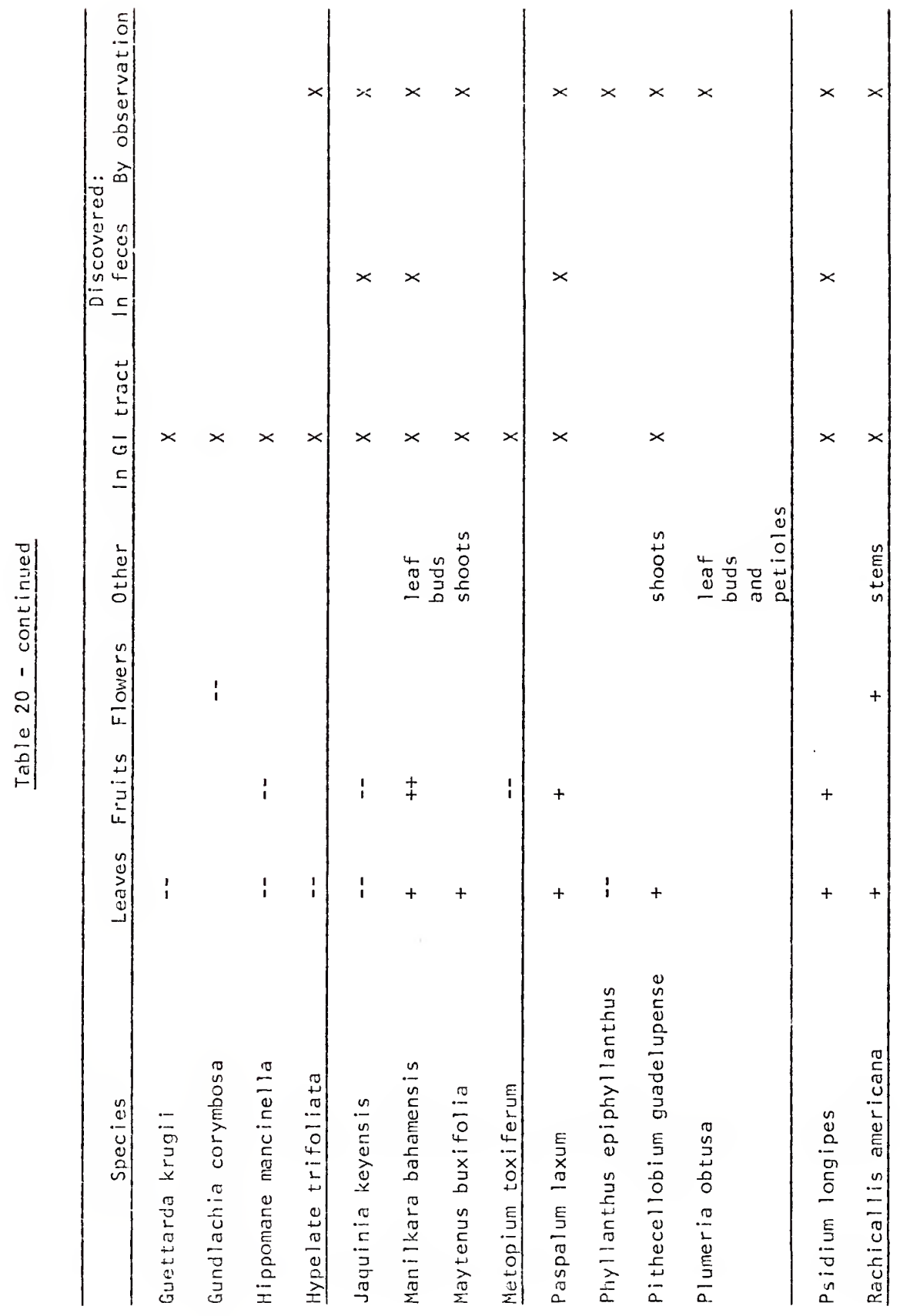




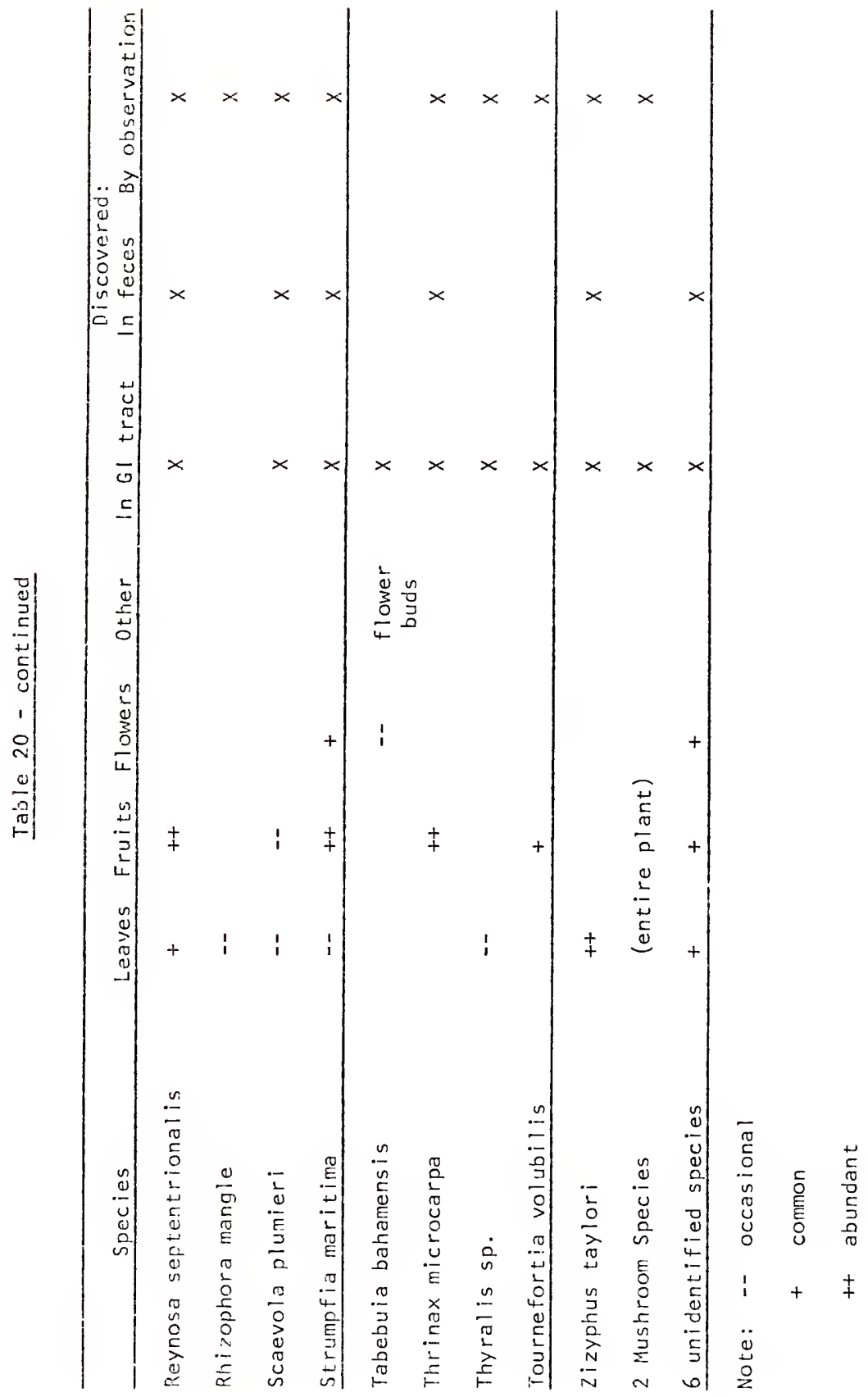


Table 21. Animals known to be taken by Cyclura carinata on Pine Cay.

$\begin{array}{r}\text { Discovered: } \\ \text { In In tract feces observation } \\ \hline\end{array}$

\begin{tabular}{|c|c|c|c|}
\hline $\begin{array}{l}\text { Mollusca } \\
\text { unidentified slug }\end{array}$ & $x$ & & \\
\hline $\begin{array}{l}\text { Crustacea } \\
\text { Decapoda } \\
\qquad \text { Clibanarius (hermit crabs) } \\
\text { Cardisoma guanahumi (land crabs) }\end{array}$ & $\begin{array}{l}x \\
x\end{array}$ & $\begin{array}{l}x \\
x\end{array}$ & $x$ \\
\hline $\begin{array}{l}\text { Insecta } \\
\text { Homoptera } \\
\quad 01 \text { lanta } \\
\qquad \begin{array}{ll}\text { Ollanta } \\
\text { caicosensis }\end{array}\end{array}$ & $\begin{array}{l}x \\
x\end{array}$ & $\begin{array}{l}x \\
x\end{array}$ & \\
\hline $\begin{array}{l}\text { Lepidoptera } \\
\text { Pseudosphinx tetrio larvae } \\
\text { Hymenoptera } \\
\text { unidentified honeybee }\end{array}$ & $x$ & & \\
\hline $\begin{array}{l}\text { Isoptera } \\
\text { Nasutitermes costatus }\end{array}$ & $x$ & & \\
\hline $\begin{array}{l}\text { Coleoptera } \\
\text { unidentified adult weevils } \\
\text { unidentified beetles }\end{array}$ & $\begin{array}{l}x \\
x\end{array}$ & $x$ & \\
\hline $\begin{array}{l}\text { Diptera } \\
\text { unidentified species }\end{array}$ & $x$ & $x$ & \\
\hline $\begin{array}{l}\text { Odonata } \\
\text { unidentified wing fragments }\end{array}$ & $x$ & $x$ & \\
\hline $\begin{array}{l}\text { Aracinnida } \\
\text { Solpugidae }\end{array}$ & & $x$ & \\
\hline $\begin{array}{l}\text { Reptilia } \\
\text { Cyclura carinata juveniles } \\
\text { Cyclura carinata skin }\end{array}$ & $\begin{array}{l}x \\
x\end{array}$ & $x$ & $x$ \\
\hline $\begin{array}{l}\text { Aves } \\
\text { various species (as carrion) } \\
\text { unidentified feathers }\end{array}$ & $x$ & & $\begin{array}{l}x \\
x\end{array}$ \\
\hline
\end{tabular}


eaten at least one of the three species; by June and July (age, 9-10 months) this proportion was two of six. This may reflect the accurrence of the three plant species in nearly all habitats, as well as the fact that fruit is produced throughout an extended reproductive season ( $W$. Auffenberg, in preparation; pers. observ.).

In addition to fruits of the above three species, adults are especially fond of fruits of Antirhea, Casasia, Coccoloba, Eugenia, Manilkara, Psidium, Reynosa, and Thrinax. Evidence of the fruits of at least one of these species was found in the gut of nearly every adult lizard dissected.

\section{Geophagy}

The guts of nearly all Cyclura carinata examined contained sand grains and/or other soil fragments. There is some controversy as to whether reptilian geophagy and/or lithophagy is intentional or accidental (see Kennedy and Brockman, 1965, and Sokol, 1967, for literature review). Despite Sokol's (1971) observations (in captivity?) of apparently intentional geophagy in the iguanines Iguana iguana and Ctenosaura pectinata, 1 believe that Cyclura carinata does not purposely ingest particles of the substrate. I have never observed geophagy in this species either in captivity or the field.

\section{Coprophagy}

The intentional ingestion of feces, whether from their own or other species, has been documented for herbivorous tortoises (Auffenberg and leaver, 1969; Mares, 1971) and has been reported in herbivorous lizards in Amblyrhynchus cristatus (Wilcox et al., 1973; bird feces), 
Dipsosaurus dorsalis Norris, 1953; Stebbins, 1954; Minnich and Shoemaker, 1970; mammal and reptile, including their own), Iguana iguana (Swanson, 1950; believed by natives to eat human excrement), Sauromalus obesus (Nagy, 1973; fecal origin unspecified; and Sanburn, 1972; Neotoma lepida droppings), and Uromastix acanthinurus (Dubuis et al., 1971; gazelle droppings). However, feces ware not found in the upper gastrointestinal tracts of any Cyclura carinata dissected.

The inportance of coprophagy to iguanines is unknown. Unfortunately Nagy (1973) did not speculate on the significance of the occurrence of feces in the stomachs of Sauromalus. Mares (1971) hypothesized that ingestion of the scats of herbivores by other herbivores might increase the latter's efficiency of assimilating the contained cellulose materials since they are already partially digested. Minnich and Shoemaker (1970) suggested that the ingestion of fecal material may provide specific nutritional requirements (vitamins and proteins) otherwise lacking in a plant diet. Another possible benefit of coprophagy is that it provides a means of acquiring potentially symbiotic intestinal micro-organisms that might also increase assimilation efficiencies (see Digestive Efficiency, this section, and INTERSPECIFIC COACTIONS).

\section{Cannabalism}

The inclusion of conspecifics in the diet of Cyclura carinata is of particular interest (Table 21): cannabalism is extremely rare among Iguanid lizards, especially in non-captive situations (Bowie, 1973; Groves, 1971; Montanucci, 1965, 1967; Burt, 1923; Dodge, 1938; Mayhew, 1963c; C. Johnson, 1965; Shaw, 1950). No herbivorous lizard is known to exhibit cannabalism in nature; but Alvarez dol Toro (1972) reports 
that Ctenosaura similis in captivity will eat "young iguanas" (species not given). However, a hatchling $\underline{c}$. carinata was found in the stomach of a conspecific adult female $(203 \mathrm{~mm}$ SV) collected near the Ridge Area on Pine Cay on 2 January 1974.

In addition one natural observation of a possible cannabilism was made. On 3 September 1974, while walking along a trail near the SW Blind, I flushed a hatchling Cyclura from a low perch near the trail's edge. He ran directly away from me into the bush, and directly toward an adult male which he had apparently not seen. As the hatchling ran to within $1.5 \mathrm{~m}$ of the male, the adult charged and snatched the hatchling up in his mouth by its entire left foreleg. As the hatchling flailed in an attempt to escape, the male vigorously shook it. I stooped to get a better view, and frightened the adult, which ran off out of sight with the hatchling dangling in his mouth. It is most likely that the young lizard was ingested.

\section{Epidermophagy}

Shed skin is commonly found in the gastrointestinal tracts and/or feces of Cyclura carinata. Murphy (1969) observed Cyclura cychlura in captivity to pull shedding skin from other iguanines and feed on it. Unfortunately, ingestion of skin in neither wild nor captive $\underline{c}$. carinata was observed. Of 54 adult iguanas dissected, 12 had skin fragments in their guts. Wine of these were females and three were young males (222-289 mas SV). A shed male dorsal spine was found in the large intestine of amother female. These observations suggest that ferales groom dead skin from nales. Eighty percent of all records of skin in guts or feces fell between 5 March and 13 August. 
The adaptive significance of epidermophagy in reptiles is unknown; Bustard and Maderson (1965) reviewed the subject and speculated that, as in birds and mammals (Rawles, 1969; Mercer, 1961), the ingested skin represents an alternative source of Vitamin $D$.

\section{Carrion Feeding}

Cyclura carinata do not hesitate to feed on carrion when it is encountered. They are, in fact, attracted to carcasses by olfactory cues. I have observed iguanas locate and feed on the decaying soft parts of hermit crabs. On several occasions birds shot for diet analysis and not immediately retrieved were found by foraging iguanas. In every case, the lizard immediately began feeding on the carcass. (See example under Social Feeding.) Fish carrion was found in the stomach of one iguana. Several-day-old canned sardines were consumed as readily as fresh ones at the SW Blind.

Among iguanines, carrion feeding has been reported for Iguana iguana (Loftin and Tyson, 1965) and Dipsosaurus dorsalis (Norris, 1953). I suspect necrophagy is more common among iguanine lizards than the literature suggests.

\section{Comparisons With Other Iguanines}

An extensive literature, supolemented by dissections of previously unstudied forms, indicates that all 30 species of the subfamily iguaninae are primarily harbivorous throughout their lives. Some iguanid and agamid species are believed to exhibit an ontogenetic change from camivory to herbivory (Pope, 1969; Mertens, 1960; Carey, 1975: Fleet and Fitch, 197! ; Fitch and Henderson, Ms.; and review in Pough, 1973), 
but this definitely is not the case in Cyclura carinata. Unfortunately, captive and anecdotal natural observations form the basis for suggesting this strategy for other iguanine species (Iguana iguana, Amblyrhynchus cristatus, and most species of cyclura). Further study is necessary to determine if the juveniles of other iguanines for any other herbivorous lizards) ingest animal matter opportunistically or intentionally. Table 22 reviews the literature on diet within the genus Cyclura. Fruits of such widespread forms as Coccoloba, Erithal is, and Opuntia are probably eaten by iguanas wherever they co-occur. Auffenberg (in preparation) compares breadth of the food niche with respect to floral diversity within the genus Cyclura.

\section{Feeding Behavior}

\section{General Comments}

Cyclura carinata will feed anywhere within their home ranges (see ACTIVITY AND MOVEMENTS), but males feed within their defended territories more oftei than outside them (see SOCIAL ORGANIZATION). Feeding activity is bimodal during the warmer months (because of high midday environmental temperatures) and unimodal during those colder. Lizards generally make one to several feeding forays away from their burrows each day. During the winter only one foray is usually possible. Weather permitting, iguanas will feed every day of the year (see ACTIVITY AND MOVEMENTS).

Hatchling lizards begin feeding soon after emergence from the nest. Six of seven neonates collected on 18 September 1973, contained food both in the stomach and intestines. Others collected 30 August 1974 (4); 31 August 1974 (2); and 5 September and 8 September 1975 (1 each) either 


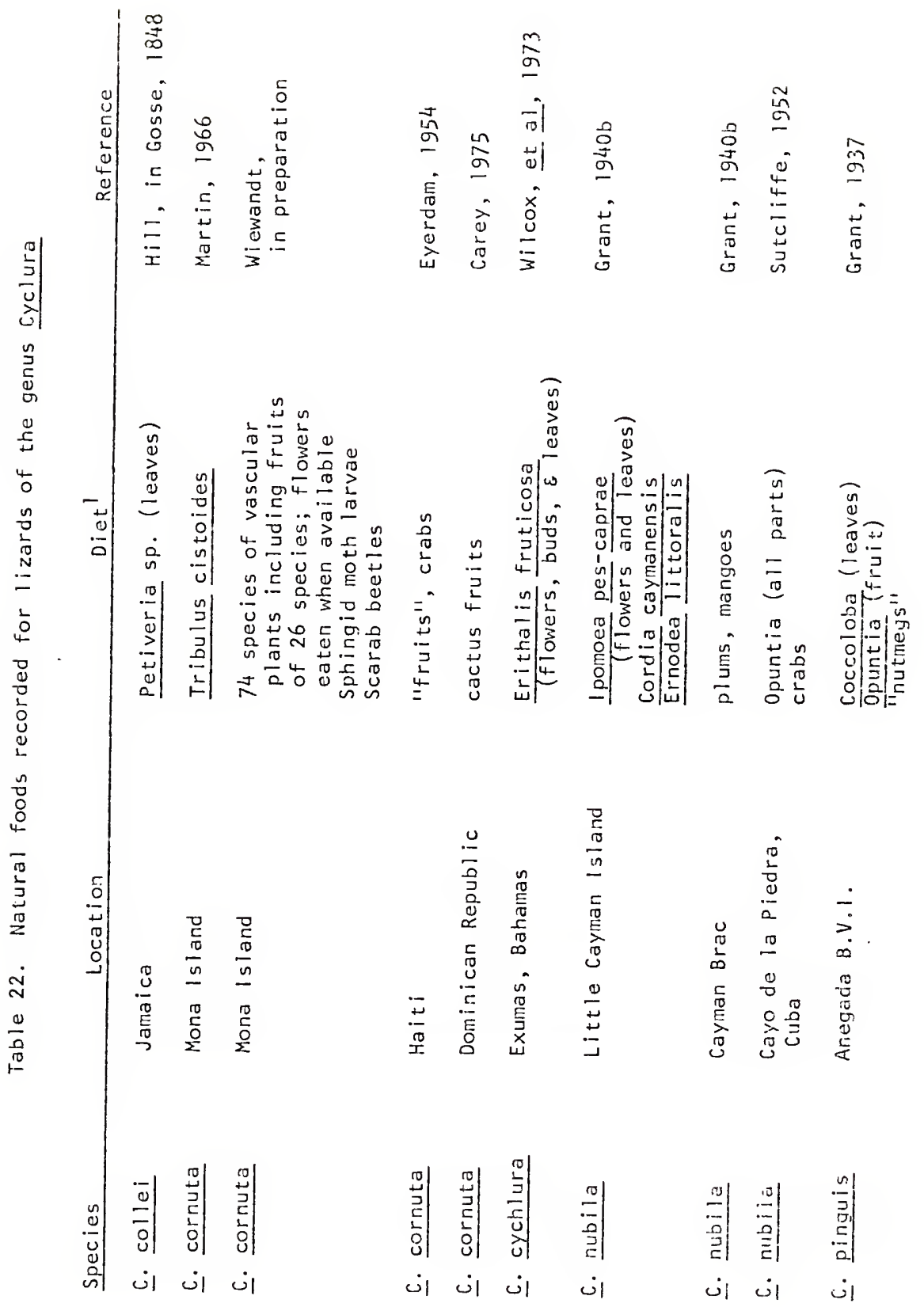




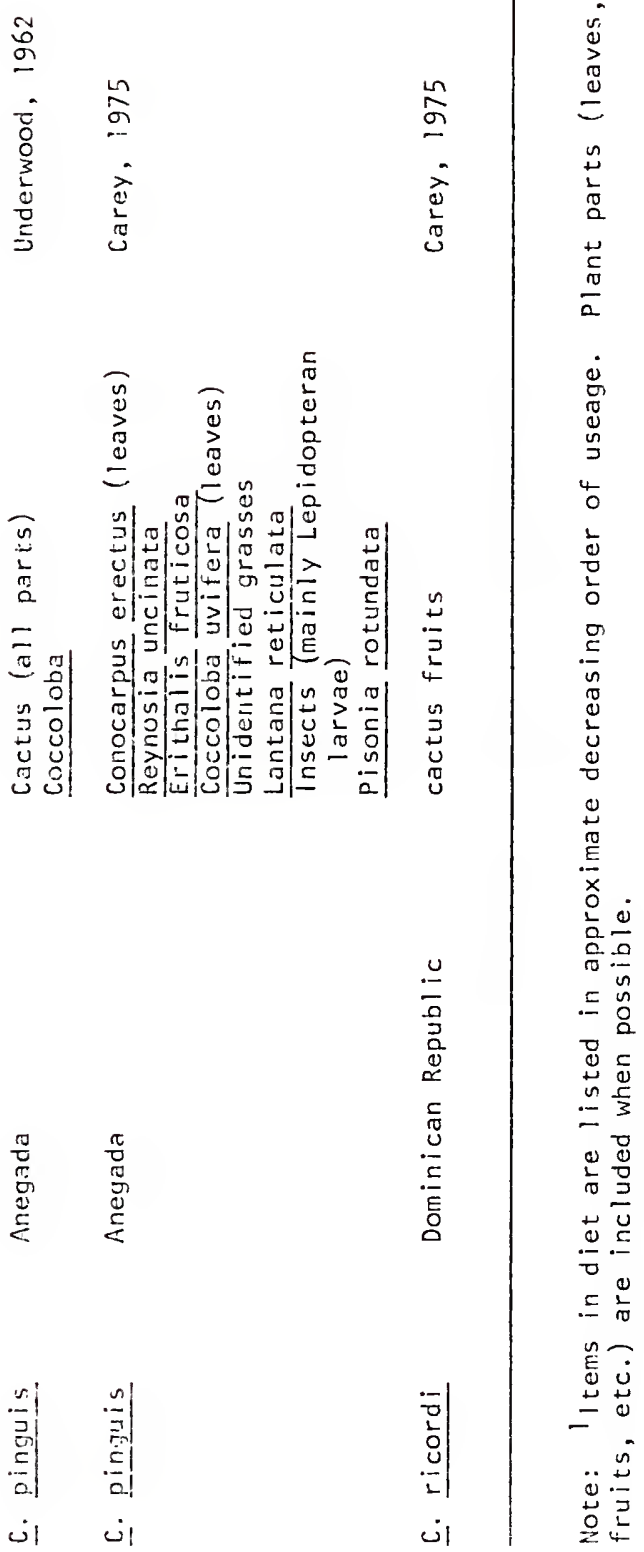


lacked food in the gut or produced no scats following capture. These were the only lizards of all those examined that lacked digesta in the gastrointestinal tract.

As in Iguana (Rand, 1967) and Dipsosaurus (Norris, 1953), feeding may also be reduced in female cyclura carinata carrying eggs. The entire gastrointestinal tract of a gravid female dissected 3 June contained only small bits of unidentifiable trash. However, the only other gravid female dissected ( 9 June) contained an almost normal load of digesta throughout its gut. Whether or not it is reduced, normal feeding is apparently resumed immediately afier the eggs are laid. A female which nested alongside the SW Blind during the morning of 6 June 1974, climbed into the nearest Conocarpus and began eating leaves immediately after her first emergence, shortly following oviposition. It is not known how much nest covering was accomplished within the burrow before she emerged. She fed for approximately 18 minutes (until 1208 hours) and retired to the shade to rest for the next four hours and 12 minutes. She then resumed the nest-covering process (see REPRODUCTION) for an additional 22 minutes before she again moved to an area of partial shade to rest for the remainder of the day.

Cyclura carinata is surprisingly macrosmatic. Observations indicate that lizards are able to accurately orient toward an odoriferous food source without visual cues as to its location. Lizards frequently noved directly to a can of sardines obscured from view by leaves fron distances exceeding $20 \mathrm{~m}$. A few iguanas moved to the bait from $50 \mathrm{~m}$. This ability allows the lizards to tahe advantage of rich, temporal food sources such as fruiting trees, even if they lie outside the normal home range of the lizard. 
When foraging, Cyclura carinata apparently supplements narial reception of olfactory stimuli by frequently tonguing the substrate. Norris (1953) and Carey (1975) observed similar behavior in Dipsosaurus dorsalis and cyclura pinguis, respectively. The relative importance of taste versus smell was not investigated.

Auditory stimuli can also be very important in initiating feeding responses in Cyclura, providing that the sounds simulate the fall of a fruit. Lizards were observed to abruptly run to the site of a freshly fallen fruit of the seven year apple (Casasia clusiaefolia) based only on an auditory cue. Since the fruits of this species are edible by iguanas only for a short period before and after being dropped, the ability to utilize such cues is important if the resource is to be used. Fruits, stones, a wad of paper--essentially any small object--can be used to invoke this response simply by throwing them such that they fall through the canopy to the substrate within the audible range of the lizard. The immediate response is an investigative charge to the site of the sound's origin.

\section{Arboreal Feeding}

Cyclura carinata are extremely capable arboreal feeders. Lizards were frequently observed cropping fruits or flowers as they walked across the tops of bushes or trees at heights up to five meters. Their climbing texterity and integrative learning is exemplified by several lizards observed to depart from trees simply by moving distally along a branch until their (the lizards') weight caused the branch to bend down to the ground. The lizard could then step or drop deftly to the ground, allowing the branch to swing upward to its normal position. If 
disturbed while above ground, however, they typically jump to the ground and flee. Lizards leaped, apparently unharmed, from heights up to five meters when 1 disturbed them. Seasonal and daily variation in arboreal activity (including feeding) is discussed under ACTIVITY AND MOVEMENTS.

It is my subjective opinion that arboreality in Cyclura carinata is inversely related to wind speed. Considerably fewer lizards were observed in trees during period of high winds. Unfortunately, objective data were impossible to obtain due to the complicated relationship of arboreality to all aspects of the weather (not simply wind), time of day, and season of year. The decreased ability to hear lizards during such periods of increased background noise is in part responsible for these observations.

Jackson (1974) observed lizards of the genus Sceloporus using periods of high sensory complexity (such as wind gusts) to shift perch sites. This behavior was not evident in Cyclura. In fact, the noise created by strong gusts of wind often elicited a fright response (running away).

Among other iguanines, Brachylophus fasciatus (Cahi11, 1970; Cogger, 1974), Conolophus pallidus (dVries, 1974), Ctenosaura pectinata (Alvarez del Toro, 1972), Ctenosaura similis (Tamsitt and Valdivieso, 1963; Alvarez del Toro, 1972), Cyclura collei (Gosse, 1848; Lewis, 1944), Cyclura cornuta (Thomas Wiewandt and Peter Meylan, pers. comm.), Cyclura cychlura (Wilcox et al., 1973), Cyclura nubila (Lewis, 1944; Buide, 1951; Cooper, 1958), Cyclura ricordi (Diderot Gicca and Thomas Viewandt, pers. comm.), Cyclura rileyi (Stejneger, 1903; Paulson, 1966), Dipsosaurus 
dorsalis (Cowles, 1946), Iguana iguana (Rand and Humphrey, 1968; Alvarez del Toro, 1972; Henderson, 1974), Sauromalus hispidus and $\underline{\text { S. varius }}$ (Norris and Dawson, 1964), s. obesus (Shaw, 1945; Johnson, 1965; Berry, 1974; Prieto and Sorenson, 1975a) and even Amblyrhynchus cristatus (deVries, 1974) are all known to $\mathrm{climb}$ into bushes, trees, and/or cactus thickets, presumably to feed. Iguanine lizards probably exhibit arboreality wherever the vegetation permits it.

\section{Habitual Use of Feeding Sites}

Upon locating a particularly attractive food source, Cyclura carinata will frequent the site up to several times a day and for several days. This was particularly the case when trees began fruiting. Two iguanas (always a male and a female) often both habitually fed at such sites. The energetic benefit of not having to continually search for new food sources, perhaps even of lower quality, bespeaks the adaptive advantage of this behavior.

In several cases the attractiveness of an habitually used food source was not apparent to me. I often observed lizards at the SW Blind to climb completely through a tree to reach a particular branch on which to feed. The site would be utilized until no leaves (or fruit) remained. The entire tree would then be abandoned as a food source. What distinguished those particular portions of the tree remains a mystery. Perhaps the quality of the food source is not as important as the certainty on the part of the lizard that it is not a toxic one (see discussion of toxicity versus seed predators in Janzen, 1971, and Freeland and Janzen, 1974).

Iguanas often frequented a food source until branches or even whole bushes were completely defoliated; small trees and bushes were even killed 
as a result of this heavy foraging. Considerable information on food species was accumulated by investigating these sites.

\section{Social Feeding}

The possibility that social interactions can influence feeding behavior in lizards has only recently come under scrutiny. Greenberg (1976) recognized three basic types of interactions related to feeding: 1) social facilitation, 2) food-stealing, and 3) social learning. Behavior classifiable under the first category was frequently observed in Anolis and Leiocephalus on Pine Cay, but not in Cyclura. However, the common occurrence of more than one iguana feeding simultaneously in the same tree suggests the possibility of facilitation in Cyclura carinata.

Food-stealing behavior was noted several times in the field, but in each case the circumstances were not entirely natural. This behavior could sometimes be induced by throwing a food item in the vicinity of more than one lizard. The following observation (abbreviated and paraphrased from my fieldnotes) best illustrates this behavior.

The brief fluttering of a ground dove shot with an air pistol for diet analysis attracted the attention of two resident males at the S: Blind, on August 2,1975 . The bird had not only fallen to a point nearly equidistant from each lizard, but also almost exactly in the middle of the zone of overlap of their respective home ranges. As Male $" 2$ looked on, Male $\# 8$ moved to the carcass immediately and dragged it three meters in the direction of his territory (into the shade). He immediately began feeding on the bird, consuming several mouthfuls of feathers. He finally removed the bird's head and as he was manipulating it for swallowing, the remainder of the bird's body was temporarily ignored. At this time Male \#2 bolted from his position five meters away (in the direction of its territory), grabbed the carcass in his mouth, and headed back toward his territory with \#8 hotly pursuing him. Apparently afraid $\# 8$ would overtake him due to his burden, $\# 2$ dropped 
the bird's body in a sunny area near where it had originally fluttered. Number 8 immediately stopped short of the carcass, and $\# 2$ moved only 2.5 meters farther before turning to posture laterally. Number 8 , seeing $\mathbb{\# 2}$ terminate his retreat and posture, then retreated to a point approximately 2.5 meters from the carcass and also postured. A.fter approximately 1 minute, $\# 8$ abruptly ran at the bird in an attempt to grab it and flee. However, a lunge by $\# 2$ prompted $\# 8$ to again retreat without the bird. Immediately $\# 2$ charged for the bird, \#8 lunged at him, and $\# 2$ again retreated without his dinner. Both lizards then maintained their postured positions on either side of the carcass for nearly 90 seconds, when \#2, apparently disinterested, slowly moved off. Once \#2 was out of sight, \#8 resumed feeding on the carcass.

Although food stealing was never observed under completely unaltered natural conditions in Cyclura carinata, the ease with which it was induced suggests it is a naturally occurring phenomenon.

Behavior suggesting social learning (or imitation) in Cyclura carinata was not observed. Early in the study it was hypothesized that hatchling iguanas might learn arboreal behavior from conspecifics, however newly emergent hatchlings were observed to $\mathrm{climb}$ extensively in bushes and trees long before they actually began feeding. Social learning seems to be of little importance in at least this behavior. Its role in other behaviors, especially the establishment and maintenance of a defended area, deserves further study.

Food related social behavior in lizards is unfortunately much more frequently observed than recorded. It is hoped that Greenberg's (1976) paper will provide the impetus for documentation of social feeding and its evolutionary implications to natural lizard populations.

\section{Defecation}

Defecation characteristically occurs during morning hours following emergence and basking. Most defecations occurring at other times of 
the day also occurred following a basking period (see ACTIVITY AND MOVEMENTS). Presumably the body temperatures near the maximum preferred temperature range facilitate elimination of wastes. Since defecation typically follows the morning basking period the distribution of scats is not randon. Feces are more abundant in the area of a lizard's preferred basking sites.

Defecating posture is typical of iguanid lizards (Greenberg, 1973; Carpenter, 1966); the body is elevated above the substrate by hind 1 imb extension and the proximal portion of the tail is arched sharply upward and the distal portion arched downward to the substrate. A single fecal pellet is typically egested, but sometimes two are eliminated. Whether these discrete pellets represent different feeding periods is unknown.

Fecal analysis has frequently been used to determine diet in mammals (e.g., Ward, 1970; Free et al., 1970; and Steward and Stewart, 1970) and birds (e.g., Korschgen, 1962). Among reptiles, scat analysis has chiefly been used in food studies of herbivorous tortoises (see bibliography in Douglass, 1975; and Hansen et al., 1976), carnivorous snakes (Fitch, 1960, 1963; Platt, 1969; among others), and insectivorous lizards (Hall, 1972; Fitch, 1954, 1956; among others). Except for Hansen's (1974) analysis for Sauromalus, scats have not generally been utilized for food studies of herbivorous lizards (Carey, 1975). This is certainly a result of the potential unreliability of fecal analysis due to a lack of representation of the softer food items in the diet. However, many of the above listed studies have shown scatological analysis to be nearly as reliable as stomach analysis at least for tabulation of food species and information on frequency of occurrence. Despite the 
disadvantages of relying on fecal examination to represent an animal's actual diet, the advantage of not having to sacrifice study animals remains. This is not only very important when studying a ratural population, but it becomes more important as populations continue to decline to sizes potentially critical to their survival. Other than direct feeding observations, scatological analysis is the only feasible approach to the diet of herbivores facing extinction. The feces of Cyclura carinata are typical of the scats reported for other lizards, except in their larger size. The compacted oblong fecal pellets may occasionally exceed $75 \mathrm{~mm}$ in length and $20 \mathrm{~mm}$ in diameter for large males. After deposition, the pellets dry out rapidly and, depending on the amount of rainfall, can resist decomposition for months. Thus, great stores of dietary information are available to the student without risk of damaging natural populations.

\section{Nasal Secretions}

Cyclura carinata frequently expels fluids from the nostrils in a sneezing manner similar to that described for Amblyrhynchus cristatus by Schmidt-Nielsen and Fange (1958), Brachylophus fasciatus by Cogger (1974), Dipsosaurus dorsalis by Norris and Dawson (1964), Cyclura cychlura by James B. Murphy (pers. comm.) and Cyclura pinguis by Carey (1975). Although no analysis of the expellent was made, it is presumably a secretion of the nasal salt gland functioning as an accessory kidney, nainly for potassium excretion as in several other iguanine lizards: Ctenosaura pectinata, Dipsosaurus dorsal is, Iguana iguana, Sauromalus hispidus, S. obesus, and $\underline{S}$. varius (Schnidt-Nielsen 
and Fange, 1958; Schmidt-Nielsen et al., 1963; Templeton, 1964, 1967; Norris and Dawson, 1964). High concentrations of salt ions (notably potassium) in the diet of these herbivorous lizards (including cyclura) and the general unavalability of free water in their respective habitats make extrarenal salt secretion necessary for survival in physiologically xeric habitats. Cyclura carinata were never observed to drink fresh water (from lakes or rain pools) in nature, but they frequently did in the outdoor observation enclosure in Gainesville. No physiological explanation for this behavior is offered.

Seed predator or disperser? The importance of Cyclura carinata as a seed predator and/or seed disperser is unknown. Aspects of this problem are under investigation by Walter Auffenberg. I have on numerous occasions failed to completely dry fecal samples before packaging them and have found, on laboratory examination several days later, that seeds had germinated. My subjective impression is that the seeds of Coccoloba were the most frequent germinators. Whether traversing an iguana's digestive tract increases or reduces seed viability in Coccoloba or in any other species awaits testing. Without study, it should never be flatly assumed that seeds from a particular species are so adapted to seed predation that their fitness is ultimately increased (Janzen, 1976). The actual effects of seed eating by Cyclura on the survival rates of plant species cannot be known until increases or decreases in fitness for seeds passing through the vertebrate digestive tract are determined and then related to the advantages of dispersal. It must also be remenbered that dispersal, even of eaten seeds with considerably reduced germination success, can still be advantageous to 
that species' survival (see Janzen, 1971). Further discussion of herbivory as an adaptive strategy in Cyclura appears in Auffenberg (in preparation).

\section{Gastrointestinal Tract Anatomy}

Figure 38 illustrates a ventral view of the anatomy of the intact gastrointestinal tract of cyclura carinata. The iguana tract is for the most part one of typical vertebrate plan, with a tubular stomach, a "small" intestine, and a wider "large" intestine (or colon). A colic caecum is also typically present. As in all reptiles, a cloaca is also present distal to the colon.

In four adult Cyclura, the stomach comprised about $18.5 \%(17.0$ to 19.4 ) of the gastrointestinal tract length, the small intestine $48.5 \%$ $(45.3$ to 54$)$, and the large intestine $33.1 \%(29.0$ to 35.9$)$. The absolute length of the small intestine ranges from one to $11 / 2$ times the body length, compared to 7 or 8 times body length (or higher) in birds and mammals (Romer, 1962: 357).

Three adult Crotaphytus collaris dissected for comparison had stomachs 19.0 to $26.7 \%(\bar{X}=24.0)$ of gastrointestinal tract length; small intestines 42.8 to $47.4 \%(\bar{X}=44.5)$; and colons 26.3 to $38.2 \%$ $(\bar{x}=31.5)$. The small intestine of the Crotaphytus averaged slightly longer than body length as in Cyclura carinata. Surprisingly there is no significant difference in gut segment lengths between the carnivorous Crotaphytus and the herbivorous Cyclura.

The only significant deviation from the generalized reptilian alimentary canal plan in Cyclura carinata involves an elaboration of 


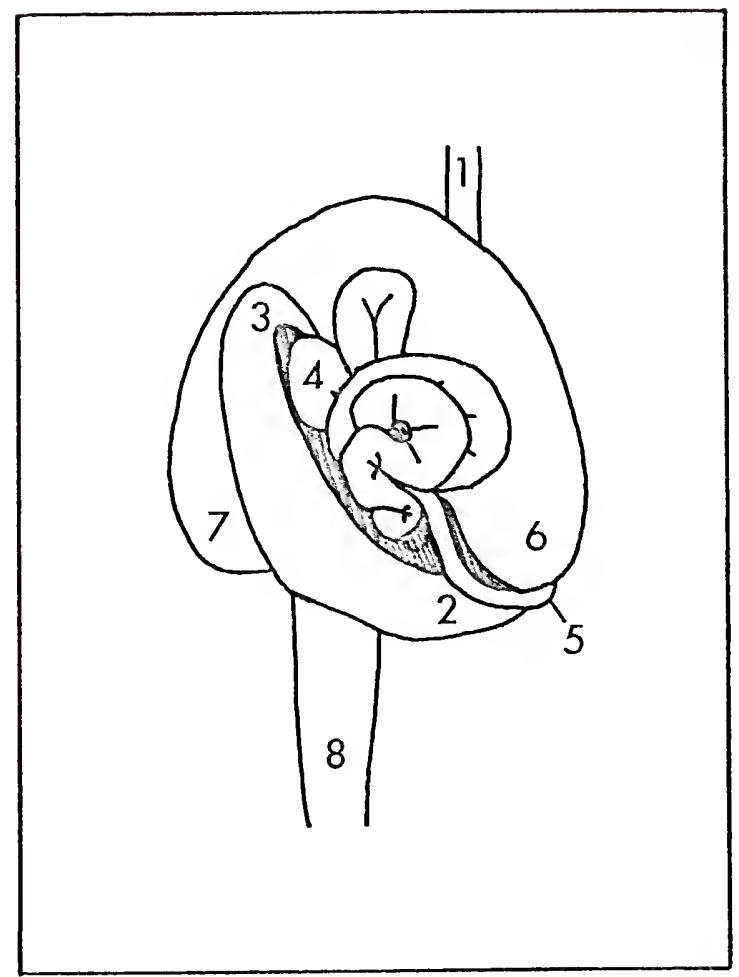

Figure 38. Ventral view of gastrointestinal tract of Cyclura carinata. Numbered organs include: 1) esophagus, 2) $\frac{\text { cardiac }}{\text { cagion }}$ region of stomach, 3) pyloric region of stomach, 4) proximal, and 5) distal ends of small intestine, 6) proximal, 7) medial, and 8) distal ends of colon. 
of the proximal portion of the colon which has resulted in a relative increase in its internal surface to volume ratio.

Approximately the distal half of the colon is expanded to form a large pouch obstructed regularly along its length by five partial septa (the "values" of Loennberg, 1902; the "valvulae" of Beattie, 1926) (Figure 39). By precise definition (a blind outpocketing or cavity open at only one end), only the most proximal diverticulum of the colon (adjacent to the illeocolic valve; see Figure 41 ) should properly be called a caecum. However, if loosely defined as the pouch which is the beginning of the large intestine, the term could be applied to the entire partitioned proximal portion of the colon. In order to avoid confusion in using the term caecum, quotation marks will be used whenever it is used in the latter context; the restricted definition applies if quotation marks are lacking.

The structure of the proximal colon in Cyclura carinata is diagrammed in Figure 39. It averages $18.3 \%$ (16 to 19.8) of the gastrointestinal tract length, more than $1 / 2$ of the entire length of the large intestine. However, its usual volume exceeds $40 \%$ of the entire tract including stomach, small, and large intestines. In Crotaphytus collaris this percentage is significantly reduced to approximately $30 \%$. Figure 40 illustrates the relationship of "caecal" volume to lizard body size in Cyclura carinata.

Five septa are always present, even in the "caecae" of hatchling lizards. The septal area decreases from the anteriormost to the posteriormost. The septa themselves are double walled and are actually simple infoldings of the medial colon wall. This modification is an effective means of increasing internal surface area without increasing the volume. 


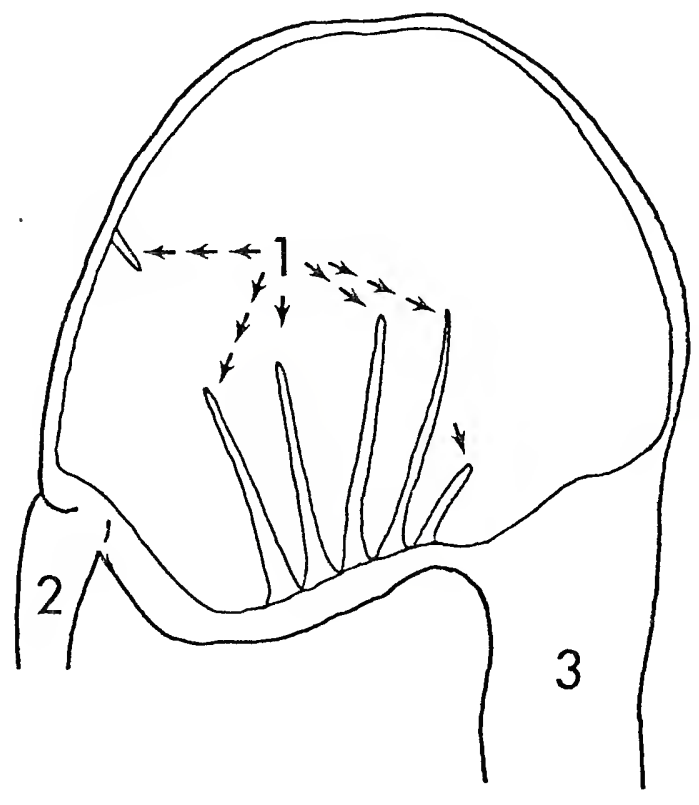

Figure 39. Frontal section of proximal colon ("caecum") of Cyclura carinata (dorsal view) indicating location of septa (1) in relation to distal portions of small intestine (2) and colon (3). 


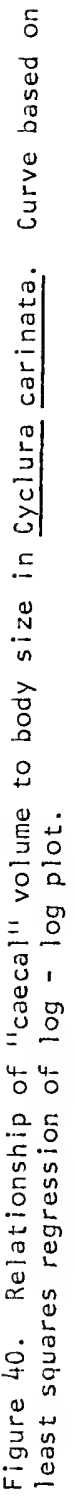




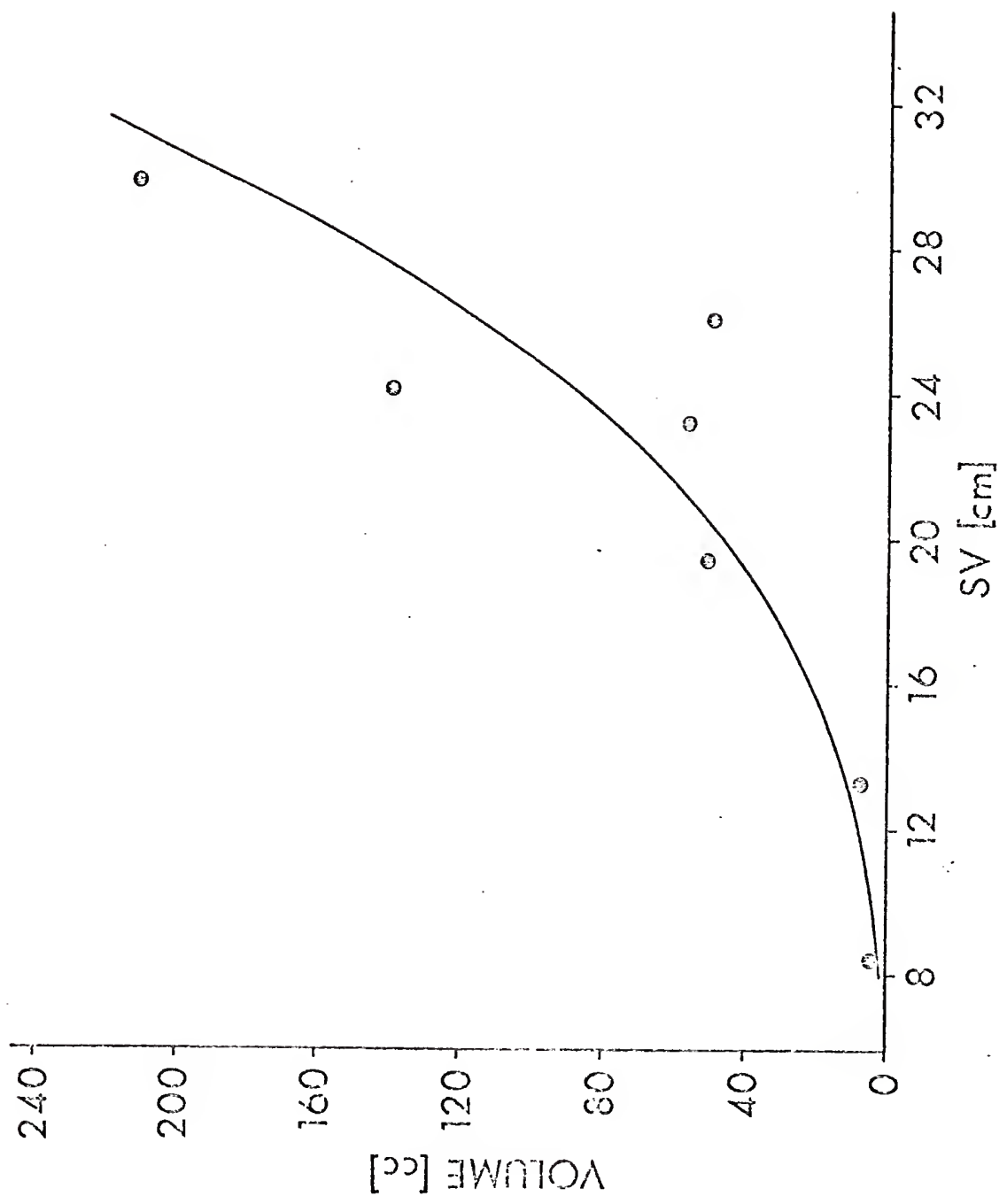


This colic partitioning was not found in several species of carnivorous iguanid lizards I dissected (including Crotaphytus collaris, Leiocephalus carinatus, Sceloporus horridus, Stenocercus empetrus) nor in five other species examined by Loennberg (1902); their colons were unmodified smooth tubular organs. However, all lizards of the subfamily iguaninae examined (except Amblyrhynchus; see below) exhibit "caecal" modification similar to that found in Cyclura carinata; each features at least one septum formed by an unfolding of the colon wall. The number of septa shows interspecific variability but relative constancy seems to prevail within species (Table 23). Sokol's (1967) failure to note this modification in Dipsosaurus, Iguana, or Sauromalus (two species) while looking for gut structures commonly associated with the culture of cellulytic gut symbionts is unexplainable. In several of the iguanine species the septum nearest the ileocolic valve is so well developed as to nearly occlude the colon. A comprehensive anatomical study of the gastrointestinal tracts of lizards, with analytical comparisons between carnivorous and herbivorous species, is warranted in the light of the above findings. Basic functional aspects of digestion in the hindgut also receive at least the attention in lizards that they have received in birds (see review in Gasaway et al., 1976). A better understanding of the evolution of the bertebrate alimeniary tract would surely result. In the absence of such a study, a hypothetical evolutionary sequence deriving the elaborated iguanine "caecum" from the unfolded colon of some carnivorous ancester appears in Figure 41. The colon of Amblyrhynchus is relatively primitive among iguanines and falls between stages two and three in the hypothetical sequence; the proximal colon exhibits only numerour medial transverse folds (Loennberg, 1902). 
Table 23. Variation in number of septa in the proximal portion of the colon in iguanine lizards.

\begin{tabular}{|c|c|c|c|}
\hline Species & Location & $\begin{array}{l}\text { Sample } \\
\text { Size } \\
\end{array}$ & $\begin{array}{l}\text { \# of } \\
\text { Septa }\end{array}$ \\
\hline$\frac{\text { Brachylophus }}{\text { fasciacus }}$ & $-\infty$ & 1 & $4^{a}$ \\
\hline Ctenosaura acanthura & -- & 1 & $4^{a}$ \\
\hline$\frac{\text { Conolophus }}{\text { subcristatus }}$ & Galapagos Islands & 1 & $5^{a}$ \\
\hline Ctenosaura bakeri & $\begin{array}{l}\text { Isla de Bahias, } \\
\text { Honduras }\end{array}$ & 3 & $4(67 \%), 3$ \\
\hline Ctenosaura hemilopha & Sonora \& Sinaloa, Mexico & 2 & 2 \\
\hline Ctenosaura pectinata & Tamaulipas, Mexico & 1 & 3 \\
\hline Ctenosaura pectinata & Campeche, Mexico & 1 & 4 \\
\hline Cyclura carinata & Turks and Caicos Islands & $15+$ & 5 \\
\hline Cyclura cornuta & Dominican Republic & 1 & 9 \\
\hline Cyclura cychlura & Andros & 3 & $7(67 \%), 8$ \\
\hline Cyclura ricordi & Dominican Republic & 1 & 6 \\
\hline Dipsosaurus dorsalis & Arizona & 2 & 2 \\
\hline Enyaliosaurus clarki & Michoacan, Mexico & 7 & $2(71 \%), 1$ \\
\hline$\frac{\text { Enyal iosaurus }}{\text { quinquecarinatus }}$ & 0axaca, Mexico & 4 & 2 \\
\hline Iguana iguana & Veracruz, Mexico & 3 & 6 \\
\hline Iguana iguana & -- & 1 & $5^{a}$ \\
\hline Sauromalus obesus & California \& Arizona & 3 & 2 \\
\hline
\end{tabular}

Note: adata from Loennberg (1902) 


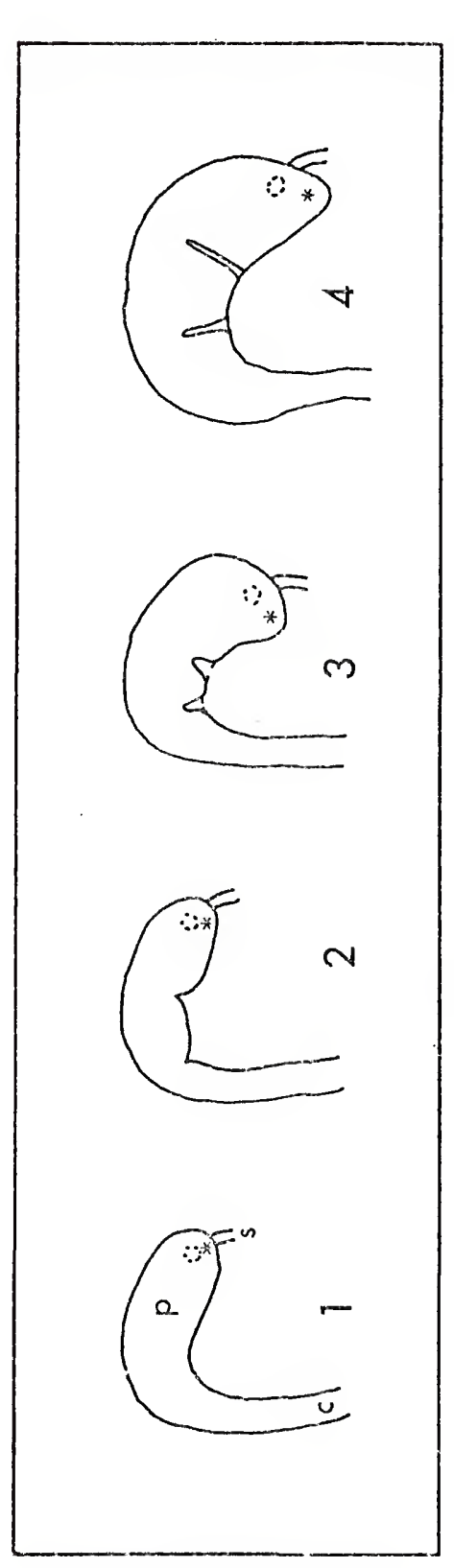

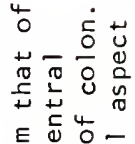

단원

- is 으 흥

于 4

ज立

등⿺ㄴ

$0 \tilde{u} \frac{0}{0}$

迹 $\frac{\pi}{\pi}-$

. 퓨

등

.

-

은 는

$4 \div$ 응

눙 -

-

눈 응

드른

D的。

즌듀웜

文.

五合

®一

둥웡

可芯䏠

is 0 (1)

$>\underset{T}{\mathrm{C}}$

文西.

등

-

긍면

$8 n 4$

1) 등

б

Uำ

푼

凹

苛兵元응

空.

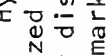

. ㄱ 3

$\exists \frac{0}{2} \frac{n}{n} \frac{x}{n}$

1) 㐫

文完管㐫

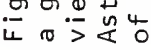




\section{Digestive Efficiency}

Although this aspect of feeding was not investigated, certain observations relative to previous work are pertinent. Digestive efficiencies (relating ingested and egested caloric content) of carnivorous lizards are known to vary from about 70 to $90 \%$ (Table 24 ). Herbivorous lizards have as yet been poorly studied. Szarski (1962) suggested that perhaps only a small amount of the energy potentially available in the food is utilized by herbivorous lizards. Throckmorton (1973) has reported digestive efficiencies similar to those of carnivorous lizards from Ctenosaura pectinata fed sweet potato tubers. However, Minnich (1970) and Harlow et al., (1976) found lower digestive efficiencies for Dipsosaurus dorsalis fed natural diets (mainly leaves) and force fed commercial rabbit food, respectively.

Cyclura carinata (for that matter, most herbivorous lizards) probably do not have such an easily digestable food source as sweet potato tubers readily available in nature. Like Dipsosaurus, many of these herbivores must rely for at least parts of the year on a diet of leaves which are fibrous and difficult to digest. Although Rand (Ms) believes Iguana iguana is an efficient folivore, ingested leaves often pass through the entire gastrointestinal tract of cyclura carinata intact. This is perhaps related to the more xerophytic nature of the vegetation in the areas inhabited by cyclura as well as the more modified "caecum" of Iguana.

In any case, I support Szarski (1962) in my belief that digestive efficiencies in at least the herbivore Cyclura carinata (in natura) popuiations) are probably lower than those of carnivorous lizards. The 
Table 24. Apparent Digestibility Coefficients (ADC) of lizards, where $A D C=$ (calcries consumed - calories of fecal waste) $\times(100) /$ calories consumed.

Species $\operatorname{ADC}($ in $\%)$ Food Source

Anolis carolinensis

54.4

88.9

69.5

Tenebrio adults Tenebrio larvae

Licht \& Jones,

\begin{tabular}{|c|c|c|c|}
\hline Anolis carolinensis & $69.9-72.2$ & Tenebrio larvae & $\begin{array}{l}\text { Kitchell \& } \\
\text { Windell, } 1972\end{array}$ \\
\hline$\frac{\text { Sceloporus grasiosus }}{\text { and S. Occidentalis }}$ & 83 & Tenebrio larvae & Mueller, 1970 \\
\hline $\begin{array}{l}\text { Crotaphytus wislizeni } \\
\frac{\text { Comidophorus }}{\text { Dta stansburiana }} \\
\text { Utaris }\end{array}$ & $\begin{array}{c}77.8-78 \\
79.8 \\
83.5-85.8\end{array}$ & natural diets & $\begin{array}{l}\text { Essghaier } \varepsilon \\
\text { Johnson, } 1975\end{array}$ \\
\hline Lacerta vivipara & $\begin{array}{l}89 \\
(84-91)\end{array}$ & Tenebrio larvae & Avery, 1971 \\
\hline Ctenosaura pectinata & $\begin{array}{c}86.3 \\
(77.8-94.0)\end{array}$ & $\begin{array}{l}\text { Sweet potato } \\
\text { tubers } \\
\text { (Ipomoea) }\end{array}$ & $\begin{array}{l}\text { Throckmorton, } \\
1971,1973\end{array}$ \\
\hline Sceloporus ol ivaceus & 83.5 & crickets & $\begin{array}{l}\text { Dutton, et al, } \\
1975\end{array}$ \\
\hline Diposaurus dorsalis & $30-70^{a}$ & natural diets & $\begin{array}{l}\text { Minnich, } 1970 \\
\text { Porter, et al, } \\
1973\end{array}$ \\
\hline Diposaurus dorsalis & $\begin{array}{l}54.3 @ 33^{\circ} \mathrm{C} \\
62.8 @ 37^{\circ} \mathrm{C} \\
69.5 @ 41^{\circ} \mathrm{C}\end{array}$ & $\begin{array}{l}\text { commercial } \\
\text { rabbit food }\end{array}$ & $\begin{array}{l}\text { Harlow, et al, } \\
1976\end{array}$ \\
\hline
\end{tabular}

Note: a method of calculation of digestive efficiency was not indicated 
results of Minnich (1970) and Harlow et al. (1976) seem to verify this hypothesis. It is hoped this easily tested paradox will soon be satisfactorily rectified by further investigation.

Another aspect of digestive efficiency which has received almost no attention is whether the massive "caecal" nematode faunas found in at least all iguanines contribute to the efficiency of cellulose digestion or have some other as yet unsuggested effects (favorable or deleterious). If nematode faunas are advantageous, the "caecal" modification seen in iguanines would not only be adaptive in increasing relative absorptive surface area, but also in providing pockets in which those faunas can proliferate. Nematodes residing in these colic microhabitats are not as subject to egestion due to the peristaltic flow of digesta, as would be the case in the unmodified colon. Whether large nematode faunas evolved with, or in response to, colic modification in iguanine lizards remains unanswered. I believe that worm burdens in virtually all Cyclura carinata are too great for their effects to be detrimental and suspect a beneficial effect (see INTERSPECIFIC COACTIONS). The role of the intestinal microflora and fauna in lizard digestion is completely unknown. Microbial fermentation products may be important to nutrition in herbivorous 1 izards as they are to herbivorous birds and mammals (see review in McBee, 1971 ).

\section{Fat Bodies}

Abdominal fat storage is typical not only of all temperate reptiles but also occurs in at least those tropical species inhabiting seasonally fluctuating environments. Some tropical forms from areas lacking seasonality (physical or biotic) do store fat in abdominal vesicles 
(Berry and Lim, 1967; Smith, 1968), while other species apparently do not (Church, 1962). Many studies have been conducted on lipid deposition and utilization in reptiles, most of which have suggested that deposition is negatively correlated with gonadal activity (Rollinat, 1934; Miller, 1954; Darevsky, 1957; Saint Girons, 1957; Barwick, 1959; Dessauer and Fox, 1959; Tinkle, 1962; Hahn and Tinkle, 1965; Smith, 1968; Hoddenbach, 1966; Telford, 1970; Aleksiuk and Stewart, 1971; Mayhew, 1971; Minnich, 1971; Sexton et al., 1971; Goldberg, 1972; and Jameson, 1974). However, a few studies have commented on the mobilization of lipids for maintenance metabolism, especially during hibernation (Dessauer, 1955; Mueller, 1969; Telford, 1970). Stored lipids (particularly those in abdominal vesicles) are probably mobilized to some extent both for reproduction and maintenance (notably during hibernation), as in scleroporus graciosus (Derickson, 1974), Cnemidophorus tigris (Gaffney and Fitzpatrick, 1973), and Takydromus tachydromoides (Telford, 1969). Such seems to be the case in Cyclura carinata, which does not hibernate, but nevertheless must considerably reduce its winter activity due to decreased temperatures (see ACTIVITY AND MOVEMENTS).

Abdominal fat body size shows a bimodal seasonal fluctuation in c. carinata (Table 25). Minimum levels are attained in January and June; maximum levels in March (or April?) and November (?) or December. Comparison of the fat body cycle with the reproductive cycle (Table 6 and Figures 14 and 15) reveals the expected negative correlation between fat body size and gonadal activity during spring and Summer. Both sexes exhibit this relationship although for obviously different reasons: females for egg production and males for increased activity associated 


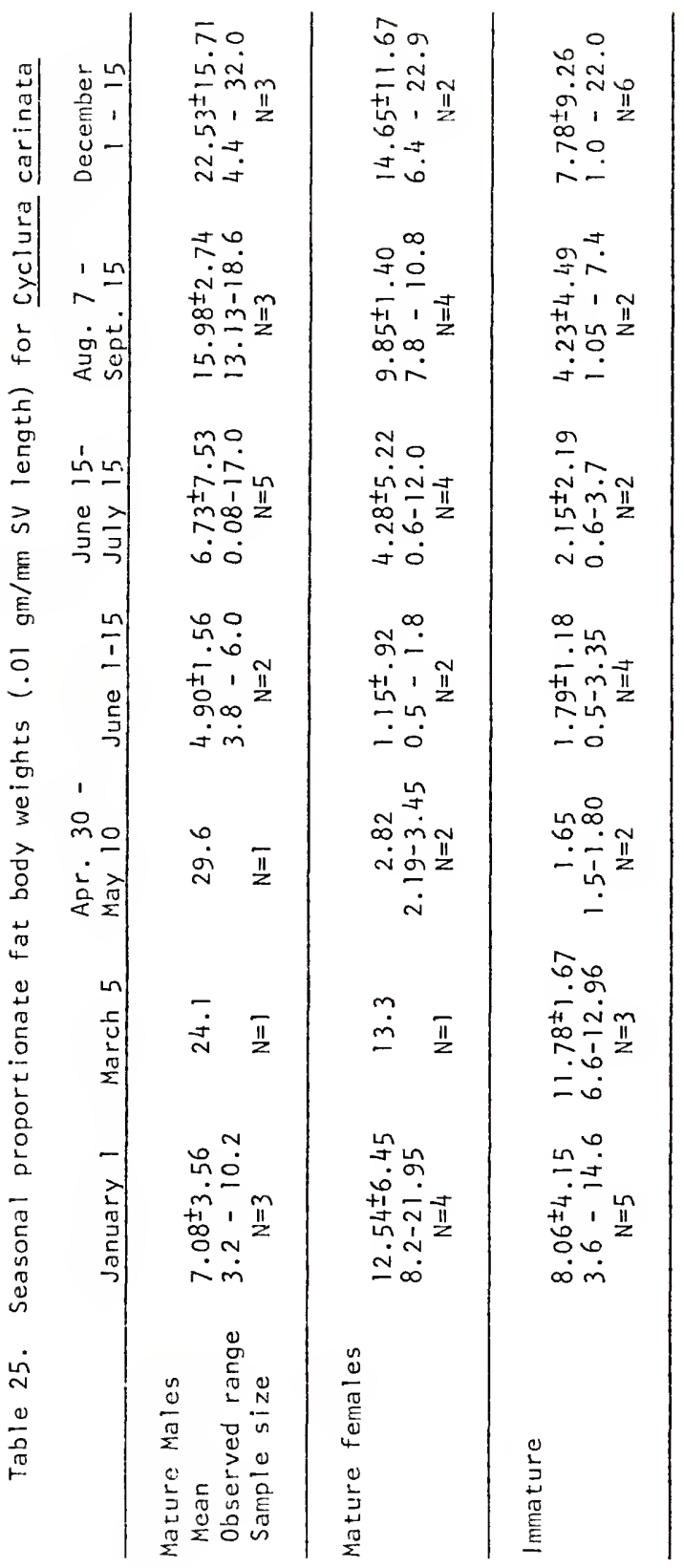


with mating and territorial defense. Following the nesting season fat body reserves increase to an absolute maximum in late fall. Late Decenber and January bring a decrease in fat body size, probably as a result of decreased activity related to environmental conditions. However, it may also be in part due to decreases in quantity and quality of available food resources. A second increase in lipid deposition in the fat bodies apparently occurs in February prior to reductions related to gonadal activity. This phenomenon of a second peak in fat storage has previously been reported among the reptiles only in the montane lizard, Sceloporus graciosus (Jameson, 1974). It is certainly due to the existence of a period of activity (including feeding) early in the year at a time between the winter period of reduced activity and the spring period of vitellogenesis. Due to selection for early clutches, most lizards lack a spring activity period before vitellogenesis, and their fat bodies therefore necessarily decrease from a prehibernation maximum continually and regularly through hibernation and vitellogenesis to a post-oviposition minimum. It should be pointed out that for cyclura carinata maximum adaptive value does not 1 ie in production of the earliest possible clutch following the winter season as in most temperate species; clutch deposition is cued by early summer rains which guarantee an energy-rich food supply for emerging hatchlings in September (see REPRODUCTION). More temperate species without a late winter period for the accumulation of extra energy must leave hibernation with vitellogenesis in full progress, thus precluding the possibility of increasing lipid rescrves prior tis vitellogenesis. 


\section{Food as a Limiting Factor}

The limiting effects of food supply on animal population numbers have received considerable discussion and experimentation (Lack, 1954; Windberg and Keith, 1976; et al). Several demographic features of Cyclura carinata populations suggest that food availability is one of the more important factors limiting population numbers and densities of this species.

Reproductive success has been shown to be related to food availability (usually as represented by rainfall) in several lizard species (Hoddenbach and Turner, 1968; Mayhew, 1965, 1966a, 1966b; Pianka, 1970b; Vinegar, 1975; Zweifel and Lowe, 1966; and review in Mayhew, 1968); populations of Sauromalus obesus are known not to reproduce at all during particularly harsh years (Nagy, 1973). Increased reproductive rates with increased food supply in birds and other animals have also been discussed (Lack, 1954). That the same relationship is true of Cyclura carinata is evidenced by the substantially higher fecundity of well-fed captive lizards (see REPRODUCTION). Fat reserves in these captives were also considerably greater and oscillated with much less amplitude than in field animals (see Fat Bodies, this chapter). The apparent failure of these lizards to fulfill these higher reproductive potentials in the field suggests that insufficient food resources (in quantity and/or quality) are imposing some restraint on fecundity.

Sirice buty size in cyclura carinata is directly correlated with fecundity, grouth rate is ultimately related to reproductive success, and therefore, population levels. Any restriction of growth rate should reduce fecundity. Case (1976) showed that Sauromalus obesus in habitats 
with more diverse and abundant food resources grew faster than those in less productive environments. By artificially supplementing the diet of Anolis in the field, Licht (1974) has shown that natural growth rate and energy storage are probably limited by insufficient food. Andrews (1976) has even suggested that most island anoles are probably food limited. The same may be true of Cyclura, at least on the smaller islands inhabited, and certainly deserves further study. Cyclura carinata is unquestionably capable of much more rapid growth and energy storage in captivity (with unlimited food) than in the field (see GROWTH). This again suggests that food may limit population increase via its direct effects on growth.

Several herbivorous iguanine species show considerable sexual size dimorphism (see Table 9). Although this dimorphism may have evolved in response to strong sexual selection, I believe its selective advantage in Cyclura carinata may lie in reducing intraspecific competition for limited food resources (see discussion by Wilson, 1975: 334).

Perhaps the strongest support for food limitation comes from the territorial behavior exhibited by adult males throughout the year. Dominant males probably defended territories to guarantee priority of access to 1) food and 2) females; access to both of these resources was restricted for subdominants. If access to food was not important, defense might be expected to coincide only with the breeding season. Since it was maintained year-round, and since most feeding occurred within this defended area, I believe that these areas were primarily feeding territories (see SOCIAL ORGANIZATION). Simon (1975) has denonstrated this to be the case in Sceloporus jarrovi, in which food 
abundance was inversely correlated with territory size. Unfortunately sample sizes made it impossible for me to make analogous comparisons in Cyclura, however, iguana density was found to vary directly with diversity and abundance of vegetation (i.e. potential food soruces) in occupied habitats (see DENSITY AND DENOGRAPHY). Furthermore, two areas on Pine Cay where abundant unnatural supplemental food was available supported local densities higher than any other place in the study islands. These were the island's refuse dump and a garden not far from the SW Blind (generally unsuccessful due to decimation by the abundant iguanas). This evidence all suggests that food availability is extremely important in regulating population size and/or growth in Cyclura carinata. It is quite possible that food may be limiting to this species for only part of the year. Rand (Ms.) suggested the same possibility for Iguana iguana in highly seasonal habitats in the neotropics. For cyclura during the winter, food resources are not only restricted to items more difficult to digest (see Digestive Efficiency) and of less quality energetically (Walter Auffenberg, pers. comm.), but environmental temperatures may physiologically limit the effectiveness of the lizards' use of those resources which are available (see Harlow et al., 1976). Furthermore, even during optimal times of the year, i.e. when fruit may be temporarily super-abundant, lizards can eat and assimilate only so much. They may thus only be able to use but a small portion of the energy which is abundantly available at such times. The importance of these factors in predator-prey relations deserves further investigation under notural conditions. 


\section{Herbivory as a Feeding Strategy}

Since Szarski's remarks on lizard herbivory in 1962, interest in and controversy concerning the evolution of this feeding strategy among lizards has escalated. Only a "dozen or so" lizard species were known to be herbivorous at that time (0strom, 1963). Nearly 90 species are now known to feed at least occasionally on herbaceous material; about 60 of these (including all 30 members of the subfamily Iguaninae) are known to be primarily herbivorous.

Among the extant lizards, at least $5.7 \%$ of the species of the Agamidae, $7.9 \%$ of the Iguanidae, $1.9 \%$ of the Tei idae, $2.4 \%$ of the Lacertidae, $1.6 \%$ of the Scincidae, $33 \%$ of the Xantusi idae; $6 \%$ of the Cordylidae, and $0.3 \%$ of the Gekkonidae are known to take plant matter (Table 26). Speculations on the adaptive relationships of an herbivorous feeding strategy in lizards have been numerous (Szarski, 1962; 0strom, 1963; Sokol, 1967; Pough, 1973; Keeling, 1974; and Rand, Ms.). Unfortunately, an understanding of the mechanisms involved in the evolution of herbivory in lizards must necessarily await investigation of the many involved components. Among these are: 1) the relationships of the gastrointestinal flora and fauna to digestion; 2) digestive efficiencies for natural dietary materials and the energies available from those materials; 3) ability of lizards to detoxify secondary compounds; 5) relationships of ion and water balance to diet; 6) relationships of temperature (and hence metabolism) to the above; 7) the functional ariatomy of the feeding apparatus (Throcknorton, 1976 , provides an excellent example); 8) actual predation pressures and intra- and inter-specific competition; 9) ontogenetic and seasonal 
Tuble 26. Lizard species known to include plants in their diets

IGUANIDAE ${ }^{-a}(560)$

Anolis equestris, A. ricordi, Basiliscus basiliscus, B. plumifrons,

Cailisaurus draconoides, Crotaphytus collaris, Leiocephalus

psamnodromus, Liolaemus multiformis, Phiynosoma platyrhinos,

Sceloporus magister, Uma (all three species), Uta stansburiana,

and all species of the subfamily Iguaninae (ca. 30).

AGAMIDAE (315)

Agama againa, A. atra, A. caucasica, A. nupta, A. planiceps, A.

tuberculata, Amphibolurus barbatus, A. pictus, Hydrosaurus

amboinensis, Leiolepis belliama, Physignathus ieseuri, Uromastix

acanthirurus, $\underline{u}$. aegyptius, $\underline{U}$ hardwickii, $\underline{U}$. Ioricatus, $\underline{U}$.

microlepis, $\underline{U}$ ocellatus, $\underline{U}$. ornatus, and $\underline{U}$ princeps.

TEIIDAE (210)

Cnemidophorus arubensis, $\underline{C}$ gularis, Dicrodon guttulatum, Tupinambis tequixin.

LACERTIDAE. (164)

Eremias arquta, Lacerta galloti, ㄴ. lepida, ㄴ. viridis

SCINCIDAE (700)

Acontias meleagris, A. plumbeus, Coruccia zebrata, Egernia bungana,

E. cunninghami, Eumeces algeriensis, Macroscincus coctaei,

Scincopus fasciatus, Tiliqua gigas, I. scincoides, Trachydosaurus

rugosus

XANTUSIIDAE (i2)

Kiauberina riversiana, Xantusia arizonae, $\underline{x}$. henshawi, $\underline{x}$ vigilis 
Table 26 - continued

\section{CORDYLIDAE (47)}

Angolosaurus skoogi, Gerrhosaurus flavigularis, G. validus

GEKKONIDAE (585)

Phel suma $\mathrm{sp}$.

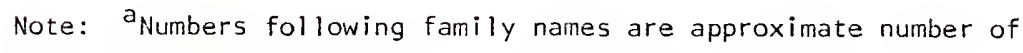
species in family. The list is not assumed to be definitive. 
dietic variation; 10) the affects of habitat productivity on 9); and 11) diet versus reproductive output.

Many of these components should not be difficult to pursue; hard data are badly needed. Auffenberg (in preparation) focuses attention on sone of these previously neglected subjects for cyclura carinata. 


\section{ACTIVITY AND MOVEMENTS}

\section{Locomotion}

Although primarily terrestrial, Cyclura carinata are adept arboreal lizards. Climbing is commonly used to secure food (see discussion of Arboreality under FOOD AND FEEDING), as well as for thermoregulation (Dave Auth, in preparation; pers. observ.). Lizards of all ages can climb. Hatchlings less than two weeks old were frequently observed climbing in Erithalis bushes to heights of 1.5 meters. They had not yet begun feeding.

Natural aquatic activity in Cyclura carinata was never observed during this study. Cyclura collei (Hill, in Gosse, 1848), C. cornuta (Noble, 1923), C. nubila (Hardy, 1956; Lando and Williams, 1969) and C. pinguis (Carey, 1975) are the only members of the genus known to enter freshwater, usually as a means of escape. However, Cuban fishermen claim that $\underline{\underline{C}}$. nubila swim between islands and the mainland of Cuba (Buide, 1951). Iguana iguana (Swanson, 1950, among others) is the only other iguanine lizard (exclusive of the marine iguana, Amblyrhynchus cristatus) which commonly uses water as an escape route. Alvarez del Toro (1972) has even observed Iguana at night "sleeping" under water. Cyclura carinata could be made to enter the sea only if strongly pressed and then only if no other retreat was available. Once in the water, the body was typically inflated such that the lizard floated at the water's surface. If pursued further, it would attempt to "swin" 
away using serpentine body and tail undulations. The limbs were not used and trailed posteriorly along the body. This behavior rarely lasted more than three to five seconds. On several occasions, iguanas were carried into the water in order to observe aquatic behavior. The behavior was always that described above; as a result of body inflation, ro lizard attempted to escape by submerging. When carried distances of 10 to 30 meters out from shore and watched from below the water, $\underline{C}$. carinata showed no inclination to return to land. They simply floated with the surf out to sea. The length of time these lizards can remain inflated and thus avoid drowning is unknown. This mechanism could potentially be important to dispersal, especially under hurricane conditions, and deserves further study.

\section{Retreats}

Hollows in trees are known to be used as retreats by cyclura carinata (present study, occasionally), cyclura collei (Gosse, 1848), and Cyclura ricordi (Diderot Gicca, pers. comm.); natural cavities (honeycomb limestone, rock crevices, crab burrows, etc.) are used by C. carinata (Cochran, 1934; present study, occasionally), ․ cornuta (Klingel, 1929; Grant, 1944; Wiewandt, in preparation), c. cychlura (Bailey, 1925; Rabb and Hayden, 1957; Carey, 1975; W. Auffenberg, pers. comm), C. nubila (Grant, 1940b; Hardy, 1956; Carey, 1966), C.. pinguis (Carey, 1975); C. ricordi (Carey, 1975), and C. rileyi (Cochran, 1934; Carey, 1975). Only Cyclura carinata (present study), c. cornuta (Noble, 1923; Carey, 1975), C. nubila (Hardy, 1956, occasionally), ‥ pinguis (Carey, 1972, 1975, occasionally); and C. ricordi (Noble, 1923; 
Carey, 1975) in this genus are known to completely excavate their own retreat burrows. Whether natural cavities or self-constructed burrows are used as retreats most likely depends on the physiography of the inhabited region; soils substantial enough for burrowing are often unavailable in some areas, and natural cavities often absent in others. Cyclura carinata subadults and young adult males show little allegiance to a particular retreat. However, as adults, the older, and in the case of males, the more dominant they become, the greater retreat tenacity they exhibit.

\section{Activity Cycle}

\section{Home Range}

Although the concept and measurement of an animal's home range has received extensive treatment and review, no method or model has received universal support or useage (for literature review, see Burge and Jorgensen, 1973; Davis, 1953; Jennrich and Turner, 1969; Jewell, 1966; Kaufmann, 1962; Southwood, 1966; Van Winkle, 1975). Several studies have considered the subject of home range specifically in lizards (Jorgensen and Tanner, 1963; Milstead, 1961, 1970; Stebbins, 1944; Tanner and Hopkin, 1972; Tinkle, 1967a; Tinkle and Woodward, 1967). Most of the techniques for calculating home range size are based on isolated recapture or resite records. Only a few studies have utilized direct continuous observations in delineating home ranges. This is especially true anong lizard species (Irwin, 1965; Rand, 1967; Tinkle, 1967t; Andrews, 1971; Berry, 1974;

Mackay, 1975). The advantages and disadvantages of this direct method are aptly discussed by Adams ard Davis (1967) and Mackay (1975). My 
observations on home range in Cyclura are based either on direct observation or on maps of activity as recorded by tracks in the sand. 1 define home range, or activity range, for Cyclura carinata, as the area most frequented during a year's activity. This definition is fundamentally the same as Kaufmann's (1962) "core area". There is an area within which an iguana spends most of his time during a yearly cycle. The great majority of all activities are performed within this core area. However, lizards do make forays outside of this mostfrequented area for food as well as other resources. Temporary high quality food resources (flowering or fruiting plants, for example) frequently lure them from their normal activity ranges. This made baiting successful in attracting lizards for marking and observation. Because of these extra-core area activities, lizards are familiar with the neighboring habitat and its occupants. Lizard knowledge of the locations of other than their own burrows has previously been discussed (see HABITAT, Burrows). Since these burrows may occasionally offer the only route of escape available to a lizard, this information is important. Home range size was determined from plots of observed movements during 34 days of observation at the SW Blind (on five trips) from June, 1974, through August, 1975. Area of the home range was calculated oniy for those lizards with the most complete movement records (Figures 42 and 43). Home ranges for six dominant males $(286-308 \mathrm{~mm} \mathrm{SV})$ at the SW Blind averaged $0.159 \pm 0.050$ he $(0.103-0.248)$; five subdominant males $(254-267 \mathrm{~m} 3 \mathrm{v})$ averaged $0.126 \pm 0.041$ ha $(0.070-0.187)$; and four adult feriales $(203-238 \mathrm{~mm} \mathrm{SV}), 0.098 \pm 0.019$ ha $(0.078-0.118)$. Home range size among these lizards was significantly positively correlated with body 


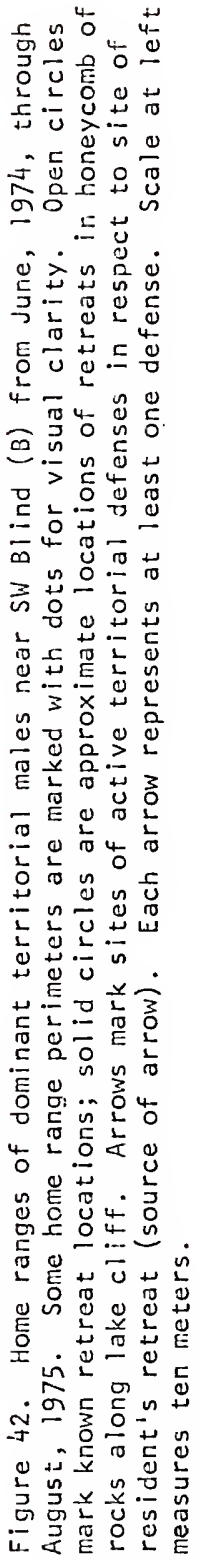




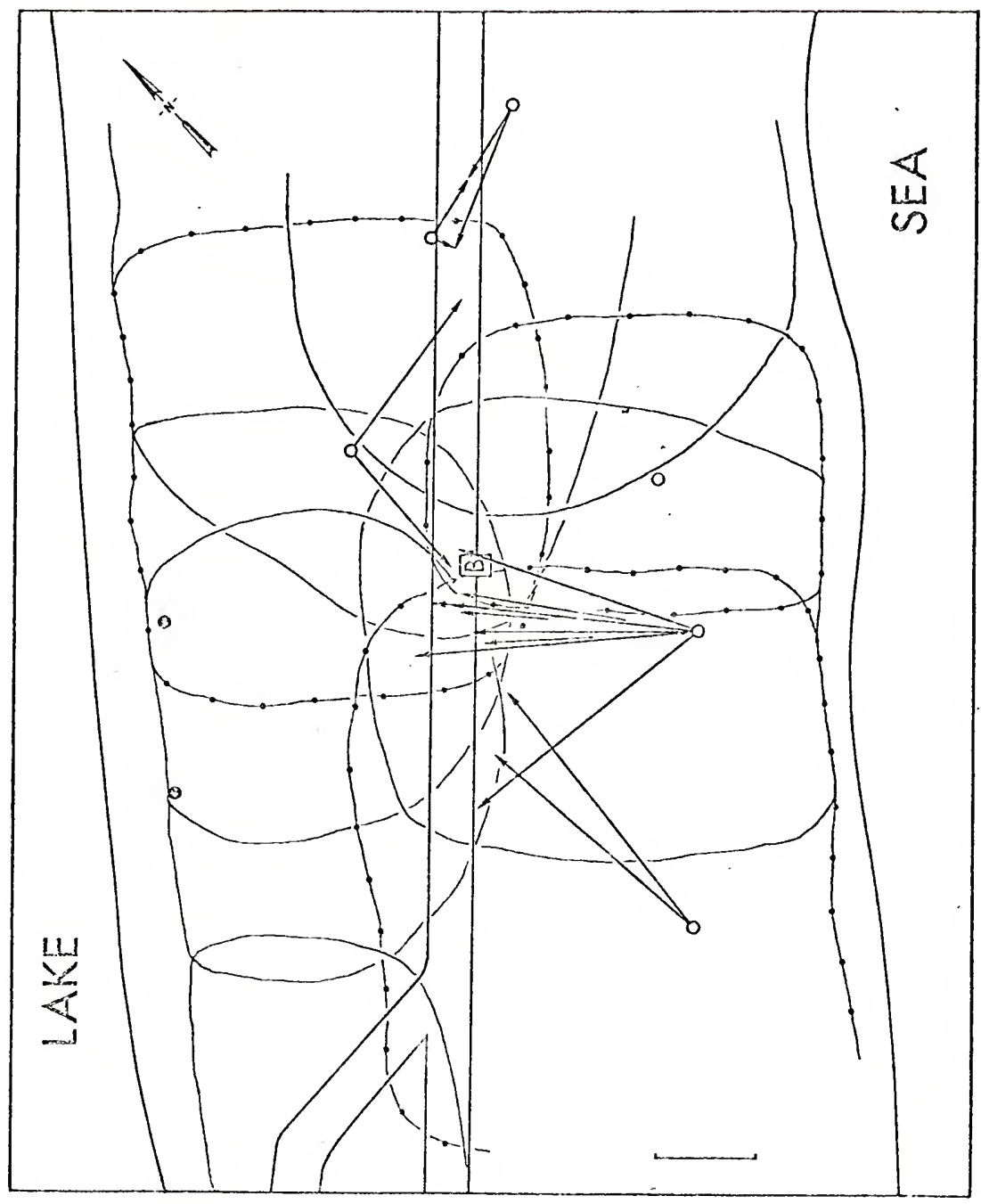




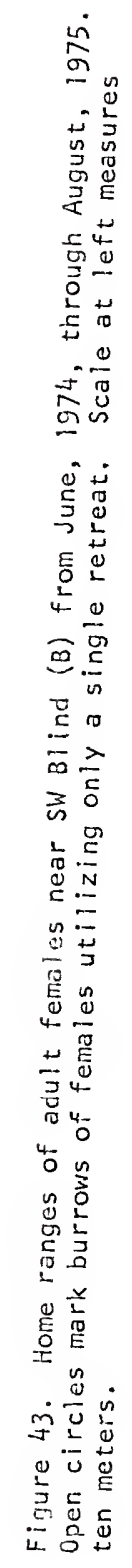




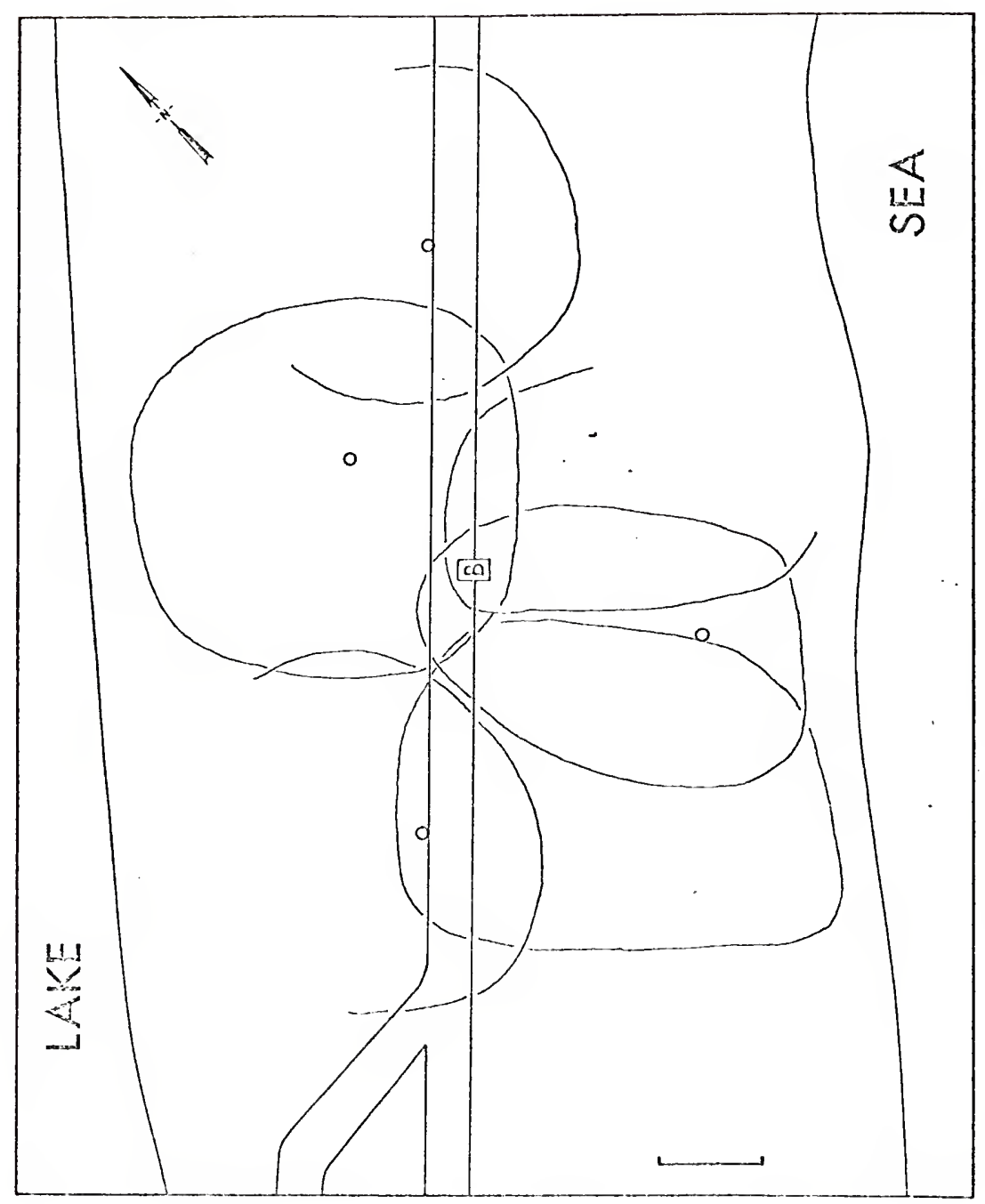


size (Figure 44). This was expected in light of similar correlations previously found among species of birds (Armistrong, 1965; Schoener, 1968), mammals (MCNab, 1963) and terrestrial lizards (including Sauromalus obesus; Turner et al., 1969).

Auth (in preparation) calculated home ranges for four adult males $(1.51$ to $1.87 \mathrm{~kg})$ in an area of Dense Scrub on Vater Cay at between 0.233 and 0.379 ha. These home range sizes are larger than those at the SW Blind because the lizards are generally smaller and more dense, and the habitat more productive at the latter site. Home range size for three additional adults living near the SW end of Pine Cay in a sparsely vegetated open scrub habitat was very accurately determined from plots of their movements as recorded by tracks in the sand. Calculated home ranges were 0.0943 ha (male; $260 \mathrm{~mm} \mathrm{SV}$ ), 0.0895 ha (male; $257 \mathrm{~mm} \mathrm{SV}$ ), and 0.0672 ha (female; $200 \mathrm{~mm} \mathrm{SV}$ ). These values are low in comparison to those at the SW Blind. Higher values should be expected in this poorer habitat since intuitively a greater area would be necessary to provide equivalent amounts of food energy. However, in this extremely open dune habitat, the food sources are distinctly clumped and lizards usually excavate their burrows amid this vegetation. (Lizard densities are also lower.) Therefore, movement beyond the nearest patch of food is usually unnecessary. Another estimate of adult home range size was obtained in June 1976, along a portion of a $950 \mathrm{~m}$ sand spit on Little Vater Cay (Figure 4). This peninsula has formed since 1967 by a redeposition of sand, as the northern point of the island is being croded away. The vegetation is sparse and composed entirely of psamophilous, primary successors (Uniola, Scaevola. Ernodea, Chamaesyce, Cenchrus, etc.). Adult male 


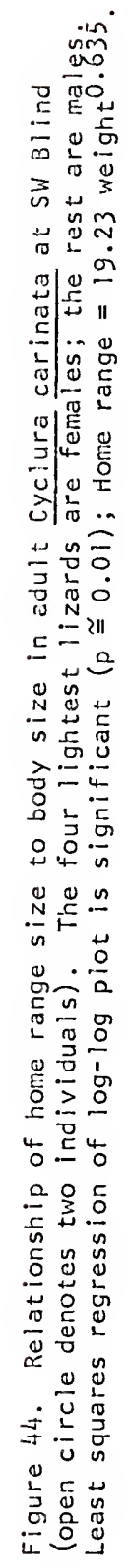




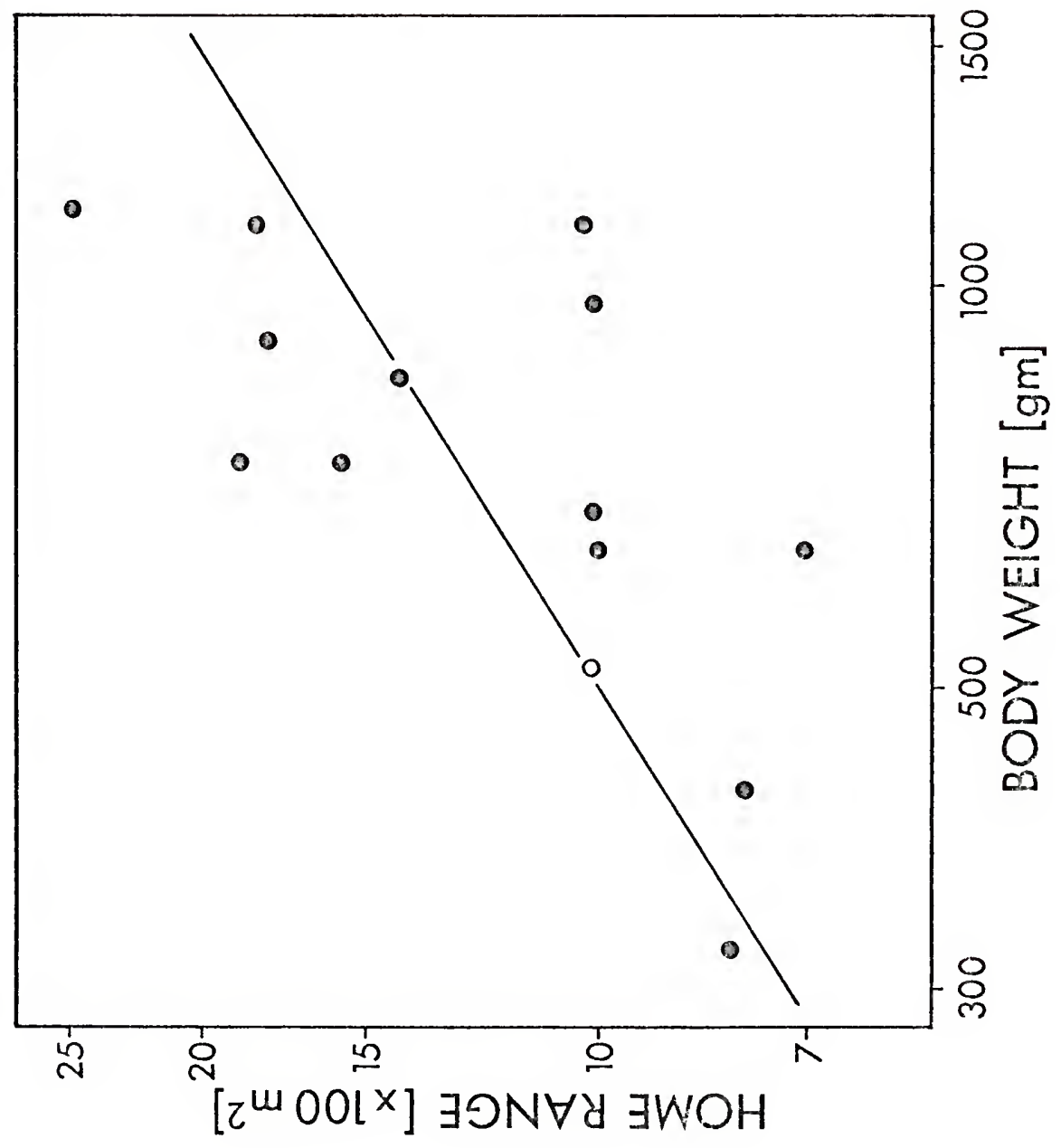


lizards have colonized the spit as fast as it has built. Lizard burrows are located along the main axis of the spit where altitude is greatest (but nowhere over two $m$ above mean sea level). The mean distance between large active (presumably male) burrows was $43.85 \pm 16.28 \mathrm{~m}$ (range 30.7 to $87.8 ; 16$ measurements). However, the two longest interburrow distances $(87.8$ and $82.7 \mathrm{~m})$ each are nearly twice the average remaining recorded distances. Perhaps the lack of an active burrow somewhere near the middle of these lengths indicates the death or emigration of a former occupant of the area, with subsequent destruction of his burrow. If these two measurements are omitted, the recalculated mean interburrow distance is $37.93 \pm 4.73 \mathrm{~m}$ (range 30.7 to $48.3 ; \mathrm{N}=14$ measurements). At the S:A Blind the mean interburrow distance for males was $26.6 \pm 6.9 \mathrm{~m}$ (13 measurements). If these same averages are considered approximately equal to the average diameter of male home range, areas of $1129.94 \mathrm{~m}^{2}$ and $555.72 \mathrm{~m}^{2}$ are indicated for the sand spit and SW Blind study areas, respectively. This method obviously underestimates male home range size since it assumes no overlap of male ranges. However, it does suggest that home ranges on the spit are at least twice those at the SH Blind. This is certainly related to the lower lizard density on the sand spit due to its extremely low productivity and dispersed resources. Tinkle and Woodward (1967) found a similar inverse relationship between density and home range size in the lizard, Uta stansburiana.

Movement and activity data for only a single juvenile lizard vere complete enough to allow home range size determination (Figure 45). Between hatching and seven months of age, this lizard nintained an activity range of $118.9 \mathrm{~m}^{2}$. Although data from additional juveniles 


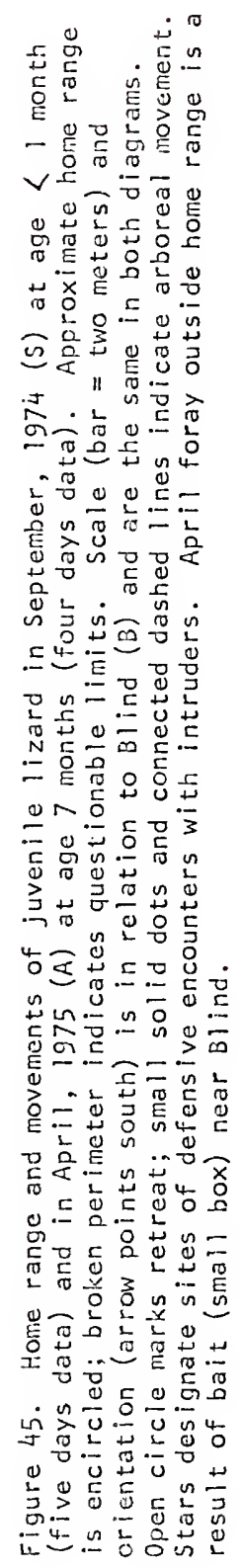




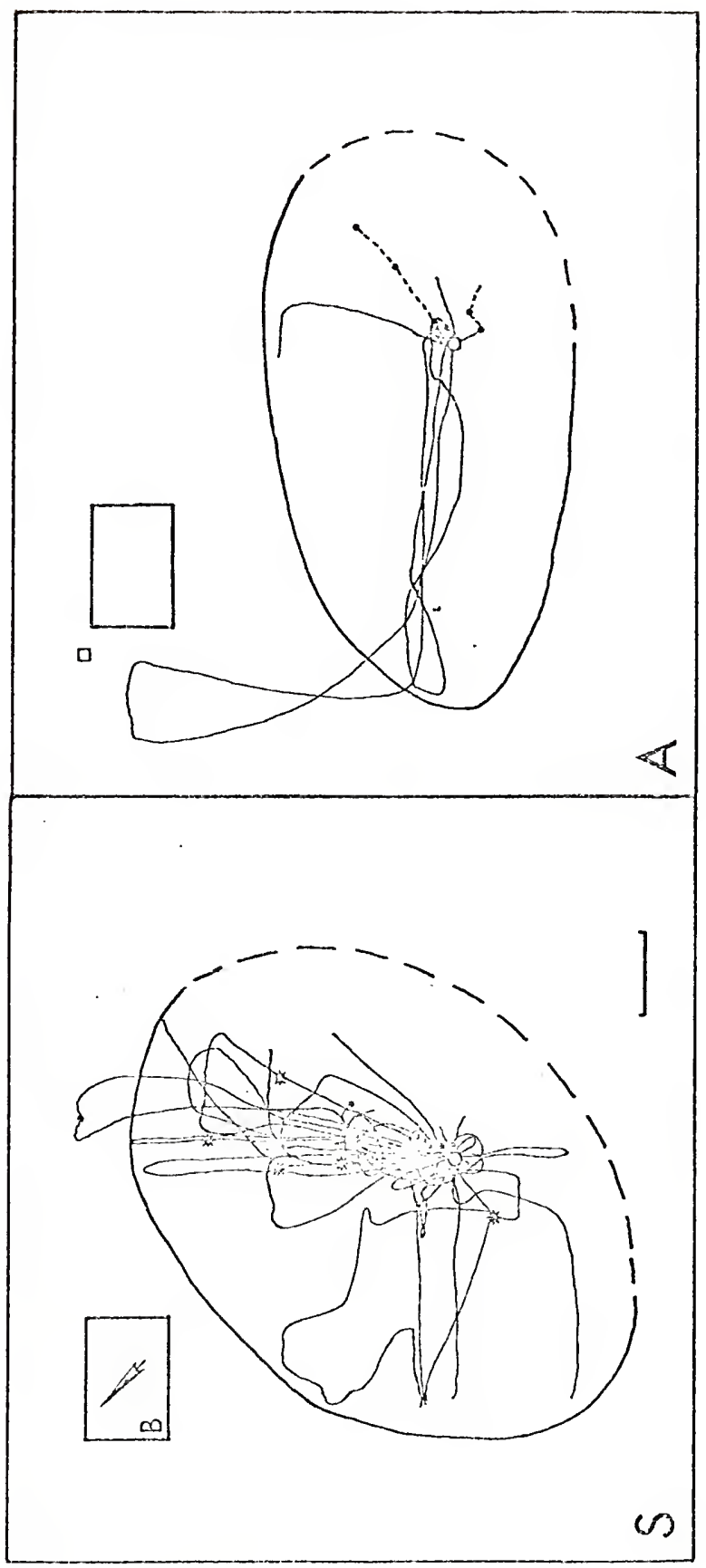


less than one year of age were fragmentary, they support this figure as representative of lizards of this age group. Home range data for subadult lizards greater than one year of age were very inconclusive. The lizards apparently show little philapatry. Juveniles frequently appeared near the SW Blind only to disappear after one to several days in the area. Although feral predators are at least in part responsible for this disappearance, 1 believe most of these juveniles were transients. The area covered during a year's activity probably greatly exceeds that of most adults. This is possible since the social structure permitted complete freedom of juvenile movement (see SOCIAL ORGAMIZATION). of the few species of iguanines for which data are available, only Cyclura pinguis is reported to utilize smaller adult ranges than Cyclura carinata (Table 27). However, home range size for Cyclura pinguis was determined from sightings during only a five-week period (Carey, 1975) and the values probably greatly underestimate areas inhabited during the entire year. Although C. Carinata are slightly larger than Sauromalus obesus, the latter's home range is over ten times as large. Additional data both on activity range size and habitat productivity are sorely needed if meaningful comparisons among the iguanines are to be made. Male home ranges overlapped broadly, as did those of females (Figures 42 and 43). Although a female's home range was usually centered within a single dominant male's, they sometimes overlapped the ranges of more than one. Subdominant male home ranges overlapped those of duminant males, and tended to bo centered in areas where the ranges of dominant males overlapped (i.e. away from the center of a dominant male's activity). 


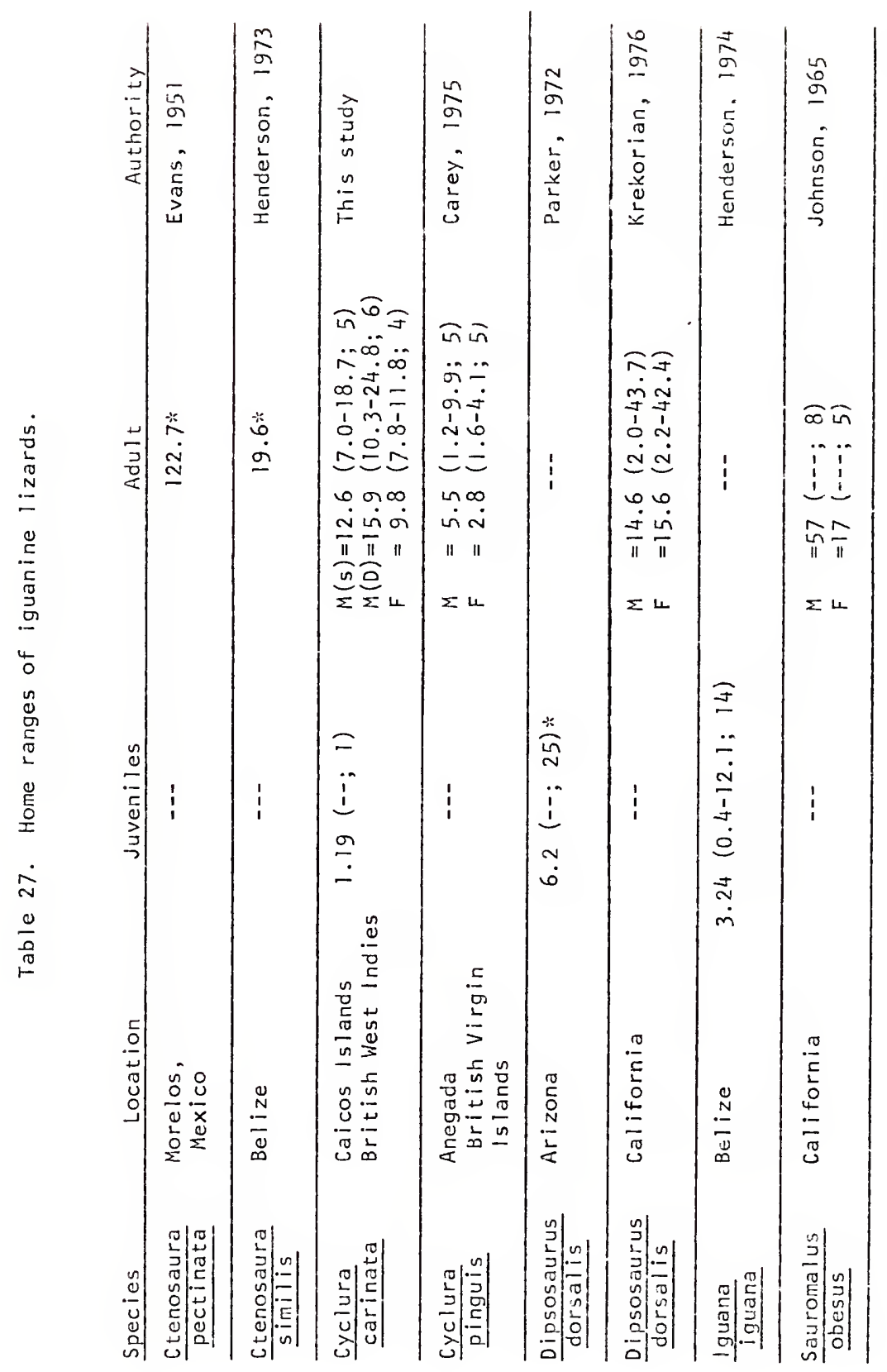




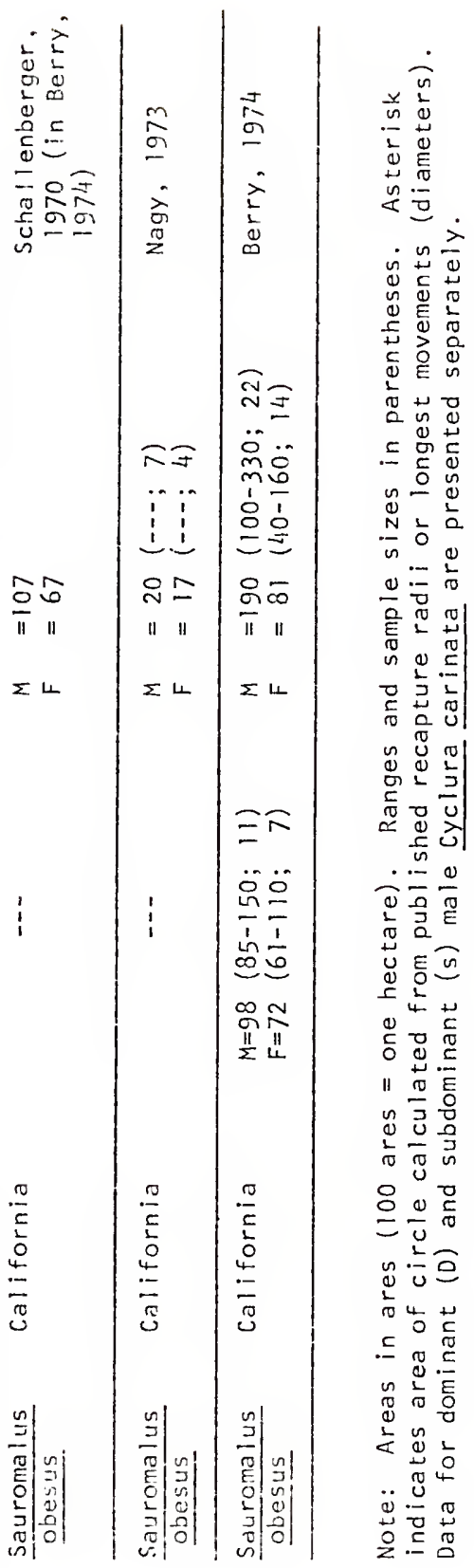


Seasonal Patterns

Initiation and termination of daily activity in Cyciura carinata, as evidenced by times of burrow emergence and submergence, show considerable seasonal variation (Table 28). Average energence times in early December, early April, and June-July were 0930, 0849, and 0751 hours, respectively. Corresponding submergence times were 1530,1611 , and 1718 hours. Lizards were never active before sumrise or after sunset. Time of extra-burrow activity averaged only 5 hrs 55 min during the winter. During the spring it averaged 7 hrs $22 \mathrm{~min}$ and during summer, 9 hrs $27 \mathrm{~min}$.

A bimodal diurnal activity cycle is exhibited by cyclura carinata during the warmer parts of the year (Figure 46); lizard activity is typically reduced in respect to high midday temperatures. Cyclura cychlura (Wilcox et al., 1973) and ‥ nubila (Carey, 1966) also demonstrate this bimodality during at least the warmer seasons of the year. During the winter, $\underline{C}$. carinata demonstrates a unimodal diel cycle; activity peaks during the warmerst time of the day (Figures 46 and 47; Table 29).

General activity, i.e. lizard movement, is greatest during the warm, dry, spring months. A tally of the number of lizards entering or leaving my field of view at the SW Blind during different seasons of the year supports this (Figure 46 ). During 11 spring days, an average of 30.4 arrivals and/or departures was logged por day. An average of 20.3 per day recorded during the suminer and only 13.75 during the winter. The spring activity peak is related to both courtship and optinal climate. I could detect no sexual differences in general activity levils. 


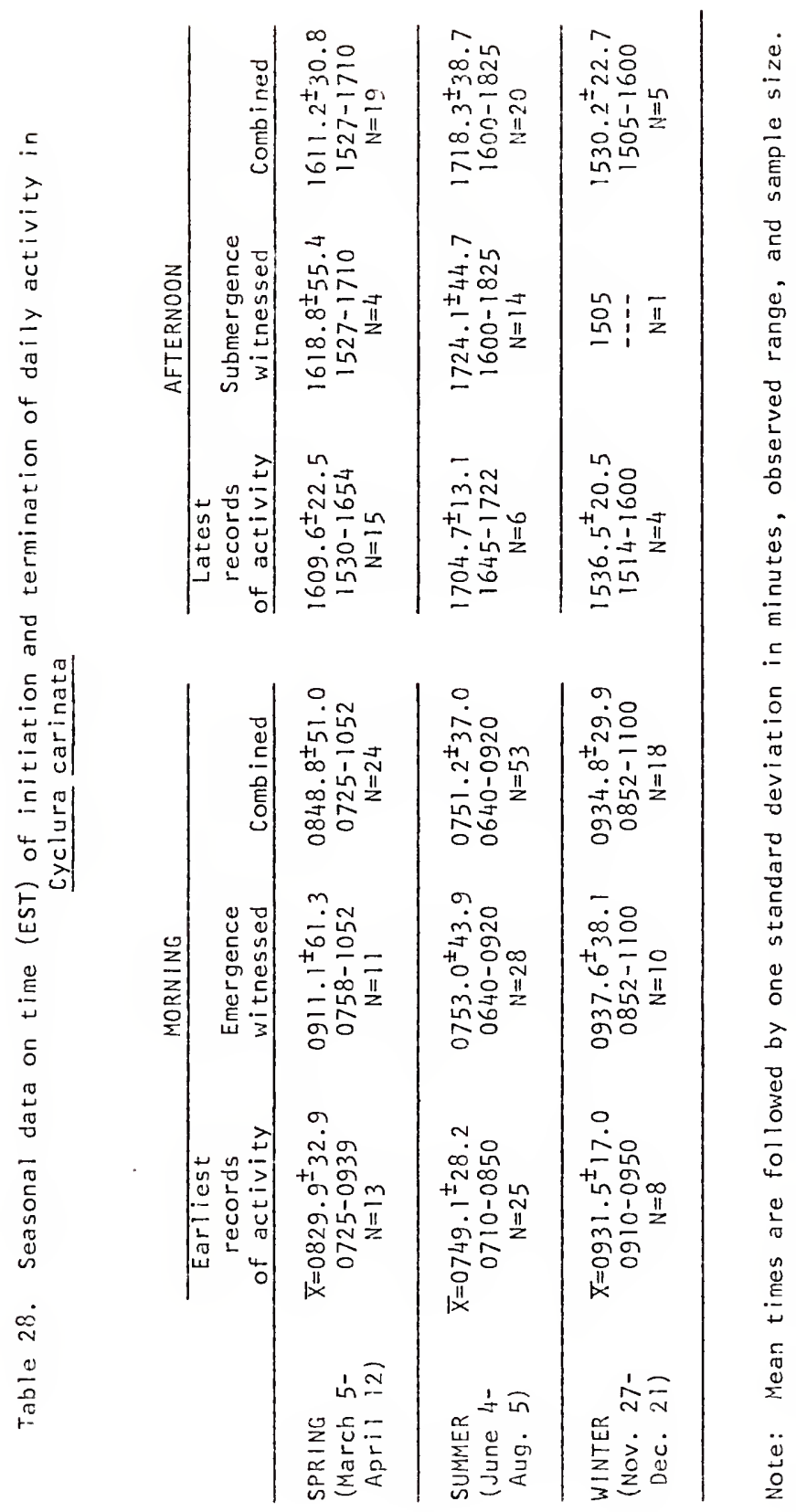




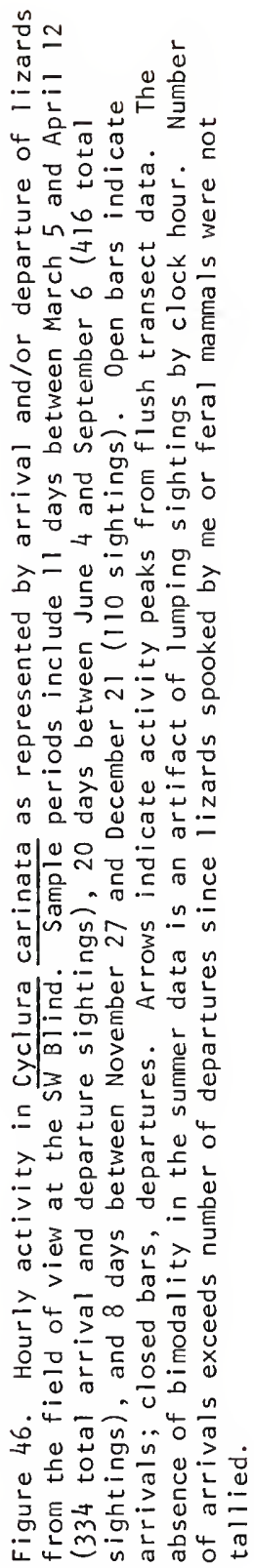




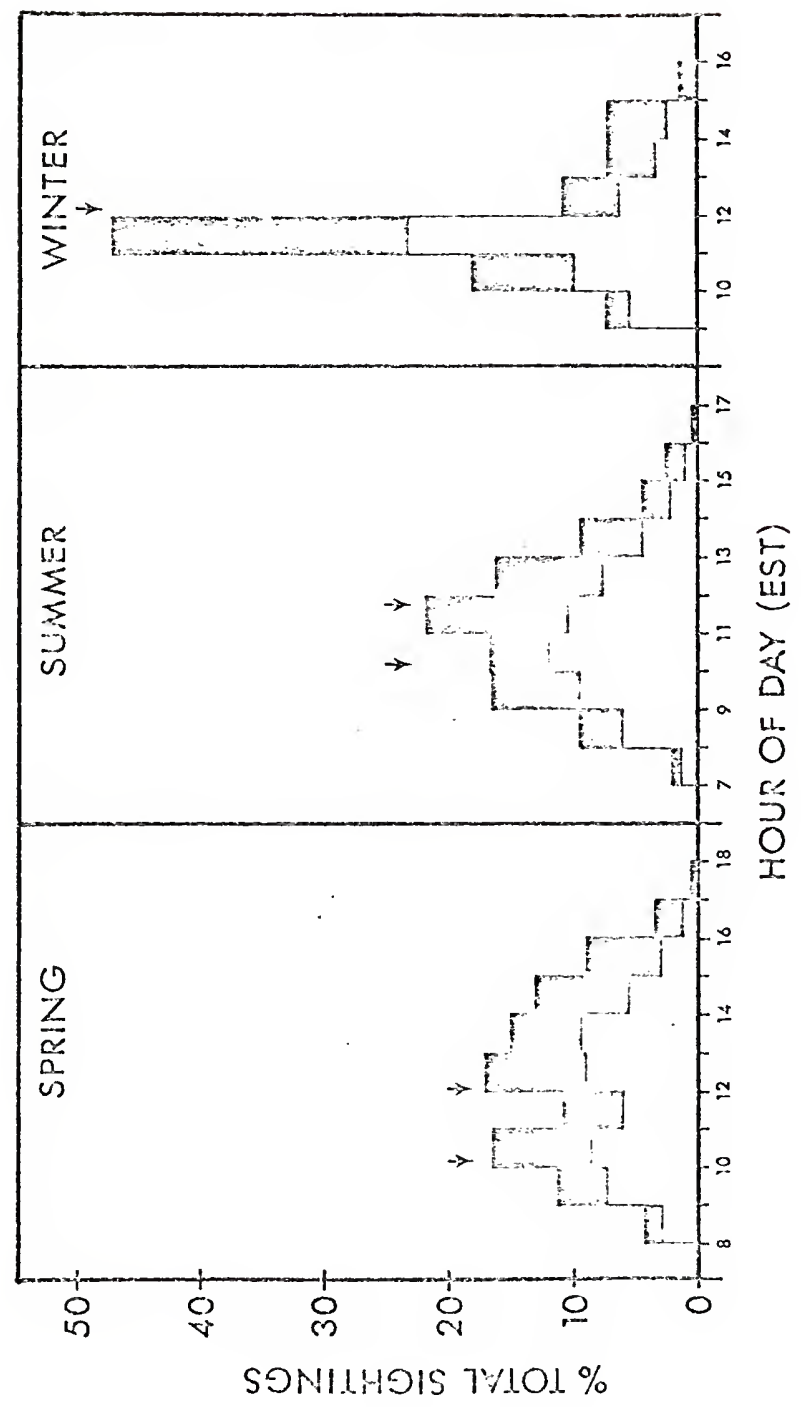




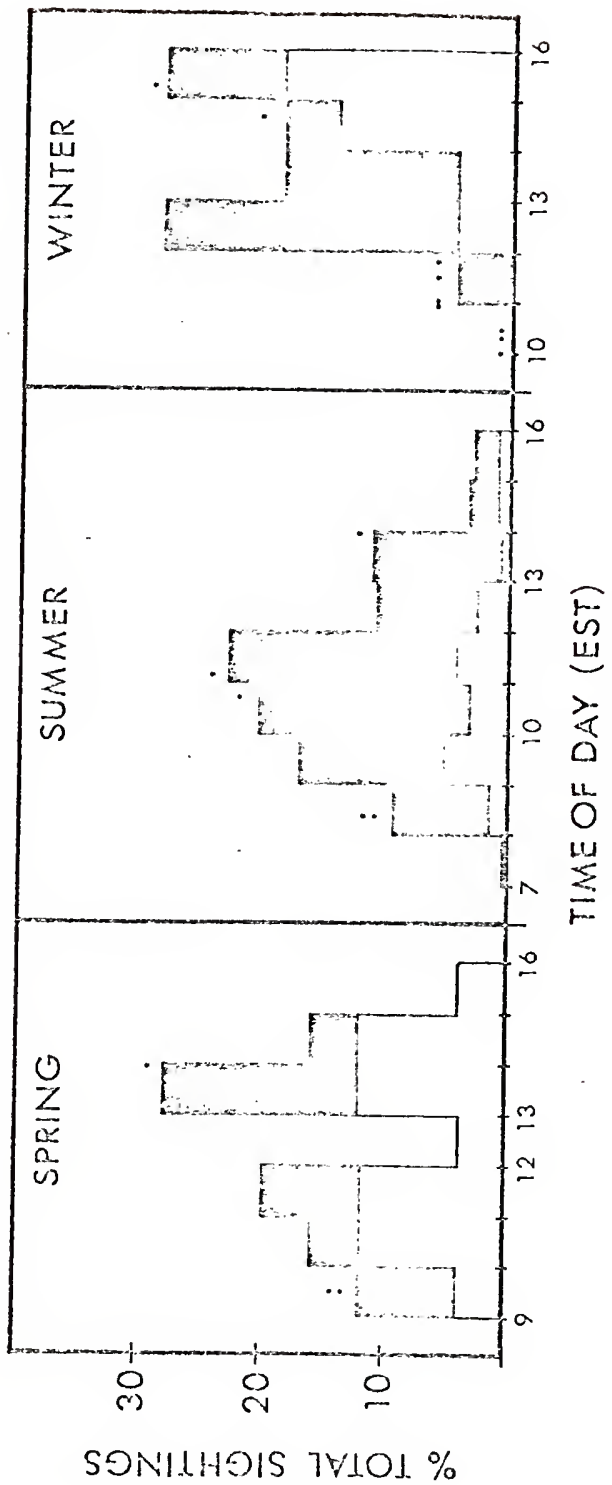

ᄂ)

๑

1 है

ㄴ $0 \frac{0}{0}$

들 $\stackrel{2}{2}$

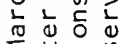

$\sum \pm \ldots$ in

$\therefore \frac{0}{0}$

$03>$

든 品

응 웡

iั की

(1)

苗艺

든

ปั

ब

ป

ن

ง!

ᄃ

-

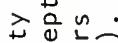

$\pm \stackrel{1}{\circ} \frac{1}{\sigma}$

$\therefore$,

บ๖ บั

० 204

西方

1) is.

능

兵

ᄂ 至 出 U

an

क क

o $匚+$

뜸ำ

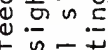

4 品立

주음

วัㅇํㅇ

I $\frac{1}{\sigma}$

ฟิํํㄴ

的步

$\simeq U \frac{1}{\sigma}$

ข -

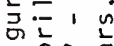

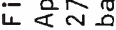




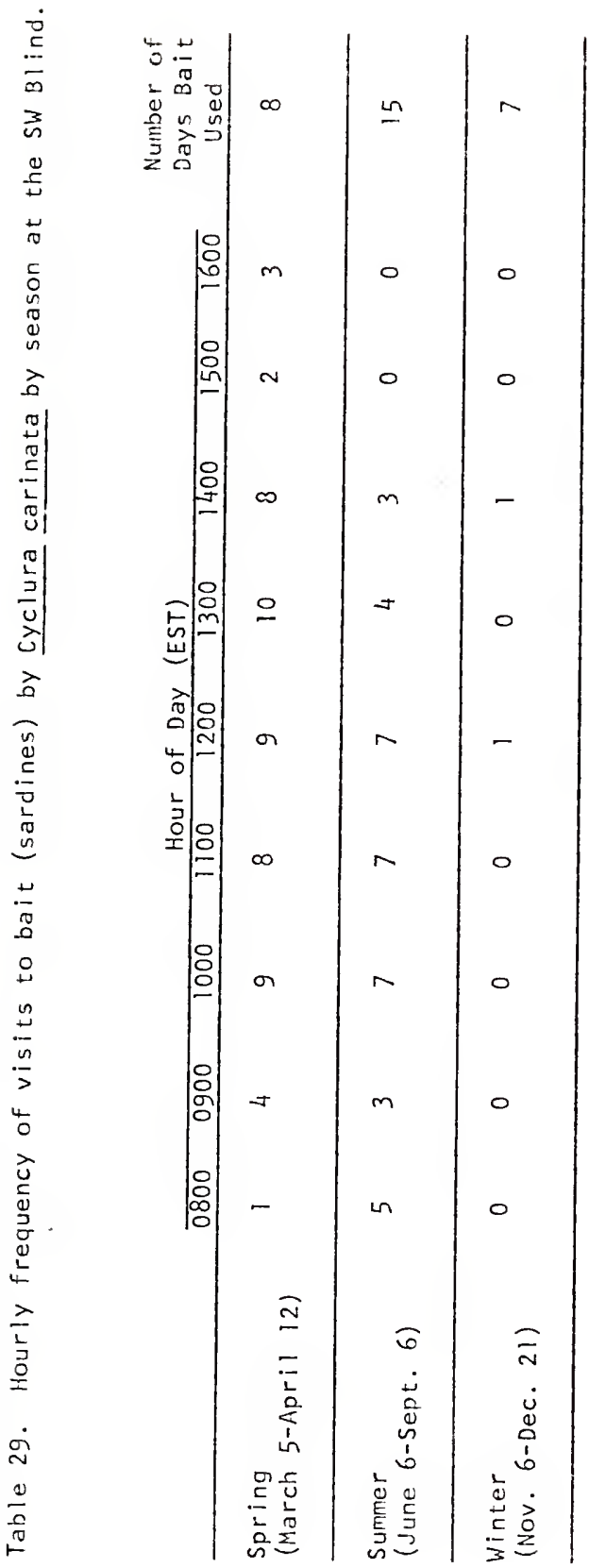


Weathar conditions have a profound effect on all phases of activity. Lizard emergence wa: only rarely precluded during sumner days due to cool, wet and windy conditions ( 1 of 65 days), but often precluded during winter days ( 4 of 19 days). Furthermore, on many winter days when eriergence was observed, lizard activity was restricted to basking in the vicinity of the retreat; body temperatures high enough to permit other activities were apparently never reached. Cold weather effects a reduction in activity range size. An adult male at the S: Blind maintained a home range of $702 \mathrm{~m}^{2}$ between June, 1974, and August, 1975, but occupied only about $40 \%\left(279 \mathrm{~m}^{2}\right)$ of that area in November, 1974. Similar activity range reductions were typical of all lizards during the colder parts of the year.

Throughout most of the year an iguana is capable of traversing its entire home range within any single day. During the colder winter months (November-January), all phases of activity are reduced and it is unlikely that the entire home range will be visited in one day. Mevertheless, individual Cyclura carinata are active every day of the year, weather permitting. This is in contrast to Sauromalus obesus in California (Nagy, 1973) and Cyclura cornuta on Mona Island (Wiewandt, in preparation), which may remain inactive for at least 2 or 3 days at a time, regardless of weather conditions.

\section{Daily Activity}

Diel activily patterns of Cyclura carinata reflect their heliothermic nature. The probability that a lizard will exhibit a particular behavior at a particular time during the day is directly related to the 
thermal regime. A detailed study of the thermoregulatory ecology of this species is in preparation by David Auth. My discussion of thermoregulatory behavior will therefore be limited.

Cyclura carinata are active and will feed on every day of the year that the wather permits. After morning burrow emergence, iguanas move immediately into the sun to bask. Morning basking usually lasts less than 45 minutes during the summer, but lizards were observed to bask for up to 5 hours (their entire time of energent activity) on winter days. (Basking postures are discussed by Auth, in preparation.) Defecation most frequently occurs immediately following termination of morning basking (Figure 47). Since the same basking site may be used for many days by the same lizard, large numbers of fecal pellets accumulate nearby, identifying the site.

Following basking (or defecation), lizards make forays through their home range to feed. Most of the remainder of the day is spent feeding, interacting with other lizards, and shuttling in the sun-shade mosaic for thermoregulatory pruposes. A similar daily routine is reported for Cyclura cychlura (Wilcox et al., 1973), Cyclura nubila (Grant, 1940b; Carey, 1966), and Cyclura pinguis (Carey, 1975). Ais previously stated, there are usually two peaks in the iguana's diel acti $\because$ ty cycle, with but a single peak during the winter. Midday temperatures during most of the year dictate a period of rest to prevent the lizard from overheating. This midday activity decline is illustrated $i_{i}$ the dacreesed number of lizards flushed on transects (Figure 48) and moving into or out of riy field of view from the s.4 Blind (Figure 46 ), the reduction in natural feeding and arboreal activity (Figure 47) and the decreased use of the artificial bait at the Sit 81ind (Table 29). 


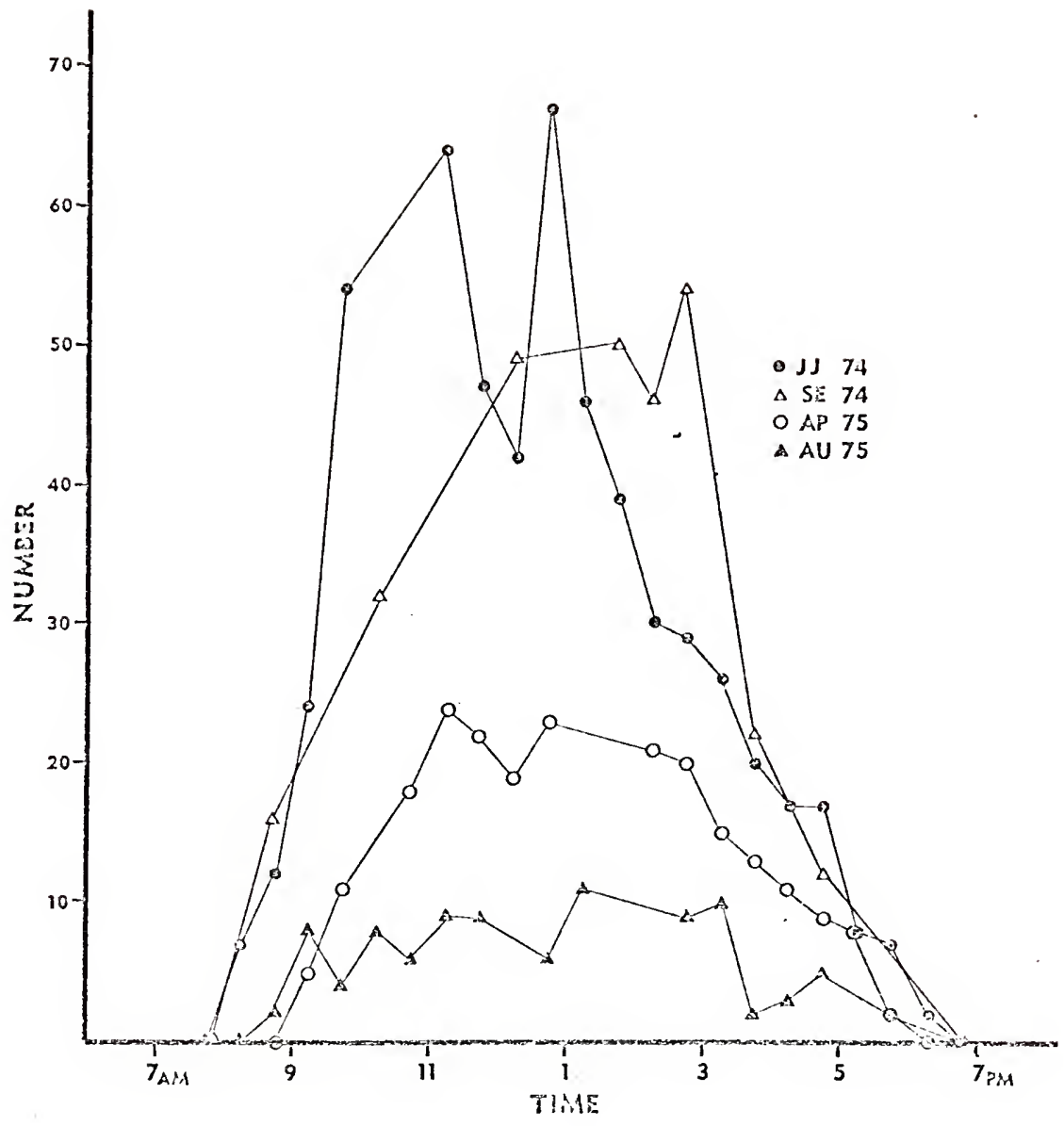

Figure 48. Variation in total number of adult Cyclura carinata sighted during half-hour flush transects on four separate trips to Pine Cay: June-July, 1974 ; September, 1974; April, 1975; and August, 1975. Times are EDT. See Figure 2 for transect location. 
The winter feeding and/or arboreal activity record (Figure 49) appears anomalously bimodal because of a morning burst in arboreol activity. The morning peak reflects the increased use of arboreal basking sites during the winter. The bushy vegetation of the low thick canopy reduces the flow of cooling air currents, and the green leaves absorb more warming radiation than the light coral sand substrates, providing a warmer microclimate in which to bask.

The midday resting location is usually not far from the retreat; morning and afternoon forays take the lizard to the periphery of his home range. During the winter there is usually no midday resting period and lizards typically make only one foray a day.

Following the afternoon activity peak, as temperatures fall, lizards spend increasingly more time in the sun. Thigmotropic basking is often employed late in the afternoon in an attempt to maintain elevated body temperatures. When their body temperatures drop below the preferred range, the lizards enter their burrows.

Unlike Cyclura nubila (Grant, 1940b) and Sauromalus obesus (Berry, 1974) which avoid rain, Cyclura carinata (and Cyclura pinguis; Carey, 1975) often endured temporary rain showers in prostate postures. If the rain continued for more than 20 or 30 minutes and/or was especially intense or cold, the lizards would retreat to their burrows. As soon as the sun reappeared, the iguanas would re-emerge if the clearing preceded their nomel submergence time. As that time approached, lizards were increasingly urvilling to re-cmerge.

Re-emargence after disturbance by humans or feral mamnals was similarly affected. Lizards usually left their burrows (if the threat 
was no longer present) within 45 minutes after submergence, unless spooked shortly before normal submergence $t$ imes.

\section{Orientation and Homing}

In order to test for navigational ability, several lizards fitted with transmitters were displaced distances of 0.6 to $5.6 \mathrm{~km}$ and released into a burrow in the dune area of Pine Cay, $500 \mathrm{~m} \mathrm{N.E.} \mathrm{Of} \mathrm{the} \mathrm{Ridge} \mathrm{Area.}$ The lizards were subsequently relocated one to several times after intervals of approximately $1 / 2$ to five diurnal periods. It was often possible to trace and map the lizard's travels by his tracks in the sand. The results appear in Table 30. None of these animals homed successfully. Each of the first four took an immediate general southward heading toward their capture sites, suggesting navigational capabilities, but this might simply reflect the avoidance of human activity (to the north and northeast) and the sea (northwest). To test this affect, lizards from Fort George Cay, north-northeast of the release site, were displaced. Their initial headings were homeward, toward the area of human activity. All lizards, during at least the first interval of freedom following displacement, moved in a direction within $43^{\circ}$ of that to their original capture point (arithmetic mean $=20.5^{\circ} \pm 11.7$, range $7-43$; geometric mean $=+0.5 \pm 21.6^{\circ}$, range $=43^{\circ}$ east to $14^{\circ}$ west of home direction). In no case was it believed possible that displaced lizard had ever visited the area of their displacement. Therefore, despite the small sample size directional navigational abilities are strongly indicated.

Unfortunately the lizards did not maintain their initial directional movements. This might suggest a failure of their navigationa! mechanism, 


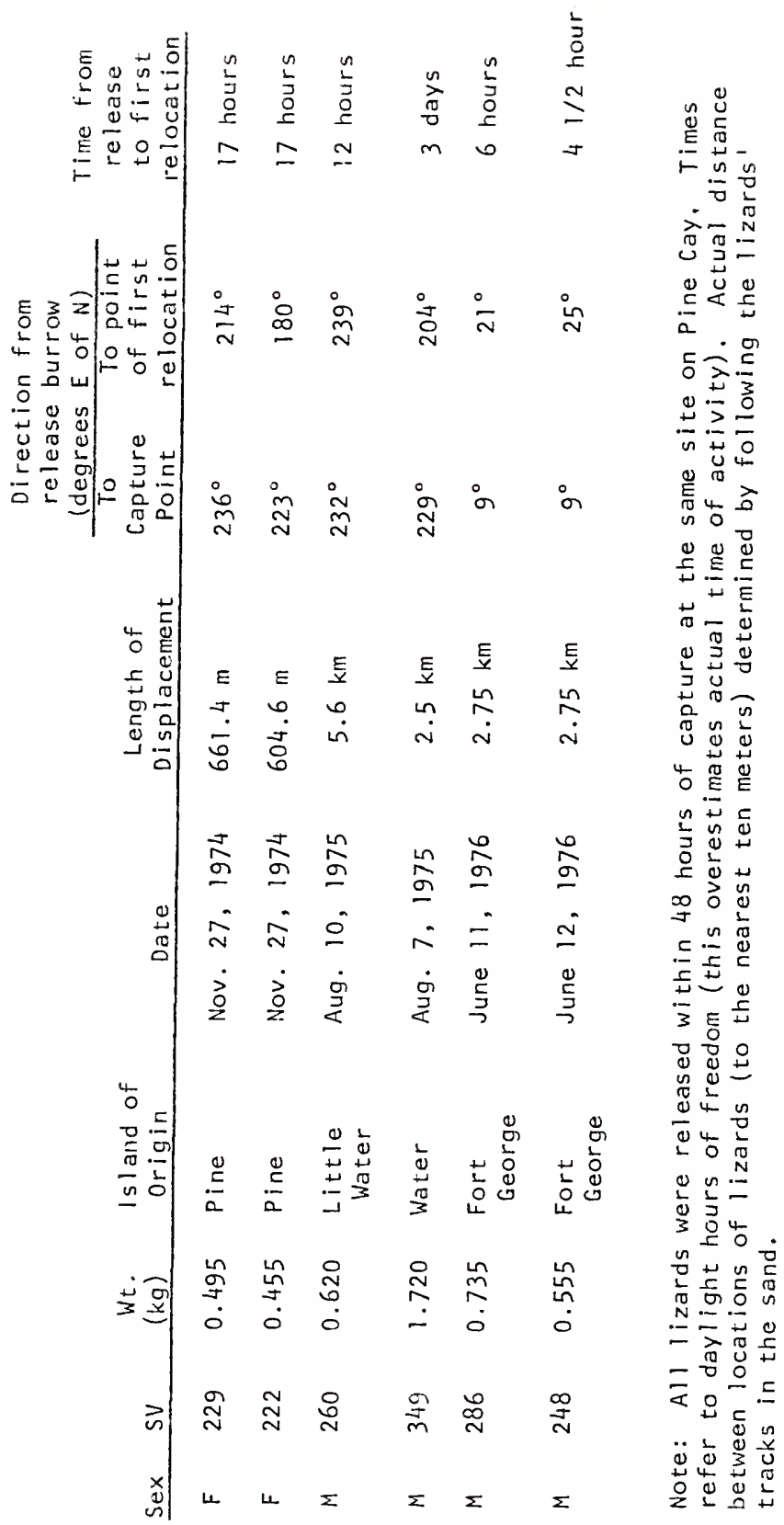




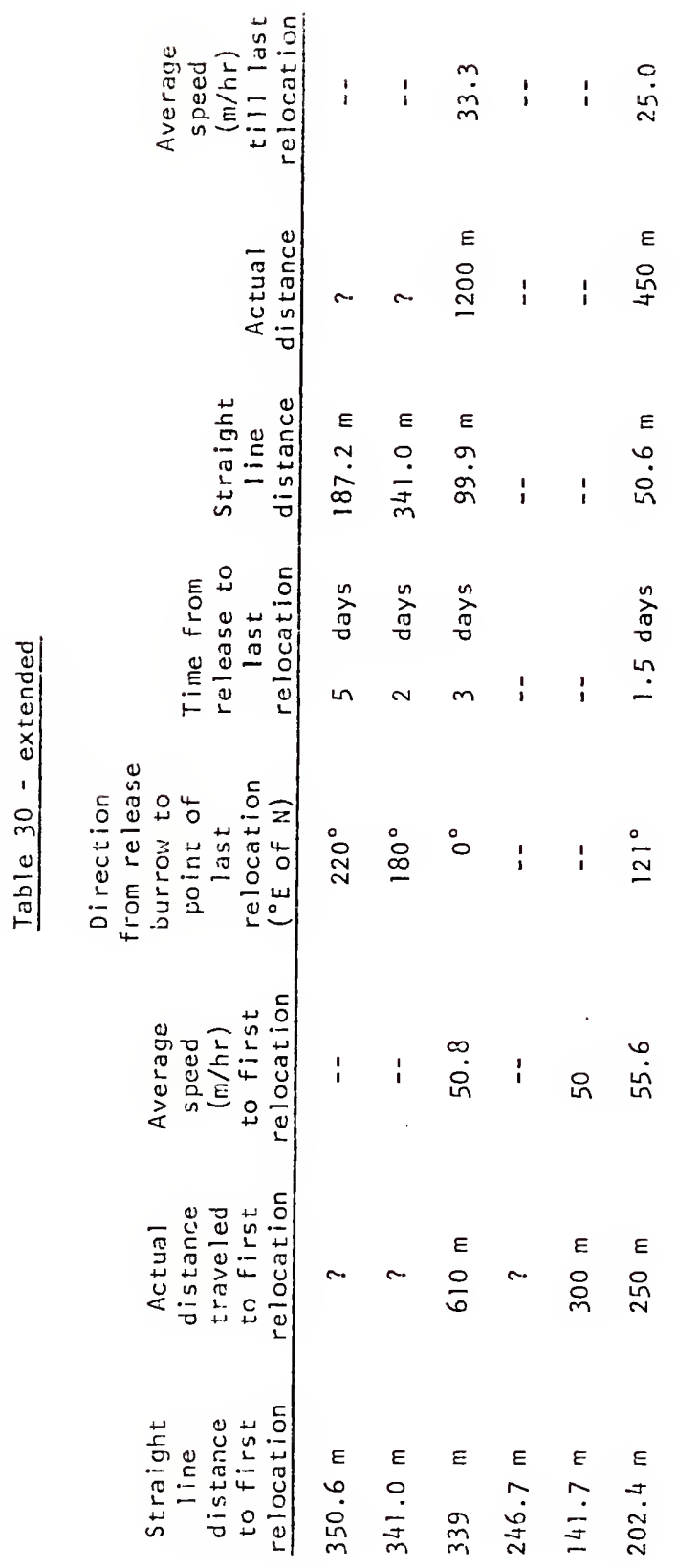


but might also reflect their reactions to disturbances inherent to relocation. As these lizards often simply buried themselves in the leaf litter in the center of huge patches of Coccoloba, they were apparently well aware of my presence (and that of a beeping receiver) long before their precise location was determined.

Since females of at least Cyclura cornuta (Wiewandt, in preparation) and Iguana iguana (Mongtomery et a1., 1973), among the iguanines, migrate long distances year after year to the same nesting areas (and presumably return to their normal activity ranges), homing ability in Cyclura carinata might be expected. Further study is needed on the entire subject of homing in lizards (see review in Weintraub, 1970).

With the present availability of biotelemetric equipment (including radioactive marking), structured experimentation using large sex and age samples displaced over a variety of distances could be very enlightening. Of particular importance is the relationship of the size of a lizard's normal activity range to his homing ability. Return success in Sceloporus orcutti decreased considerably for displacement distances not greatly exceeding the lizard's home range diameter (Weintraub, 1970). However, I observed Cyclura carinata make occasional forays beyond the periphery of their nomal activity range for distances up to twice its diameter in order to exploit a temporary food source. I believe that Cyclura could home successfully after displacement up to 3 or 4 times the normal activity range diameter; but lizards in this study were displared at least 20 times that diameter. 
SOCIAL ORGANIZATION

\section{Displays}

Iguanid lizards are typically diurnal and communication is mainly via visual sensory modes. Tactile communication may be important in some interactions, such as courtship, but in general, very little information is probably exchanged via the tactile, auditory, or chemical-olfactory sensory modes. All iguanid lizards apparently perform stereotyped displays, typically with head movements or "bobs" (Carpenter, 1967; et al.). These displays are believed to function primarily in intraspecific interactions, including aggression, assertion and courtship. They exhibit both individual and geographic variation within lizard species (e.g. Ferguson, 1971; Jenssen, 1971; Crews, 1975a), and are thought to serve in species recognition (Ferguson, 1972) and possibly, sexual and/or individual recognition (e.g. Berry, 1974).

Displaying rock iguanas were videotaped in the field and laboratory. f.ll head bob disolavs (except the male courtship display; see REPRODUCTION) contained the same basic units (Figure 49). I follow Stamps and Barlow (1973) in calling these apparently species-constant headbobs the 'signoture' displays or bobs. This term is preferred to the "assertion" display of Jenssen (1971) and others, since, in at least cyclura carinata, it is rarely perfomed in an assertive context.

Unlite many Anoline lizard species which exhibit complex display or head bot repertoires (Stamps and Barlow, 1973; Jenssen, 1975), that of 
Figure 49. Display action pattern graph (DAP) for Cyclura carinata. Top: headbobs of female displaying submissively to approaching male (single, double, and single unit bobs); bottom: headbobs of same male in response to female display (three single unit bobs). See discussion of units in text. Numbers are time between bobs in seconds. Time increments are 0.06 second. Amplitude is proportional to distance from lizard's eye to the substrate. Graph is accurate to 0.015 second. 


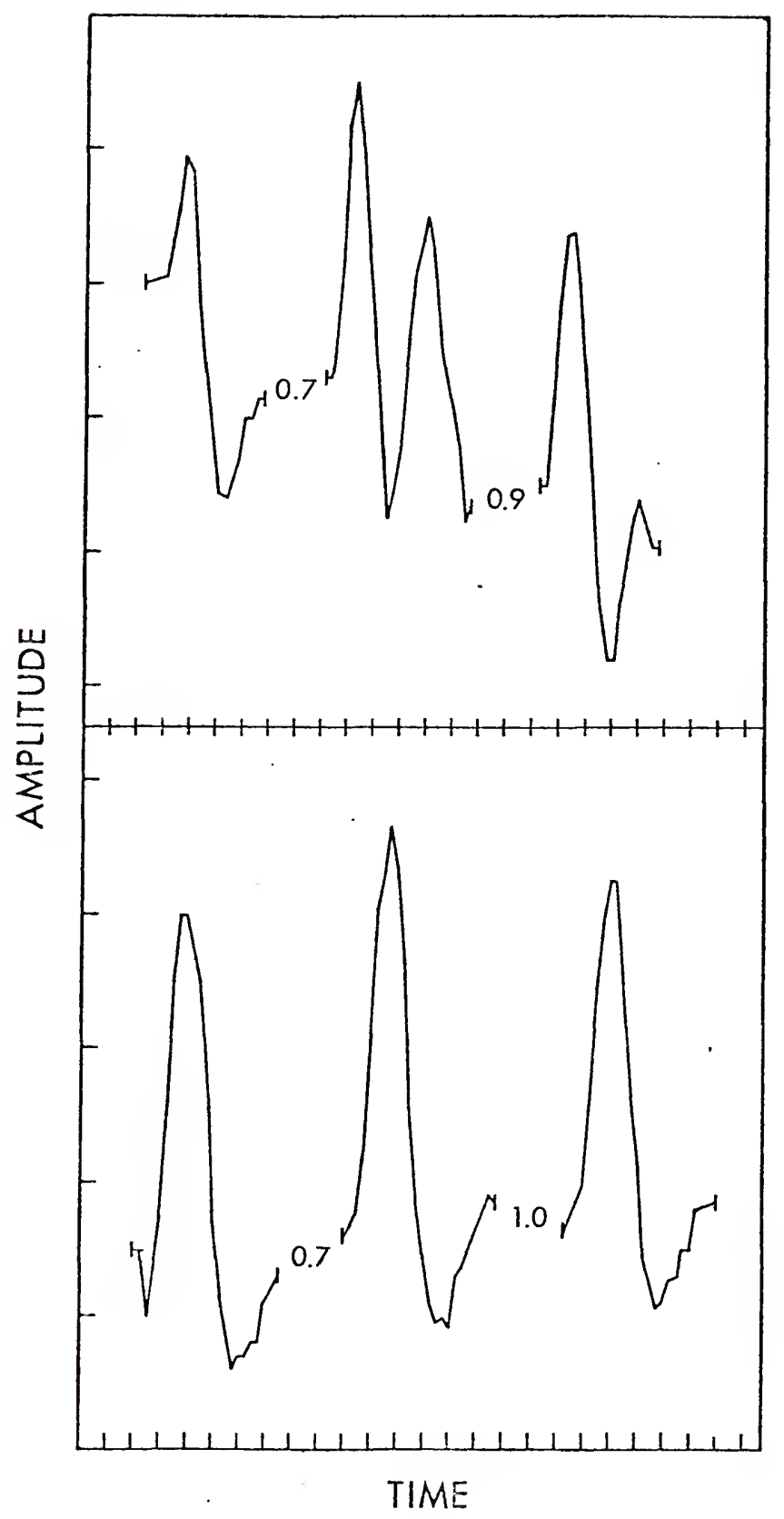


Cyclura carinata was relatively simple, with complexity involving frequency of conbination of only two signature units: a single, or a double vertical oscillation of the head. These units are illustrated in Figure 49 as they comprise a communication between two lizards. Each of the two units were very stereotyped. The single bob unit ranged from 0.28 to 0.35 second $(\bar{x}=0.31)$. Male single bobs averaged slightly longer than females $(0.33$ versus 0.28$)$, presumably because of the heavier heads of the larger males. Double bobs ranged from 0.37 to 0.50 second $(\bar{x}=0.44)$. The pauses between units of the same bobbing sequence ranged from 0.69 to 1.03 seconds $(\bar{x}=0.835)$.

Based on 40 interactions involving no more than two lizards and recorded in their entirety, the composition of a bobbing sequence differed between dominant males in their territories and other lizards. Dominant male sequences averaged 1.25 units (range 0 to $5 ;$ mode $=0$; median $=1$ ); other lizards averaged 5.475 units per sequence (range 1-13; mode = 3; median 5). Maxinum length for a dominant male sequence was 5.5 seconds (one single followed by four double units); maximum for other lizards was 12.3 seconds (four single, eight double, and one single).

Dominant males in 17 of 40 interactions did not display to bobbing subdominant lizards. If they did display, the sequence consisted most frequently of one to four single units $(\bar{X}=1.82 ; 11$ of 40 ; Figure 49, botto- $)$, or one to three double units $(\bar{x}=1.60 ; 5$ of 40$)$. In most of the rating seguences one or two single units either preceded or folloned one or two double units. In only one case did single unit(s) both precede and follow double units (two); the reverse was never true. The naan number of total single units in a sequence was 0.72 ; double units, 0.47 . 
Bobbing sequences of non-dominant lizards were much more variable. In most displays, $(37$ of 40$)$ zero to five single units preceded $(\bar{X}=1.68)$ or followed $(\bar{x}=0.84)$ (or both) one to eight double units $(\bar{x}=3.03)$. All but one sequence was composed of: 1) only single units (two cases of 40); 2) only double units (six cases); 3) single unit(s) preceding double unit(s) (12 cases); 4) single unit(s) following double unit(s) (seven cases); or 5) single unit(s) both preceding and following double unit(s) (11 cases; Figure 49, top). The remaining sequence consisted of two single units, followed by two double units, then one single unit, one double unit and finally one single unit. No other sequences had double unit(s) both preceding and following single unit(s).

The sequence of units in a display was not constant for individuals; great variation, related to emotional state, existed. There was a tendency for more excited lizards to use longer bobbing sequences, but this relationship was impossible to quantify. The reaction of a male caged within the territory of male $\# 8$ at the SW Blind illustrated this trend. As \#8 approached, the caged male bobbed a sequence including five single units followed by four double units. Male $\# 8$ postured threateningly but did not bob. The caged male responded with a foursingle-six-double-unit sequence. Lacking a response from $\# 8$, the male miade five single and three double unit bobs. Without responding further, \pm 8 simply moved off.

Further display variation involved several modifiers including gular, nuchal, and roach extension; mouth opening; and other postural changes. These modifiers permitted the scaling of behavior in relation to aggression levels. Cyclura cyclura did not perform pushups; bobs involved 
only the head and neck. Courtship and female rejection displays were discussed under REPRODUCTION; the other displays and their integration into behavioral patterns are discussed here. The frequency of use of each display type by each of several social categories appears in Table 31 .

Threat or Aggressive Display. In this primarily postural display the threatening male extended all four legs, raising and arching the body high above the ground; elevated the mid-dorsal roach, enhancing the prominance of the erect crests of neck and body spines; bloated and laterally compressed the trunk region; and inflated the gular region (Figure 50). The effect was an increase in the lizard's apparent size. These pastural changes were most pronounced during the challenge display (see below). Headbobbing usually accompanied this posturing but was only rarely initiated by the resident or dominant male; the intruding lizard usually bobbed first. Females employed a similar display during mating (male rejection) and nesting season (nest defense), but modified it with intense open-mouthed headbobbing and, in nest defense, short sidestepping lunges in the direction of the intruder (see REPRODUCTION).

Challenge Display. Performed by males only, this display was an intensification of the male threat display. The postures were the same, but further modified by headbobs (only rarely), short siderstepping linges (for maxinum laterel presentation), and lashing of the tail on the ground from side to side.

Submissive or Appeasement Display. Performed by both males and Ferales, this display always included signature headbobs, which themselves served a submissive or appeasing function. Subordinate males 
Table 31. Frequency of display types recorded for severa! categories of adult Cyclura carinata at the SW Blind in 1974 and 1975 .

\begin{tabular}{lcccc} 
Threat & $\begin{array}{c}\text { Dominant } \\
\text { Males }\end{array}$ & $\begin{array}{c}\text { Subdominant } \\
\text { Males }\end{array}$ & $\begin{array}{c}\text { Females } \\
\text { (except } \\
\text { nesting) }\end{array}$ & Total \\
\hline Challenge & 73 & 8 & 0 & 81 \\
\hline Submissive & 47 & 1 & 0 & 48 \\
\hline Total & 14 & 34 & 89 & 137 \\
\hline
\end{tabular}

Note: aexcludes lizard that retreated without displaying 


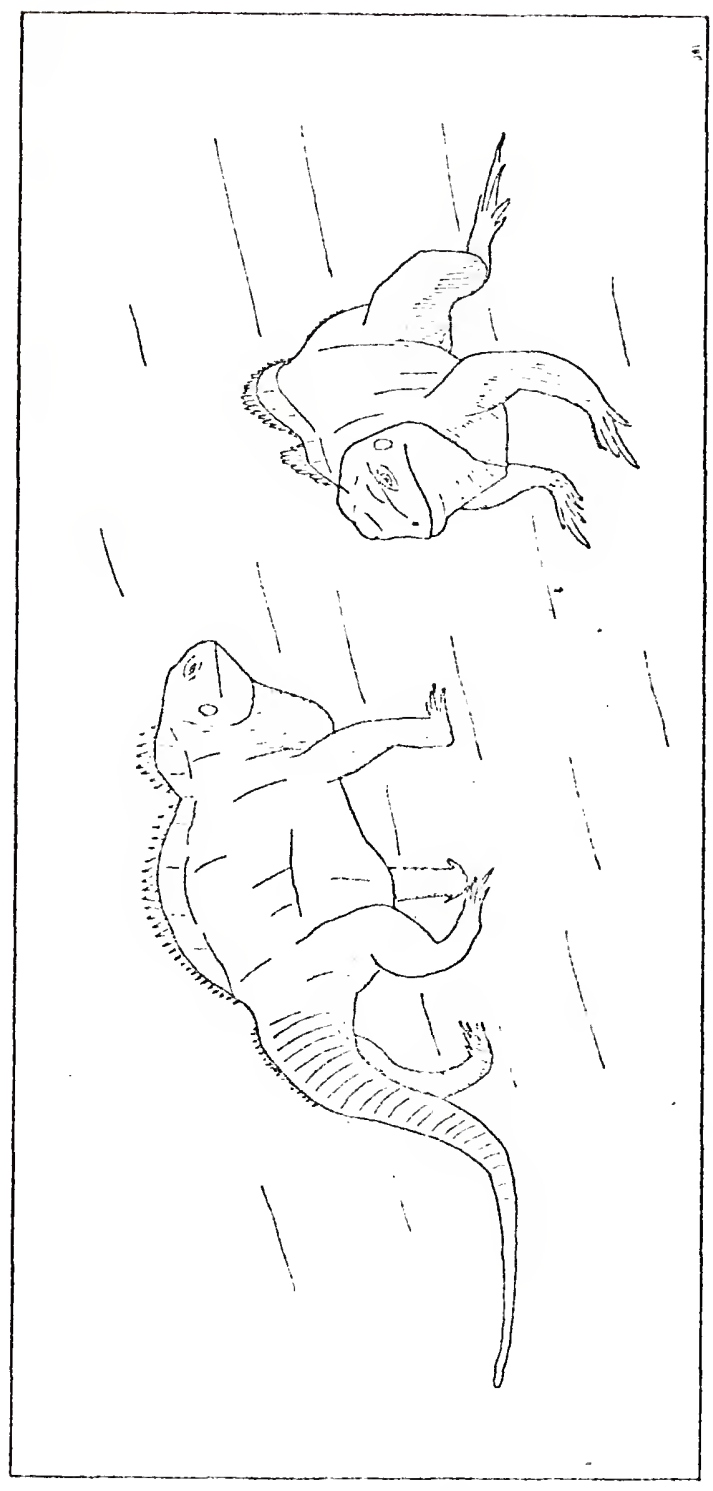

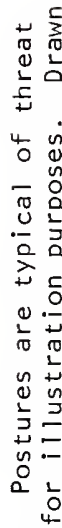

둼ำ

ㄴ.

4.

$\begin{array}{ll}0 & 0 \\ 1 & 0 \\ 0 & 1 \\ 0 & 0 \\ 0 & 0\end{array}$

4.

.

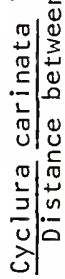

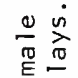

$\stackrel{0}{\frac{0}{2}}$

눔

웅

은

윤중

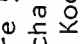

竞它 
modified the display by assuming a $10 \%$ profile with head and body on the ground. Sontimes the bobbing continued in the absence of response from a domirant. Large submissive males allowed their dorsal spines to lie to the side in an unerect position.

Exploratory Display. Females and subdominant and young adult males often arched the distal two-thirds of their tails hing in the air each time thay stopped as they maved through the bush (Figure 51). Dominant males arched their tails rarely and only when outside their territories. The tail was most often raised when the resident male was not in sight. 1 suspected this was a simple appeasement mechanism which prevented the attack of the explorer by some undetected (by the lizard) resident male before it could display submissively by bobbing. As iguanas did not otherwise display in the absence of conspecifics as Anoline and Sceloporine lizards often do (pers. observ.), this explanation is feasible. I was unable to quantify this behavior in the field, and captive individuals never exhibited it.

The communicating function of these various displays in Cyclura carinata is clear in the following typical sequences. A dominant, territory-holding male, on detecting another lizard in its vicinity, did not display, but rather assumed a simple alert stance, with forelegs extended, head high, and pelvic and tail regions on the ground. If the intruder was a very young adult male or a female (i.e. relatively small and lacking dorsal spine development) the resident male's further response was determined by the behavior of the approaching lizard. On seeing the resident male, the intruder immodiately displayed submissively. The resident male typically responded with a headbob display and the two 


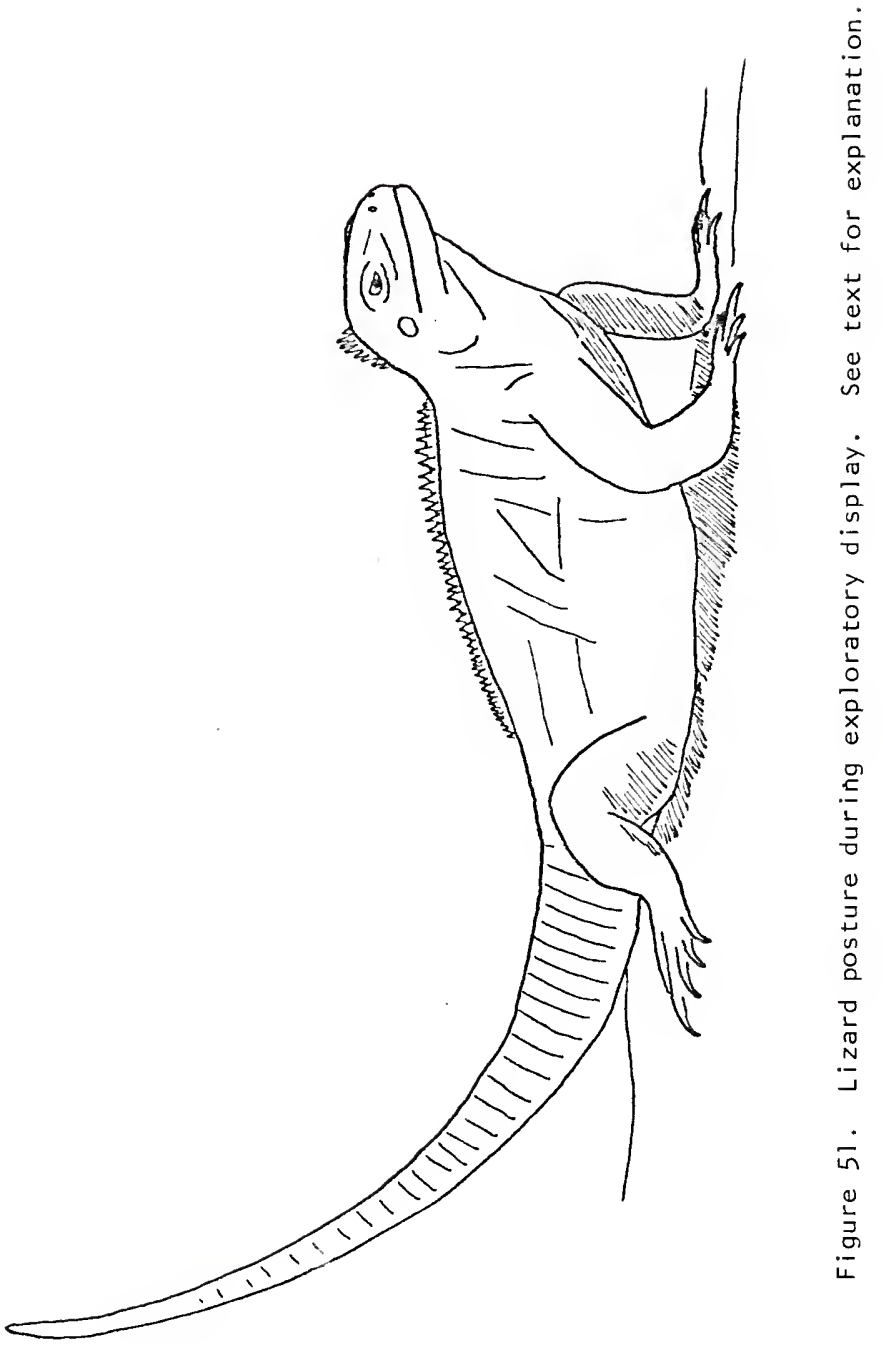


lizards exchanged up to five bobbing sequences, although the resident soentimes did not reciprocate with any bobbing. Perhaps he recognized the individual lizard; he certainly recognized it as no threat. This lack of response was typical in the case of juvenile intruders.

It was very clear that dominant males: 1) bobbed much less frequently than females or subdominant males; and 2) initiated very few bobbing exchanges. During 158 interactions involving no more than two lizards and observed in their entirety at the S!U 81 ind, dominant males performed only $18.4 \%$ of the bobs and initiated only $11.4 \%$ of the sequences; subdominant males performed $26.6 \%$ of the bobs and initiated $23.4 \%$ of the sequences. Females accounted for the remainder. Females and subordinate males also were most commonlv the last to bob during these exchanges. Table 32 shows a similar relationship among captive lizards. This reduced display frequency by the most dominant individuals is contrary to the pattern found in most other iguanid species (e.g. Carpenter, 1962). Since dominant male Cyclura are rarely challenged on their own territories, it is energetically advantageous for them to display only when necessary.

If an intruding lizard was recognized as a male, the resident territorial male quickly shifted from his alert stance to a threat display. The components of the behavioral sequence that followed were very constant and determined by the actions of the intruder (Figure 52). Since the sex of all but the youngest adult males is apparent (both to the observer and the iguanas) from the size of the dorsal neck and back spines (see GROWTH). spine development is probably the main criterion of sex recognition in the species. This is supported by the 
Table 32. Headbob displays initiated (left of slash) versus those answered (right) for various captive lizard pairs between April 23 and May 1, 1975.

\begin{tabular}{|c|c|c|c|c|c|}
\hline \multicolumn{2}{|c|}{$\begin{array}{l}\text { Initiator of } \\
\text { Bobbing sequence }\end{array}$} & \multicolumn{4}{|c|}{ Intended Respondent } \\
\hline $\begin{array}{l}\text { Lizard } \\
\#\end{array}$ & $\begin{array}{c}\text { SV } \\
(\mathrm{mm})\end{array}$ & $1 M$ & $2 M$ & $3 M$ & $4 M$ \\
\hline IM & 349 & $-\infty$ & 0 & 0 & 0 \\
\hline $2 M$ & 324 & $1 / 1$ & -- & 0 & 0 \\
\hline $3 M$ & 286 & $3 / 1$ & $13 / 2$ & -- & $3 / 2$ \\
\hline $4 M$ & 219 & $61 / 13$ & $4 / 0$ & $39 / 20$ & - \\
\hline $\mathrm{FF}$ & --- & 0 & 0 & $76 / 28$ & $9 / 7$ \\
\hline
\end{tabular}

Note: Courtship bobs and sequences involving more than two lizards are not included. Male status in hierarchy is indicated by 1 izard number ( $1=$ most dominant). Note infrequency of bob initiation and response by dominant males. $M=$ male; $F F=$ females. 
Intruding Male

Resident inale

Conspicuous appezrance
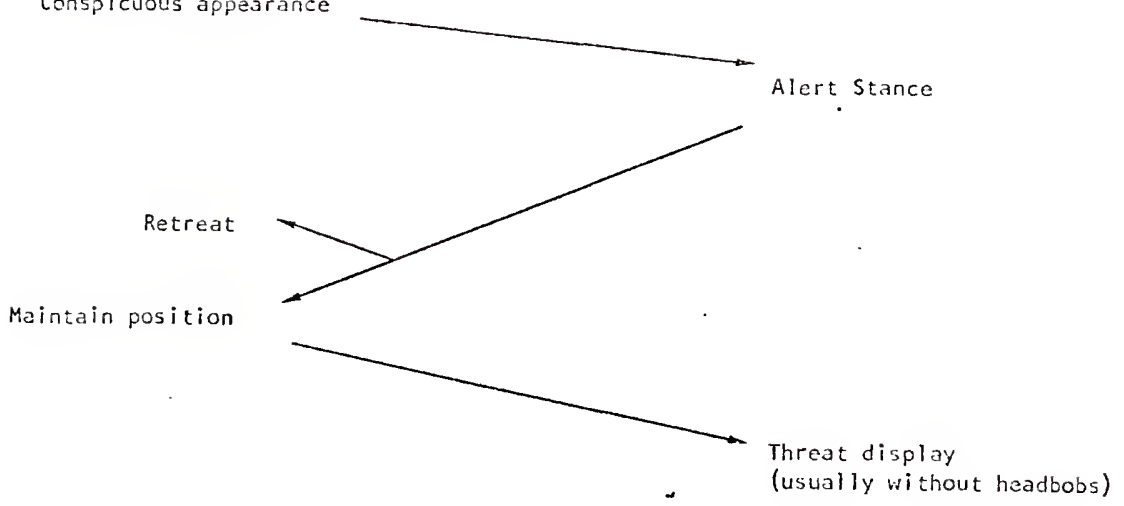

Retreat

(with or wi thout

subrissive display)

Return Threat display or Remain passive (with headbobs)

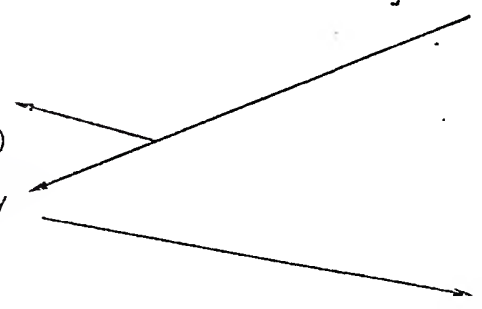

(usually without headbobs)

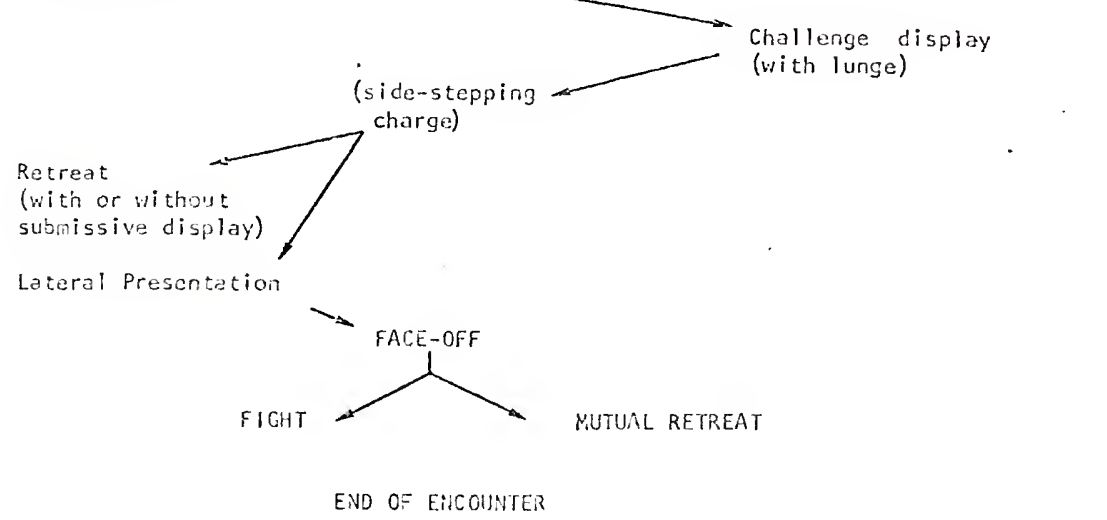

Figure 52. Behavioral components of territorial defense in Cyclura carinata. 
experiments performed at the SU Blind. Caged alien females or males without spine development placed in a male's territory never elicited a threat display; caged or tethered males with well-developed dorsal spines always did bne resident even attacked the cage). Females on which 1 mounted a crest of dorsal body spines (dissected from a preserved specimen) at first seemed to confuse resident males as they approached. The males sometimes approached rapidly in a very lowintensity threat display when they first saw the strange female, but terminated this approach quickly, apparently as they recognized the disguise. The smaller size, lack of neck spines, and subaissive displaying of the modified female probably contributed to his recognition. I never saw a dominant male 1) mistake the sex of a female and threat posture to her, or 2) refrain from threat displaying to a male with observable dorsal spine development. Young adult males without spine development were treated as females.

Presentation of a threat display by a resident to an intruding male was usually sufficient to cause the intruding male to flee (with or without a submissive display), usually with the resident male chasing after him. The resident male never overtook the chased lizard although in several cases he surely could have. If the encounter occurred just outside the intruder's territory, he retreated slowly, side-stepping as he went, in a low intensity threat posture. The resident did not chase the intruder in this case. If the intruder returned the threat display or sinply ignored the male, the resident increased the intensity of his display and charged with side-stepping lunges (challenge display). In only six cases at the SM Blind did this challenge fail to induce 
the intruder to flee. The intruder that refused to run oriented his body perpendicular to the lunging resident and continued his threat display. The resident always stopped his charge short of this theatening intruder and presented himself laterally in a "face-off" position (after Carpenter, 1967; Figure 50).

Fights followed four of the six face-offs observed in the field; both lizards withdrew following the other face-offs (2 July 1974 and 2 August 1975), side-stepping and threat posturing as they separated. In one of these instances, the lizards chased one another in circles from the face-off position before moving apart.

All four fights (16 July, 2 September, 29 November, 1974, and 8 April 1975) were between the same two males (\#33, and Y; both 285-290 $\mathrm{mm}$ SV) and occurred between their respective burrows along the road northeast of the SW Blind (Figure 42; intersection of arrows marks fights). Three of the four fights were observed in their entirety; one was video-taped as was part of antoher. Each fight was instigated when each male challenged the other, but neither withdrew. Lunging charges brought the lizards to face-off position. Bobbing was rare during face-offs or fights.

Fights began with the simultaneous open-mouthed charge of each lizard from the face-off position (about $0.6 \mathrm{~m}$ apart). Contact was cither cheek to cheek (only one fight), as in the ritualized fawsparring of Cyclura nubila (photographed in Street, 1952) and C. cornuta (Wiewandt, in preparation), or shoulder to shoulder (with adjacent forelers interlocked) as in Dipsosaurus dorsalis (Norris, 1953). Rostrum to rostrum contact as in nale Amblyrhynchus (Carpenter, 1966; 
Eibl-Eibesfeldt, 1955) was not observed. The lizards then attempted to push one another back. This was accompanied by tail thrashing, but the tai! was not directed at the opponent as in Dipsosaurus (Carpenter, 1961). Perhaps this tail movement increased momentum or traction, or was simply intended to intimidate the opponent. Although lizards had their mouths open during fights, I saw no biting. Scars and missing soines in the anterior trunk recions of several adult males suggest, however, that it does occur.

Pushing bouts (up to five) lasted four to ten seconds before the combatants suddeniy backed apart to a face-off position. Five to 15 seconds separated each pushing bout. The males missed each other's shoulder in the last three charges of one fight; they came to lie with their forelimbs on the posterior trunk and limbs of their opponents. This seemed to surprise them and they remained motionless for two to three seconds before breaking to again face-off. The loser of the fight was that lizard that during a face-off began to back away (laterally) from his opponent usually with his head inclined downward). Two of the fights were apparently draws as both lizards simultaneously withdrew, side-stepping and threat-posturing as they separated. Number 33 won the other two fights; after the first he remained stationary as $Y$ left the area, but after the second he lunged several times at $Y$ to prompt his retreat. From 30 to 70 seconds elapsed between the beginning of the first pushing bout to the withdrawal of at least one of the combatants.

Fighting is obviously rare even in populations as dense as those at the SW Blind. The fact that all four fights I observed were between 
the same two males in the area between their burrows is probably related to the fact that the distance between their burrows was the least of any pair of dominant male burrows 1 lacated and was much less than the average radius of territorial defense by males at the SW Blind (see later). The area between them must have been in constant dispute.

The fights of the male iguanines Cyclura carinata (this study), C. cornuta (Wiewandt, in preparation), ‥ nubila (Street, 1952), Dipsosaurus dorsalis (Norris, 1953; Carpenter, 1961), and Amblyrhynchus cristatus (Carpenter, 1966) are highly stereotyped, whereas those of Brachylophus fasciatus (Cogger, 1974), Conolophus (Carpenter, 1969), Ctenosaura similis (Henderson, 1973), and Sauromalus obesus (Berry, 1974) are apparently not.

Displays in other species of Cyclura have been poorly studied. The display of Cyclura rileyi on San Salvador (smaller than $\underline{c}$. carinata) includes both pushups and bobs (Diderot Gicca, personal communication); that of $\underline{c}$. cornuta on Mona Island (larger than Cyclura carinata) consists only of slow rolling of the head (Wiewandt, in preparation). This information suggests a size-related display complexity within the genus. Purdue and Carpenter (1972) observed a similar correlation among 21 species of sceloporus. Since it is more costly energetically for a large lizard than a small one to perform the same display, this decrease in display complexity in larger species is not unexpected. This energetic argument may explain the reluctance of large territorial male cyclura carinata to bob. Whether or not other species of Cyclura or iguanines follow this trend must await further study, however Sauromalus and Dipsosaurus (Berry, 1974; Carpenter, 1961; et al.) are smaller than 
c. carinata and employ pushups and headbobs, whereas Iguana iguana is larger and has a very simple bobbing pattern (Mueller, 1972).

Male displays in Cyclura carinata are probably extremely important not only in attracting females (as suggested by Berry, 1974, for Sauromalus). but in governing their reproductive physiology (as shown for Anolis by Stamps and Crews, 1976; et al.). These relationships within the Iguaninae deserve further attention since their longevity permits the formation of much more complicated male-female relationships than occurs in short-lived lizard species.

Displays were rarely used in interspecific interactions in the field; though iguanas sometimes bobbed at me when approached closely. Hunsaker and Burrage (1969) documented interspecific displaying among several species of iguanines, including cyclura nubila and $\underline{\mathcal{C}}$. cornuta.

\section{Dominance Relationships}

Territoriality Among Males

The concept of territoriality with respect to Cyclura carinata is precisely the same, whether defined functionally (an area where an individual or group has priority of access to the resources) or behaviorally (a defended area). The reader is referred to Kaufmann (1971) and Wilson (1975) for recent reviews and discussion of the concept.

Social structure in Cyclura carinata was controlled by dominant males, each with a large body size and a full or completely regenerated tail, a territory which he defended against other males, and a wellconstructed burrow. Females defended their nest sites during the 
nesting season and exhibited no dominance relationships during the remainder of the year in the field or captivity. Dominance among young adult males (those subordinate to territorial males) was infrequently observed in the field, but commonly seen in captivity.

Territory sizes for dominant males at the SW Blind were calculated using, as the radius of a circle, the mean distance from the burrow to the site of defense (challenge display or chase) against a neighboring territory-holder. These defense radi i ranged from 2.2 to $29.1 \mathrm{~m}$ (Table 33; Figure 42). The mean radius for 21 defenses involving five males was $18.98 \mathrm{~m}$, defining an average circular territory area of $1379 \mathrm{~m}^{2}$. Home range data for three of those males were complete enough to indicate that about one half to all of the home range was defended. Incomplete data for other territorial males suggested this estimate was high.

Territorial males at the SW Blind did most of their feeding within their territories. The similarity between average defense and feeding radii values in Table 33 reflects the daily movements of dominant males at the perimeter of their territories (patrolling?). Territorial males have undeniable priority of access to food and any other resource found within their territories.

Except during the nesting season, $\underline{C}$. carinata's social system permitted freedom of movement for juveniles, adult females, and subadult males, while greatly restricting that of mature males. In order to avoid aggression, subdominant males shuttled between the territories of one or more dominants arid apparently "free zones" between these territories. In many cases these subordinates had to occupy marginal or suboptimal areas, or colonize previously uninhabited areas. Thus 


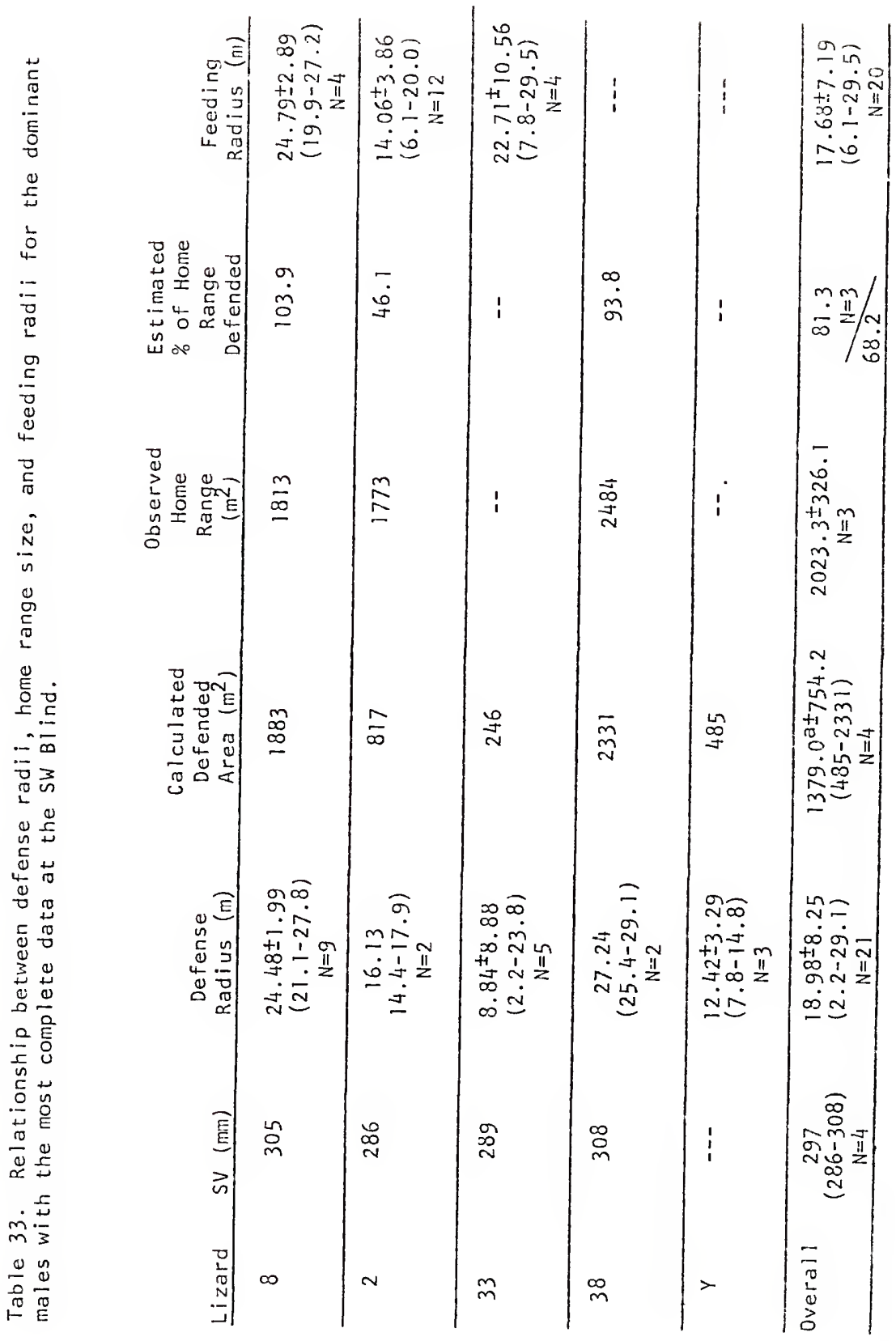




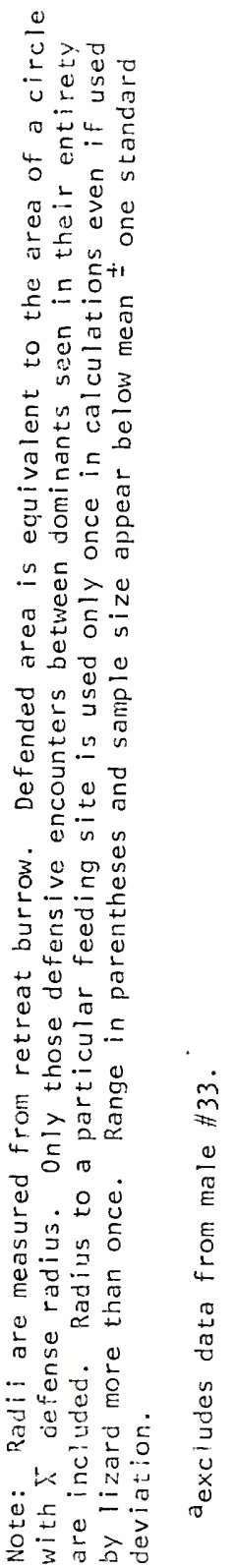


the distal two-thirds of the recently depostied $950 \mathrm{~m}$ sandpit on Little Water Cay was inhabited only by males. Dominance amonq male rock iquanas was reinforced not by bob frequency, but by posturing, chasing, ard, if necessary, fighting. The frequency of these aggressive acts among males at the SW Blind appears in Table 34. Threat displaying was the most frequent and least aggressive means by which a dominant males intimidated intruders ( $54.5 \%$ of all encounters). When unsuccessful in driving off an intruder, the threat was followed by a challenge display and chase. A face-off or fight resulted in only $7.5 \%$ of the observed encounters.

Although four fights were observed, I found no evidence that any of the dominant territorial males at the SW 81 ind were ever completely displaced. The territories of males that disappeared during the course of the study (presumably dog or cat-killed) were not immediately occupied by other big males. I believe that complete displacement of one male by another is rare in Cyclura carinata. Information on the rate of replacement of dominant residents in the field will require further study. Observations of one subdominant male at the SW Blind during each visit for two years provided some insight into the probable mechanism by which an adult male establishes dominance. The first lizard seen (December, 1973) and marked (March, 1974) at the SW Blind ( $/ 1$ ) measured approximately $245 \mathrm{~mm} S \mathrm{~V}$ and was at first mistaken by me as a female due to its undeveloped dorsal spines (see Figure 35) and the lack of aggression toward it by dominant male residents. By March and especially by June, 1974, his sex became obvious toth by the growth of his neck spines and by the insreased rale aggression toward him. 
Table 34. Aggression among male Cyclura carinata at the SW Blind during 1974 and 1975.

Lizards Involved

$\begin{array}{ccc}\text { Dominant } & \text { Dominant } & \text { Subdominant } \\ \text { to } & \text { to } & \text { to }\end{array}$

Encounter Dominant Subdominant Subdominant Total

Threat

41

32

5 78

Challenge

(with chase)

27

24

1

52

\begin{tabular}{lcccc}
\hline Face-off & 6 & 0 & 0 & 6 \\
\hline Fight & 4 & 0 & 0 & 4 \\
\hline Total & 78 & 56 & 6 & 140
\end{tabular}


This lizard used retreats within the territory of dominant male \#8 (305 mim SV) from December, 1973, through July, 1974, but spent most of its active time in the area of home range overlap of the four nearest doninant nales: \#8; \#6,300 $\mathrm{mm}$ SV; $\# 2,290 \mathrm{~mm} \mathrm{SV}$; and $\# 3,305 \mathrm{~mm}$ SV. This area was immediately to the west of the SW Blind (Figure 42). Like most other subdominant males monitored, \#1 used more than one retreat early in the study. In early June, 1974, he maintained three retreats and often alternated between retreats from one $n$ ight to the next. Each was only a small depression cleared beneath large flat rocks. Aggression from dominants during June and July continued to restrict \#I's activity to the area where their (the dominant's) ranges overlapped and finally, between 20 July and 30 August 1974, he dug a burrow precisely in that area (due west of the blind at the road's edge). From that time until his disappearance between November, 1975, and Apri1, 1976, (dogs dug his burrow up) he used only that retreat. During the same interval in which the burrow was dug, one of the nearby dominants disappeared (\#6, to the west) and this allowed \#1 additional freedom of movement in that direction. I believe that with further growth and experience $" 1$ would likely have become a dominant.

Because these lizards are so long-lived, experience probably plays an important part in the establishment of dominance. The youngest territorial males at the SW Blind were estimated to be six to seven years post-naturity. Thus while the chances of a young nale successfully displacing an older territorial male are small, his chances of outliving that nale and inhabiting his area are good, especially if he avoids the aggression of the dominant. The transition of dominance in a partic- 
ular area is clearly very slow; the abrupt displacement of one territorial male by another, rare. Maturing males, necessarily established in peripheral or socially "neutral" areas, apparently provide the major poal from which future dominant, territorial males will ascend.

The Evolution of Male Territoriality

The cost of defending an area must necessarily be exceeded by the resources gained or that behavior would lose its selective advantage (Rand, 1967). The energetic cost of defense in Cyclura carinata has been minimized by a general reduction in displaying by the dominants and by settling disputes via simple displays rather than by fighting. Although the latter strategy is common among territorial lizards, the former has been reported for no other lizard species except Varanus komodoensis ( $W$. Auffenberg, personal communication). Although access to other resources (e.g. basking sites) is also guaranteed, I believe that the primary advantages leading to the evolution of male territorial defense in this species have been in guaranteeing access to food, to females, and to permanent retreats (in probable order of decreasing importance).

Evidence presented under FOOD AND FEEDING suggests that food is the most potentially limiting of these three and is the primary resource defended. I hypothesize that territorial defense evolved in C. carinata (or its ancesior) as an atiempt to gain access to patchily distributed, $1 \mathrm{imited}$ food sources, such as the clumped thichets of Scaevola, Coccaloba, and Strumpfia found today in Open Scrub and Beach habitats on the study islands. A defending male would gain an immediate food and shelter 
advantage, and by permitting females to share the food source would also guarantee mating partners. The observed sexual dimorphism in this species would be expected as selection worked to reduce competition for food between males and their resident females (the evolution of small female body size), and to increase the effectiveness of male-male defense (the evolution of large male body size and display modifiers, such as dorsal spines). Similarly female nest defense probably evolved in response to competition for limited nest sites (see REPRODUCTION).

\section{Juvenile Aggression}

Hatchlings were aggressive as they emerged from nests. They were frequently seen chasing one another, as well as yearling Cyclura and adult Leiocephalus, during hatching season. Twenty such chases were observed during 24.5 hours of observation at the SW BI ind between $\mathrm{I}$ and 6 September 1974. This agonistic behavior effectively dispersed the neonates from the nest site. It apparently subsided within a month following hatching because it was not observed during November or December visits and since up to four juveniles greater than three months of age could occasionally be found in the same retreat.

\section{Population Effects of Social Systen}

Territoriality among male Cyclura carinata acts as an effective dispersal mechanism; non-territorial males are always available for colonization of newly abandoned or otherwise available habitats. Aggression among neonates also functions in dispersal.

The social system in Cyclura carinata probably also functions to limit population size via its restrictions on access to food and nest sites. Male territoriality can limit male population size only by 
restricting the access of subordinates to food. Since it does not affect the number of nesting fenales, it cannot ultimately limit the population. However, the success of a female in locating and defending an optimal nest site is directly related to the success of her brood. This is probably the primary mechanism limiting population size in this species. Bustard (1970b) and Philobosian (1975) have also suggested that social behavior limits population size in several other species of lizards.

\section{Dominance Hierarchies}

Dominance hierarchies have been shown to develop under crowded laboratory conditions in many normally territorial lizards (review in Carpenter, 1967). Among the iguanines, Amblyrhynchus cristatus (Pawley, 1969), Brachylophus fasciatus (Cogger, 1974), Dipsosaurus dorsalis (Carpenter, 1961), and Sauromalus obesus (Carpenter, 1967; Prieto, 1971), have shown similar shifts in social structure in captivity. In a field population studied by Berry (1974), dominant tyrant male Sauromalus obesus were territorial, while subdominant males were organized in a predominately size-related dominance hierarchy. Evans (1951) and Schmidt (1935) observel hierarchies in field populations of usually territorial Ctenosaura pectinata and Amblyrhynchus cristatus, respectively, in areas with reduced space for basking and/or refuge. Brattstrom (1974) evoked this transition among male ctenosaura hemilopha in an outdoor enclosure by combining numerous rock piles into one; each pile was originally defended by a single male. Although 1 found no evidence of dominance hierarchies in the field, adult male Cyclura carinata developed them, in the laboratory. 
Captive male hierarchies were 1 inear; the dominant or tyrant male had unrestrained access to the entire enclosure, including the primary feeding and basking areas. He also had priority of access to females; only dominant males copulated with females in captivity (see REPRODUCTION). Dominant males rarely bobbed (Table 32); subordinates moved very little and were constantly displaying submissively. Because of their positions in the hierarchy, these subdominant males were often unable to bask or eat at will. In sone cases they did not even leave their burrows for several days at a time. These lizards lost weight rapidly and would surely have died if I had not removed from the socially stressful situation.

In order to observe behavior involved in dominance shifts, I repeatedly removed and reintroduced males to the enclosure. 1 also partitioned the pen, with high-ranking males on either side, and later removed it when the lizards were active. None of these manipulations induced challenge displays, chases, or fights; a few produced threat displays. Dominance shifts in captivity were immediate and lacked aggression. As soan as a new male emerged from the remotely operated release box, he immediately assumed his position in the predominately size-related linear hierarchy, despite having never previously seen the other lizards. The lack of aggression in the following specific example was characteristic of all introductions.

Male 43 (286 m SV) was introduced into the captive enclosure on 23 April 1974 and immediately established dominance over two smallor males. He had freetom of access to the prinary feeding and basking stations and to the females for courting, and even chased smaller males 
a:vay from females (see REPRODUCTION). At 1153 hrs on 1 May, Male ( $349 \mathrm{~mm}$ SV) was introduced. During $31 / 2$ hours of observation during the 26 hours prior to releasing $\# 1$, \#3 did not bob to other males. However, when $\# 1$ male carried only half of his body out of the release box, $\# 3$ inmediately ran to the opposite end of the pen and bobbed submissively. Within the next hour he bobbed at least three more times to $\# 1$; \#1 never responded. Number 3 remained at the far end of the pen in the shade for the remainder of the day, bobbing occasionally, while \#l moved freely' between the main food source and the best patch of sunlight, without responding to \#3. I know of no lizard for which such a subtle unaggressive shift in dominance has been documented.

Since fights were so rarely observed in the field, I made many specific attempts to induce them in captivity, all without success. Despite continual manipulation (removal and reintroduction) of captive adult, similar-sized males in both David Auth's and my enclosures over 36 months, only one fight was induced in Auth's pen, entirely by chance. The following sequence of events leading to the fight in late August, 1975, was provided by Auth:

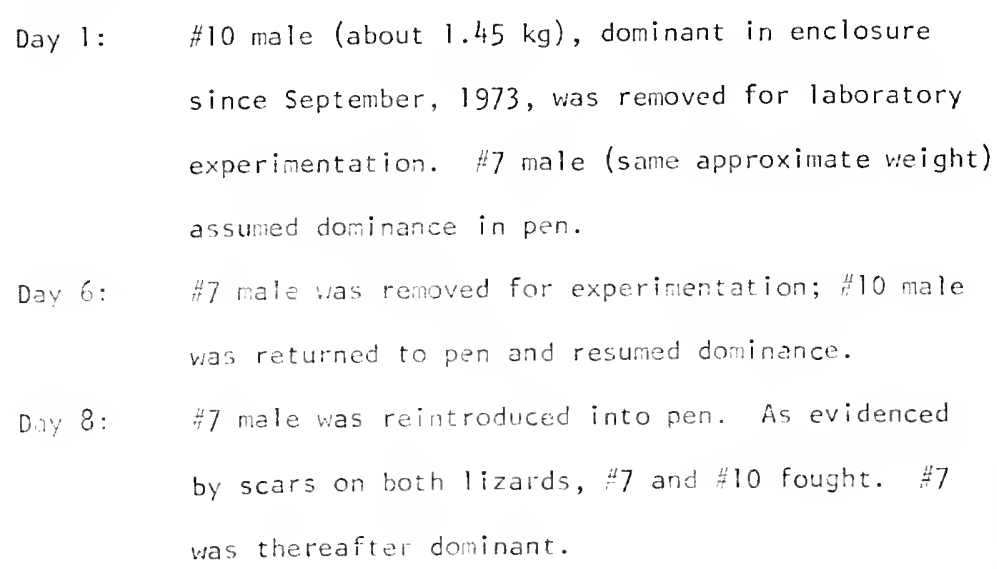


Very unusual physical, physiological, and psychological circumstances most obviously prevail for a male-male confrontation to result in actual combat.

A full or completely regenerated tail is extremely important to male social status. The rank of one male in the captive hierarchy decreased significantly when I accidentally broke his tail. He had been the dominant male, but following the break he greatly restricted his movements, appeared very nervous, and headbobbed more frequently. None of the dominant males at the SW Blind had tails freshly broken or incompletely regenerated.

\section{Mirror Experiments}

Mirrors were used in an attempt to elicit aggressive behavior, however no lizards responded to mirrors placed in their territories, either in the field or captivity. This was unexpected in light of the effectiveness with which mirrors evoke aggression in many other iguanids (Hunsaker, 1962; among others), and since the introduction of an adult male cyclura into a resident male's territory resulted in an immediate defensive reaction. Cyclura carinata may be able to detect the artificiality of the mirror and its images.

\section{Comparisons With Other Iguanines}

Some type of dominance relationships probably characterizes all natural populations of Cyclura (e.g. Hunsaker and Burrage, 1969; Wiewandt, in preparation; Carey, 1975), despite Carey's (1976) implication that neither teritorial nor hierarchial behavior are important in C. cychlura, 
based on his ten day visit to Guana Cay (Exuma Islands, Bahamas). I suspect that the Guana Cay population is only seasonally aggressive, perhaps in response to some seasonally $1 \mathrm{imited}$ resource such as mateable females or nesting sites. It may be too energetically costly for this species to defend territories or maintain hierarchies year-round. This might also be the reason that defense of territories by males is restricted to the breeding season in Amblyrhynchus and Conolophus (Wilson, 1975; et al.), some Mona Island Cyclura cornuta (Wiewandt, in preparation); Cyclura nubila (Street, 1952); Dipsosaurus dorsalis (Norris, 1953); and perhaps Iguana iguana (Alvarez del Toro, 1972). Male Cyclura carinata (this study), some male Cyclura cornuta (Wiewandt, in preparation), and male Sauromalus obesus (Berry, 1974), however, defend territories throughout their active seasons. In contrast, no female iguanines are known to exhibit territorial defense other than during the nesting season.

Our knowledge of the social organization of most Iguanine species is very incomplete. Basic information or social behavior, complimented by quantitative analyses of the availability of potentially limiting resources, is necessary for our better understanding of the evolution of dominance relationships within this subfamily. 


\section{INTERSPECIFIC COACTIONS}

\section{Natural Cohabitants}

Predation. The large size of adult Cyclura makes them almost invulnerable to predation by natural cohabitants; potential natural predators on adults are probably limited to birds. In addition to avian predators (and cannabalistic adults), juvenile iguanas may also fall prey to crabs, but no direct evidence of this was found. The Turks and Caicos Island boa, Epicrates $\subseteq$. chrysogaster, does not occur on Pine Cay, but probably feeds on Cyclura on islands where they are sympatric. No other reptiles reach a size large enough to take even the smallest iguana in these islands.

The Pearly-eyed thrasher (Margarops furcatus) was frequently seen successfully catching Anolis on Pine Cay and was once observed to capture and carry off an adult Leiocephalus psammodrommus in the same size range as one to two-year-old Cyclura carinata. This bird probably does eat young iguanas. The remains of the diurnal lizard Anolis scriptus have been found in Barn owl pellets (Tyto albo) from caves on Mayaguana Island, probably as a result of this lizard's habit of sleeping along exposed branches at night (Buden, 1974). Since Cyclura are not exposed during the night, it is unlikely that they are included in the diet of the barn owl, or the short eared owl (Asio flammcus), both of which have been recorded in the Turks and caicos Islands (Buden, personal communication).

In the Galapagos islands, the Lava Gul! (Creagrus furcatus), the diumal short-eared owl (Asio galapagoensis), the Galapagos Hawk (Buteo 
galapagoensis), and unidentified herons are all known to capture and feed on the marine iguana Amblyrhynchus and probably also on the two terrestrial species of Conolophus (Dowling, 1964; Carpenter, 1966). Ospreys (Pandion halioetus; Van Denburgh, 1922 and Shaw, 1945) and Sparrow hawks (Falco sparverius; Prieto and Sorenson, 1975b) prey on lizards of the Iguanine genus Sauromalus. Both the Laughing and Herring gulls (Larus atricilla and $\underline{L}$. argentatus) are known from the Turks and Caicos Islands and each is probably capable of subduing at least juvenile iguanas. Nine species of herons and egrets as well as the Frigate bird (Fregata magnificens) are also present and represent additional potential predators. Possible raptorial predators on Cyclura in the Turks and Caicos include the Osprey, Pigeon hawk (Falco columbarius) and Sparrow hawk. Anolis scriptus remains were found in the gut of a single Sparrow hawk (W. Auffenberg, personal communication).

\section{Introduced Cohabitants}

The native flora and fauna of the Galapagos islands are threatened with destruction by introduced goats, pigs, rats, dogs, cats, donkeys, and cattle (Dowling, 1964). All of these are also feral in the Turks and caicos, and each has had its destructive effects. In the caicos Islands, feral goats, pigs, and cattle are generally uncommon. This is no doubt due to the premium placed on non-fish food sources by the local people; feral cattle are hunted on uninhabited East Caicos. The effects of these introductions on iguanas have therefore been minimal. Such has not been the case for Cyclura cornuta stejnegeri on Mona Island where nearly 100\% of the lizards' nests in one area were 
destroyed by pigs in 1972, and the annual loss was about 25\% (Wiewandt, in preparation).

Rats and mice are probably found on nearly every island in the Turks and Caicos. Rabb and Hayden recorded rats on uninhabited Fort George Cay in 1957. Previously destructively high rat densities on Pine Cay have recently decreased considerably due to the introduction and proliferation of feral cats. Although I was unable to detect any effects of these introduced rodents on Pine Cay lizard populations, Whitaker (1973) and Crook (1973) have documented decreased 1izard densities (including Sphenodon) on islands off New Zealand inhabited by the introduced Polynesian rat (Rattus exulans). Cyclura is probably susceptible to predation by rats throughout its life.

As is the case for many of the wildlife species in the United States (Denny, 1974), dogs and cats represent the greatest threat to Pine Cay lizard populations. Dogs frequently range over the entire island in a single day. They often cross the sandy isthmus to water Cay and have been observed making forays on its most southerly shores, nearly $5 \mathrm{~km}$ from human habitation. In 1976 they began swimming the channel north of Pine Cay to reach Fort George Cay and its iguanas. Dogs were frequently observed chasing and killing adult cyclura, and attempting to dig up lizards they had chased into retreats. This latter behavior is probably responsible for the deaths of nore iguanas than direct predation, since the dogs frequently succeed only in plusging the lizard's burrow, entombing it within. Dogs on Pine Cay apparently chese and kill Cyclura mainly for sport; since they are regularly fed by humans, they leave as many carcasses as they consume. 
Nunerous freshly killed iguanas were taken literally from the mouths of dogs (and cats). On several occasions only portions of the bodies could be salvaged. Dried carcasses of 18 obviously dog-killed cyclura were collected on Pine Cay and Water Cay during field work, although rany more were seen. As long as free-ranging dogs are present on Pine Cay, the Cyclura population there is doomed to complete extirpation. Grant (1937) and Hirth (1963b) both recognized dogs as the most serious predator on Cyclura pinguis and Iguana iguana, respectively.

The force most destructive to the Pine Cay Cyclura population is unquestionably feral house cats (Felis domesticus). Rand (1967) also believed that domestic cats were the most important predators on Anolis lineatopus in Jamaica. Their detrimental effects on natural ecosystems are well documented (George, 1974; Coman and Brunner, 1972; and review in McKnight, 1964). Domestic cats on Pine Cay employ at least three foraging strategies to obtain lizards, depending on the time of day with respect to the lizard's activity cycle. During early morning hours before lizard emergence, cats are able to find and dig up shallow burrows inhabited by Leiocephalus and juvenile Cyclura. This is presumably also the case during late afternoon following submergence, although this was not documented. I have seen cats with freshly caught lizards in their mouths as early as 15 to 20 minutes before sunrise. As lizard burrows have a distinct odor, detectable at their entrances by even the human nose, I believe that cats are capable of following the odor gradient to its greatest concentration at the burrow. Support for this comes from observations made when captive juvenile cyclura placed in plastic bags were occasionally brought into my quarters for measure- 
ment. Within minutes, cats were scratching at the door to gain entry. If allowed to enter they would always find the lizards within 30 seconds, even when the plastic bags were hidden under cloth bags atop an overhead shelf. Such macrosmatic capabilities greatly decrease search times and increase prey capture success.

As emergence time approaches, cats employ their usual sit and wait strategy (Christian, 1975) near lizard burrows. Emerging torpid lizards are a very easy prey, and Leiocephalus and juvenile cyclura suffer heavy mortality by this method. This technique is also commonly used by natives in securing adult Cyclura for food. This sit and wait strategy is to some extent used during the lizard's normal activity period, but active stalking is much more common. Cats were observed to take Cyclura up to $235 \mathrm{~mm}$ SV and 510 grams, subduing them immediately with neck bites. Unlike dogs, cats always ate the lizards they killed. Only three scats from feral cats on Pine Cay were found during the course of the field work, but two of these contained skin and skeletal elements of adult iguanas. During two months of field work during early suminer of 1974, pet cats were observed daily bringing lizards (Leiocephalus and cyclura) to their kittens. Most of the offspring of the cats became feral as they matured, and thus subsisted entirely on other animals. Although rot as efficient as cats and dogs, man represents the next most important predator. Natives capture lizards to supplement their diets with snares or by excavating burrows. This results only in the death of those lizards which are caught. Tourists and non-native residents use guns, usually pneumatic, to shoot iguanas. No better reason is offered than the novelty of providing the fare for an "iguana 
roast". Unfortunately for every iguana that is shot and killed outright, many others are mortally wounded and destined to die in their retreats.

Some Cyclura populations have experienced predation by native fishermen for hundreds of years (Middleton and the Ambergris Cays, for example) with no apparent threat of extirpation. However, iguanas have been extirpated or very nearly so on every island in the Turks and Caicos inhabited by feral cats or dogs. The effects of these unnatural predators cannot be underestimated.

Defensive Behavior. When disturbed during early morning or late afternoon, or in sparsely vegetated areas, Cyclura carinata run directly to and into their burrows. During mid-day in thickly vegetated areas, however, the lizards simply run to a new location at some "safe" distance. Most of the attempts to chase adults into their burrows during mid-day at the SW Blind were unsuccessful. This behavior unfortunately contributes to the ease with which feral dogs and cats are able to capture the lizards. Cyclura carinata exhibited considerable interisland differences in shyness. This phenomenon appeared to be related to past interference by man, and domestic and feral mammals. Lizards on small islands rarely visited by humans were quite tame and would allow approach to within a meter or two. On those islands with heavy human traffic, the mere sight of a human often elicited an escape reaction in the lizards. The lizards on Pine Cay fell about midvay between these two extremes. Like Sauromalus (Van Denburgh, 1922) Cyclura defend themselves by beating their adversaries with their tails. To prevent extraction from crevices and burrows, Cyclura inflate their bodies as in Sauromalus obesus and Dipsosaurus dorsalis (Van Denburgh, 1922). 


\section{Broken Tail Frequency}

Cyclura carinata commonly exhibited broken and regenerated tails; individuals with up to three tail forks have been captured. Digits were also cominonly missing; one adult female collected on Little Water Cay had the lateral four digits on her right rear leg missing. Two juveniles from Little Water Cay each lacked their entire front left legs. External scars were so slight that the possibility of genetic anomaly was suspected. In each case, the musculature of the remaining foreleg was greatly hypertrophied and the lizards seemed not to be hindered by the impaiment.

The incidence of broken and regenerated tails in lizards is often used as an indication of predation rates (Pianka, 1967, 1970; Tinkle and Ballinger, 1972; Parker and Pianka, 1973). As suggested by Parker and Pianka (1973), however, and substantiated by Vitt et al. (1974), social interactions, especially male territorial defense, are responsible for some broken tails.

$\therefore$ ong the iguanids at least Sceloporus magister (Parker and Pianka, 1973; Vitt and Ohmart, 1974; Vitt et al., 1974), Urosaurus graciosus (Vitt and Ohmart, 1974), Urosaurus ornatus (Vitt, 1974), and some populations of Sceloporus undulatus (Tinkle and Ballinger, 1972) exhibit increasing tail break frequencies with age, presumably due to greater exposure to predators and conspecific conflicts. Adult males of these species also had broken tails more often than females, probably because nales are exposed more during territorial defense.

In Cyclura carinata there is a general tendency for increased frequency of tail breaks with age, but there appears to be a secondery 
decline in very large (presumably very old) lizards (Table 35; Figure 53). This is perhaps because of the social ramifications of tail loss in this species. Experimental and natural observations indicate that social status declines in males experiencing tail loss; adult lizards with abbreviated tails were always subordinant to lizards of equal size (sometimes smaller) under captive conditions (see SOCIAL ORGANIZATION). It would presumably be much easier for a challenging male to usurp the territory of a male who had just lost his tail. Considerable time and energy would then necessarily have to be expended by this lizard, first, to regenerate his tail, and second, to re-establish and maintain a territory. This does not even take into account the increased probability of conflict with other territorial males, the decreased certainty of food sources, and the concomittment increase in exposure to predators. Such a series of events must greatly reduce the likelihood of the lizard's survival to large adult size. An analogous decrease in social status and therefore prospect for survival, would result from tail loss in females even though their territorial behavior is confined to the nesting season. With this information, it is not surprising that very large lizards tend to exhibit fewer broken tails than young adults.

The higher frequency of tail breaks among males of other lizard species is absent in Cyclura carinata (Table 35). No significant sexual differences in frequencies within size classes, or island populations (or both) were found. Unlike males, which are territorial throughout the year, female C. carinata are territorial only during and following nesting. Females also have smaller activity ranges. However, both male and female strategies appear to be equally expensive with respect to tail 
Table 35. Frequencies of broken regenerated tails by size class, sex, and island for Cyclura carinata.

\begin{tabular}{|c|c|c|c|c|c|c|c|c|}
\hline & & & & & $\mathrm{SIZE} \mathrm{Cl}$ & ASS & & \\
\hline & & & & 1 & & & 111 & \\
\hline & & & $75-124$ & $\mathrm{~mm} \mathrm{SV}$ & 125 & 64 & $\begin{array}{ll}F & 165-1 \\
M & 165-1\end{array}$ & \\
\hline Island & Sex & $\begin{array}{c}\text { Sample } \\
\text { Size }\end{array}$ & $\begin{array}{l}\text { Number } \\
\text { broken }\end{array}$ & $\%$ & $\begin{array}{l}\text { Number } \\
\text { broken }\end{array}$ & $\%$ & $\begin{array}{l}\text { Number } \\
\text { broken }\end{array}$ & $\%$ \\
\hline Pine Cay & $F$ & $N=56$ & 2 & 10.0 & 1 & 33.3 & 0 & - \\
\hline & $M$ & $N=56$ & 1 & 6.25 & 3 & 37.5 & 0 & - \\
\hline Little & $F$ & $N=17$ & 0 & - & 1 & 100.0 & 0 & - \\
\hline Water Cay & $M$ & $N=16$ & 0 & - & 0 & - & 0 & - \\
\hline Water Cay & $F$ & $N=7$ & 1 & 100.0 & 0 & - & 0 & - \\
\hline & $M$ & $N=10$ & 0 & - & 0 & - & 0 & - \\
\hline All four & $F$ & $N=84$ & 3 & 12.0 & 3 & 50.0 & 0 & - \\
\hline $\begin{array}{l}\text { study } \\
\text { islands }\end{array}$ & $M$ & $N=86$ & 1 & 5.56 & 3 & 33.3 & 0 & - \\
\hline
\end{tabular}

Note: Percentages indicate proportion of particular size and sex sample with tail breaks. Only data for sexed lizards are included. Juvenile size classes (I, 11 , and III) each approximately represent a two year growth interval. Due to sexual dimorphism in size, adult size classes were defined to include females and males of approximately the same ages. 
Table 35 - extended

\begin{tabular}{|c|c|c|c|c|c|c|c|}
\hline & & SIZ & CLASS & & & All size & \\
\hline 1 & & 7 & & VI & & classes & \\
\hline F 19 & 214 & $\mathrm{~F} 21$ & 239 & F over & 240 & combinec & \\
\hline$M 20$ & 249 & $M 25$ & 299 & M over & 300 & & \\
\hline $\begin{array}{l}\text { Number } \\
\text { broken }\end{array}$ & $\%$ & $\begin{array}{l}\text { Number } \\
\text { broken }\end{array}$ & $\%$ & $\begin{array}{l}\text { Number } \\
\text { broken }\end{array}$ & $\%$ & $\begin{array}{l}\text { Number } \\
\text { broken }\end{array}$ & $\%$ \\
\hline $\begin{array}{l}5 \\
0\end{array}$ & $\begin{array}{c}41.67 \\
-\end{array}$ & $\begin{array}{l}8 \\
8\end{array}$ & $\begin{array}{l}57.1 \\
42.1\end{array}$ & $\begin{array}{l}1 \\
4\end{array}$ & $\begin{array}{l}25.0 \\
44.4\end{array}$ & $\begin{array}{l}17 \\
16\end{array}$ & $\begin{array}{l}30.4 \\
28.6\end{array}$ \\
\hline $\begin{array}{l}2 \\
4\end{array}$ & $\begin{array}{l}66.7 \\
80.0\end{array}$ & $\begin{array}{l}1 \\
2\end{array}$ & $\begin{array}{l}16.7 \\
50.0\end{array}$ & $\begin{array}{l}1 \\
2\end{array}$ & $\begin{array}{l}50.0 \\
50.0\end{array}$ & $\begin{array}{l}5 \\
7\end{array}$ & $\begin{array}{l}29.4 \\
43.8\end{array}$ \\
\hline 0 & - & 1 & 100.0 & 0 & - & 2 & 28.6 \\
\hline 0 & - & 2 & 50.0 & 1 & 20.0 & 3 & 30.0 \\
\hline $\begin{array}{l}7 \\
4\end{array}$ & $\begin{array}{l}41.2 \\
36.4\end{array}$ & $\begin{array}{l}10 \\
14\end{array}$ & $\begin{array}{l}50.0 \\
48.3\end{array}$ & $\begin{array}{l}1 \\
6\end{array}$ & $\begin{array}{l}11.1 \\
35.2\end{array}$ & $\begin{array}{l}24 \\
28\end{array}$ & $\begin{array}{l}28.6 \\
32.6\end{array}$ \\
\hline
\end{tabular}




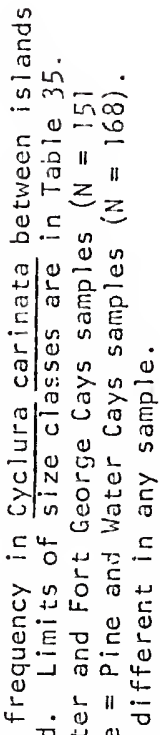

吕岕

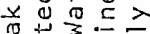

:

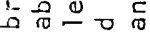

다워

$=\div \frac{5}{5}$

곡

$40110 \frac{5}{0}$

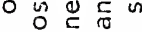

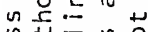

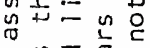

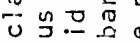

บ 그용

N 2 i 0 i 03

ज $>\frac{5}{0}$

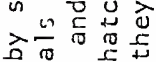

包 n

ᄃ

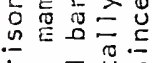

的品舟

돈동

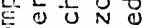

$04 \div$

>동

- $\lambda$

mi

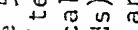

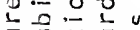

วั0

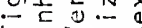




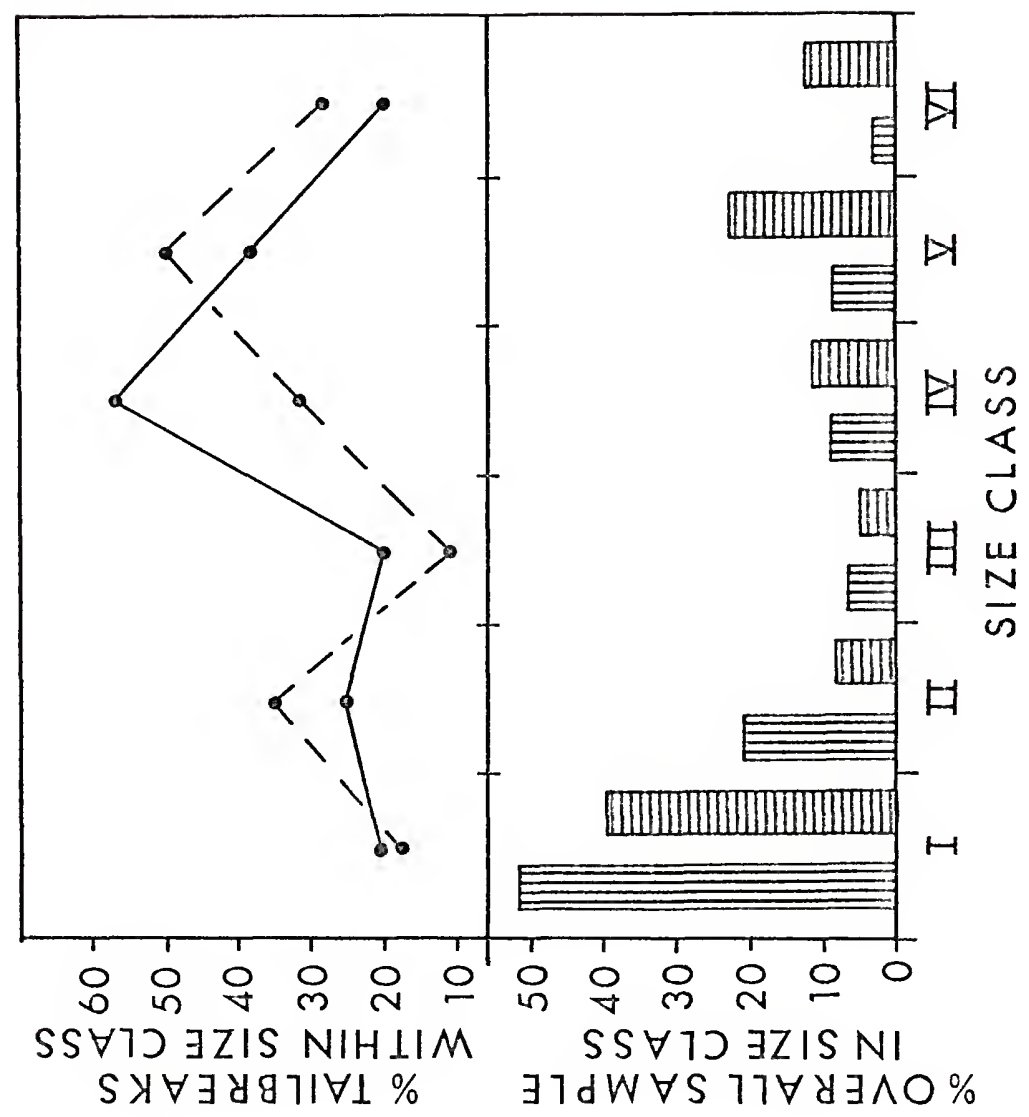


breakage. The lack of territoriality in nesting females in lizard species for which tailbreak frequency has previously been studied perhaps accounts for the observed disparity in the proportions of males and females with broken tails in those species.

Interisland comparisons of tailbreak data indicate only slight differences. Even when all size classes were lumped together, approximately $30 \%$ of the captured lixards of each sex had broken tails, no matter on what island the collection was made. This might suggest similar rates of predation on all the islands, which is very definitely not the case. Little Water and Fort George Cays are essentially free of introduced predators, while Pine and Water Cays are overrun with them. The similar interisland tailbreak frequencies perhaps show the greater importance of causes other than predation in determining observed tailbreak frequencies.

\section{Epifauna}

Ticks of the genus Amblyomma have been recorded as parasites of Cyclura cornuta (Robinson, 1926; Carey, 1974); C. nubila (Robinson, 1926); ‥ pinguis (Kohls, 1969); and Cyclura cychlurae and $\underline{C}$ rileyi (Carey, 1975). Amblyomma cruciferum was found on C. cornuta; A. albopictum on $\underline{C}$. nubila (Robinson, 1926); and $\underline{A}$. antillorum on $\underline{C}$. pinguis (Kohls, 1969); no specific identifications of the ticks occurring on the other lizard species are available. Ticks were present on $\underline{C}$. carinata in Caicos islands on only a single specimen from Lon Cay. The specimen bore approximately 15 ticks along the lateral regions of its abdomen and in its axillary and inguinal regions. No other ticks were found on over 250 additional lizards checked in the Caicos 1slands. 
The low infestation rate, the proximity of Long Cay to the principal port of entry (by air or sea) to the Caicos 1 slands and the frequency of human and pet visitation to the island, suggest the possibility that these ticks have been recently introduced in the caicos. The ticks have been forwarded to Cluff E. Hopla for study.

\section{Endofauna}

Oxyuroid nematodes were found in the "caecae" of nearly all Cyclura carinata dissected. Infestation begins soon after hatching. Although neonates collected in September lacked intestinal worms, by late November and December nearly all lizards contained small caecal nematode faunas (less than 100 worms). The worm burden increases with age. From counts of nematodes in known homogeneous volumes of caecal digesta, estimates of total macroscopic worm burdens exceeded 15,000 in typical adults $(300-320 \mathrm{~mm}$ SV).

1 isolated at least three different nematodes from the "caecae" of Pine Cay Cyclura carinata. Four species (Cyrtosomum mega, Travassozolaimus travassori, Macracis microtyphlon and Mamillomacracis cyclurae) have been described from the intestinal tract of cyclura carinata, but whether the described species correspond to the forms I noted was not determined (Table 36). Much confusion surrounds the taxonomy of the oxyuroid nematodes inhabiting the guts of iguanine lizards, especially within the genus Cyclura (Table 36). The systematics of these helminths and their implications to lizard coogeography deserve attention.

The nearly 100 infection rate and the massive nematode infections found in seemingly healthy cyclura carinata suggests their relationship 


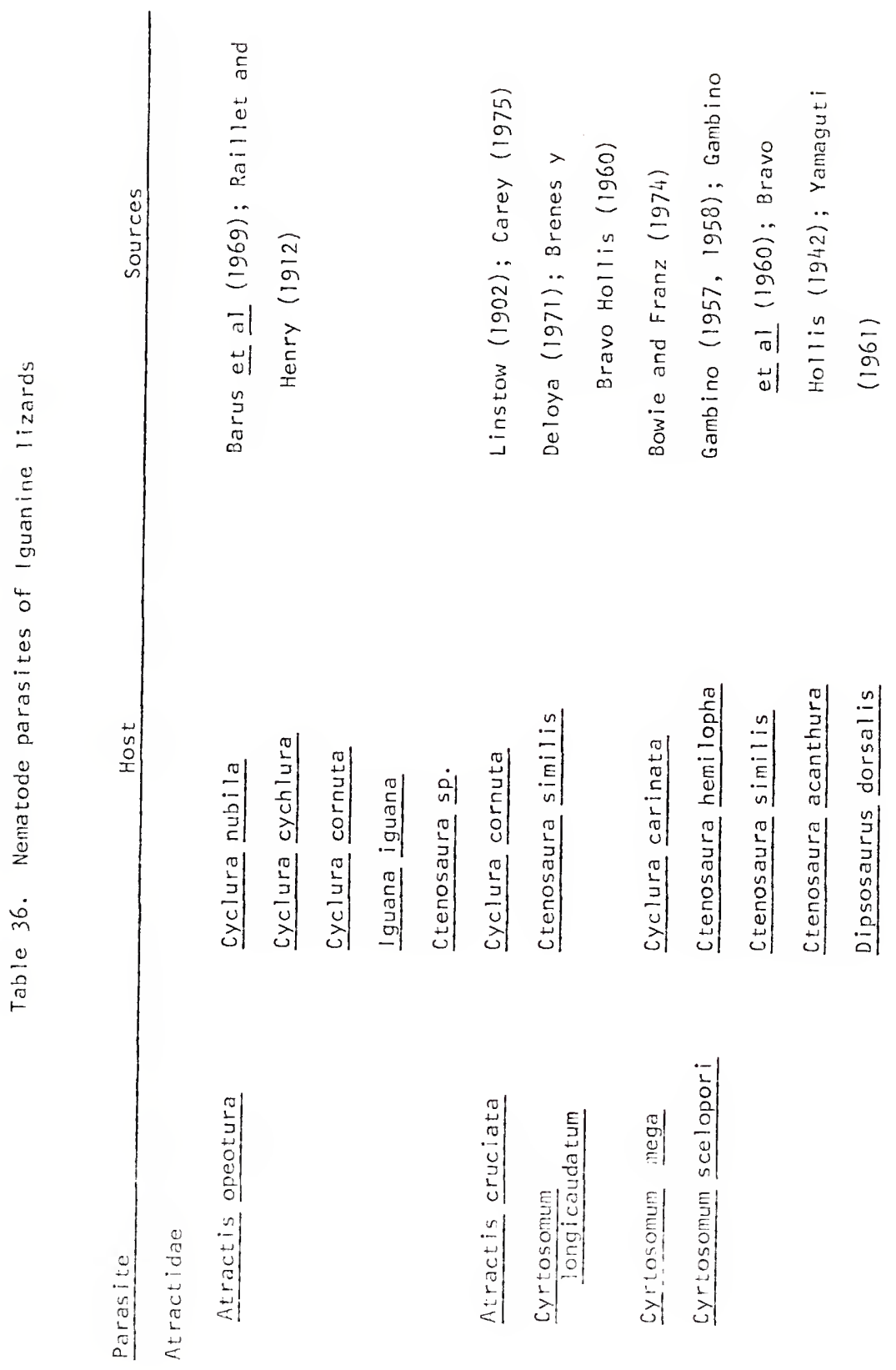



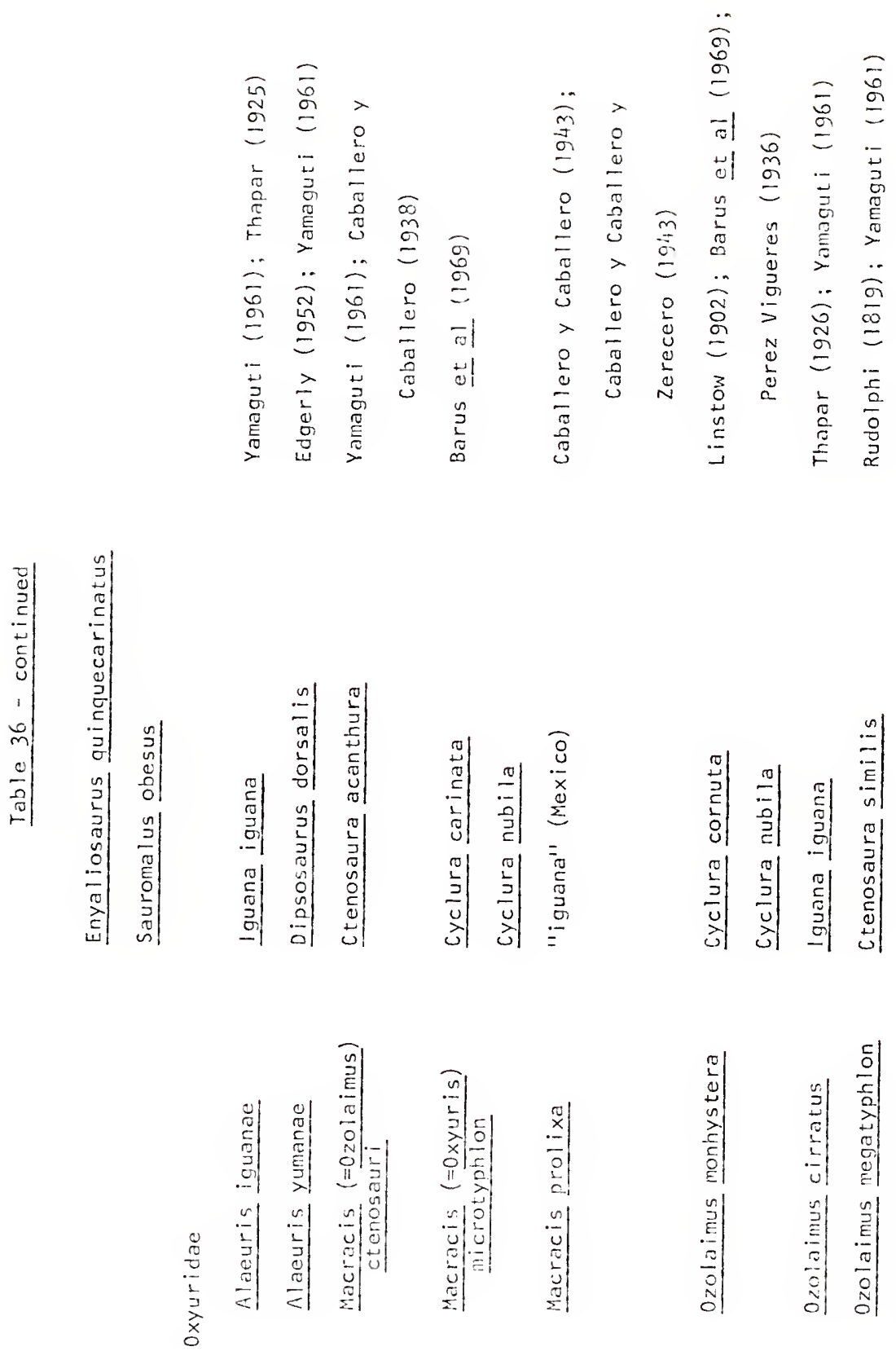


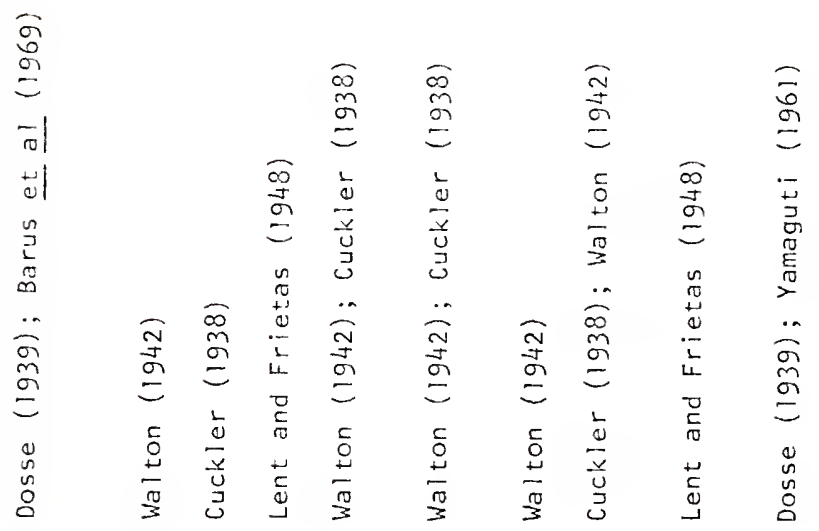

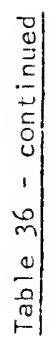
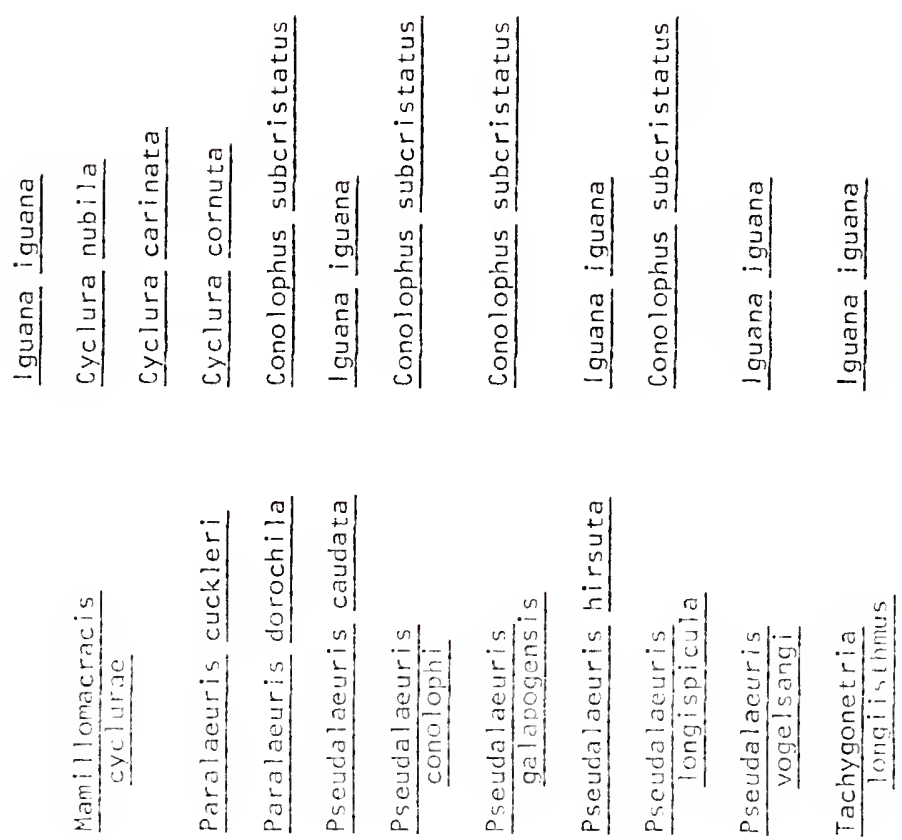
\begin{tabular}{c|c}
0 \\
0 \\
3 \\
. \\
5 \\
5 \\
0 \\
1 \\
0 \\
$m$ \\
0 \\
01 \\
0 \\
5
\end{tabular}

क
on
$E$
0
in
0
0

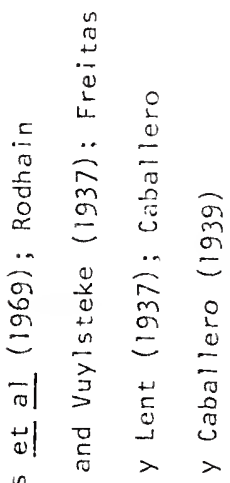

$n$
1
$\pi$
$\infty$

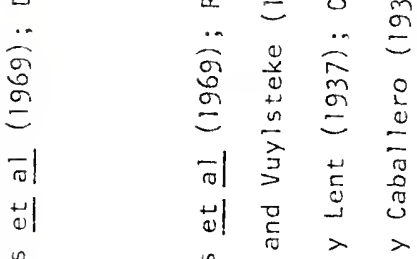

5
$\frac{1}{3}$
0
0
0

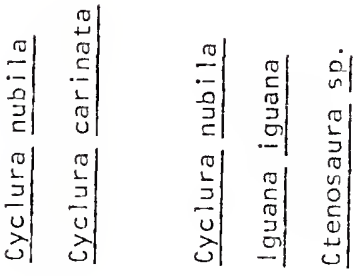

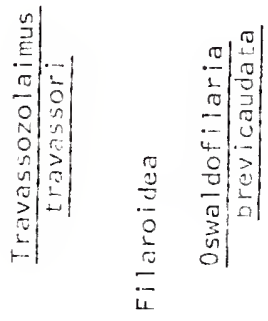


is not simply a parasitic one. Perhaps the role is mutualistic, the nematodes functioning to increase the efficiency of the digestive process (by physical and/or chemical means) much as the microflora in the gut of an herbivorous mammal does (McBee, 1971). No other helminths were found in Cyclura carinata during this study. 
DENSITY AND DEMOGRAPHY

\section{Sex Ratio}

Males and females are approximately equally represented in all age classes, but due to sexual size dimorphism the same is not true of adult size classes (Figure 54). The observed sex ratio differs insignificantly from unity, with $51.5 \%$ of 167 sexed 1 izards being males.

\section{Characteristics of Juvenile Populations}

Survivorship. Too few juvenile lizards were recaptured to provide accurate estimates of mortality. Therefore, in an attempt to estimate juvenile survivorship, it was necessary to evaluate time-specific juvenile age class distributions (see Deevey, 1947, or Giles, 1971, for procedures). This assumes a stable age-class distribution, i.e. that age-specific natality and mortality do not change from year to year and that age-specific immigration and emigration do not differ (Avery, 1975; among others). Since this species is predominately $k$-selected (after Pianka, 1970), this assumption is probably justified. In all further discussion, it is assumed that mortality rate (proportion of a group which died during some interval) plus survivorship rate (proportion surviving through the same time interval) equals unity.

Age class distributions used to estimate juvenile survivorship in Cyclura carinata are in Table 37. Of the four samples presented, the most reliable is that from the Little Water Cay study area (other samples are biased due to small sample sizes, and/or interference by 


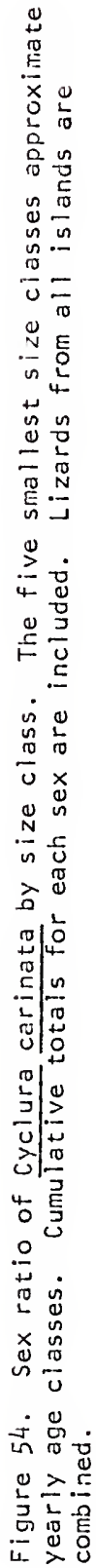




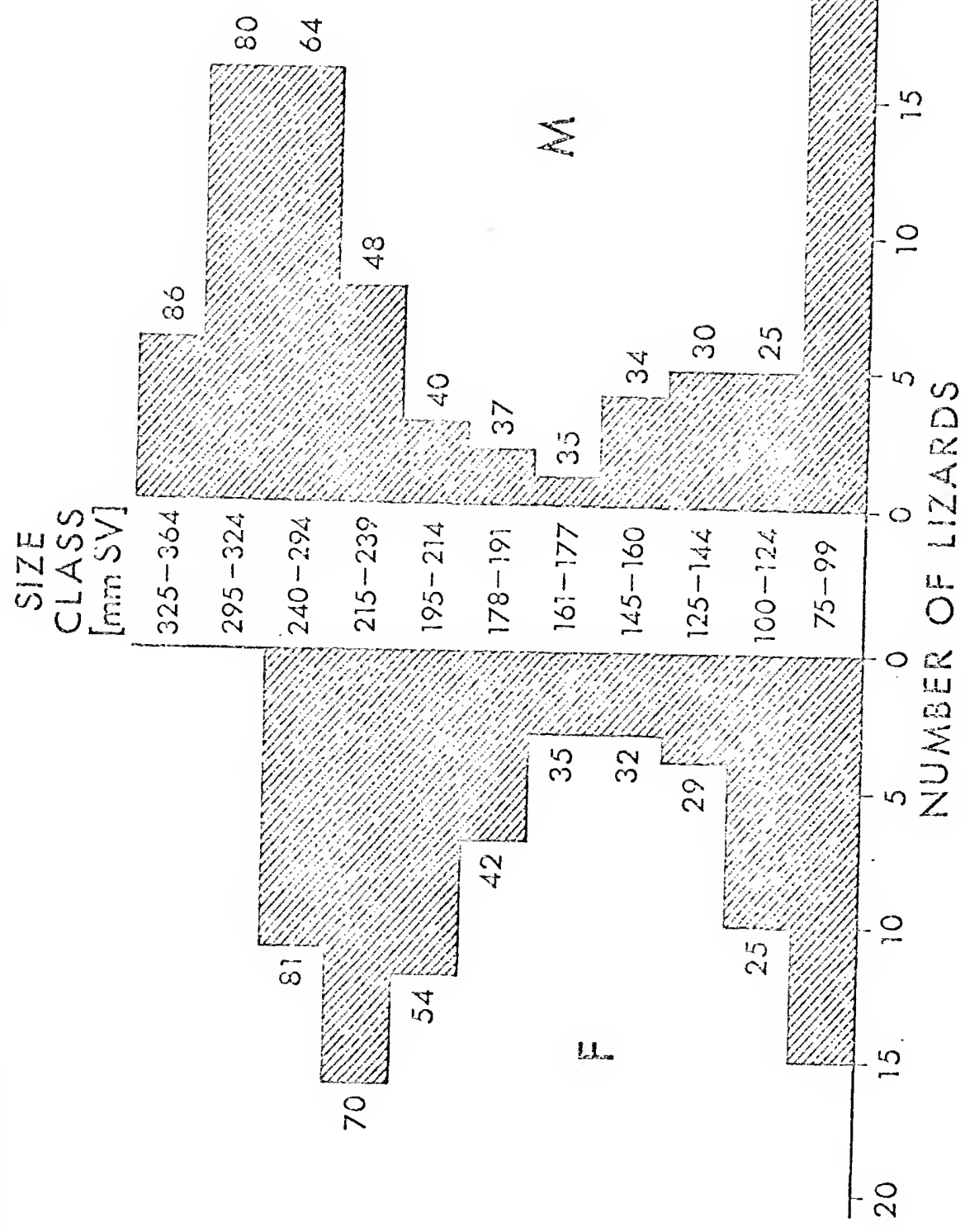


Table 37. Juvenile age class distributions for various samples of Cyclura carinata.

\begin{tabular}{|c|c|c|c|c|}
\hline $\begin{array}{c}\text { Age } \\
\text { (yrs.) } \\
\end{array}$ & $\begin{array}{l}\text { LWC } \\
\text { Study } \\
\text { Area }\end{array}$ & $\begin{array}{l}\text { Pine Cay } \\
\text { captures } \\
\text { Sept. } 1973 \\
\end{array}$ & $\begin{array}{l}\text { Post-Sept. } 1973 \\
\text { captures on all } \\
\text { islands except } \\
\text { Little Water Cay }\end{array}$ & $\begin{array}{c}\text { Dissected lizards } \\
\text { all islands } \\
\text { (See Figure 54) }\end{array}$ \\
\hline$<1$ & 55 & 14 & 12 & 35 \\
\hline$<2$ & 32 & 6 & 5 & 15 \\
\hline$<3$ & 17 & 5 & 2 & 9 \\
\hline$<4$ & 9 & 0 & 0 & 7 \\
\hline$<5$ & 6 & 0 & 0 & 4 \\
\hline$<6$ & 4 & 2 & 2 & -- \\
\hline$<7$ & 2 & 1 & 1 & - \\
\hline Totals & 125 & 28 & 22 & 70 \\
\hline
\end{tabular}

Note: The first three samples are nutually exclusive; the fourth represents portions of each of the first three. 
man). The Little Water Cay data indicate annual survivorship rates of $58,53,53,67,67$, and 50\% for the first six years of 1 ife, respectively. In general the rates calculated from the other samples support these estimates. Therefore, for simplicity in further discussions I have utilized the following survivorship schedule for juveniles based mainly on the Little Water Cay results: 55\% per year through the first three years of 1 ife and $67 \%$ per year for years 4 through 6 . The age-class distributions observed in the other 3 samples (see Table 37) are insignificantly different from those expected by this schedule $\left[x^{2}\right.$ for the September, 1973, Pine Cay sample is $5.63\left(\mathrm{df}=6 ; \chi_{0.05}^{2}=12.59\right)$; for the post-september, 1973 captures from all islands except Little Water Cay it is $6.295\left(\mathrm{df}=6 ; \chi_{0.05}^{2}=12.59\right)$; and for the dissected sample it is $\left.1.209\left(d f=4 ; x_{0.05}^{2}=9.49\right)\right]$.

The calculated juvenile survivorship schedule with its higher mortality in the smaller (and younger) size classes is a logical one. As juvenile iguanas grow, the number of potential natural predators is significantly reduced to a point where diurnal raptors (and large Boid snakes on islands where they occur) are probably the only significant predators on adults. The schedule further estimates that only about $5 \%$ of the lizards born live to maturity ( 6 years).

Ctenosaura similis is the only other iguanine species for which population structure and survivorship have been investigated. Fitch (1973) graphed the change in age struciure throughout the year for Ctenosaura in Costa Rica. Based on extrapolation from his graph, an annual rate of survival between 25 and $30 \%$ is indicated for juvenile Ctenosaura similis (to age 2). The great pool of potential predators on the mainland undoubtedly accounts for this low survivorship. 
Density and Bionass. The simple Lincoln Index (Southwood, 1966; Giles, 1971) was employed to estimate juvenile (<195 mm SV) population size from recapture data on Little Water Cay (Table 38). In all, 103 lizards, including adults, were marked; 15 were recaptured once, and four, twice. Due to small sample sizes, population estinates based on the Jolly (Jolly, 1965) and Bailey triple catch methods (Bailey, 1951) proved unreliable and are not included in this analysis. The Lincoln index was computed separately for each pair of consecutive mark-recapture periods. If a new hatchling cohort was added between censuses, however, captures of these neonates were not included in the calculations of original population size. Since juvenile survivorship has been calculated to be 0.55 per year for the first three years of 1 ife and 0.67 after age three, an estimate of yearly cohorts can be determined from the equation:

$$
\begin{aligned}
T= & x+0.55 x+(0.55)^{2} x+(0.55)^{3} x+(0.55)^{3}(0.67) x+ \\
& (0.55)^{3}(0.67)^{2} x+(0.55)^{3}(0.67)^{3} x \\
\text { or } T= & 2.255 x
\end{aligned}
$$

where $T=$ total population size, $X=$ the youngest cohort, and the sum of the exponents in the coefficient of $X=$ age (in years) of the cohort which it represents (Table 39).

It is also possible to apply the previously calculated survivorship schedule to population estimates for times of year other than at hatching in order to determine cohort and total population sizes immediately preceding and following hatching (Table 40). These calculations reveal that the Little Water Cay population typically consists of nearly 170 juveniles in September (post-hatching) and then decreases to just under 100 immediately prior to hatching a year later. 


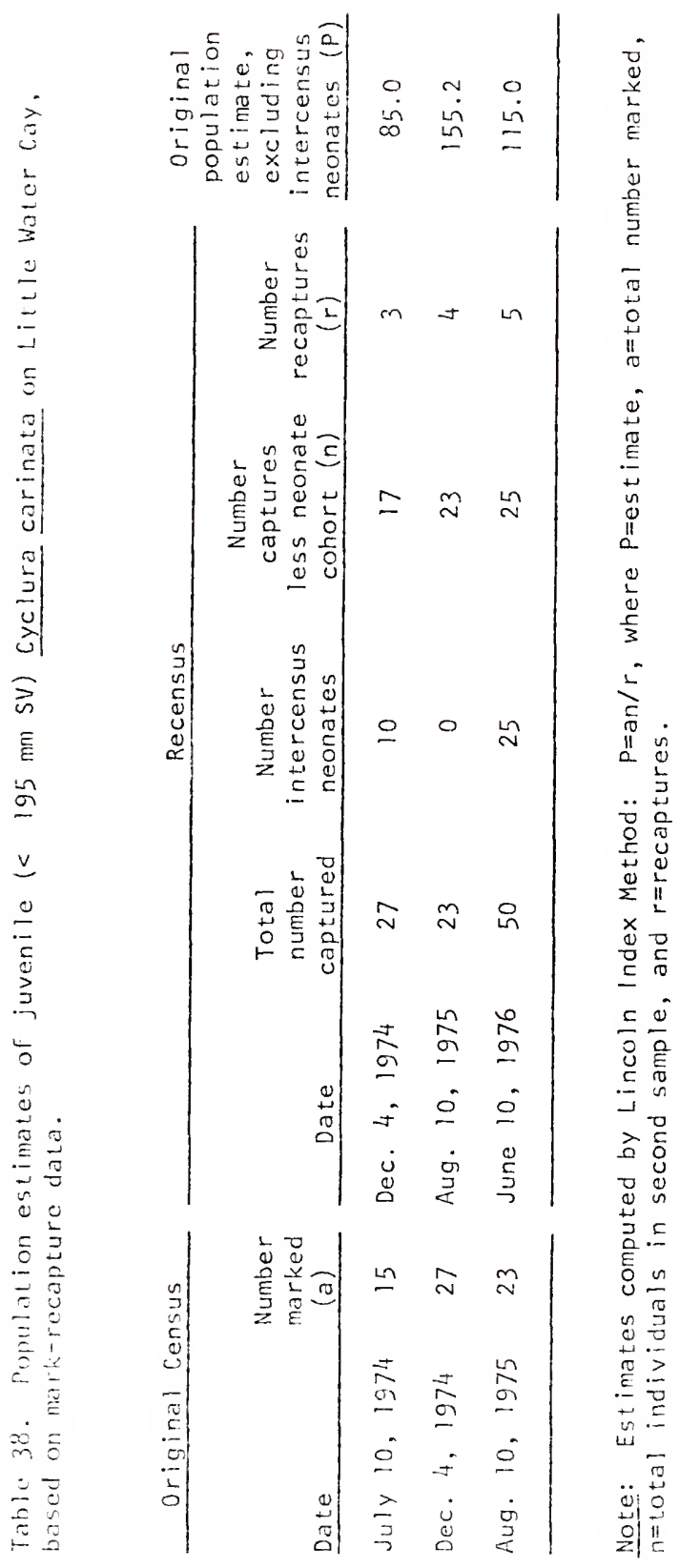


Table 39. Estimated juvenile cohorts for three census dates based on 0.55 survivorship per year for age 0 to three and 0.67 for age three to six, and total population estimates from Table 37.

Age (yrs.)

$<1$

$<2$

$<3$

$<4$

$<5$

$<6$

$<7$

Total

\begin{tabular}{ccc}
\multicolumn{4}{c}{ Original census date } \\
\hline July, 1974 & December, 1974 & August, 1975 \\
37.7 & 68.8 & 51.0 \\
20.7 & 37.9 & 28.0 \\
11.4 & 20.8 & 15.4 \\
6.3 & 11.5 & 8.5 \\
4.2 & 7.7 & 5.7 \\
2.8 & 5.1 & 3.8 \\
1.9 & 3.4 & 2.6 \\
\hline 85.0 & 155.2 & 115.0 \\
\hline
\end{tabular}




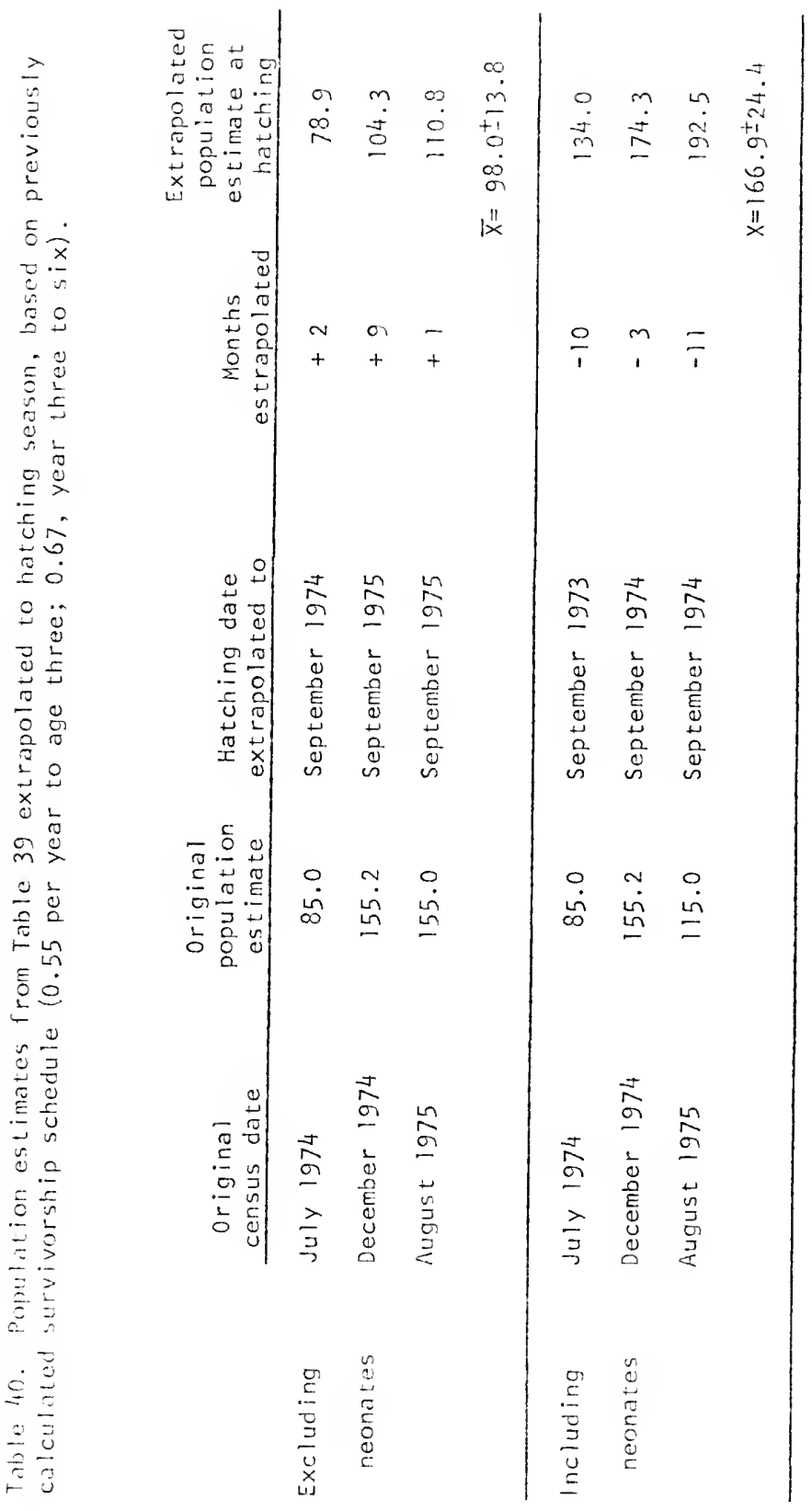


The mean of the extrapolated population estimates (including neonates) for hatching season (from Table 40) was used to estimate juvenile population structure on Little Water Cay study area immediately following hatching (Table 4T), when maximum yearly densities obviously occur. Since the study area covers 1.848 ha, lizard density averages 90.3 juveniles/ha at this time. Immediately prior to the addition of the next hatchling cohort, the juvenile population size is estimated to be about 93 (Table 41; excluded neonate estimate) or 98 (Table 40; top). These estimates represent densities of 50.3 and $53.01 \mathrm{izards} / \mathrm{ha}$ respectively. Although this is a considerable decline in lizard numbers (about 43\%), biomass decreases relatively little (about 15\%); biomass estimates for juvenile age classes during the hatching season are given in Table 41. Immediately following hatching, the Little Water Cay study area supports over $9.5 \mathrm{~kg}$ of juvenile lizards $(5.15 \mathrm{~kg} / \mathrm{ha})$. This vegetatively simple, relatively unproductive Open Scrub habitat at the Little Water Cay study site therefore supports an extraordinary juvenile lizard biomass. This abundance is supported by observations made at the study site during each visit to the island; the 1 izards always seemed unbelieveably abundant. Similar subjective observations on Pine Cay at the beginning of the study, and on Fort George Cay several times during the study, indicate these densities to be typical for juveniles.

\section{Characteristics of Adult Populations}

Survivorship. Long life and low adult mortality in Cyclura carinata made survivorship in adults difficult to determine. Due to the small number of adult recaptures, it was necessary to estimate 


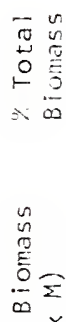

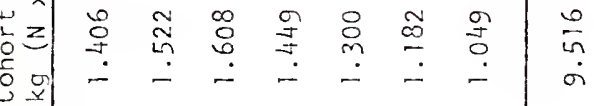

茪|

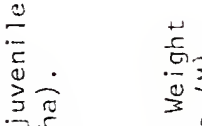

$40 \frac{1}{0}$

$n$.

$\stackrel{0}{0}=$

ह

0

产

0.

ปे

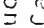

in

$5 \frac{5}{3}$

范

픙

음

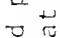

$\pm$

$\stackrel{\Xi}{E}$

$\pm \frac{5}{U}$

जै

$\div$

c)

की

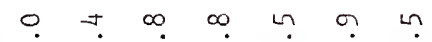

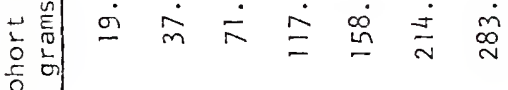

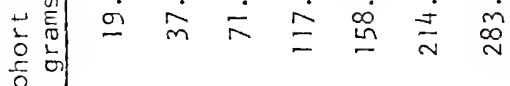

今.

$\infty \cdot=$

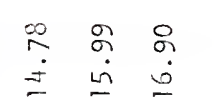

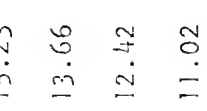

\begin{tabular}{l}
0 \\
0 \\
0 \\
\hline
\end{tabular}

호.

1

等

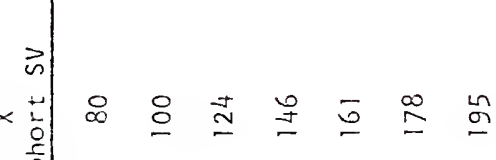

s

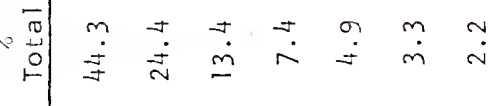

ஜ்

글

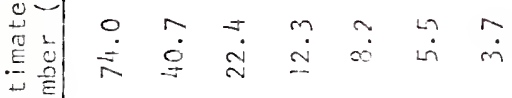

0
6

(4)

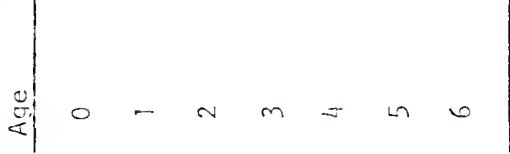

$\frac{5}{0}$ 
survivorship from adult age class structure. Table 42 presents the observed population structure of a sample of randomly collected females early in the study. The data indicate the annual survivorship rate, if constant throughout adult life, is approximately $90 \%$. The expected population structure, based on that schedule, also appears in Table 42 , and is not significantly different from the observed structure $\left(x^{2}=\right.$ 2.563, $d f=6 ; p=0.86)$. The expected adult female population structure with $95 \%$ constant annual survivorship is only slightly less significant $\left(x^{2}=2.9995, d f=6 ; p \cong 0.81\right)$ than that with the $90 \%$ schedule. The assumption that adult mortality in females is constant is probably valid due to the relatively narrow adult size range. In addition this is the typical pattern recorded in most previous studies of $1 \mathrm{izard}$ populations (Blair, 1960; Turner et al., 1970; Fitch, 1973; among others), although others have documented changing survivorships from year to year (Turner et al., 1969; Turner et al., 1969, and Turner et al., 1970). A similar, though higher, rate of survival is indicated for males. Observed population structure of males (age-size classes based on average growth rate of field recaptures: $0.66 \mathrm{~mm} / \mathrm{month}$ ), was significantly different from that expected with constant $90 \%$ annual survivorship $\left(x^{2}=26.74, d f=6, p<0.01\right)$. However, the structure expected if survivorship were $95 \%$ annually is not significantly different from that observed $\left(x^{2}=8.4, \mathrm{df}=6, p \cong 0.21\right)$. Survivorship is obviously extremely high in Cyclura carinata once maturity is reached. Subjective support for such a high rate of survival comes from my failure to ever find a dead adult or juvenile iguana on Little Water Cay, which to my knowledge, supports no feral mamals and has the highest lizard densities of any island 1 visited. 
Table 42. Population structure of randonly collected sample of adult female Cyclura carinata.

\begin{tabular}{cccc}
$\begin{array}{c}\text { Age } \\
\text { (years) }\end{array}$ & $\begin{array}{c}\text { Approximate } \\
\text { SV Range }\end{array}$ & $\begin{array}{c}\text { Observed } \\
\text { Number in } \\
\text { Age Class }\end{array}$ & $\begin{array}{c}\text { Expected, if } \\
\text { mortality=10\% }\end{array}$ \\
\hline $7-9$ & $197-210$ & 10 & 13.17 \\
$10-12$ & $210-223$ & 9 & 9.60 \\
$13-15$ & $223-236$ & 10 & 6.99 \\
$16-18$ & $236-249$ & 6 & 5.10 \\
$19-21$ & $249-262$ & 4 & 3.72 \\
$22-24$ & $262-275$ & 2 & 2.71 \\
25 on & $275+$ & 1 & 0.73 \\
\hline Total & & 42 & 42.02 \\
\hline
\end{tabular}

Note: Age-size classes based on mean adult growth rate of field recaptures $(0.36 \mathrm{~mm} \mathrm{SV} / \mathrm{month})$. Expected population structure based on $90 \%$ annual survivorship is also indicated. 
The highest adult annual survival rate previously suggested for 1 izards is approximately $80 \%$ for Xantusia vigilis in California (Zweifel and Lowe, 1966) and Lacerta vivipara in England (Avery, 1975b). Both are viviparous, relatively long-lived ( 11 to 12 years), late-maturing (3 years), seasonal breeders, with small brood sizes (1-2 and 7-8, respectively). The major difference between these two species lies in the ratio of adult to juvenile mortality. Annual juvenile mortality in Xantusia is similar to that of the adult, whereas in juvenile Lacerta it is over four times that of the adult. Xantusia therefore exhibits a Type I survivorship curve (Slobodkin, 1962; Deevey, 1947); Lacerta, a Tyfe IV curve (Slobodkin, 1962; Type 111 of Deevey, 1947).

All other lizard population studies of which 1 am aware have shown adult annual survivorship to range between about 10 and $65 \%$ (Uta stansburiana in Texas, Tinkle and Ballinger, 1972; and Sceloporus poinsett $i$ in Texas, Ballinger, 1973, respectively). Although adult survivorship in Eyclura carinata is higher than in any other previously studied lizard species, similar rates are likely to be found in other predominately k-selected (after Pianka, 1970) species. I would speculate that at least the other undisturbed island-inhabiting iguanines probably also exhibit rates comparable to those in $\underline{C}$. carinata. Unfortunately adult survivorship has been studied in no other iguanine species.

Because of the difficulty in both marking and observing a population large enough for adequate sample sizes at the SW BIind study site, as well as the interference from feral mammals, it was impossible to evaluate several factors that undoubtedly relate significantly to survivorship. Anong these are the effects of quality of the habitat, 
doninance-subdominance relationships aniong males, and female nestguarding. Information on these and related factors in this or other island species could be important in understanding the evolution and adaptive significance of lizard social systems.

Density. Flush transect data were used to compute adult lizard densities by four methods. The first (Method $A$ ) is a madification of the Frye strip census method used by Overton (1953) for quail and utilizes the following formula:

$$
\text { Density }=\frac{\text { Number }}{\text { Area }}=\frac{N}{2 L(2 d)}=\frac{N}{4 L d}
$$

where $N=$ total number of flushed lizards

$L=$ length of the transect

$d=$ average perpendicular distance from transect line to flushed lizard

This formula assumes equal probability of flushing a lizard anywhere in an area up to two times the average flush distance on either side of the transect line, and tends to underestimate actual lizard density. However, typical average distances are under 6 meters and one can be fairly certain that the majority of all lizards will be flushed (and heard) up to twice that distance from the 1 ine of transect.

The second method (Method B) utilizes only the number of lizards flushed within 10 meters of the transect, and assumes that all lizards within this bourdary could be seen or heard. The density is expressed in the formila:

$$
\text { Density }=\frac{\text { Number }}{\text { Area }}=\frac{N}{d L}
$$

where $\|=$ number of 1 izards flushed within 10 neters 


$$
\begin{aligned}
& L=\text { length of transect } \\
& d=\text { width of transect (in this case, } 20 \text { meters) }
\end{aligned}
$$

A more direct census method, this formula assumes equal probability of flushing a lizard on the transect line as one ten meters from it. I believe this to be a valid assumption, and therefore accept the accuracy of the density estimate derived from this method. This is despite the argument of Eberhardt (1968) against restriction of the censused strip. A comparison of the results of this method with Method A supports the acceptability of this technique (Table 43).

Method $C$ is a variation of the King strip census method as discussed by Hayne (1949) and expanded by Giles (1971). The following formula was used:

$$
\begin{aligned}
& \qquad \text { Density }=\frac{1}{2 L} \sum_{\text {obs }} \frac{1}{d j} \\
& \text { where } L=\text { transect length, and } \\
& d j=\text { distance from transect route to } j \text { th animal }
\end{aligned}
$$

This formula bases its density estimate on the generally logical idea that there is a decreasing probability of flushing an animal with increased distance from the transect route, and that the probability is inversely related to that distance (for further discussion and examples, see Giles, 1971). However, this argument is not strictly valid for $\underline{c}$. carinata. There seems to be a threshold distance inside of which nearly all lizards flush. Only those lizards near (inside or outside) this threshold limit seem to obey a probablistic model based on distance. Therefore, this method tends to slightly overestimate densities (Tables 43 and 44). The values do, however, provide an upper limit to the estimates. 


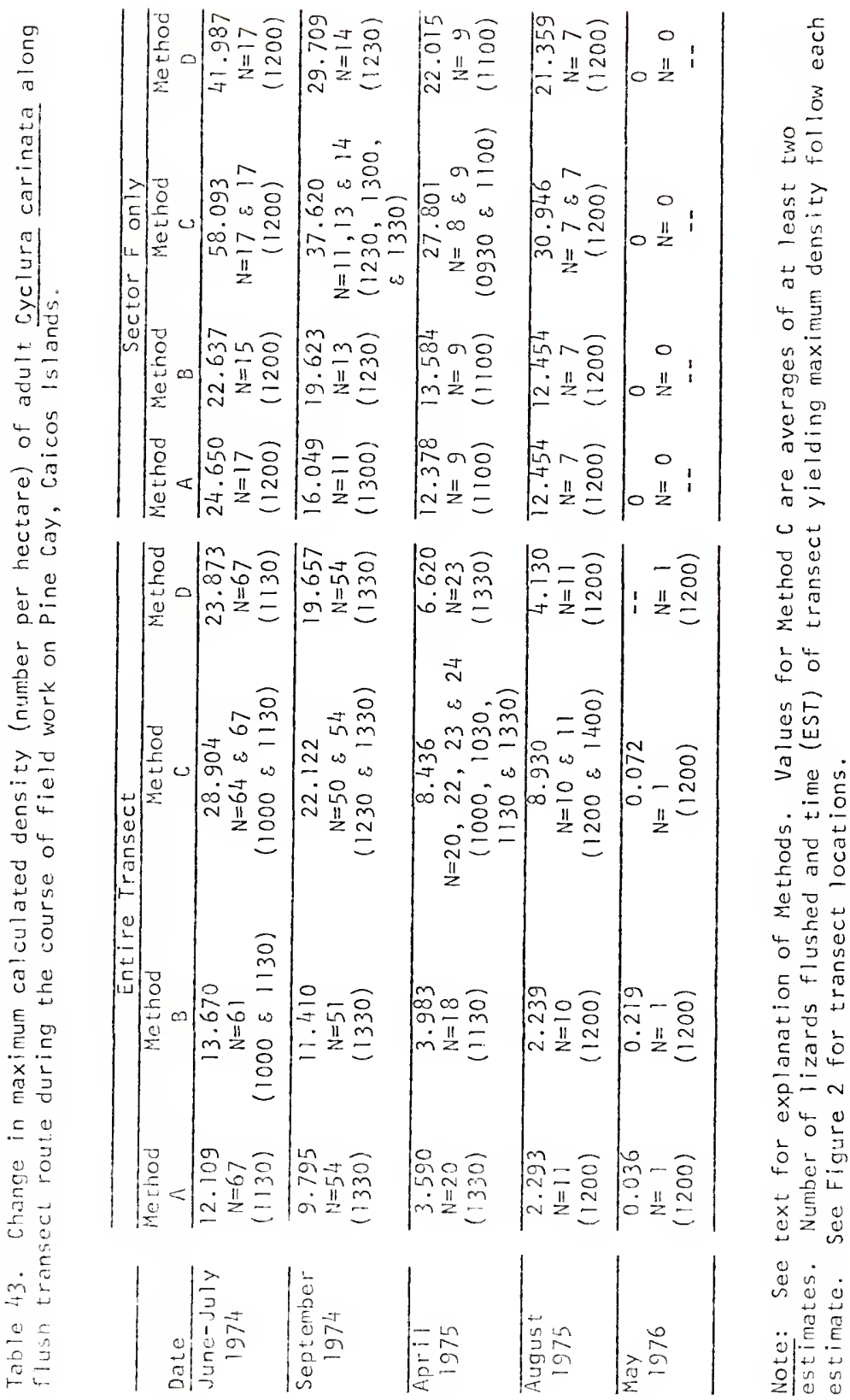




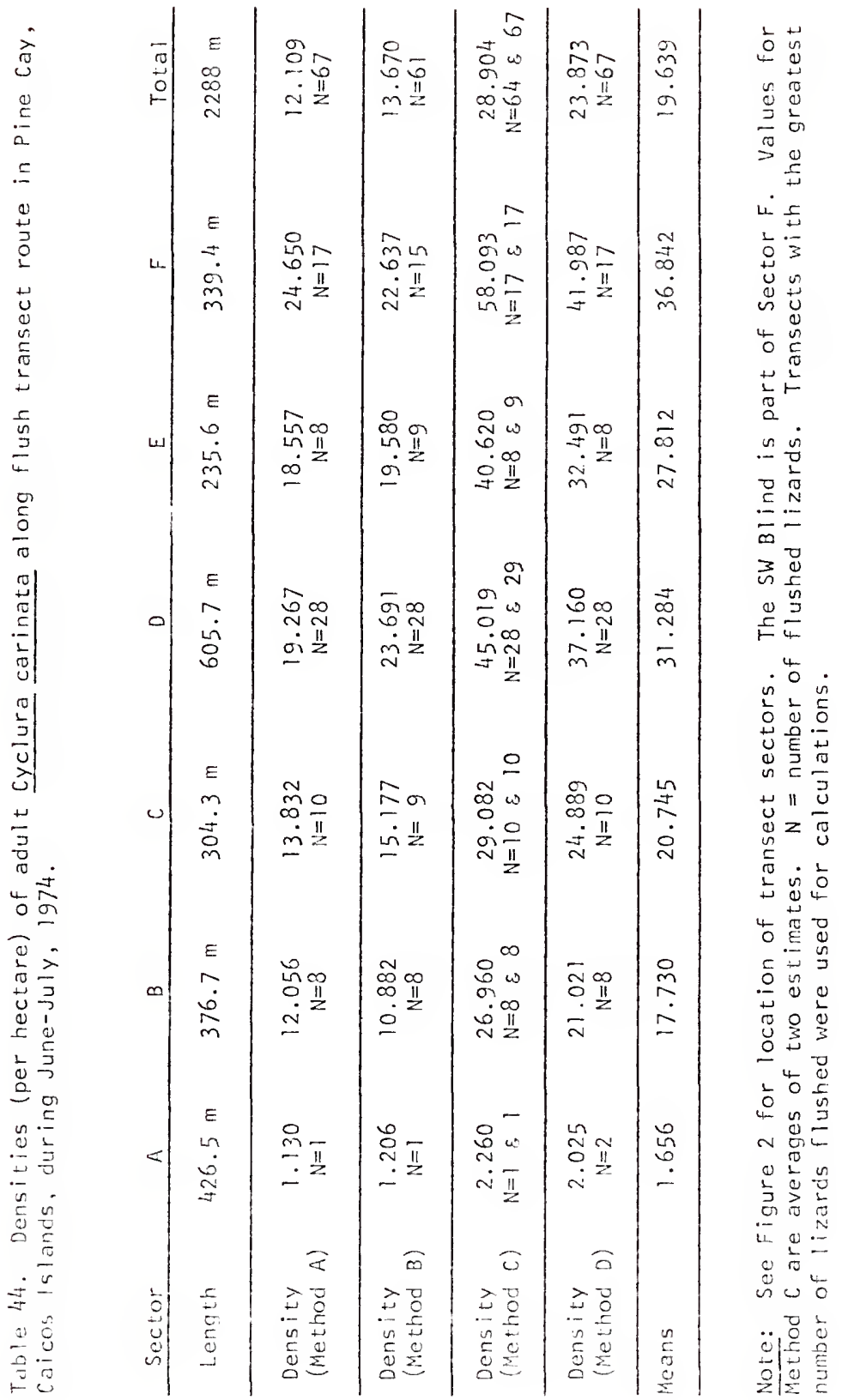


The final method (Method D) is that of Gates et al. (1968) and utilizes the formula:

$$
\begin{aligned}
\text { Density }=\frac{\text { Number }}{\text { Area }}=\frac{(n)(n-1)}{2 L \Sigma d} \\
\text { Where } n=\text { number of flushed lizards } \\
L=1 \text { ength of transect } \\
d=\begin{array}{l}
\text { perpendicular distance from transect line to } \\
\text { flushed lizard }
\end{array}
\end{aligned}
$$

This method differs from Method C (basically the King method) only in its measure of 'average' flush distance (see equations). Which measure is the most reliable must await further testing (Gates et al., 1968).

Adult densities calculated by the above four methods for Pine Cay flush transect data during June and July, 1974, are in Table 44.

Sector A of the transect route, because of its proximity to human activity, supported extremely low densities of lizards even at the beginning of the study. Therefore a reliable estimate of typical adult density should exclude that sector. The mean of all density estimates obtained for sectors B through $F$ by all four methods is $26.88 \pm 12.04$ $(N=20)$ per hectare. This is undoubtedly a fairly accurate estimate of the density of adult iguanas in the habitat adjacent to the transect route. The vegetative zone represented along most of the transect is Rocky Coppice and this habitat type supports the highest densities of iguanas on the study islands.

Based on the known adult inhabitants of the SW Blind area early in the study, a density of $31.1 /$ ha is indicated. The vegetative type here is also Rocky Coppice. This value further substantiates the accuracy of those obtained from flush transect data. 
If the mean distance beiween active male burrows is calculated and used as an estimate of spacing, another reliable density estimate is obtained. At the SW Blind, mean interburrow distence for males was $26.6 \pm 6.9 \mathrm{~m}(\mathrm{~N}=13$ measurements $)$ indicating an average male density of $17.99 / \mathrm{ha}$. Since the sex ratio is unity, density of all adults should te 35.98. This value corresponds well with the density estimate for the area based on flush transects (Table 44, Sector $F ; \bar{X}=36.84$ ). Similarly, mean interburrow distance for adult males on the Little Water Cay sand spit was $37.9 \pm 4.7 \mathrm{~m}$, giving a density of $8.85 / \mathrm{ha}$. This is only $65.8 \%$ of the density of males expected along the flush transect route on Pine Cay (13.44). However, the dune habitat on this spit is the most unstable, unproductive, and simplest of those inhabited by this species.

On Water Cay, in a Dense Scrub vegetational zone, Dave Auth (in preparation) calculated an adult density of $9.8 /$ ha; mean male interburrov: distances $(33.1 \pm 9.2 \mathrm{~m})$ suggested a male density of $11.6 / \mathrm{ha}$. These estimates are intermediate to those near the SW Blind and those on the little water Cay spit.

lquana density on the study islands is clearly positively correlated with habitat productivity (i.e. food availability); highest densities occur in the densely vegetated Rocky Coppice and lowest densities in sparsely vegetated beach areas. Intermediate habitats (e.g. Dense scrub) have intermediate densities. Since this species is primarily foot-linited (see FOod AND FEEUING) this trend is expected. Lizard density is probsbly also related to burrow availability in some areas. Biomss. Since the sex ratio is unity and average adult female and ale body weights on Pine Cay are 433.5 and 832.5 gm respectively, 
the density calculated from the flush transect data represents a biomass of approximately $17.01 \mathrm{~kg} / \mathrm{ha}$.

Iguanine lizards, especially those inhabiting islands, typically maintain population biomasses much higher than most lizard species (Table 45). This fact is undoubtedly related to their position in the food chain (primary consumers) as well as the structure of the food web itself (reduced predation on islands, for example). Unfortunately, more data on lizard species' biomass are needed before these relationships can be explored in detail.

Most of the previously studied populations of primarily carnivorous lizards maintain biomasses considerably less than $5 \mathrm{~kg} / \mathrm{ha}$ (Fitch, 1954 , 1955, 1975; Harris, 1964; Jenssen, 1970; Tinkle, 1972, 1973; Tanner and Hopkin, 1972; Western, 1974; Busack, 1975; among others). However, Anolis acutus (St. Croix, U.S. Virgin Islands) has been reported to reach densities of 2000-5600 individuals/ha, and a biomass of 13 to $23 \mathrm{~kg} / \mathrm{ha}$ (Ruibal and Philobosian, 1974); and Henidactylus garnoti (Tinian, Mariana Islands) may reach densities exceeding $22,000 /$ ha (Cagle, 1946), over $67 \mathrm{~kg} / \mathrm{ha}$ if average lizard weight is $3 \mathrm{gm}$.

Crook (1975) has reported densities of Sphenodon punctatus as high as 500 animals/ha or about $250 \mathrm{~kg} / \mathrm{ha}$. This is perhaps the greatest biomass hnown among all reptiles. However, Crook's estimate is based on only 30 individuals occupying an area of $625 \mathrm{~m}^{2}$. It may represent an aggregation of burrow sites and therefore not accurately reflect the true density for the total area used by the lizards. Carpenter (1966) reported that the biomass of basking Amblyrhynchus cristatus may exceed $71,000 \mathrm{~kg} / \mathrm{ha}\left(4.43\right.$ individuals $\left./ \mathrm{m}^{2}\right)$. Since this is an obvious aggregation, ho::ever, the estimate does not represent average habitat density. 


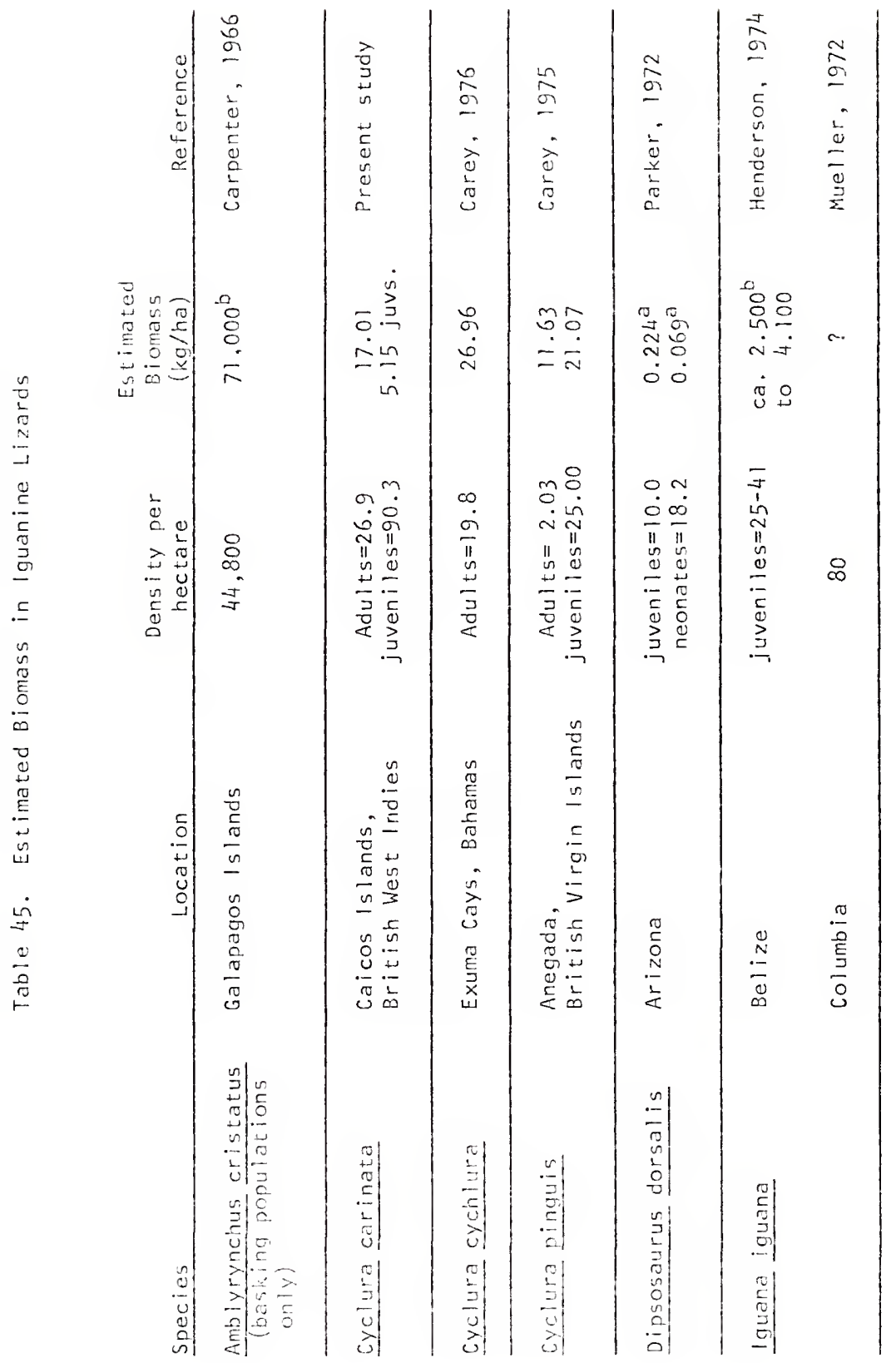




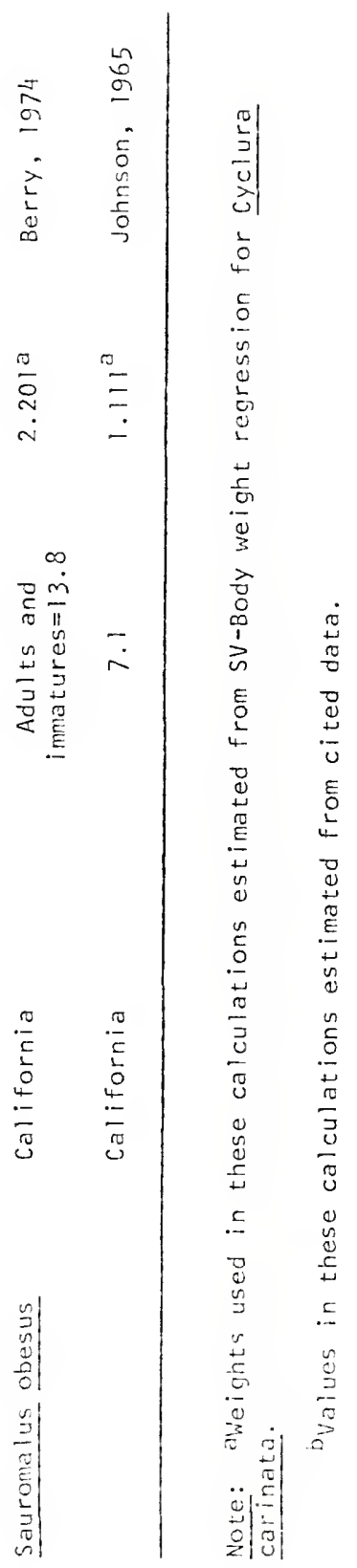


There are few bionass data available for Cyclura species. Carey (1975) estimated $11.6 \mathrm{~kg}$ of adults and $21.1 \mathrm{~kg}$ of juveniles/ha for $\underline{c}$. pinguis. An adult biomass of $27.0 \mathrm{~kg}$ is indicated from Carey's (1976) data on Cyclura cychlura. These values correspond well with the 17.0 and $5.15 \mathrm{~kg} / \mathrm{ha}$ for adult and juvenile Cyclura carinata, respectively. Population Size. It is possible to estimate Pine Cay's total adult Cyclura population since lizard density in each habitat type and the area of each habitat type on the island are both known. Densities early in the study in the Dense Scrub and Mesic Coppice habitat types were similar to that in the Rock Coppice (26.9/ha); densities in areas of Open Scrub and Beach and Rocky Coasts were similar to those obtained from the Little Water Cay sand spit (7.7/ha); and almost no iguanas inhabitated areas of Mixed Woodland. The area each habitat type occupies on Pine Cay appears in Table 3. From these data, a total adult population of nearly 5500 is indicated for Pine Cay (total area about $350 \mathrm{ha})$. Since juveniles typically greatly outnumber adults, the total Pine Cay population certainly exceeded 15,000 individuals at the onset of this study.

\section{Life Tables}

Based on the survivorship data previously calculated (prenatal mortality $=21.7 \%$; juvenile mortality to age $3=45 \%$; juvenile mortality age 3 to $6=33 \%$; and adult mortality $=10 \%$ ), a life table for Cyclura carinate was constructed (Table 46). Age-specific fecundity (Table 47) was determined from adult female growth rate and the body size-clutch size regression. Since the sex ratio is unity, one half of this agespecific fecundity represents potential female offspring $\left(m_{x}\right)$ in 


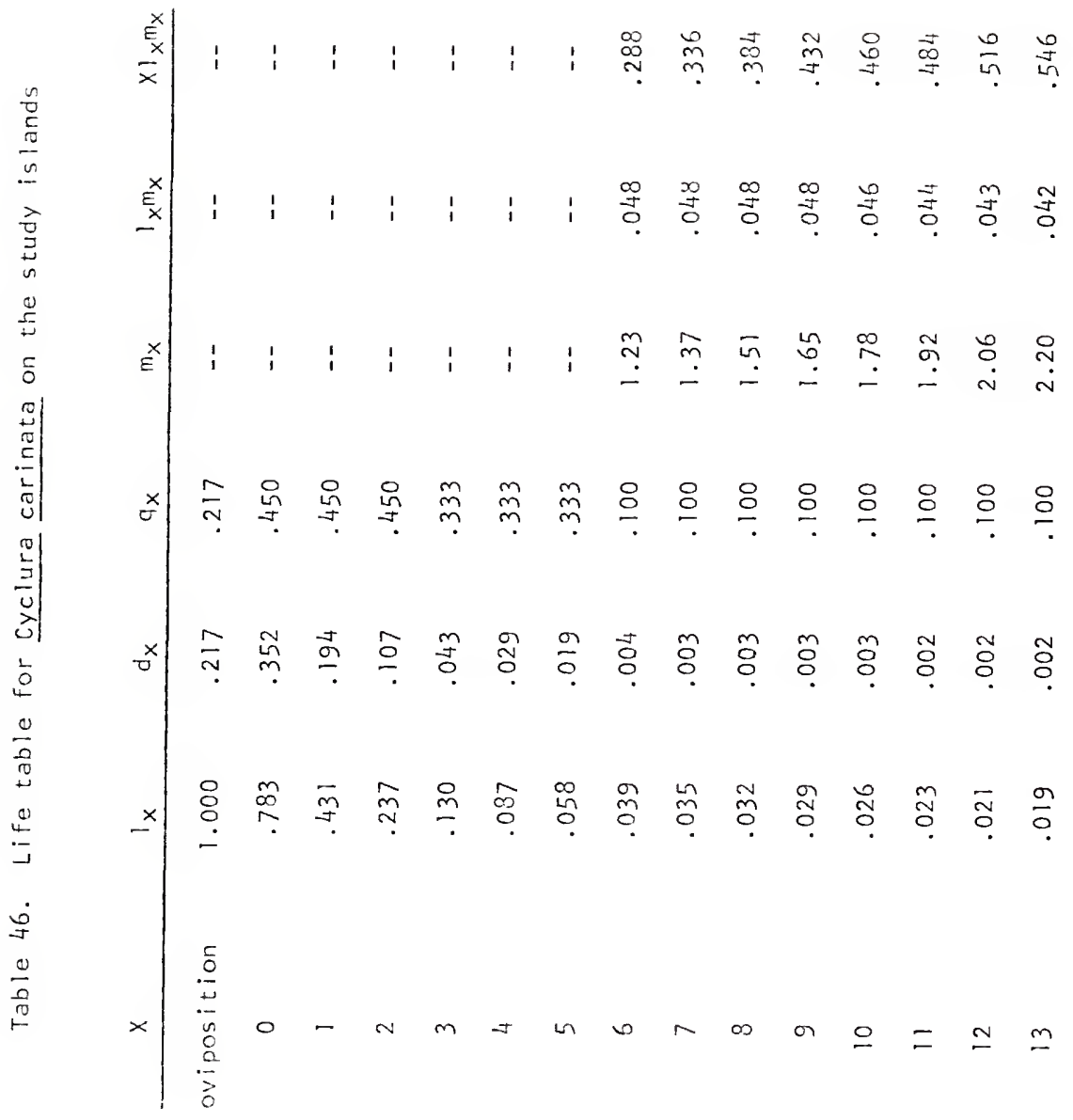




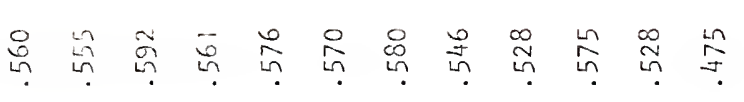

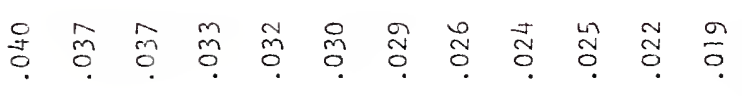

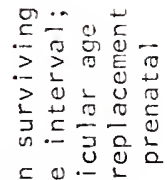

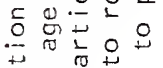

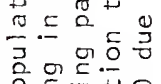

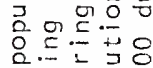

$\therefore=\frac{1}{3}=$

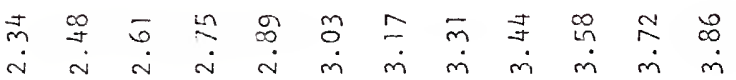

$\overline{0} \div$

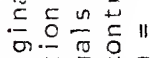

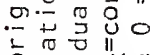

- $\frac{1}{3} \times \frac{0}{0}$

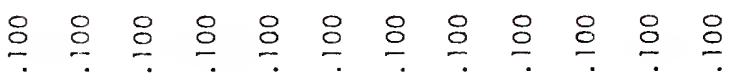

渮 응

$5 \therefore \ldots \frac{1}{0}$

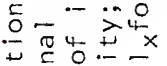

1.00

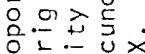

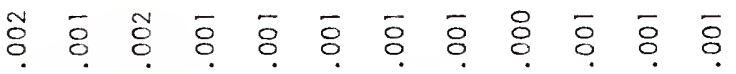

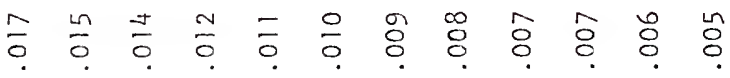

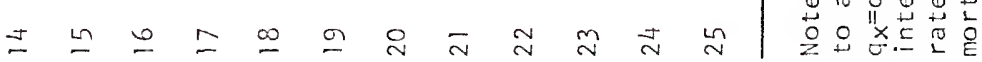

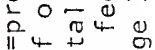

"范苗U

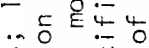

in.

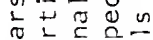

¿ $>$ 음

ᄃ 눈 응 0) $x$ 응 ${ }^{\prime \prime} x$

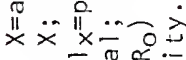

o $>\geq$

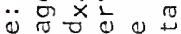


Table 4\%. Specific fecundity of female Cyclura carinata calculated from clutch size-body size regression.

\begin{tabular}{|c|c|c|}
\hline SV & $\begin{array}{l}\text { Probable } \\
\text { year class }\end{array}$ & $\begin{array}{l}X \text { clutch } \\
\text { size }\end{array}$ \\
\hline 195.0 & 6 & 2.46 \\
\hline 199.3 & 7 & 2.74 \\
\hline 203.6 & 8 & 3.02 \\
\hline 208.0 & 9 & 3.30 \\
\hline 212.3 & 10 & 3.56 \\
\hline 216.6 & 11 & 3.84 \\
\hline 220.9 & 12 & 4.12 \\
\hline 225.2 & 13 & 4.40 \\
\hline 229.6 & 14 & 4.68 \\
\hline 233.9 & 15 & 4.96 \\
\hline 238.2 & 16 & 5.22 \\
\hline 242.5 & 17 & 5.50 \\
\hline 246.8 & 18 & 5.78 \\
\hline 251.2 & 19 & 6.06 \\
\hline 255.5 & 20 & 6.34 \\
\hline 259.8 & 21 & 6.62 \\
\hline 264.1 & 22 & 6.88 \\
\hline 268.4 & 23 & 7.16 \\
\hline 272.8 & 2.4 & 7.44 \\
\hline 277.1 & 25 & 7.72 \\
\hline
\end{tabular}

Note: Age-class body sizes based on estimated female growth rate of 0.36 min SV per month. 
Table 45. The life table data indicate a survivorship schedule ficting Slobodkin's (1962) Type IV curve (= Type 111 of Deevey, 1947) with rortality acting most heavily on the younger ages (Figure 55).

Although the replacement rate value $(0.721$; Table 48$)$ indicates a declining population, each of my nortality estimates is probably too high. The two estimates of which 1 am least confident are those of adult and prenatal mortaltiy. A reduction in adult mortality of only $5 \%$ (10 to $5 \%$ ) results in a much more stable age distribution $\left(R_{0}=1.155 ;\right.$ Table 48$)$. It was shown earlier that while both a $95 \%$ and $90 \%$ annual survivorship schedule produced age structures which were insignificantly different from the observed adult female population structure, the schedule assuming the $90 \%$ rate was less different.

The necessity for such high adult survival rates is apparent when it is realized that only about four of 100 offspring (five out of 100 hatchlings) survive to maturity (see Table 46). In order to successfully replace herself, a newly matured female must produce about 50 eggs in her lifetime.

Reduction in prenatal mortality by one half increases the replacement rate to 0.826 ; if it is ignored completely, $R_{0}=0.919$ (Table 48). Since the sample on which this mortality was estimated was small, egg mortality may well be overestimated.

Mean generation time $\left(\Sigma x 1_{x} m_{x} / \Sigma l_{x} m_{x}\right)$ for Cyclura carinata, calculated from the Life Table (Table 46), is 14.00 years, the longest for any lizard population yet studied.

\section{Life History Strategy}

The dichotomy of lizard life history strategies suggested by Tinkle et al. (1970) has been shown to represent correlates of the 


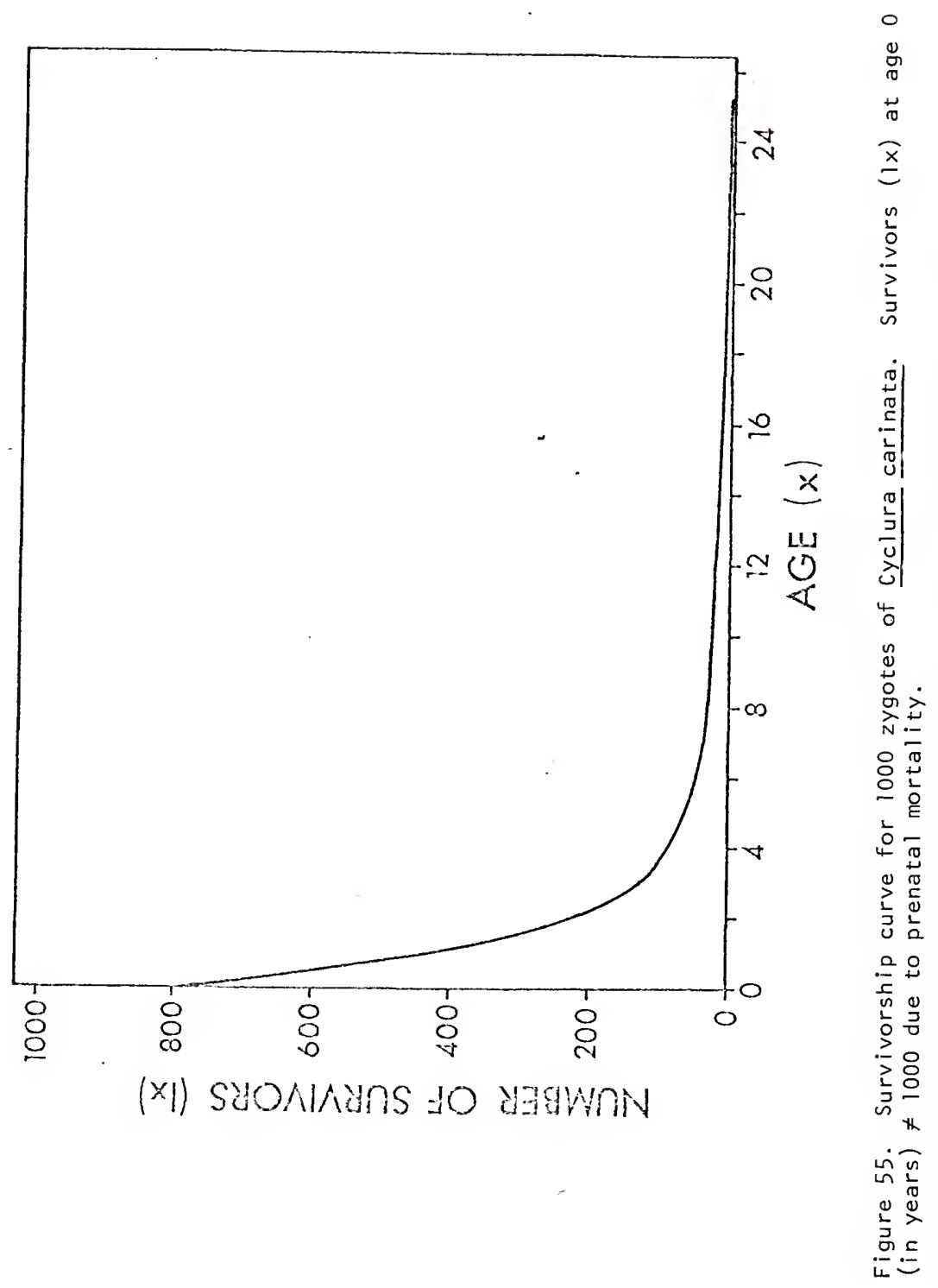



Table 48 . Replacement rates in Cyclura carinata with changing
cohort mortalities

\begin{tabular}{lcccc}
$\begin{array}{c}\text { Juvenile } \\
\text { mortality }\end{array}$ & $\begin{array}{c}\text { mortality } \\
\text { age } 0 \text { to } \\
3 \text { years }\end{array}$ & $\begin{array}{c}\text { Juvenile } \\
\text { mortality } \\
\text { age } 3 \text { to } \\
6 \text { years }\end{array}$ & $\begin{array}{c}\text { Annul adult } \\
\text { mortality }\end{array}$ & $R_{0}$ \\
\hline 0.217 & 0.45 & 0.33 & 0.10 & 0.721 \\
0.217 & 0.45 & 0.33 & 0.05 & 1.155 \\
0.100 & 0.45 & 0.33 & 0.10 & 0.826 \\
0.000 & 0.45 & 0.33 & 0.10 & 0.919 \\
\hline
\end{tabular}


extremes of the $r-k$ selection continuum (Pianka, 1970). The dichotomy has and will necessarily continue to become less distinct as more lizard populations are studied (Tinkle and Ballinger, 1972; Ballinger and Schrank, 1972; Ballinger, 1973; among others). Nevertheless, it remains a useful procedure to rank life history characteristics of a population along the selection continuum for comparison with other populations of the same or different species.

In its slower development, delayed maturity, production of a single annual brood many times, large body size, high intraspecific competition levels (evidenced by its sexual size dimorphism, for example), parental care (here nest defense) and longevity, cyclura carinata is one of the most k-selected species yet studied (Pianka, 1970). However, its survivorship schedule, with mortality greatest in juveniles, is more characteristic of an r-related strategy. This is undoubtedly related to size-dependent predation pressures and may bear on why cyclura carinata does not produce fewer, larger young (see discussion of reproductive strategy under REPRODUCTION).

Most of the remaining undisturbed populations of other species of Cyclura are presumably also predominately k-selected, and 1 would expect their life-history tactics to be very similar to those of cyclura carinata. It is important that demographic studies of these species, as well as all other iguanines, commence immediately if we are to learn more about these h-strategists; few undisturbed natural populations, at least of the island forms, remein. Of particular potential importance to understanding variation anong k-related species is specific knowledge of the denography of the marine iguana (Amblyrhynchus cristatus) which, 
anong other things, produces the fewest and largest eggs of all the Iguanines (see REPRODUCTION). 


\section{OUTLOOK}

\section{Populations on Turks and Caicos Islands}

When this study was initiated in september of 1973, rock iguanas were the most conspicuous members of the terrestrial fauna on Pine Cay, as they are on other minimally disturbed islands. Pine Cay was chosen as the primary study island not only because of the obvious abundance of lizards, but because construction had just begun on a large hotel and club house complex. This offered the opportunity to measure the effects of increased human occupation on a theretofore relatively undisturbed iguana population. The catastrophic decline observed during the following three years was, however, not expected when the study was initiated.

Both the maximum number of iguanas encountered on flush transects (Table 49) and the densities computed from those transects (Table 43, Figure 56) decreased steadily during the study period. These data also clearly indicate the effects of proximity to human settlement; lizards in those sectors nearest to human activity (i.e. those alphabetically closer to $A$; see Figure 2) showed the earliest declines and disappeared first (Table 43, Figure 56). Since lizards were not disturbed or removed from the transect route in the course of my studies, their disappearance was entirely the result of other human-related interferences.

The adult population on Pine Cay was estimated at over 5000 individuals in June and July of 1974 (see DENSITY). It was almost 


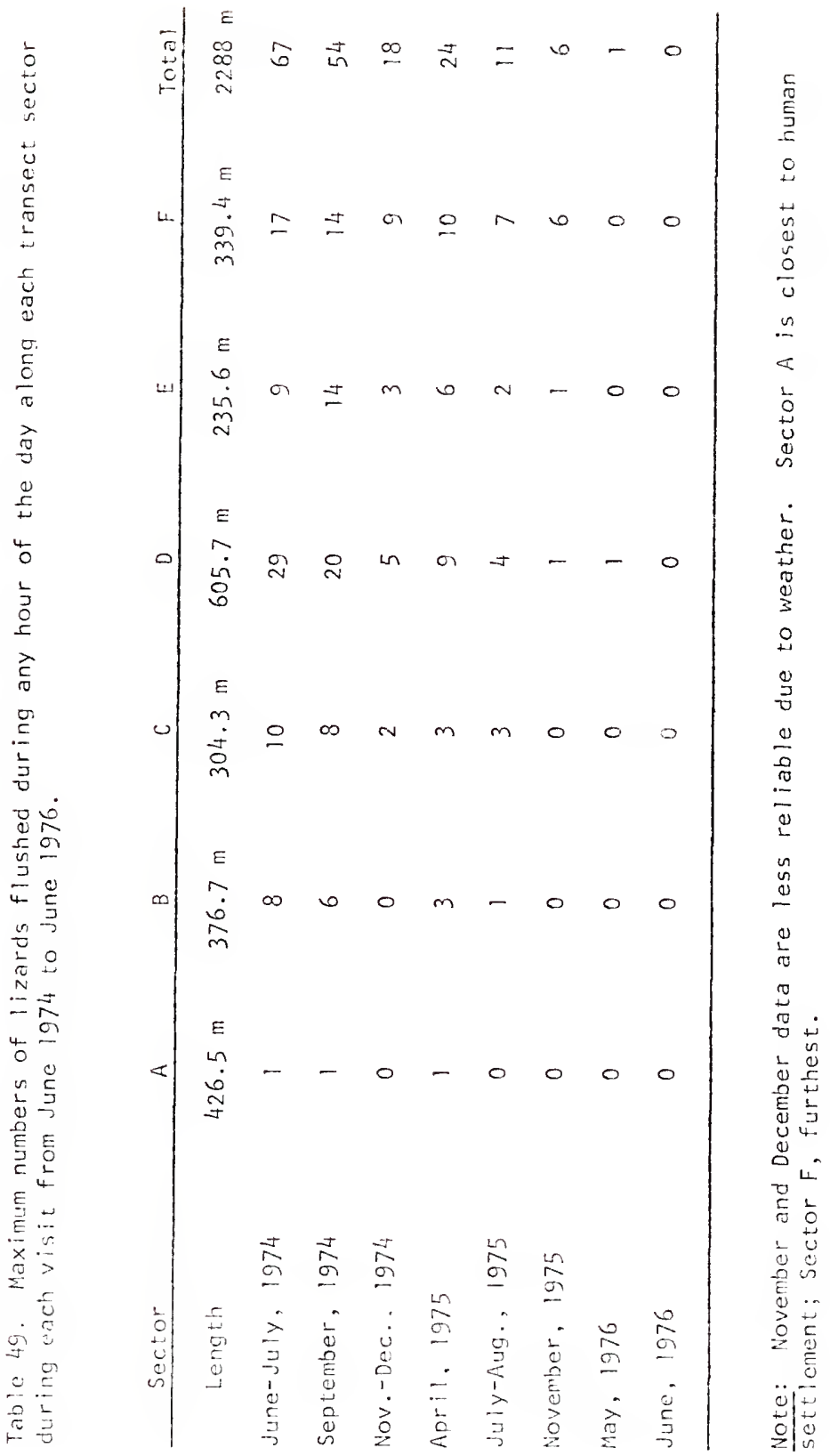




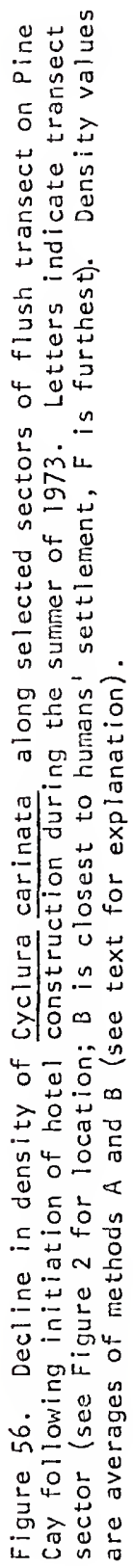




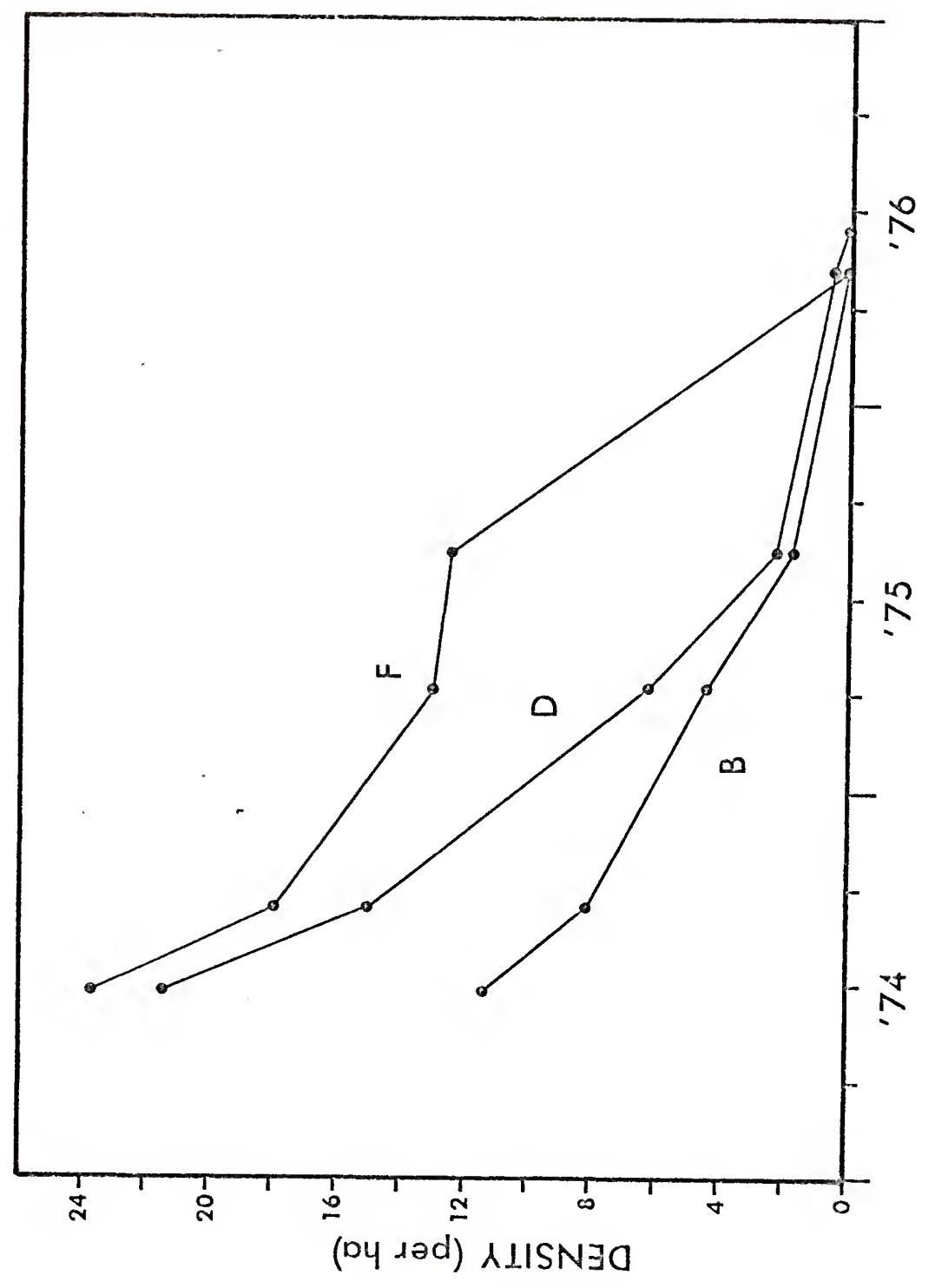


completely extirpated during the following 2 years. Not a single iguana vas flushed during 5 transects, and evidence (by spoor) of only five iguanas (4 large males and 1 young adult) could be found on the entire island during a week of investigation in June of 1976. Cyclura carinata has thus been effectively extirpated from Pine Cay. A similar decline also occurred on water Cay which is connected by a narrow isthmus to Pine Cay. However, no such declines were noted on Little water Cay or Fort George Cay (at least until 1976), both which have received very little human interference in recent history (but see later). The relationship of the observed population decreases to human occupation cannot be denied.

of all the ramifications of human exploitation, those which affect the survival of Cyclura carinata most are habitat destruction, direct predation by humans, and direct predation by animals introduced by man. As discussed under COACTIONS, the last of these is the most critical; dogs and cats have been the most significant contributors to the demise of Cyclura on Pine and Water Cays. This determination is based on direct observations as well as circumstancial evidence.

Prior to the construction of the hotel on Pine Cay in 1973 several cats lived on Pine Cay. There was, however, little evidence that these feral cats were affecting the iguana population. I believe this can be attributed to a more easily available food source; rats thrived on Pine Cay in high densities in the 1950's and 1960's (Rabb and Hayden, 1957; Liam Vaguire and George Nipanich, persona! communication). In addition, iniensive inbreeding of the resident cat population my have restrained their increase. 
When construciton began on the hotel in September of 1973, there was a sudden influx of staff and workmen, many of whom brought their pet cats and dogs. These pets were free-ranging and many became feral. Mother cats removed litter after litter born in residences to the "bush" (personal observation). Initially, rats provided a ready food resource. The once dense rat populations soon virtually disappeared. Only small populations remained during this study around older buildings.

At this point, the cats apparently began to include a larger proportion of lizards, crabs, and birds in their diet. This suggestion is supported by direct observations of feeding and fecal examination. As a result, there has been a rapid decline of terrestrial vertebrates, especially Cyclura and Leiocephalus.

The feral cat population on Pine and Water Cays increased continually during the study. In 1974, feral cats were encountered at a rate of about 1/two weeks of field work. By June of 1976, daily sightings were the rule. Cat tracks on sandy roads were rare in 1973 at a time when iguana tracks were so plentiful that estimating lizard numbers on this basis was impossible. By late spring 1976, lizard spoor was almost non-existent and that of cats could be found virtually everywhere on both Pine and Water Cays.

Free-ranging dogs on Pine Cay were also responsible for killing many iguanas. Though the total dog population averaged between two and three during the study, these few individuals spent the bulk of each day chasing and killing iguanas. Iguana carcasses became common, and the frequency of burrows partially excavated by dogs increased. Whereas Iizard numbers near the SW Blind decreased slowly during most of the 
study period (due to its distance from the center of the dogs' activity ranges at that time), between November, 1975, and May, 1976, the population was totally decimated! The majority of the burrows showed evidence of digging by the dogs; many had been caved in and all were inactive.

During this same time interval, the dogs first began swimming the channel separating Pine Cay from Grouper and Fort George Cays, both with dense iguana populations. Prior to that time, only one iguana carcass had ever been found on Fort George, but in June of 1976, four were discovered (they were not the object of search) in a small area at the western end of the island. While adults seemed to be less abundant than in the past, inactive burrows were unquestionably more common. In June the dogs were visiting Grouper and/or Fort George Cays daily. I see little hope for lizards on either island if the dogs are not restrained. I believe that similar reductions in cyclura populations can be expected on other islands where dogs, and especially, cats are introduced.

Fortunately for Cyclura carinata, dense populations still occur in the Caicos Islands on numerous small isolated islands (Table 50). As long as direct human interference is minimized and feral mammals are banned from these islands, the populations should continue to thrive. The status of Cyclura carinata on the islands of the Turks and Caicos banks is tabulated in Table 50. In addition to data collected by myself and Walter fuffenberg, much information was provided by numerous local residents. The majority of the terrestrial habitat in the Turks and Caicos is represented in Table 50, although some additional isolated 
Table 50. Status of Cyclura carinata on 1 slands of the Turks and Caicos Banks.

Feral

\begin{tabular}{|c|c|c|c|c|}
\hline Island & $\begin{array}{l}\text { Approximate } \\
\text { Area }\left(\mathrm{km}^{2}\right)\end{array}$ & Status & $\begin{array}{l}\text { manmals } \\
\text { present }\end{array}$ & Source \\
\hline Grand Turk & 18.1 & $R$ & $\begin{array}{l}\text { dogs } \\
\text { cats }\end{array}$ & Hesse \\
\hline Salt Cay & 6.5 & $E$ & $\begin{array}{l}\text { dogs } \\
\text { cats }\end{array}$ & Hesse \\
\hline $\begin{array}{l}\text { Turks Island Cays } \\
\text { Gibbs } \\
\text { Long } \\
\text { Penniston } \\
\text { Pear } \\
\text { Cotton } \\
\text { East }\end{array}$ & 2.6 & $\mathrm{R}$ ? & $?$ & -- \\
\hline
\end{tabular}

\begin{tabular}{lllll}
\hline Big Sand Cay & 0.8 & A & $?$ & Hesse \\
\hline South Caicos & 22.0 & $R$ & $\begin{array}{l}\text { cats } \\
\text { dogs } \\
\text { donkeys }\end{array}$ & $\begin{array}{l}\text { Iverson, } \\
\text { Auffenberg, } \\
\text { Hesse }\end{array}$ \\
\hline $\begin{array}{l}\text { East Caicos Cays } \\
\text { Plandon } \\
\text { Middle Creek } \\
\text { Nigger } \\
\text { Hog }\end{array}$ & 22.0 & A-U & none & Auffenberg \\
\hline
\end{tabular}

\begin{tabular}{lcccc}
\hline East Caicos & 46.6 & A? & $\begin{array}{c}\text { cows } \\
\text { donkeys }\end{array}$ & Hesse \\
\hline Iguana Cay & 0.1 & A & $?$ & $\begin{array}{c}\text { Ray } \varepsilon \text { Sprunt } \\
(1971: 37)\end{array}$ \\
\hline Middlo Caicos & 124.3 & $R$ & $\begin{array}{l}\text { dogs } \\
\text { cats }\end{array}$ & Hesse \\
\hline Norith Caicos & 108.8 & R & $\begin{array}{l}\text { dogs } \\
\text { cats }\end{array}$ & Hesse \\
\hline
\end{tabular}


Table $50-$ cont inued

\begin{tabular}{|c|c|c|c|c|}
\hline Is land & $\begin{array}{l}\text { Approximate } \\
\text { Area }\left(\mathrm{km}^{2}\right)\end{array}$ & Status & $\begin{array}{l}\text { Feral } \\
\text { mammals } \\
\text { present }\end{array}$ & Source ${ }^{a}$ \\
\hline $\begin{array}{l}\text { Worth Caicos Cays } \\
\text { Highas } \\
\text { Conch } \\
\text { Bay } \\
\text { Major Hill }\end{array}$ & 7.8 & $?$ & $?$ & -- \\
\hline Parrot & 5.2 & $E$ & dogs & $\begin{array}{l}\text { Coleman, } \\
\text { Hesse }\end{array}$ \\
\hline Dellis Cay & 1.6 & $A$ & none & Hesse \\
\hline Grouper & 0.8 & A & $\begin{array}{c}\text { (recently) } \\
\text { dogs }\end{array}$ & Hesse \\
\hline Ft. George & 0.5 & A & $\begin{array}{c}\text { (recently) } \\
\text { dogs }\end{array}$ & Iverson \\
\hline Pine Cay & 3.9 & $R$ & $\begin{array}{l}\text { cats } \\
\text { dogs }\end{array}$ & $\begin{array}{l}\text { Iverson, } \\
\text { Hesse }\end{array}$ \\
\hline Water Cay & 3.9 & $U$ & cats & $\begin{array}{l}\text { Iverson, } \\
\text { Hesse }\end{array}$ \\
\hline Little Water Cay & 0.5 & $A$ & $\begin{array}{l}\text { no cats or } \\
\text { dogs }\end{array}$ & $\begin{array}{l}\text { Iverson, } \\
\text { Hesse }\end{array}$ \\
\hline Donna Cay & 0.3 & A & none & Coleman \\
\hline Hatgole Cay & 1.0 & A & none & Coleman \\
\hline Pro:idenciales & 97.1 & $E$ & $\begin{array}{l}\text { dogs } \\
\text { cats }\end{array}$ & Auffenberg \\
\hline
\end{tabular}


Table 50 - cont inued

\begin{tabular}{|c|c|c|c|c|}
\hline Island & $\begin{array}{l}\text { Approximate } \\
\text { Area }\left(\mathrm{km}^{2}\right)\end{array}$ & Status & $\begin{array}{c}\text { Feral } \\
\text { mammals } \\
\text { present }\end{array}$ & Source \\
\hline West Caicos & 23.3 & $E$ & $?$ & Coleman \\
\hline Southern Cays & 7.8 & & & \\
\hline White & & $?$ & $?$ & -- \\
\hline Pear & & $?$ & $?$ & -- \\
\hline Bush & & $?$ & $?$ & - \\
\hline Ambergris & & $A$ & $?$ & Hesse \\
\hline Fish & & $?$ & $?$ & -- \\
\hline Six Hills & & A & $?$ & $\begin{array}{l}\text { Honegger } \\
(1968)\end{array}$ \\
\hline Middleton & & A & none & $\begin{array}{l}\text { Iverson, } \\
\text { Hesse }\end{array}$ \\
\hline Long & & $U$ & cats & Iverson \\
\hline Total & 505.5 & & & \\
\hline
\end{tabular}

Note: The Caicos Islands are listed geographically counterclockwise around the bank. Areas are from Sadler (1975) or estimated from

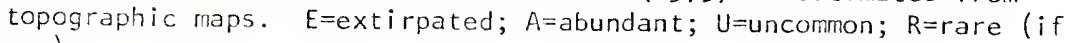
any).

apersonal observations by Chuck and Kathy Hesse of Pine Cay, Tommy Coleman of Parrot Cay, Walter Auffenberg, and myself. 
islets may aiso support small populations. The total land area in these islands is appruxinately $505 \mathrm{~km}^{2}$ all of which probably once supported Cyclura. The lizards are today found on only about $83 \mathrm{~km}^{2}(16.4 \%)$ of that total (representing at least 18 discrete island populations). Based on average Pine Cay density (26.9 adults/ha), an absolute maximum of just over 200,000 adult Cyclura carinata would exist in the Turks and Caicos, however the density of the majority of the other populations is far below that. The actual numbers are certainly not this high, and an estinate of half that value is probably optimistic. When a population of over 5,000 adults can be decimated in just over two years by a few dogs and several cats, the need for immediate protection of the remaining populations is apparent.

\section{Basic Lizard Requirements}

Any successful attempt to insure the survival of a population must first consider those factors which normally limit the population. Any conservation effort that ignores such factors may further jeopardize the population. Unfortunately, much of the world's endangered flora and fauna remains unstudied and programs must often be initiated with little data in hand. This study is intended to provide the necessary background information to effectively administer a successful conservation program for Cyclura carinata and perhaps the remaining endangered populations of West Indian rock iguanas as well.

Several resources emerged as most important in limiting natural populations of Cyclura carinata. They are availability of food (both quantity and quality), nest sites, and burrow sites. Since this species' 
social behavior is believed to have evolved in an attempt to guarantee access to these resources, certain behavioral aspects must also be considered in efforts to provide them.

Food is probably a critical resource to most natural populations and thercfore competitors such as goats and pigs rnust not be allowed to occupy habitats where Cyclura are expected to survive. Destruction of natural vegetation should also be avoided. Insuring maximum dispersion of available food resources will reduce social stress and allow dominant males to successfully maintain feeding (and breeding) territories.

Suitable substrates for nesting burrows are essential to the survival of all iguanine lizards. Although these areas are apparently more limiting to such species as Iguana iguana and Cyclura cornuta (Mona Island population), which must migrate to restricted nesting grounds, failure to provide adequate nesting areas for Cyclura carinata during conservation efforts will unquestionably limit population growth. Under optimum conditions, nesting areas should be dispersed in order to reduce costly feriale aggression during nesting and decrease the possibility of one female destroying another's nest.

Limitations on available retreats will also retard population growth, since dominant males will deny other males access to their retreats, exposing them to climate and predation. Extremely rocky islands, with little soil or few subterranean cavities, will therefore support few iguanas. Such islands are unlikely candidates for stocking prograns despite the attractiveness of their isolation or lack of landing sites. 


\section{Population Control}

\section{Historical}

Legislation protecting the iguana in the Turks and Caicos Islands is practically nor-existent. Although iguanas were formerly protected by Jamaican law, the independence of that country has left cyclura carinata extrenely vulnerable. Protection is at present indirectly afforded the lizards only through attempts at preserving areas of particular historical or non-herpetological (usually marine or avian) interest. Even this protection is generally ineffective due to lack of enforcement. However, since the Honorable C. S. (Liam) Maguire, an ardent supporter (both financially and morally) of our iguana studies, has recently been appointed the Minister of Natural Resources for the Turks and Caicos Islands, it is hoped that this lack of protective legislation may soon be rectified.

In addition, a recently incorporated non-profit scientific and educational foundation--PRIDE, a society for the Protection of Reefs and Islands from Degradation and Exploitation--has established field headquarters on Pine Cay in the Caicos Islands. I hope that their interest in the conservation of the islands' natural resources will benefit Cyclura carinata.

\section{Protecting the Iguana}

In light of the population declines documented earlier in this chapter, it is imperative that conservation measures be taken immediately if Cyclura carinate is to persist in the Turks and Caicos islands. If the spread of feral dogs and cats in the islands is not curtailed, and present populations of feral predators and competitors are not reduced, 
the iguano stunds little chance of survival. Leash laws for dogs, if rigidly enforced, might permit dogs to successfully coexist on islands with Eyclura. Any senctuaries designated to protect iguanas should be hept free of feral dogs and cats.

The effects of other feral mammais (pigs, goats, donkeys, etc.) on Cyclura carinata were unfortunately not documented in this study. Nevertheless, their detrimental effects on iguana populations in the Galapagos (Hillaby, 1964; Dowling, 1964; among others) and on other islands of the West Indies (Wiewandt, in preparation), suggest that their introductions should also be restricted.

it is aiso important to eliminate pressure from pet dealers who contincie to exploit the West Indian faunas and who currently receive $\$ 150.00$ and more for individual iguanas. Prohibiting exportation from the Turks and Caicos as well as importation into the United States would substantially benefit existing populations.

The designation of numerous small uninhabited islands in the Turks and Caicos Islands as wildlife sanctuaries seems the most logical way to insure the survival of Cyclura carinata and other native plants and animals. Fort Gaorge, Littie Water, Donna, Iguana, Six Hills, and the Ambergris Cays all support viable iguana populations and are uninhabited by humans or feral mammals. Each would be ideal as a wildlife sanctuary, however, the appointment of wardens or resident caretakers would probably be recessary to enforce protective legislation.

\section{Restocking and Transplantation}

Restocking iguanas on islands from which they were previous?y extirpated, after the islands have been cleared of their introduced 
faunas, would help to stem the general population decline. That this method should be successful is suggested by the dense, stable population of iguanas now inhabiting fort George Cay, an island which probably completely lacked Cyclura little more than 100 years ago due to human habitation. The method has already proved successful in re-establishing Ameive polops on an island from which it was earlier extirpated by introduced mongooses (Philobosian and Ruibal, 1971).

Transplantation of C. Carinata to other suitable islands in the West Indies, even outside the species' present range, is at least worthy of experimentation. Many of the sinall privately-owned Bahamian islands could potentially serve as reservoirs from which to recycle lizards back to endangered natural populations. Many of these islands offer abundant food, shelter, and nesting areas, as well as the possibility of direct supervision by conservation-minded residents. Utilizing these situations may ultimately be the most valuable means of perpetuating much of the flora and fauna of the west Indies.

\section{Potential in Captivity}

Our experience with Cyclura carinata in captivity suggests great potential for captive breeding programs. The species is among the smallest of the genus, decreasing the problem of severe space limitations. Adult feriales maintained essentially normal reproductive lives for up to 20 nonths we kept them in captivity, and growth rates exceeded those obtained in the field. Establishment of a breeding colony in the warmer southarn portions of California, Texas, or Florida is entirely feasible end could ultimately provide specimens both for the world's zoos and for restoching programs. 


\section{Conclusions}

More important than anything else, this study has demonstrated the rapid, devastating effects of the intervention of man and his animals on a population of the rock iguana Cyclura carinata. It is therefore urgent that the information presented here be employed immediately in efforts to protect not only Cyclura carinata but all remaining Cyclura populations. With an intelligent management program, immediately initiated, and carefully maintained, there is no reason for Cyclura carinata to join the several other Cyclura populations which have disappeared since man's arrival in the West Indies. 


\section{LITERATURE CITED}

Adams, L. and S. D. Davis. 1967. The internal anatomy of home range. J. Mammalogy, 48: 529-536.

Aleksiuk, M. and K. W. Stewart. 1971. Seasonal changes in body composition of the garter snake (Thamnophis sirtalis parietalis) at northern latitudes. Ecology, 52: 485-490.

Alvarez del Toro, M. 1972. Los Reptiles de Chiapas. Inst, Zool. del Estado, Tuxtla Gutierrez, Chiapas. $178 \mathrm{pp}$.

Andrews, R. M. 1971. Structural habitat and time budget of a tropical Anolis lizard. Ecology, 52: 262-270.

Andrews, R. M. 1976. Growth rate in island and mainland anoline lizards. Copeia, 1976: 477-482.

Arlton, A. V. 1936. An ecological study of the mole. J. Mammalogy, $17: 349-371$.

Armstrong, J. T. 1965. Breeding home range in the nighthawk and other birds: its evolutionary and ecological significance. Ecology, 46: 619-629.

Auffenberg, W. In preparation. Feeding strategy of Cyclura carinata.

Auffenberg, W. and W. G. Weaver, Jr. 1969. Gopherus berlandieri in southeastern Texas. Bull. Fla. State Mus., 13: $741-203$.

Auth, D. In preparation. Thermoregulation and physiology of Cyclura carinata.

Avery, R. A. 1971. Estimates of food consumption by the lizard Lacerta vivipara Jacquin. J. Anim. Ecol., 40: 351-365.

Avery, R. A. 1975a. Clutch size and reproductive effort in the lizard Lacerta vivipara Jacquin. Oecologia (Berlin), 19: 165-170.

Avery, R. A. 1975b. Age-structure and longevity of common lizard (Lacerta vivipara) populations. J. Zool., London, 176: 555-558.

Avery, D. F. and W. W. Tanner. 1971. Evolution of the Iguanine lizards (Sauria, Iguanidae) as determined by osteological and myological characters. Brigham Young Univ. Sci. Bull., 12: 1-79. 
Bailey, A. M. 1925. The iguanas of Bitter Guana Cay. Nat. Hist., 25: $390-393$.

Bailey, N. T. J. 1951. On estinating the size of mobile populations from recapture data. Biometrika, 38: 293-306.

Ballinger, R. E. 1973. Comparative demography of two viviparous iguanid lizards (Sceloporus jarrovi and Sceloporus poinsetti). Ecology, 54: 269-283.

Ballinger, R. E. and G. D. Schrank. 1972. Reproductive potential of female whiptail lizards, Cnemidophorus gularis gularis. Herpetologica, 28: 217-222.

Bartholomew, G. A. 1966. A field study of temperature relations in the Galapagos marine iguana. Copeia, 1966: 241-250.

Bartholomew, G. A., A. F. Bennett, and W. R. Dawson. 1976. Swimming, diving, and lactate production of the marine iguana, Anstyrhynchus cristatus. Copeia, 1976: 709-720.

Barus, V., A. C. Otero, and 0. H. Garrido. 1969. Helmintofauna de Cyclura macleayi Gray (Sauria, Iguanidae) en Cuba. Torreia, Nueva Ser., $8: \overline{1-20 .}$

Barwick, R. E. 1959. Life history of the common New Zealand skink Leiolopisma zelandica. Trans. Royal Soc. New Zealand, 86: 331-380.

Beattie, J. 1926. The lleo-caecal region in the Reptilia.--l. The l leo-caecal region of Tupinambis teguexin. Proc. Zool. Soc. London, 28: 931-939.

Beard, J. S. 1949. The natural vegetation of the Windward and Leeward 1s. 0xford Forestry Memoir, 21: 1-192.

Beebe, W. 1944. Field notes on the lizards of Kartabo, British Guinea, and Caripito, Venezuela. Part 2. Iguanidae. Zoologica, 29: $195-216$.

Berry, K. H. 1974. The ecology and social behavior of the chuckwalla, Sauromalus obesus obesus Baird. Univ. of California Publ. Zool., 101: 1-60.

Berry, P. Y. and G. S. Lim. 1967. The breeding pattern of the puff-faced water snake, Homalopsis buccata Boulenger. Copeia, 1967: 307-313.

Blair, W. F. 1950. The rusty lizard: A population study. Univ. Texas Press, Austin. $185 \mathrm{pp}$.

Bond, J. 1971. Birds of the West Indies. Houghton Mifflin, Boston. $256 \mathrm{pp}$. 
Bowie, A. 1973. Predation on lizards by Sceloporus woodi. J. Herpetol., 7: 318 .

8o:1ie, A. and R. Franz. 1974. Cyrtosomum mega sp. n. (Nematoda: 0xyuroidea) from the lizard, Cyclura carinata. J. Parasitology, 60: $628-631$.

Brattstrom, B. H. 1974. The evolution of reptilian social behavior. Amer. Zool. 14: 35-39.

Bravo-Hollis, M. 1942. Acerca de un nematoda parasito de la iguana, Ctenosaura acanthura (Shaw). An. Inst. Biol. Mexico, 13: 533-537.

Brenes, R. R. and M. Bravo-Hollis. 1960. Helmintos de la Republica de Costa Rica. IX. Nematoda 3. Algunos nematodos de reptiles, con descripcion de dos nuevas especies: Atractis caballeroi n. sp. y Cyrtosomum longicaudatum n. sp. Edit. Politechnica Mexico Libro. Homenaje al Dr. E. Caballero y Caballero: 451-464.

Brockelman, W. Y. 1975. Competition, the fitness of offspring, and optimal clutch size. Amer. Natur., 109: 677-699.

Buden, D. W. 1974. Prey remains of barn owls in the southern Bahama Islands. Wilson Bull., 86: 336-343.

Buden, D. W. 1975. A taxonomic and zoogeographic appraisal of the bigeared bat (Macrotus waterhousii Gray) in the West Indies. J. Mamma logy, $\overline{56: 758-769 .}$

Buide, M. S. 1951. Observation on habits of the Cuban iguana. Herpetologica, 7: 124 .

Burge, J. R. and C. D. Jorgensen. 1973. Home range of small mammals: a reliable estimate. J. Mammalogy, 54: 483-488.

Burt, C. E. 1928. Insect food of Kansas lizards with notes on feeding habits. J. Kansas Ent. Soc., I: 50-68.

Busack, S. D. 1975. Biomass estimates and thermal environment of a population of the fringe-toed lizard, Acanthodactylus pardalis.

Brit. J. Herpetol., 5: 457-459.

Bustard, H. R. 1969. Tail abnomalities in reptiles resulting from high temperature egg incubation. Brit. J. Herpetol., 4: 12i-123.

Bustard, H. R. 1970a. Turtles and an Iguana in Fiji. Oryx, 10: 317322 .

Bustard, H. R. 1970b. The role of behavior in the natural regulation of numbers in the gekkonid lizard Gehyra variegata. Ecology, 51 : $724-728$. 
Bustard, H. R. and P. F. A. Maderson. 1965. The eating of shed epidermal material in Squamate reptiles. Herpetologica, 21: 306-308.

Caballero y Caballero, C. E. 1938. Nematodes parasites des reptiles du Mexique. Ann. Parasitol., 16: 327-333.

Caballaro y Caballero, C. E. 1939. Nernatodos de los reptiles de Mexico.11. An. Inst. Biol. Mexico, 10: 73-82.

Caballero y Caballero, C. E. 1943. Nematodos de los reptiles de Mexico. VIl. Acerca de la presencia de Camallanus scabrae MacCallum, 1918 en las tortugas de aguas dulce, del sureste de Mexico (English summary). An. Inst. Biol. Mexico, 14: 195-200.

Caballero y Caballero, C. E. y M. C. Zerecero. 1943. Nematodos de los reptiles de Mexico. VIII. Descripcion de tres nuevas especies. An. Inst. Biol. Mexico, 14: 527-539.

Cagle, F. R. 1946. A lizard population on Tinian. Copeia, 1946: 4-9.

Cahill, C. 1970. The banded iguana of Fiji. Fiji Mus. Educ. Ser., 2: $1-14$.

Carey, W. M. 1966. Observations on the ground iguana Cyclura macleayi $\frac{\text { caymanensis on Cayman Brac, British West Indies. Herpetologica, }}{22 \cdot 265-268}$

Carey, W. M. 1972. The herpetology of Anegada, British Virgin Islands. Carib. J. Sci., 12: 79-89.

Carey, W. M. 1973. Some notable longevity records for captive iguanas. Intl. Zoo Yearbook, 13: 154-156.

Carey, W. M. 1975. The rock iguana, Cyclura pinguis, on Anegada, British Virgin Islands, with notes on Cyclura ricordi and Cyclura cornuta on Hispaniola. Bull. Florida St. Mus. Biol. Sci., 19: 189-233.

Carey, W. M. 1976. Iguanas of the Exumes. Wildlife, 5: 59-61.

Carpenter, C. C. 1961. Patterns of social behavior in the desert iguana, Dipsosaurus dorsalis. Copeia, 1961: 396-405.

Carpenter, C. C. 1962a. Patterns of behavior in two Oklahoma lizards. Amer. Midland Natur., 67: 132-151.

Carpenter, C. C. 1962b. A comparison of the patterns of display of Urosaurus, Uta and Streptosaurus. Herpetologica, 18: 145-152.

Carpenter, C. C. 1966. The marine iguana of the Galapagos Islands, its behavior and ecology. Proc. California Acad. Sci., 34 : 329-375. 
Carpenter, C. C. 1967. Aggression and social structure in Iguanid lizards. pp. 87-105. IN: Milstead, W. W., ed., Lizard Ecology, a Symposiun. Univ. Missouri Press, Columbia. 300 pp.

Carpenter. C. C. 1969. Behavioral and ecological notes on the Galapagos land iguanas. Herpetologica, 25: 155-164.

Carpenter, C. F. and C. Grubitz 111. 1961. Time-motion study of a lizard. Ecology, 42: 199-200.

Carr, A. 1953. High jungles and low. Univ. Florida Press. Gainesville. $225 \mathrm{pp}$.

Case, T. 3. 1976. Body size differences between populations of the shuckwalla, Sauromalus obesus. Ecology, 57: 313-323.

Christian, D. P. 1975. Vulnerability of meadow voles, Microtus pennsylvanicus, to predation by domestic cats. Amer. Midland Natur., 93: 498-502.

Church, G. 1962. The reproductive cycles of the Javanese house gecko Cosvmbotus platyurus, Hemidactylus frenatus and Peropus mutilatus. iopeia, 1962: 262-269.

Ciarke, R. L. 1963. An ethological study of the iguanid lizard genera Callisaurus, Cophosaurus and Holbrookia. Emporia State Res. Stud., 13: $1-66$.

Cechran, D. M. 1931. New Bahaman reptiles. J. Washington Acad. Sci., 21: $39-40$.

Cochran, D. M. 1934. Herpetological collections from the West Indies made by Dr. Paul Bartsch under the Walter Rathbone Bacon scholarship, 1928-1930. Smithsonian Misc. Coll., 92: 1-48.

Cogger, 4. G. 1974. Voyage of the banded iguana. Austrai ian Natur. Hist., 18: 144-149.

Conan, B. J. and H. Erunner. 1972. Food habits of the feral house cat ir Victoria. J. Wildl. Mgt., 36: 848-853.

Cooper, J. E. 1958. Ecological notes on some Cuban lizards. Herpetologica, 14:53-54.

Cope, E. D. 1896. On the hemipenes of the Sauria. Proc. Acad. Nat. sci. Philadelphia, 461-467.

Cowles, R. B. 1946. Note on the arboreal feeding habits of the desert igliena. Copeia, 1946: 172-173.

Cowles, R. B. and C. M. Bogert. 1944. A preliminary study of the thermal requirements of desert reptiles. Bull. Amer. Mus. Natur. Hist., $83: 261-296$.

Crenshaw, J. W. JT. 1955. The life history of the southern spiny lizard, Sceloporus undulatus undulatus Latreille. Amer. Midland Natur., 54: $257-298$. 
Crews, D. 1973a. Behavioral correlates to gonadal state in the lizard, Anol is carolinensis. Hormones and Behavior, 4: 307-313.

Crews, D. 1973b. Coition-induced inhibition of sexual receptivity in female lizards (Anolis carolinensis). Physiology and Behavior, $11: 463-468$.

Crews, D. 1975a. Inter- and intraindividual variation in display patterns in the lizard, Anolis carolinensis. Herpeto : $37-47$.

Crews, D. 1975b. Effects of different components of male courtship behaviour on environmentally induced ovarian recrudescence and mating preferences in the lizard, Anolis carolinensis. Anim. Behav., 23: 349-356.

Crook. I. G. 1973. The tuacara, Sphenodon punctatus Gray, on islands with and without populations of the polynesian rat, Rattus exulans (Peale). Proc. New Zealand Ecol. Soc., 20: 115-120.

Crook. 1. G. 1975. The Tuatara. Biogeography and ecology in New Zealand Wildife Publ., 167: 331-352.

Cuckler, A. C. 1938. Nematode parasites of the Galapagos Iand iguana. Rep. Hancock Pacific Exped. (1932-1938), 2: 137-165.

Cuellar, 0. 1970. Egg transport in lizards. J. Morph., 130: 129-136.

D'Arcy, W. G. 1975. Anegada Island: vegetation and flora. Atoll Research Bulletin, 188: 1-40.

Darevsky, 1. 1957. Seasonal changes of fat bodies and gonads in some lizards of the Arax river valley in Armenia. Zoologischesini Zhurnal, 39: 1209-1218.

Davis, D. E. 1953. Analys is of home range from recapture data. J. Mammalogy, 34: 352-358.

Davis, W. B., and J. R. Dixon. 1961. Reptiles (exclusive of snakes) of the Chilpancingo region, Mexico. Proc. Biol. Soc. Washington, $74: 37-56$.

Davis, W. B. and H. M. Smith. 1953. Lizards and turtles of the Maxican state of Morelos. Herpetologica, 9: 100-108.

Deevey, E. S. 1947. Life tables for natural populations of animals. Quart. Rev. Biol., 22: 283-314.

Desloya, J. C. 1971. Redescripcion de Cyrtosonum longicaudaturn Brenes y Bravo, 1960. An. Inst. Biol. Mexico, Ser. Zool., 42: 29-34.

Denney, R. N. 1974. The impact of uncontrolled dogs on wildlife and livestock. Trans. 39th North Amer. Wildl. and Nat. Res. Conference: $257-291$. 
Derickson, W. K. 1974. Lipid deposition and utilization in the sagebrush lizard, Sceloporus graciosus: its significance for reproduction and maintenance. Comp. Biochem. Physiol., 49A: 267-272.

Dessauer, H. C. 1955. Seasonal changes in the gross organ composition of the lizard Anolis carolinensis. J. Exp. Zool., 128: 1-12.

Dessauer, H. C. and W. Fox. 1959. Changes in ovarian follicle composition with plasma levels of snakes during estrus. Amer. J. Physiol., 197: 360-366.

DeVries, T. 1974. Opmerkingen over taxonomie en ecologie van de reptielen van de Galapagos-eilanden 11. Landleguanen en zeeleguanen. Lacerta, 32: 95-106.

Dodge, N. N. 1938. Amphibians and reptiles of Grand Canyon National Park. Grand Canyon Nat. Hist. Assoc. Nat. Hist. Bull., 9: 1-55.

Dosse, G. 1939. Uber einige Nematoden aus C. carinata R. Harlan, 1824 (Macracis monhystera v. Linstow, 1902; Travassozolaimus travassosi vigueras, 1938; Mammillomacracis cyclurae n. g., n. sp.). Zeitschrift fur Parasitenkunde, $10: 694-703$.

Douglass, J. F. 1975. Bibliography of the North American land tortoises (genus Gopherus). Fish and Wildl. Service Special Sci. Report, 190: $1-\overline{60}$.

Dowling, H. G. 1964. Goats and hawks--a new theory of predation on the land iguana. Animal Kingdom, 67: 51-56.

Dubuis, A., L. Faurel, C. Grenot and R. Vernet. 1971. Sur le regime alimentaire du lizard saharien Uromastix acanthinurus. C. R. Acad. Sci. Paris, Ser. D, 273: 500-503.

Duellman, W. E. 1961. The amphibians and reptiles of Michoacan, Mexico. Univ. Kansas, Publ. Mus. Nat. Hist., 15: 1-148.

Duellman, W. E. 1965. Amphibians and reptiles from the Yucatan peninsula, Mexico. Univ. Kansas, Publ. Mus. Nat. Hist., 15: $577-614$.

Duellman, W. E., and Duellman, A. S. 1959. Notes on the variation, distribution, and ecology of the iguanid lizard Enyaliosaurus clarki. Occ. Pap. Mus. Zool. Univ. Michigan, 598: 1-10.

Dutton, R. H., L. C. Fitzpatrick, and J. L. Hughes. 1975. Energetics of the rusty lizard Sceloporus olivaceus. Ecology, 56: 1378-1387.

Eberhardt, L. 1968. A preliminary appraisal of line transects. J. Wildl. Mgnt., 32: 82-88. 
Edgorly, R. H. 1952. A new oxyurid nematode, Alaeuris yumanae n. sp. from the lizard Dipsosaurus dorsalis. Trans. Fin. Micr. Soc., $71: 341-343$

Eibl-Eibesfeldt, 1. 1955. Der Kommentkampf der meerechse (Amblyrhynchus cristaius Bell) nebst einigen hotizen zur biologie dieser art. Zeitschrift fur Tierpsychologie, 12: 49-62.

Eibl-Eibesfcldt, 1. 1961. Galapagos: The Noah's Ark of the Pacific. Doubleday, New York. 192 pp.

Eibl-Eibesfeldt, 1. 1965. Das verteidigen der eiablageplatze bei der Hood-Meerechse (Amblyrhynchus cristatus venustissimus). Zeitschrift fur Tierpsychologie, 23: 127-13.

Essghaler, M. F. A. and D. R. Johnson. 1975. Aspects of the bioenergetics of Great Basin lizards. J. Herpetol., 9: 191-195.

Evans, L. T. 1938. Courtship behavior and sexual selection of Anolis. J. Comp. Psychol., 26: 475-496.

Evans, L. T. 1951. Field study of the social behavior of the black lizard, Ctenosaura pectinata. Amer. Mus. Nov., 1493: 1-26.

Eyerdam, W. J. 1954. With Dr. Eric Ekman in southern Haiti, in the sumner of 1927. Field and Laboratory, 22: 85-105.

Ferguson, G. W. 1970. Mating behaviour of the side-blotched lizards of the genus Uta (Sauria: Iguanidae). Anim. Behav., 18: 65-72.

Ferguson, G. W. 1971. Variation and evolution of the push-up displays of the side-blotched Iizard genus Uta (Iguanidae). Syst. Zool., 20: $79-101$.

Ferguson, G. W. 1972. Species discrimination by male side-blotched 1 izards Uta stansburiana in Colorado. Amer. Midland Natur. 87: 523-524.

Ferguson, G. W. 1976. Color change and reproductive cycling in female collared lizards (Crotaphytus collaris). Copeia, 1976: 491-494.

Fitch, 4. S. 1954. Life history and ecology of the five-lined skink, Euneces fasciatus. Univ. Kansas, Publ. Mus. Nat. Hist., 8: 1-156.

Fitch, H. S. 1955. Habits and adaptations of the Great plains shink Eumeres obsoletus. Ecol. Monogr., 25: 59-83.

Fitch, r. S. 1955. An ecological study of the collared lizard

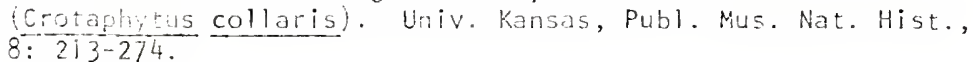


Fitch, H. S. 1960. Autecology of the copperhead. Univ. Kansas, Publ. Mus. Nat. Hist., 13: 85-288.

Fitch, H. S. 1963. Natural history of the racer Coluber constrictor. Univ. Kansas, Publ. Mus. Nat. Hist., 15: $351-468$.

Fitch, H. S. 1970. Reproductive cycles in lizards and snakes. Univ. Kansas, Mus. Nat, Hist., Misc. Publ., 52: 1-247.

Fitch, H. S. 1973. Population structure and survivorship in some Costa Rican lizards. Occ. Papers Univ. Kansas Mus. Nat. Hist., 18: 1-41.

Fitch, H. S. 1973. A field study of Costa Rican lizards. Univ. Kansas Sci. Bull., 50: 39-126.

Fitch, H. S. 1975. A demographic study of the ringneck snake (Diadophis punctatus) in Kansas. Univ. Kansas, Mus. Nat. Hist., Misc. Publ.,

Fitch, H. S. and R. W. Henderson. Ms. Age and sex differences in the ctenosaur (Ctenosaura similis). Unpublished manuscript.

Fleet, R. R. and H. S. Fitch. 1974. Food habits of Basiliscus basiliscus in Costa Rica. J. Herpetol., 8: 260-262.

Free, J. D., R. M. Hansen, and P. L. Sims. 1970. Estimating the dry weights of foodplants in feces of herbivores. J. Range Mgmt., 23: $300-302$.

Freeland, G. L. and R. S. Dietz. 1971. Plate tectonic evolution of Caribbean-Gulf of Mexico Region. Nature, 232: 20-23.

Freeland, W. J. and D. H. Janzen. 1974. Strategies in herbivory by mammals: The role of plant secondary compounds. Amer. Natur., 108: 269-289.

Freitas, J. F. Teixeira De and H. Lent. 1937. Sobre Oswaldofilaria brevicaudata (Rodhain et Vuylsteke, 1937) n. comb. Mem. Inst. oswaldo Cruz, 32: 439-442.

Gaffney, F. G. and L. C. Fitzpatrick. 1973. Energetics and 1 ipid cycles in the lizard Cnemidophorus tigris. Copeia, 1973: 446-452.

Garbino, J. J. 1957. Relationships of North American Iguanidae as suggested by an analysis of their pinworm parasites, Cyrtosomum spp. Anat. Record, 128: 553-554.

Gembino, 3. J. 1958. Cyrtosonum readi n. sp. and Cyrtosomum heynemani n. sp. (osyuroidea: Atractidae) two new pinworms of iguanids. J. Parasit., $44: 439-445$. 
Gambino, J. J. and D. Heyneman. 1960. Specificity and speciation in the genus Cyrtosomin (Nematoda: Atractidae). Amer. Midland Natur., $63: 365-382$.

Gaman, S. 1888. On West Indian reptiles. Iguanidae. Bull. Essex Institute, 19: 119-138.

Gasaway, W. C., R. G. White, and D. F. Holleman. 1976. Digestion of dry matter and absorption of water in the intestine and cecum of rock ptarmigan. Condor, $78: 77-84$.

Gates, G. 0. 1957. Herpetofauna near Wickenburg, Arizona. Trans. Kansas Acad. Sci., 60: 403-418.

Gates, C. E., W. H. Marshall, and D. P. 01son. 1968. Line transect method of estimating grouse population densities. Biometrics, 24: 135-145.

George, W. G. 1974. Domestic cats as predators and factors in winter shortages of raptor prey. Wilson Bull., 86: 384-396.

Giles, Ji., R. H., ed. 197l. Wildlife management techniques. The Wildife Society, Washington, D.C. 633 pp.

Goin, C. J. and 0. B. Goin. 1962. Introduction to herpetology. W. H. Freeman and Co., San Francisco. 353 pp.

Goldberg, S. R. 1972. Seasonal weight and cytological changes in the fat bodies and liver of the iguanid lizard Sceloporus jarrovi Cope. Copeia, 1972: 227-232.

Golley, F. B. 1969. Caloric value of wet tropical forest vegetation. Ecology, 50: 517-519.

Gonzales, R. B. 1974. Behavior notes on captive Hydrosaurus pustulosus. Silliman J., 21: 129-138.

Gosse, P. H. 1848. On the habits of Cyclura lophoma, an Iguaniform lizard. Proc. Zool. Soc. London, 16: 99-104.

Grant, C. 1937. Herpetological notes with new species from the American and British Virgin Islands, 1936. J. Dept. Agric., Univ. Puerto Rico, 21: 503-52.2.

Grant, C. 1940a. The herpetology of Jamaica. 11. The reptiles. Bull. Inst. of Jamaica, Sci. Ser., 1: 63-148.

Grant, C. 1940b. The herpetology of the Cayman Islands. Bull. Inst. Jamaica, Sci. Ser., 2: 1-65.

Grant, C. 194h. Cyclura stejnegeri--a portrait. Herpetologica, 2: $139-140$. 
Greenberg, N. 1973. Behavior studies of the blue spiny lizard. Unpublished Ph.D. Dissertation. Rutgers Univ., Newark, N.J. 222 pp.

Greenberg, N. 1976. Observations of social feeding in lizards. Herpetologica, 32: 348-352.

Crove, J. D. 1971. Cannibalism in a captive Sceloporus undulatus hyacinthinus. J. Herpetol., 5: 205.

Haast, W. E. 1969. Hatching rhinoceros iguanas (Cyclura cornuta) at the Miami serpentarium. Int1. Zoo Yearbook, 9: 49.

Hackforth-Jones, J. Ms. The egg deposition burrows of the ctenosaur, Ctenosaura similis, in Costa Rica. Unpublished manuscript.

Hahn, W. E. 1964. Seasonal changes in testicular and epididymal histology and spermatogenic rate in the lizard Uta stansburiana stejnegeri. J. Morph., 115: 447-460.

Hahn, W. E. and D. W. Tinkle. 1965. Fat body cycling and experimental evidence for its adaptive significance to ovarian follicle development in the lizard Uta stansburiana. J. Exp. Zool., 158: 79-86.

Hall, R. J. 1972. Food habits of the Great Plains skink (Eumeces obsoletus). Amer. Midland Natur., 87: 258-263.

Hallinan, T. 1920. Notes on lizards of the Canal Zone, Isthmus of Panama. Copeia, 83: 45-49.

Hansen, R. M. 1974. Dietary of the Chuckwalla, Sauromalus obesus, determined by dung analysis. Herpetologica, 30: 120-123.

Hansen, R. M., M. K. Johnson and T. R. Van Devender. 1976. Foods of the desert tortoise, Gopherus agassizii, in Arizona and Utah. Herpetologica, 32: 247-251.

Hardy, J. D. 1956. Notes on the Cuban iguana. Herpetologica, 12: 323-324.

Harlan, R. 1825. Description of two species of Linnean Lacerta, not before described and construction of the new genus Cyclura. J. Acad. Nat. Sci., Philadelphia, (1) 4: 242-251.

Harlow, H. J., S. S. Hillman, and M. Hoffman. 1976. The effect of temperature on digestive efficiency in the herbivorous lizard, Dipsosaurus dorsalis. J. Comp. Physiology, 1118: 1-6.

Harris, V. A. 1964. The life of the rainbow lizard. Hutchinson Trop. Monogr., Hutchinson and Co., London. $174 \mathrm{pp}$. 
Hayne, D. W. 1949. An examination of the strip census method for estimating animal populations. J. Wildl. Mgmt., 13: 145-157.

Henderson, R. W. 1973. Ethoecological observations of Ctenosaura $\frac{\text { simi }] \text { is (Sauria: Iguanidae) in British Honduras. J. Herpetol., }}{7: 27-34}$

Henderson, R. W. 1974. Aspects of the ecology of the juvenile common iguana (Iguana iguana). Herpetologica, 30: 327-332.

Hillaby, J. 1964. The riddle of the elderly iguanas. New Scientist, 22: $438-439$.

Hirth, H. F. 1963a. Some aspects of the natural history of Iguana iguana on a tropical strand. Ecology, 44: 613-615.

Hirth, H. F. 1963b. The ecology of two lizards on a tropical beach. Ecol. Monogr., 33: 83-112.

Hoddenbach, G. A. 1966. Reproduction in western Texas Cnemidophorus sexlineatus (Sauria: Teiidae). Copeia, 1966: 110-113.

Hoddenbach, G. A. and F. B. Turner. 1968. Clutch size in Uta stansburiana in southern Nevada. Amer. Midland Natur., 80: 262-26 $\overline{5}$.

Hotton, N. 1955. A survey of adaptive relationships of dentition to diet in the North American Iguanidae. Amer. Midland Natur., 53: $88-114$.

Hunsaker, D. 1962. Ethological isolating mechanisms in the Sceloporus torquatus group of lizards. Evolution, 16: 62-74.

Hunsaker, D. and B. R. Burrage. 1969. The significance of interspecific social dominance in lguanid lizards. Amer. Midland Natur., 81: 500-511.

Irwin, L. N. 1965. Diel activity and social interaction of the lizard Uta stansburiana stejnegeri. Copeia, 1965: 99-101.

Jackson, J.F. 1974. Utilization of periods of high sensory complexity for site change in two lizards. Copeia, 1974: 785-787.

Jareson, E. W. 1974. Fat and breeding cycles in a montane population of sceloporus graciosus. J. Herpetol., 8: 311-322.

Janzen, D. H. 1971. Seed predation by animals. Ann. Rev. Ecol. and Syst., 2: $465-495$.

Janzen, D. H. 1976. Reduction of Mucuna andreang (Leguminosae) seedling fitness by artifical seed damage. Ecology, 57: 826-828. 
Jennrich, R. I. and F. B. Turner. 1969. Measurement of non-circular home range. J. Theoret. Biol., 22: 227-237.

Jenssen, T. A. 1970. The ethoecology of Anolis nebulosus (Sauria, Iguanidae). J. Herpetol., 4: 1-38.

Jenssen, T. A. 1971. Display analysis of Anolis nebulosus (Sauria, Iguanidae). Copeia, 1971: 197-209.

Jenssen, T. A. 1975. Display repertoire of a male Phenacosaurus heterodermus (Sauria: Iguanidae). Herpetologica, 31: 48-55.

Jewel1, P. A. 1966. The concept of home range in maminals. Symp. Zool. Soc. Lond., 18: 85-109.

Johnson, C.R. 1965. The diet of the Pacific fence lizard, Sceloporus occidentalis occidentalis (Baird and Girard) from northern California. Herpetologica, 21: 114-117.

Johnson, S. R. 1965. An ecological study of the chuckwalla, Sauromalus obesus, in the western Mojave Desert. Amer. Midland Natur., 73: $1-29$.

Jolly, G. M. 1965. Explicit estimates from capture-recapture data with both death and immigration--stochastic model. Biometrika, 52: $225-247$.

Jorgensen, C. D. and W. W. Tanner. 1963. The application of the density probability function to determine the home ranges of Uta stansburiana and Cnemidophorus tigris tigris. Herpetologica, 19: 105-115.

Kaufmann, J. H. 1962. Ecology and social behavior of the coati, Nasua narica on Barro Colorao Island Panama. Univ. Calif. Publ. 2001., 60:95-222.

Kaufrann, J. H. 1971. Is territoriality definable? pp. 36-40. IN: Esser, A. H., ed., Behavior and Environment. Plenum Press, New York.

Keeling, M. Ms. Herbivory in lizards. Unpublished manuscript. 43 pp.

Kennedy, J. P. and H. L. Brockman. 1965. Stomach stone in the American alligator, Alligator mississippiensis Daudin. Brit. J. Herpetol., 3: $201-203$.

Kitchell, J. F. and J. T. Windel1. 1972. Energy budget for the lizard, Anolis carolinensis. Physiol. Zool., 45: 178-188.

Klingel, C. C. 1929. Lizard hunting in the Black Republic. Nat. Hist., 29: 450-464. 
Kohls, G. M. 1969. A new species of Amblyomma from iguanas in the Caribbean (Acarina: Ixodidae). J. Med. Entonol., 6: 439-442.

Korschgen, L. J. 1962. Food habits of greater prairie chickens in Missouri. Amer. Mdiland Natur., 68: 307-318.

Kretiorian, C. O'N. 1976. Home range size and overlap and their relationship to food abundrace in desert iguana, Dipsosaurus dorsalis. Herpetologica, 32: 405-412.

Lack, D. 1954. The natural regulation of animal numbers. Oxford Univ. Press, London. $343 \mathrm{pp}$.

Lando, R. V. and E. E. Williams, 1969. Notes on the herpetology of the U.S. Naval Base at Guantanamo Bay, Cuba. Studies Fauna Curacao and other Caribbean Islands, 31: 159-201.

Lent, H. and J.F. Teixeira de Freitas. 1948. Una colecao de nematodeos, parasitos de vertebrados, do Museu de historia natural de Montevideo. Mem. Inst. Osev. $\mathrm{Cr}$, 46: 1-71.

Lewis, C. B. 1944. Notes on Cyclura. Herpetologica, 2: 92-98.

Lewis, C. B. 1946. Jamaican lizards. pp. 34-36. IN: C. B. Lewis, ed. Glimpses of Jamaican Natural History. Vol. II. Inst. of Jamaica. $97 \mathrm{pp}$.

Licht, P. 1974. Response of Anolis lizards to food supplementation in nature. Copeia, 1974: $2 \overline{15-221}$.

Licht, P. and R. E. Jones. 1967. Effects of exogenous prolactin on reproduction and growth in adult males of the lizard Anolis carolinensis. Gen. Comp. Endocrinol., 8: 228-2/4.

Licht, $P$. and W. R. Moberly. 1965. Themal requirements for embryonic development in the tropical lizard Iguana iguana. Copeia, 1965: 515-517.

Linstow, 0. von. 1902. Atractis cruciata und Oxyuris monhystera, zwei Nematoden aus Metopoceros cornutus. Centralbl. Bakt. I Abt. orig., 31: 28-32.

Loonberg, E. 1902. The morphological structure of the intestine and the diet of reptiles. Bihang. Tillk. Svenska Vet.-Akad. Handinger, $28(4): 3-53$.

Loftin, h. and E L. Tyson. 1965. Iquanas as carrion eaters. Copeia, $1964: 515$.

Lynn, U. G., M. C. O'Brien and P. Herhenreader. 1966. Thyroid morphology in lizards of the families Iguanidae and Agamidae. Herpetologica, 2.2: $90-93$. 
MazArthur, R. H., and E. O. Wilson. 1967. The theory of island biogeography. Princeton University Press, Princeton, N.J. 203 pp.

Macksy, U. P. 1975. The hone range of the banded rock lizard Petrosaurus nearnsi (Iguanidae). Southwestern Matur., 20: 113-120.

Mares, M. $\dot{A}$. 1971. Coprophagy in the Texas tortoise, Gopherus berlandieri. Texas J. Sci., 23: 300-301.

Marsha11, A. J. and R. Hook. 1960. The breeding biology of equatorial vertebrates: reproduction of the lizard Agama agama Boulenger at latitude $0^{\circ} 01^{\prime} \mathrm{N}$. Proc. Zool. Soc. London, 134: 197-205.

Martin, F.W. 1966. Collecting the cacti of Mona Island. Cactus and Succulent J., 38: 122-126.

Mayhew, W. W. 1963a. Some food preferences of captive Sauromalus obesus. Herpetologica, 19: 10-16.

Mayhew, W. W. 1963b. Reproduction in the granite spiny lizard, Sceloporus orcutti. Copeia, 1963: 144-152.

Mayhew, W. W. 1963c. Biology of the granite spiny lizard, Sceloporus orcutti. Amer. Midland Natur., 69: 310-327.

Mayhew, W. W. 1965. Reproduction in the sand-dwelling lizard Uma inornata. Herpetologica, 21: 39-55.

Nayhew, W. W. 1966a. Reproduction in the psammophilous lizard Uma scoparia. Copeia, 1966: 114-122.

Mayhew, W. W. 1966b. Reproduction in the arenicolous lizard Uma notata. Ecology, 47: 9-18.

Mayhew, W. W. 1968. VI. Biology of desert amphibians and reptiles. in: Brown, G. W., Desert Biology, Vol. 1. 1-635.

Mayine:, W. W. 1971. Reproduction in the desert lizard, Dipsosaurus dorsalis. Herptetologica, 27: 57-77.

McBee, R. H. 1971. Significance of intestinal microflora in herbivory. Ann. Rev. Ecol. and Syst., 2: 165-176.

itciab. E. … 1963. Bioenergetics and the detemination of home range size. Aner. iatur., 97: $133-140$.

Maicht, T. 1964. Feral livestoch in Anglo-America. Univ. of California Publ. $\operatorname{Gog} ., 88: 1-78$.

Me:cer, E. H. 1961. Keratin and Keratinisation. An essay in molecular biology. Pergamon Press, Oxford, N.Y. 316 pp.

Martens, R. 1960. The world of amphibians and reptiles. McGraw-Hill Book Company, New York. $207 \mathrm{pp}$. 
Miller, M. R. 1954. Further observations on reproduction in the lizard Xantusia vigilis. Copeia, 1954: 38-40.

Milstead, H. W. 19ól. Observations of the activities of small animals (Reptilia and Mammalia) on a quadrat in southwest Texas. Aner. Midland Natur., 65: 127-138.

Milstead, W. W. 1970. Late summer behavior of the lizards Sceloporus merriami and Urosaurus ornatus in the field. Herpteologica, 26: $343-354$.

Minaich, J. E. 1970. Water and electrolyte balance of the desert iguana, Dipsosaurus dorsalis, in its natural habitat. Comp. Biochem. Physiol., 35: 921-933.

Minnich, J. E. 1971. Seasonal variation in weight-length relationships and fat body size in the desert iguana, Dipsosaurus dorsalis. Copeia, 1971: 359-362.

Minnich, J. E. and V. H. Shoemaker. 1970. Diet, behavior and water turnover in the desert iguana, Dipsosaurus dorsalis. Amer. Midland Natur., 84: 496-509.

Montanucci, R. R. 1965. Observations on the San Joaquin leopard lizard, Crotaphytus wislizeni silus Stejneger. Herpetologica, $21: 270-283$.

Montanucci, R. R. 1967. Further studies on leopard lizards, Crotaphytus wislizenii. Herpetologica, 23: 119-126.

Montanucci, R. R. 1968. Comparative dentition in four Iguanid lizards. Herpetologica, 24: 305-315.

Montgomery, G. G., A. S. Rand, and M. E. Sunquist. 1973. Post-nesting movements of iguanas from a nesting aggregation. Copeia, 1973: 620-622,

Mueller, H. 1968. Untersuchungen ueber Wachstum und Altersverteilung einer population der Gruenen Leguans Iguana iguana iguana L.

(Reptilia: Iguanidae). Mittl. Inst. Colombo-Aleman Invest. Cient., 2: $57-65$.

Mueller, C. F. 1969. Temperature and energy characteristics of the sagebruch lizard (Sceloporus graciosus) in the Yellowstone National Park. Copeia, 1969: 153-160.

Weller, C. F. 1970. Energy utilization in the lizards Sceloporus gracioius and $S$. occidenialis. A. Herpetol., 4: $1 3 \longdiv { 1 - 1 3 4 . }$

Meliter, H. 1972. Okologische und ethologische studien an Iguana iguana L. (Reptilia: lguanidae) in Kolumbien. Zoologische Beitrage, Breslau., 18: 109-131. 
Murphy, J. 8. 1969. Notes on iquanids and varanids in a mixed exhibit at Dallas Zoo. Irit. Zoo Yearbook, 9: 39-41.

Nagy, K. A. 1973. Behavior, diet and reproduction in a desert lizard, Sauromalus obesus. Copeia, 1973: 93-102.

Noble, G. K. 1923. Trailing the rhinoceros iguana. Nat. Hist., 23: $541-558$.

Noble, G. K. and H. T. Bradley. 1933. The mating behavior of lizards; its bearing on the theory of sexual selection. Ann. New York Acad. Sci., 35: 25-100.

Noble, G. K. and G. C. Klingel. 1932. The reptiles of Great Inagua Island, British West Indies. Amer. Hus. Novitates, 549: 1-2.5.

Norris, K. S. 1953. The ecology of the desert iguana Dipsosaurus dorsalis. Ecology, 34: 265-287.

Morris, K. S. and W. R. Dawson. 1964. Observations on the water economy and electrolyte excretion of chuckivallas (Lacertilia, Sauromalus). Copeia, 1964: 638-646.

Ostrom, 3. H. 1963. Further comments on herbivorous lizards. Evolution, 17: $368-j 69$.

Overton, W. S. 1953. Progress reports for investigations project, W-33-R, April l arid July 1. Fla. Game and Freshwater Fish Comm., Tallahassee. $12 \mathrm{pp}$.

Paganelli, C. V., A. 01 szowka, and A. Air. 1974. The avian egg: surface area, volume, and density. Condor, 76:319-325.

Parker, G. A. 1974. Courtship persistence and female-guarding as male time investment strategies. Behaviour, 48: 157-184.

Parker, W. S. 1972. Notes on Dipsosaurus dorsalis in Arizona. Herpetologica, 28: 226-229.

Parker, W. S. and E. R. Pianka. 1973. Notes on the ecology of the iguanid lizard, Sceloporus magister. Herpetologica, 29: 143-152.

Paiker, U. S. and E. R. Pianka. 1975. Comparative ecology of populations of the lizard Uta stansburiana. Copeia, 1975: 615-632.

Farher, U. S. and E. R. Pianka. 1976. Ecological observations on the leopard lizard (Crotaphytus wislizeni) in different parts of its range. Herpetologica, 32: 95-114.

Faijison, D. R. 1966. New records of birds from the Bahana Isiands. Not. Naturae, 394: 1-15. 
Pawley, R. 1969. Further notes on a captive colony of marine iguanas Amblyrhynchus cristatus at Brookficld Zoo, Chicago. Intl. Zoo Yearbool, 9: 41-44.

Peracca, M. G. 1891. Osservazioni sulla riproduzione della Iguana tuberculata. Boll. Mus. Zool. Anat. Comp. Torino., 6: $1-8$.

Perez Vigueres, 1. 1936. Sobre la validez de la especie Atractis cruciata Linstow 1902. Rev. Parasit. Clin. y Lab. Habana, T: $188-190$.

Philibosian, R. 1975. Territorial behavior and population regulation in the lizards, Anolis acutus and A. cristatellus. Copeia, 1975: $428-444$.

Philibosian, R. and R. Ruibal. 1971. Conservation of the lizard Ame iva polops in the Virgin Islands. Herpetologica, 27:450-454.

Pianka, E. R. 1967. On lizard species diverstiy: North American flatland deserts. Ecology, 48: 333-351.

Fianka, E. R. 1970a. On $r$ - and k-selection. Amer. Natur., 104: 592-597.

Pianka, E. R. 1970b. Comparative autecology of the lizard Cnemidorphorus tigris in different parts of its geographic range. Ecology, 51 : $\overline{703-720 .}$

Pianka, E. R. and W. S. Parker. 1975. Ecology of horned lizards: a review with special reference to Phrynosoma platyrhinos.

Copeia, 1975: 141-162.

Platt, D. R. 1969. Natural history of the hognose snakes Heterodon platyrhinos and Heterodon nasicus. Unv. Kansas, Publ. Mus. Nat. Hist., 18: $253-420$.

Pope, C. H. 1969. The Reptile World. A natural history of the snakes, lizards, turtles, and crocodilians. Knopf, New York. 324 pp.

Porter, W. P., J.W. Mitchell, W. A. Beckman, and C. B. DeWitt. 1973. Behavioral implications of mechanistic ecology. Oecologia (Berlin), 13: 1-54.

Pough, F. H. 1973. Lizard energetics and diet. Ecology, 54: 837-844.

Prieto, A. A, 1971. The ethology of the Arizona chuckwalla (Sauromalus obssus tumidis). Ph.D. Thesis, Univ. Missouri, Columbia. $176 \mathrm{pp}$.

Prieto, A. A. and M. W. Sorenson. 1975a. Food preferences of the Arizona chuckwalla (Sauromalus obesus tumidus). Bull. New Jersey Acad. Sci., 20: 8-11. 
Prieto, A. A. and M. W. Sorenson. 1975b. Predator-prey relationships of the Arizona chuckwalla (Sauromalus obesus tumidus). Bull. New Jersey Acad. Sci., 20: 12-13.

Purdue, J. R. and C. C. Carpenter. 1972. A comparative study of the body movenents of displaying males of the lizard genus Sceloporus (Iguanidae). Behaviour, 41: 68-81.

Rabb, G. B. and E. B. Hayden, Jr. 1957. The Van Voast-American Museum of Natural History Bahama Islands expedition record of the expedition and general features of the islands. Amer. Mus. Novitates, 1836: $1-53$.

Raillet, A. and A. Henry. 1912. Quelques nematodes parasites des reptiles. Bull. Soc. Path. Exot., 5: 251-259.

Rand, A. S. 1967. The adaptive significance of territoriality in iguanid lizards. pp. 106-115. IN: W. W. Milstead, ed., Lizard ecology: A symposium. Univ. Missouri Press, Columbia. $300 \mathrm{pp}$.

Rand, A. S. 1968. A nesting aggregation of iguanas. Copeia, 1968: $552-561$.

Rand, A. S. 1972. The temperatures of iguana nests and their relation to incubation optina and to nesting sites and season. Herpetologica, 28: $252-253$.

Rand, A. S. M.s. Reptilian arboreal folivores. Unpublished manuscript.

Rand, A. S. and S. S. Humphrey. 1968. Interspecific competition in the tropical rain forest: Ecological distribution among lizards at Belen, Para. Proc. U.S. Nat. Mus., 125: 1-17.

Rand, W. M. and A. S. Rand. 1976. Agonistic behavior in resting iguarlas: a stochastic analysis of dispute settlement dominated by the minimization of energy cost. $z$. Tierpsychol., 40: 279-299.

Rand, A. S. and M. H. Robinson. 1969. Predation on iguana nests. Herpetologica, 25: 172-174.

Rawles, M. E. 1960. The integumentary System. pp. 190-240. IN: A. J. Marstall, ed. Biology and Comparative Physiology of Birds.

Vol. 1. Academic Press, New York.

Pay, $\hat{\imath}$. E. 1965. Variation in the number of marginal tooth positions in three species of iguanid 1izards. Breviora, 236: 1-15.

Ficklefs, R. E, and J. Cullen. 1973. Embryonic growth of the green iguana Iguana iguana. Copeia, 1973: 296-305. 
Robirsor, L. E. 1926. The genus Amblyonal IN: G. H. F. Nuttal, C. Warburtun, W. F. Cooper, and L. E. Robinson, eds. Tichs, a monograph of the lxodoidale. Cambidye Univ. Press. Pt. 4. $302 \mathrm{pp}$.

Podhain, J. and C. Vuylsteke. 1937. Une filaire nowvelle d'lguana tuberculata (Ereinlia brevocaudata n. sp.). Ann. Far., 15: $225-228$.

Rollindt, R. 193't. La Vie des peptiles de la France Centrale. Librairie Delegrave, Paris. $86 \mathrm{pp}$.

Romer, A. S. 1962. The Vertebrate Body. W. B. Saunders, Co., Philadelphia. 627 pp.

Rudolphi, C. A. 1819. Entozoorum synopis cui accedunt mantissa duplex et indices locupletissimi. Berolini. $811 \mathrm{pp}$.

Ruibal, R. 1967. Evolution and behavior in West indian anoles. pp. 116-140. IN: W. W. Milstead, ed., Lizard ecology: A symposium. Univ. Missouri Press, Columbia. 300 pp.

Ruibal, R. and R. Philibosian. 1974. The population ecology of the lizard Analis acutus. Ecology, 55: 525-537.

Sadler, H. E. 1975. Turk's Island Landfall. 7 Volumes. Privately printed.

Saint Girons, H. 1957. Le cycle sexuel chez Vipera aspis (L.) dans l'Quest de la France. Bull. Biol. Fr. Belg., 91: 284-350.

Sanborn, S. R. 1972. Food habits of Sauromalus obesus obesus on the Nevada test site. J. Herpetol., 6:142-144.

Schallenberger, E. H. 1970. Tameness in insular animals. A comparison of approach distances of insular and mainland iquanid lizards.

Ph. D. Thesis, Univ. California, Los Angeles. $143 \mathrm{pp}$.

Schimidt, K. P. 1920. Contributions to the herpetology of Porto Rico. Annals i..Y. Acad. Sci., 28: 167-200.

Schidt. K. P. 1935. Notes on the breading behavior of lizards. Field My. Hist., Zool. Ser., 20:71-76.

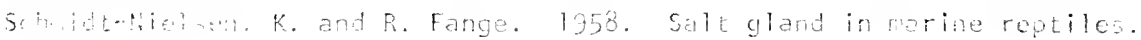
intut, Loidon, 182: $783-785$.

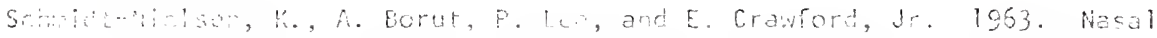
salt excrition and the posalate flunction of the clomea in water constration. Science, 142: 1300-1301.

Schoener, T. W. 1968. Sizes of feeding territories among birds. Ecology, 49: 123-141. 
Schurtz, A. 1968. The Gechos (Sphatedactylus) of the suthern Bahama Islands. Anmals of Carnegie Puseumi, 39: 227-271.

Sohwerth, A. and $M$. Carey. In press. Systematics and evolution in the West Indian iguanid genus Cyclura.

Schuarty, A. and R. Thomas. 1975. A check-list of West Indian amphibians and reptiles. Carnegie lluseum Nat. Hist. Special Publ., 1: 1-216.

Senton, 0. J. 1975. Black vultures feeding on iguana eggs in Panama. Amer. Hidland Natur., 93: 463-468.

Sexton, O. J., E. Ortleb, L. M. Hathaway, R. E. Ballinger, and P. Licht. 1971. Reproductive cycles of three species of anoline lizards from the isthmus of Panama. Ecology, 52: 201-215.

Shaw, C. E, 1945. The chuckwallas, genus Sauromalus. Trans. San Diego Soc. Nat. Hist., 10: 269-306.

Shaw, C. E. 1950. Lizards in the diet of captive Uma. Herpetologica, 6: $36-37$.

Shaw, C. E. 1952. Notes on the eggs and young of some United States and Mexican lizards, 1. Herpetologica, 8: 71-79.

Shaw, C. E. 1954. Captive-bred Cuban iguanas Cyclura macleayi nacleayi, Herpetologica, 10:73-78.

Shaw, C. E. 1966. The eggs and young of the marine iguana (Amblyrhynchus cristatus). Copeia, 1966: 585.

Shaw, C. E. 1969. Breeding the rhinoceros iguana Cyclura cornuta cornuta a! San Diego Zoo. Int1. Zoo Yearbook, 9: $45-\overline{58}$.

Sirion, C. A. 1975. The influence of food abundance on territory size in the iguanid lizard Sceloporus jarrovi. Ecology, 56: 993-998.

Slevin, I. R. 1935. An account of the reptiles inhabiting the Galapagos Islands. Bull. New York Zool. Soc., 38: 2-24.

slobrdkin, L. B. 1962. Growth and regulation of animal populations. Holt, Rinchart \& Winston, New York. $184 \mathrm{pp}$.

sith, H. H. 1946. Handbook of lizards. Comstock Publishing Associate, i: ค月, 1 , H.Y. $557 \mathrm{pP}$.

S-ith, $\therefore$ and $W$. L. Burger. 1950. Herpetological results of the Universicy of ll1inois Fidd Erpedition, Spring 1949. 111.

Sautia. Trans. Kansas Acad. Sci, , 53: 165-175. 
Snith, R. E. 1968. Experimental evidence for a gonadal-fat body relationshi, in tho teiid lizards (Aneiva festiva, Ameiva quadri ineata) Biol. Bul1., 134: 325-331.

Sohol, 0. M. 1967. Herbivory in 1izards. Evolution, 21: 192-194.

Sotol, 0. M. 1971. Lithophagy and geaphagy in reptiles. J. Herpetol., 5: $69-71$

Southrood, T. R. E. 1966. Ecological riethods. Chapman and Hall, Lonion. $391 \mathrm{pp}$.

Stamps, J. And G. W. Barlow. 1973. Variation and stereotypy in the displays of Anolis aeneus (Sauria: Iguanidae). Behaviour, 47 : 67-93.

Stearns, S. C. 1976. Life-history tactics: a review of the ideas. Quart. Rev. Biol., 51: 3-47.

Stebbins, R. C. 1944. Field notes on a lizard, the mountain swift, with special reference to territorial behavior. Ecology, 25: 233-245.

Stebbins, R. C. 1954. Amphibians and reptiles of western North America. McGraw-Hill, New York. $536 \mathrm{pp}$.

Stesl, R. G. D. and J. H. Torrie. 1960. Principles and procedures of statistics. McGraw-Hill, New York. $481 \mathrm{pp}$.

Stejneger, L. 1903. A new species of large iguana from the Bahama Islands. Proc. Biol. Soc. Washington, 16: 129-132.

Stewart, D. R. M. and J. Stewart. 1970. Food preference data by fecal analysis for African plains ungulates. Zool. Afr., 5: 115-129.

Stiest, G. B. 1952. Recent observations on the iguanas at Xaradu, Cuba. Privately Printed. $12 \mathrm{pp}$.

Sutcliffe, R. 1952. Results of the Catherwood-Chaplin West Indies expedition. 1948. Part VI. Amphibia and reptilia. Not. Naturae, 243: 1-8.

5......, P. L. 1950. The iguana lguana iguana iguane (L.). Herpeto10. ic: $6: 137-193$.

Sat:-i, H. 1962. Srme renartis on hartivorous lizards. Evolution, 16: 50

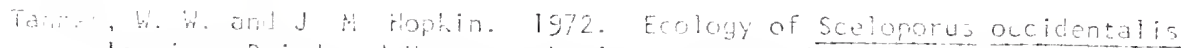
lomas Bard and Uta stansburian stansburiand Baird and Girard on Fiair Mas, Nuada test site, Nye County, Mavada. Erigham Young i Science Eull. Biol. Ser., 15: 1-39. 
Hord, 5. F. 1959. The ovarian cycle, reproductive potential, and structure in a population of the Japanesa lacertid Takydromus tachydromides. Copeia, 1969: 548-567.

Telford, S. R. 1970. Seasonal fluctuations in liver and fat body weights of tice Japanese lacertid Takydromus tachydromoides

Schlegel. Copeia, 1970: 68:-685.

Templeten, J. P. 1964. Nasal salt extetion in terrestrial lizards. Comp. Elochen. Physiol., 11: 223-229.

Templeton, J. R. 1967. Nasal salt gland excretion and adjustment to sodium loading in the lizard, Ctenosaura pectinata. Copeia, 1967: $136-140$.

Thaper, G. S. 1925. Studies on the oxyurid parasites of reptiles. J. Helm. 3: 83-150.

Thaper, G. 5. 1926. Ozolaimus Dujardin, 1845 (= macracis Gedoelst, 1916) a little know nematode from the caecum of Iguana tuberculata. J. Helm., 4: 69-74.

Throckmorton, G. S. 1971. Digestive efficiency in the herbivorous lizard Ctenosaura pectinata. Herpet. Rev., 3: 108.

Throckmorton, G. S. 1973. Digestive efficiency in the herbivorous lizard Ctenosaura pectinata. Copeia, 1973: 431-435.

Tinkle, D. W. 1962. Reproductive potential and cycles in female Crotalus atrox in northwest Texas. Copeia, 1962: 306-313.

Tinkle, D. W. 1957a. Home range, density, dynamics, and structure of a Texas population of the lizard Uta stansburiana. pp. 5-29. IN: W. W. Milstead, ed., Lizard ecology: A symposium, Univ. Missouri Press, Columbia. 300 pp.

Tinkle, 0. W. 1957b. The life and demography of the side-blotched lizard, Uta stansburiana. Misc. Publ. Mus. Zool., Univ. Michigan, $132: 1-182$.

Tinkle, 0. W. 1969. Concept of reproductive effort and its relation to the evolution of life histories of lizards. Amer. Natur., 103: $50:-516$

Tinte, E in 1972. The dyomics of a Uzah population of Sceloporus untulitus. Herpetologica, 28: $357-359$.

rins, i. !. 1973. A populotion anglysis of the sagobrush lizard, Scropo:us graciosug in southern Urah. Copeia, 1973: 234-256.

Tinte, 0. W. 1976. Comarative data on the population ecology of the desert spiny lizard, Scelopirus figister. Herpetologica, 32: 1-6. 
Tinkle, D. W. and R. E. Ballinger. 1972. Sceloporus undulatus: A study of the intraspecific comparative demography of a lizard. Ecology, 53: $570-584$.

Tirikle, D. W. and N. F. Hadley. 1973. Reproductive effort and winter activity in the viviparous montane lizard Sceloporus jarrovi. Copeia, 1973: $272-277$.

Tinkie, D. W. and N. F. Hadley. 1975. Lizard reproductive effort: Caloric estimates and comments on its evolution. Ecology, 56: 427-434.

Tinkle, D. W., H. M. Wilbur, and S. G. Tilley. 1970. Evolutionary strategies in lizard reproduction. Evolution, 24: 55-74.

Tinkie, D. W. and D. W. Woodward. 1967. Relative movements of lizards in natural populations as determined from recapture radii. Ecology, 48: $166-168$.

Trivers, R. L. 1976. Sexual selection and resource-accruing abilities in Anol is garmani. Evolution, 30: 353-369.

Turner, F. B., G. A. Hoddenbach, P. A. Medica and J. R. Lannom. 1970. The demography of the lizard, Uta stansubriana Baird and Girard, in southern Nevada. J. Anim. Ecol., 39: 505-519.

Turner, F. B., R. 1. Jennrich, and J. D. Weintraub. 1969. Home ranges and body size of lizards. Ecology, 50: 1076-1081.

Turner, F. B., J. R. Lannom, P. A. Medica, and G. A. Hoddenbach. 1969. Density and composition of fenced populations of leopard lizards (Crotaphytus wislizenii) in southern Nevada. Herpetologica, 25: $2 \overline{47-257}$.

Turner, F. B., P. A. Medica, J. R. Lannom, Jr., and G. A. Hoddenbach. 1969. Demographic analysis of fenced populations of whiptail lizard, Cnemidophorus tigris, in southern Nevada. Southwestern Natur., 14: 189-202.

Underwood, G. 1962. Reptiles of the eastern Caribbean. Caribbean Affairs (New Ser.) 1, Dept. Extra-mural Stud., Univ. West Indies, 92 pp.

Van Aperen, W. 1969. Notes on the artificial hatching of iguana eggs, tguana iguana, at Melbourne Zoo. Int. Zoo Yearbook, 9: 44-45.

VanDenburgh, J. 1922. The reptiles of western North America. Vol. 1. Lizards. 0ccas. Pap. California Acad. Sci., 1-611.

Van Winkle, W. 1975. Comparison of several probabilistic home-range models. J. Wildl. Mgmt., 39: 118-123.

Vinegar, H. B. 1975. Life history phenomena in two populations of the iizard Sceloporus undulatus in southawestern New Mexico. Amer. Midland Natur., $93: 388-402$. 
Vite, L. J. 1974. Winter aggregations, size classes, and relative tail breaks in the tree lizard. Urosaurus ornatus (Sauria: lyunida). Herpetologica, 30: $183-183$.

Vitt, L. J., J. 0. Congdon, A. C. Huls and J. E. Platz. 1974. Territurial aygressive encounters and tail breaks in the lizard Sceloporus ragister. Copeia, 1974: 990-993.

Vitl, L. J. and R. D. Ohinart. 1974. Reproduction and ecology of a Coiorado River population of Sceloporus magister (Sauria: Iguanidae). Herpetologica, 30: 410-417.

Vitt, L. J. and R. D. Ohmart. 1975. Ecology, reproduction, and reproductive cffort of the iguanid lizard Urosaurus graciosus on the lower Colorado River. Herpetologica, $31: 56-65$.

Walton, A. C. 1942. Paralaeuris cuchleri n. sp. (Nematoda) from the iguana (Cyclura cornuta). J. Parasit., 28: 165-166.

Ward, A. L. 1970. Stomach content and fecal analysis: methods of forage identification. U.S. Dept. Agr. Misc. Publ., 1147 : $148-158$.

Weintraub, J. D. 1970. Homing in the lizard Sceloporus orcutti. Anim. Behav., 18: 132-137.

Western, D. 1974. The distribution, density and biomass density of 1 izards in a seni-arid environment of northern Kenya. E. Afr. Wildi. J., 12: $49-62$.

Whitaker, A. H. 1973. Lizard populations on islands with and without Polynesian rats, Rattus exulans (Peale). Proc. New Zealand Ecol. Soc., 20: $121-130$.

Wievand, T. In preparation. Ecology, behavior, and management of the Mun 1 sland ground iguana, Cyclura stejnegeri. Fh.D. dissertation. Cornell Univ., Ithaca, New York.

Wilbur, H. M., D. W. Tinkle, and J. P. Collins. 1974. Enviromental certainty, trophic level, and resource availability in life history cvolution. Amer. Natur., 108: 805-817.

Wilcan, K. J. Y. Carter and L. V. Wilcox, Jr. 1973. Range extension of Eyelua Figninsi Barbour in the Eahatac. Carib. J. Sci., 13: $211-213$.

Withof, r. C. 1958. Observations on preferred body temperature and f..ting hits of sore selara tropical iguanas. Herpetologica, $14: 161-164$.

nilson, E. 0. 1975. Sociobiology, the ned synthesis. Belknap Press, Caribritge. $697 \mathrm{pp}$. 
Windberg, L. A. and L. B. Keith. 1976. Snowshoe hare population response to artificial high densities. J. Mammalogy, 57: 523-553.

Hoodley, J. D. 1971. The Jamaican ground iguana in Hellshire. pp. 127-133. IN: J. D. Woodley, ed. Hellshire Hills scientific survey, 1970. Univ. of hest Indies, Inst. of Jamaica. $168 \mathrm{pp}$.

Yanaguti. S. 1961. Systema Helminthum. Volume 111. The Nenatodes of Vertebrates. Part 11. Interscience Publisters, Inc., New York. $1261 \mathrm{pp}$.

Young, F. H. and C. C. Goff. 1939. An annotated list of the arthropods found in the burrows of the florida gopher tortoise, Gopherus polyphenus (Daudin). Fla. Entonol., 22: 53-62.

Ziveirel, R. 6. 1961. Another method of incubating reptile eggs. Copeia, 19ó1: 112-113.

Zweifel, R. G. and C. H. Lowe. 1966. The ecology of a population of Xantusiavigilis, the desert night lizard. Am. Mus. Novit., $2217: 1-57$. 


\section{BIOGRAPHICAL SKETCH}

John Eurton luerso?, 111 was born on 4 Octobur 1949, in Omaha, Habasta. He graduated from Benson High School in Onaha in 196\%. After comlezing undergraduate majors in Mathenatics and Biology at Hastings College, Hastings, Nebraska, in 1971, he entered Gradiate School at the Li iversity of Florida. He was awarded the Master's Degree in Zoology in March, 1974. Financial support for his graduate research has come from Unive; ity of Florida Graduate School fellowships, research assistartships, Zoology department graduate assistantships and grants to Waiter Auffenberg from the New York Zoological Society.

He is a menber of the American Society for Ichthyologists and Herpetologists, the Herpetologists Leacue, the Society for the Study of Amphibidns and Reptilas, the Ararican Soziety of zoologists, The Ecologiza! Scciety of America, and the Kansas Academy of Science.

chn lverson is married to the former sheila Ann Jelinek. 
i certify that I hava read this study and that in my opinion it conformis to acceptable standarts of scholarly presentation and is fully adequate, in scope and quality, as a dissertation for the degree of boctor of Philosophy.

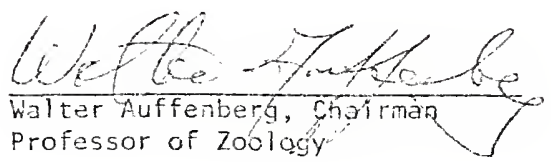

1 certicy that 1 have read this study and that in my opinion it conforms to acceptable standards of scholarly presentation and is fully adequate, in scope and quality, as a dissertation for the degree of ooctor of Philosophy.

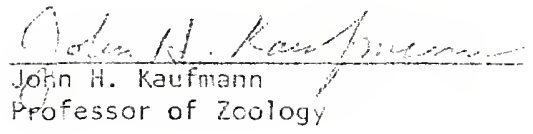

I certify that : have read this study and that in my opinion it conforms to accepcable standards of scrolatly presentation and is fully adequate, in scope and quality, as a dissertation for the degree of Doctor of Friliosopiy.

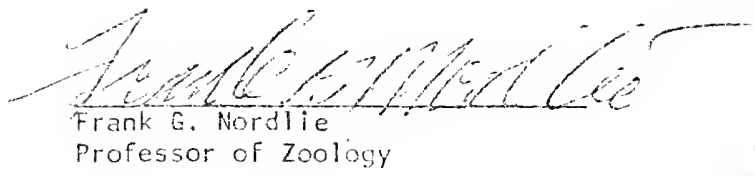

I certify that I have read this study and that in my opinion it conforms to acceptabi: standards of scholarly presentation and is fully adequate, in scope and quality, as a dissertation for the degree of cuctor of Fnilosophy.

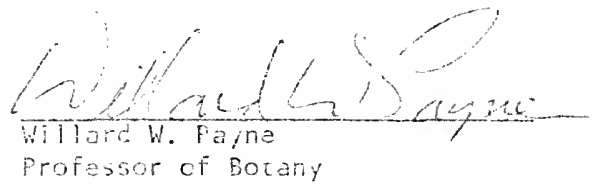


This dissertation was submitted to the Graduate Faculty of the Department of Zoology in the College of Arts and Sciences and to the Graduate Council, and was accepted as partial fulfillment of the requirements for the degree of Doctor of Philosophy.

June, 1977 
UNIVERSITY OF FLORIDA

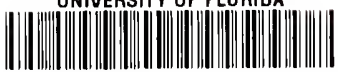

31262086662599 